Copyright

by

Cornelia Loos

2017 
The Dissertation Committee for Cornelia Loos

Certifies that this is the approved version of the following dissertation:

The Syntax and Semantics of Resultative Constructions in Deutsche Gebärdensprache (DGS) and American Sign Language (ASL)

Committee:

Richard P. Meier, Supervisor

John T. Beavers

Hans C. Boas

David Quinto-Pozos

Stephen M. Wechsler 
The Syntax and Semantics of Resultative Constructions in Deutsche Gebärdensprache (DGS) and American Sign Language (ASL)

by

Cornelia Loos

\author{
Dissertation \\ Presented to the Faculty of the Graduate School of \\ The University of Texas at Austin \\ in Partial Fulfillment \\ of the Requirements \\ for the Degree of
}

Doctor of Philosophy

The University of Texas at Austin

August 2017 


\section{Acknowledgements}

First and foremost, I want to thank my consultants for sharing their intuitions about DGS and ASL with me. I could not have started to comprehend the grammar of resultatives in these languages without my participants' enthusiastic willingness to sit down for hours and answer my many questions. I am particularly grateful to Tina Simon, Ludwig Herb, and Paloma McClelland in this respect. You could easily have pretended to have lost my number after the hundredth "just a quick question" request, but instead you replied - and helped me recruit more participants!

In the same vein, my heartfelt thanks go out to Mike Wynne, Debbie White, and Oscar Ocuto, the gracious respondents to many a "quick question" on ASL. I am further indebted to Erika Domatti and Carrie Lou Garberoglio, who put me in contact with potential consultants and language models in Austin.

In Göttingen, I owe a great debt of gratitude to the Experimental Sign Language Lab and its director, Annika Herrmann. They provided invaluable logistic and financial support, allowed me to film in their lab, and put me in contact with Jens-Michael Cramer, who did a wonderful job recording my stimuli in DGS. I am especially grateful to Liona Paulus for her very helpful insights on the structure of DGS, to Jana Hosemann for discussing and thereby much improving my experimental design with me, and to Derya Nuhbalaoglu and Annika Hübl for hosting me and making me feel at home in Göttingen.

I am indebted to my colleagues from the Sign Lab at UT for our many animated discussions of all topics (including linguistics). Kate Mesh, Grace Neveu, Justin Power, Frances Cooley, Leah Geer, Dag Lindeberg, Elena Liskova, and Lynn Hou - thank you 
for listening and providing helpful feedback to many a drafty draft of a conference paper or dissertation chapter.

A special thank you goes to my advisor Richard Meier. Your encouragement and support during the last six years have helped me grow as a researcher and writer. This dissertation has much benefitted from your thoughtful questions and your enthusiasm for my research. At the same time, your wealth of knowledge about international vacation spots and the best BBQ joints in Austin have helped me maintain the resemblance of a work-life balance. To my other committee members, Steve Wechsler, John Beavers, David Quinto-Pozos, and Hans Boas, thank you for offering a diverse set of perspectives and expertise that have helped shape this dissertation into what it has become. Steve, thank you for being the first to cite a paper of mine and making me feel more like a peer and less like an impostor. John, thank you for repeatedly pulling me up from the weeds into which I'd analyzed myself and for teaching me how to teach. David, thank you for the hours and hours we spent discussing ASL and experimental design, and for advocating a healthy work-life balance. Hans, danke for reminding me how fascinating my research topic is and for renewing my enthusiasm for resultatives whenever necessary.

"No man is an island, entire of itself", but writing a dissertation often feels rather isolating. To get through it, we need friends both inside academia and without. Claudi, Anne, Chris, Katha, Miri, Jin and Malia, thank you for your friendship, for the ocean trips, bubble teas, baby showers, and birthday parties that reminded me that there is more to life than dissertating. To the Austin salsa community for allowing me to let loose every once in a while. To Joseph for believing that I could do this before I knew I could. To Kirsten, who let me vent over countless teas (me) and coffees (her) while always telling me what I needed to hear (that I was right). And to Zach, for loving me enough to push 
me during crunch time while reminding me that it's ok "to lose a day or two" otherwise. We have talked causation and resultatives so much over the past two years that you probably cannot enjoy a conversation without noticing every single resultative in it - I hope the damage is not permanent.

Last, but never least, I want to thank my family, especially my mother and my sister. Danke für eure Unterstützung, eure Zuversicht und eure Geduld in den letzten acht Jahren meines Nomadentums. Ihr seid mein Zuhause und damit der Ruhepunkt, ohne den ich diese Dissertation nicht hätte schreiben können. Ich danke euch aus ganzem Herzen. 


\title{
The Syntax and Semantics of Resultative Constructions in Deutsche Gebärdensprache (DGS) and American Sign Language (ASL)
}

\author{
Cornelia Loos, Ph.D. \\ The University of Texas at Austin, 2017
}

Supervisor: Richard P. Meier

\begin{abstract}
Complex cause-result events such as wiping a table off can be encoded linguistically with a single verb (clean), a resultative (wipe the table clean), or a multiclausal construction (wipe the table until it's clean). Languages differ markedly in the kinds of events that can be described in a single clause; hence the present work explores whether Deutsche Gebärdensprache (DGS) and American Sign Language (ASL) can encode both manner of causation and result state within a single clause. Since an investigation of clause-level constructions presupposes a thorough understanding of clause boundaries, this dissertation starts by reviewing and adding to the existing clausehood diagnostics in spoken and signed languages. Using these diagnostics in combination with video elicitation tasks and grammaticality judgments, I show that DGS has two monoclausal resultative constructions that differ in the order of the causing and result predicates. The constructions both allow Control and ECM resultatives and may take a stative or change-of-state secondary predicate. Their semantics differ in that resultatives with [Result Cause] word order exhibit event-to-scale homomorphy while those with [Cause Result] word order do not. ASL has a single monoclausal resultative construction that encodes at least Control resultatives but, in contrast to English, does not exhibit homomorphic mappings.
\end{abstract}


ASL shares a different aspect of resultative semantics with English: directness of causation. The present work presents the first empirical investigation of directness of causation and its effect on the acceptability of resultatives in English and ASL. It finds that both English and ASL resultatives are significantly less acceptable as descriptors of causative scenarios in which there is a temporal delay between causing and result events. This study further shows a significant decrease in acceptability of English and ASL resultatives when an intermediate causer intervenes between ultimate causer and result. Through controlled experiments on resultatives in both languages, I show that temporal delays and intervening causers decrease directness independently and to significantly different degrees. Lastly, this study identifies subtle differences in the semantics of ASL resultatives and their English counterparts. While the degree of indirectness of an intervening causer is attenuated by the ultimate causer's intentionality in English, no such effect is found for ASL.

In summary, the present work demonstrates that sign languages like DGS and ASL have syntactic resources for packaging event-structural information densely. These resources exhibit different constraints on usage than their German and English counterparts and are well-integrated into the grammars of DGS and ASL. 


\section{Table of Contents}

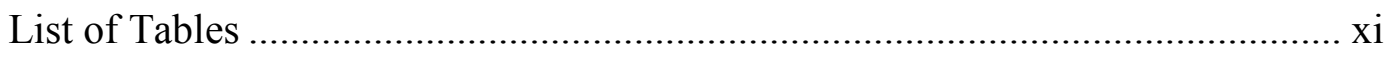

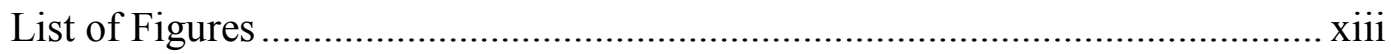

Notational Conventions for Sign Language Glosses ......................................... xiv

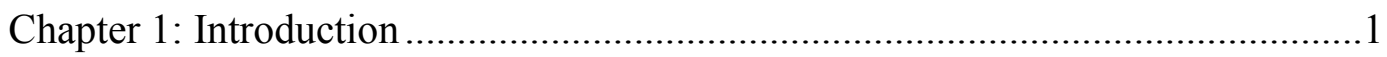

Chapter 2: Situating the resultative as a causative construction: Insights from spoken and signed languages ....................................................10

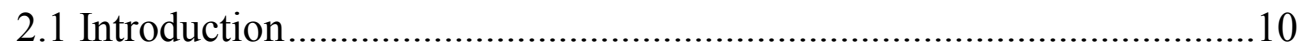

2.2 Causative constructions in spoken languages ........................................10

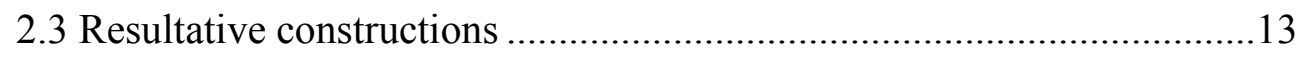

2.3.1 The resultative construction: Description and typology .............13

2.3.2 The syntax of resultatives .......................................................19

2.3.3 The semantics of resultative constructions ...................................26

2.3.4 A note on Serial Verb Constructions (SVCs) ...............................32

2.4 How are causal relations expressed in signed languages? .........................34

2.4.1 A whirlwind tour of sign language grammars .............................35

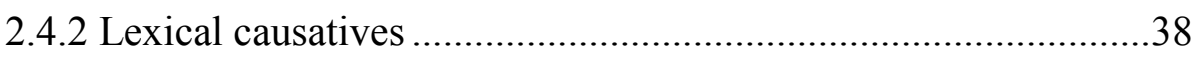

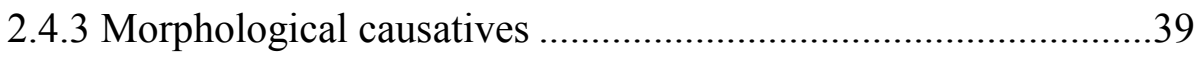

2.4.4 Periphrastic/syntactic causatives................................................45

2.4.5 Implied/pragmatic causation in signed languages ......................47

2.4.6 Previous work on resultative constructions in signed languages ...................................................................... 49

2.4.6.1 Kentner (2014) …………………………………......50

2.4.5.2 Lau (2012) ……………………………………….....

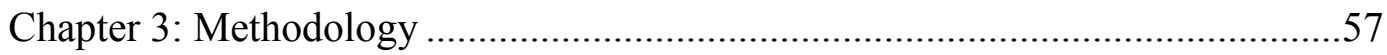

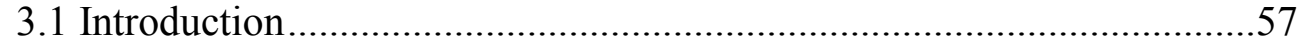

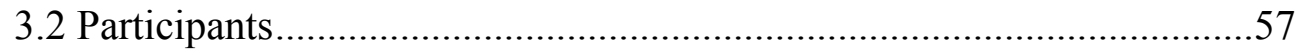

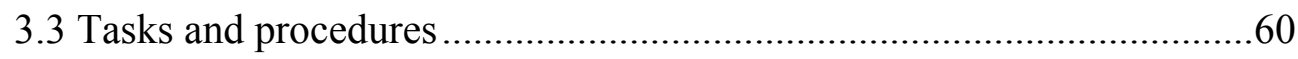




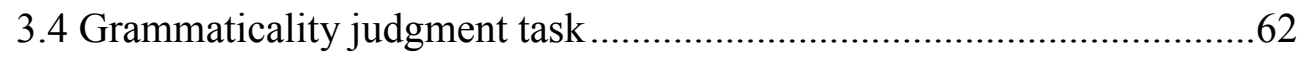

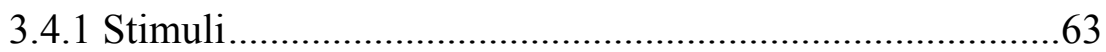

3.4.1.1 Causing and result predicates..........................................63

3.4.1.2 Further considerations in stimulus selection....................69

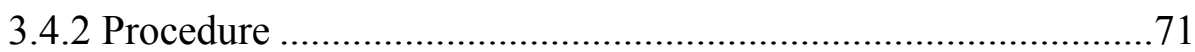

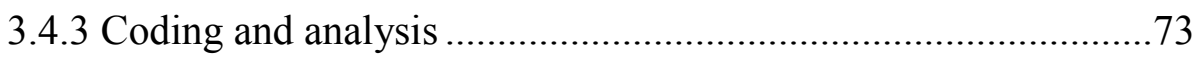

Chapter 4: Determining clause boundaries in signed languages ...........................74

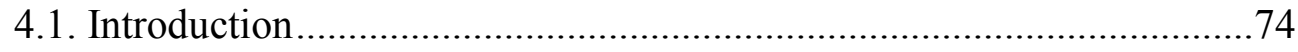

4.2. Why clauses are difficult to spot in signed languages ............................75

4.3 Why some established clausehood diagnostics fail ..................................78

4.3.1 A-Movement: Passives …………………………………….......79

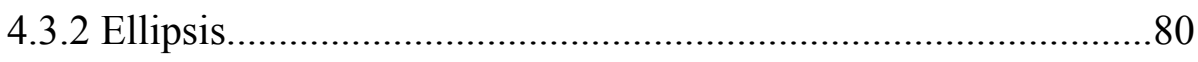

4.3.3 VP/AP adverb ...................................................................

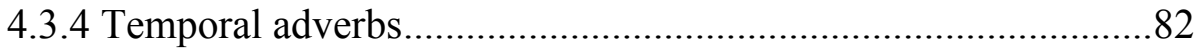

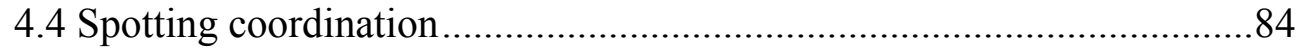

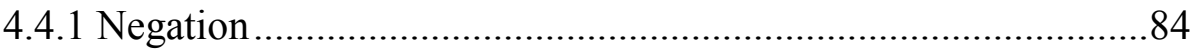

4.4.2 A' Movement: Wh-movement and topicalization.........................87

4.4.3 Subject pronoun copy ……………………………………....... 90

4.5 A closer look at embedded clauses ........................................................

4.5.1 Placement and scope of modal verbs .........................................96

4.5.2 Center-embedding .....................................................................97

4.5.3 Restrictions on rightward wh-movement - An empirical

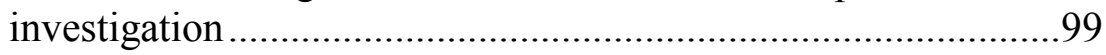

4.5.3.1 Introduction: Rightward movement does not cross clauses.....99

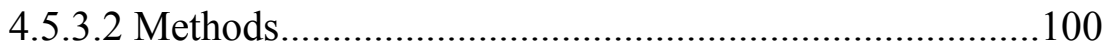

4.5.3.3 Results and discussion .................................................102

4.6 Summary of diagnostics and conclusion...............................................104

Chapter 5: The syntax and semantics of resultative constructions in

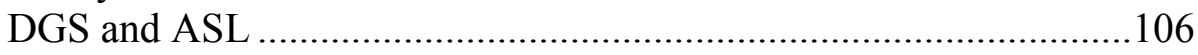

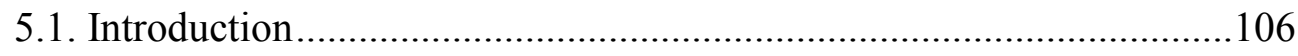


5.2. Talking about complex cause-result events: A pilot study ……….......106

5.3. Resultative constructions in DGS and ASL........................................118

5.3.1 S-O-Result-Verb (DGS)....................................................119

5.3.1.1 Evidence for monoclausality...........................................121

5.3.1.2 Control versus ECM and the homomorphy question....123

5.3.1.3 Syntax of the S-O-Result-Verb construction .................129

5.3.2 S-O-Verb-Result (DGS).......................................................133

5.3.2.1 Evidence for monoclausality..........................................134

5.3.2.2 Control versus ECM and the homomorphy question....137

5.3.2.3 The syntax of the S-O-Verb-Result construction...........141

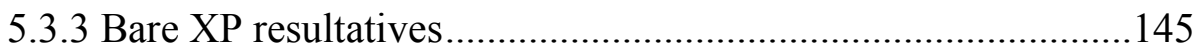

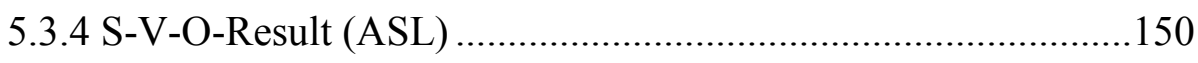

5.3.4.1 Evidence for monoclausality.........................................153

5.3.4.2 Control versus ECM and the homomorphy question....159

5.3.4.3 Syntax of the S-V-O-Result construction .......................163

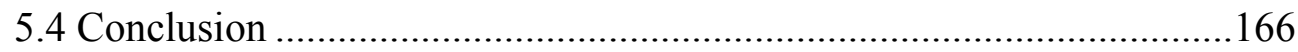

Chapter 6: Directness of causation in English and ASL resultatives.....................168

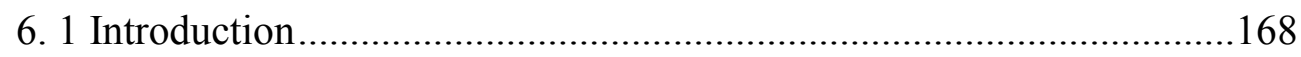

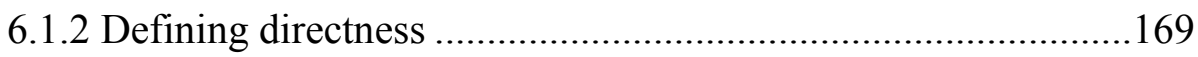

6.1.3 Directness of causation in resultatives .......................................173

6.1.4 Predictions for directness of causation in English ....................178

6.2 Experiment I: Directness of causation in English resultatives................180

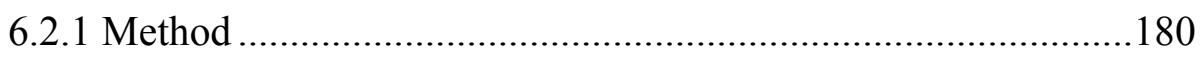

6.2.1.1 Participants.............................................................. 180

6.2.1.2 Materials ...................................................................181

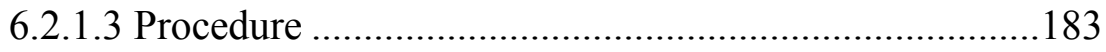

6.2.1.4 Design and statistical analysis ......................................184

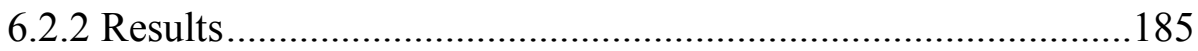

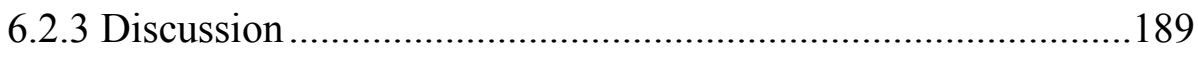

6.3 Experiment II: Directness of causation in ASL resultatives ...................194 


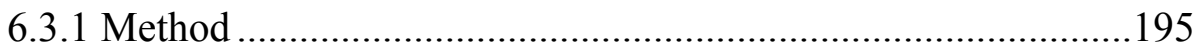

6.3.1.1 Participants....................................................................195

6.3.1.2 Materials ....................................................................196

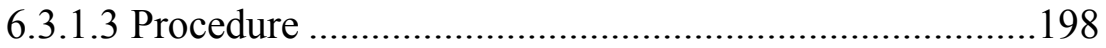

6.3.1.4 Design and statistical analysis ......................................201

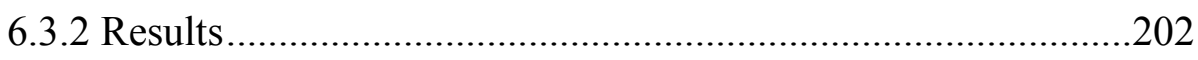

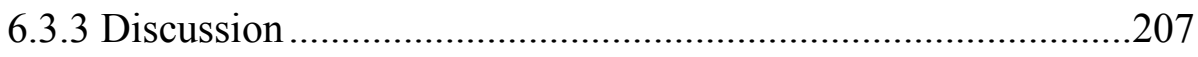

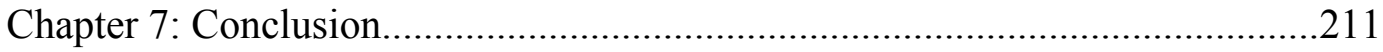

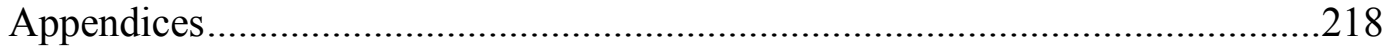

Appendix A: Video sequences for the pilot ...........................................218

Appendix B: Prompts for translation tasks including contexts..................221

Appendix C: Illustrations of some result predicates ....................................223

Appendix D: ASL Grammaticality judgment task

(Context was presented in ASL) ...................................................224

Appendix E: DGS Grammaticality judgment task........................................236

Appendix F: Causation scenarios for ASL direct causation study

(Scenarios are described in English here)..........................................249

Appendix G: Causation scenarios for English direct causation study ........254

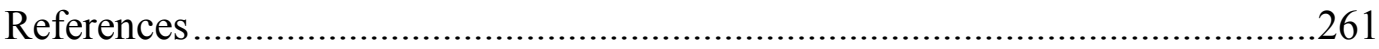




\section{List of Tables}

Table 1: $\quad$ Attested Combinations of Cause and Result Predicate in Kentner (2014) ......................................................................

Table 2: $\quad$ Linguistic and Demographic Background of ASL Participants ........58

Table 3: $\quad$ Linguistic and Demographic Background of DGS Participants .......59

Table 4: $\quad$ Cause-Result Stimuli for Grammaticality Judgment Task Organized by Durativity of Causing Predicate and Gradability of Result Predicate 63

Table 5 Means and Standard Deviations for

Grammaticality Judgment Ratings of Final Wh-words in

Different Sentence Types for DGS and ASL ....................................102

Table 6: $\quad$ Summary of Clausehood Diagnostics that are Applicable to

Cause-Result Expressions in ASL or DGS

Table 7 Means and Standard Deviations for GJ Ratings of

Center-Embedded Result Phrases in Control Resultatives

Table 8 Means and Standard Deviations for GJ Ratings of

Final Wh-Words Across Different Sentence Types (DGS). ..........136

Table 9 Means and Standard Deviations for GJ Ratings of

Control S O Verb Result Constructions with a Final Wh-Subject..139

Table 10 Means and Standard Deviations for GJ Ratings of

Subject Pronoun Copy Across Different Sentence Types (ASL) ...154

Table 11 Means and Standard Deviations for GJ Ratings of

Final Wh-Words Across Different Sentence Types (ASL) .............157 
Table 12 Means and Standard Deviations for GJ Ratings of Control

S V O Result Constructions with a Final Wh-Subject (ASL).........160

Table 13 Causative Scenarios Broken Down by Directness Components:

Intentionality, Intervening Cause(r)s and Temporal Delay ............180

Table 14 Resultatives Tested in Experiment I .........................................181

Table 15 Means and Standard Deviations for Appropriateness Ratings of

English Resultatives in Direct and Indirect Causation Scenarios ..184

Table 16 Means and Standard Deviations for Appropriateness Ratings of

General Causatives in Direct and Indirect Causation Scenarios.....188

Table 17 Means and Standard Deviations for Appropriateness Ratings

of English Resultatives in Direct and Indirect Causation

Scenarios (without spray clean and kiss awake).........................191

Table 18 Twelve Resultative Constructions Tested for Directness of

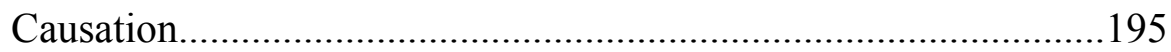

Table 19 Means and Standard Deviations for FJ Ratings of

ASL Resultatives in Direct and Indirect Causation Scenarios .......202

Table 20 Means and Standard Deviations for FJ Ratings of ASL

Periphrastic Causatives in Direct and Indirect Causation Scenarios 204

Table 21 Means and Standard Deviations for FJ Ratings of Juxtaposed

Cause and Result Clauses in Direct and Indirect Causation

Scenarios

.205 


\section{List of Figures}

Figure 1: Small clause analysis of resultatives............................................23

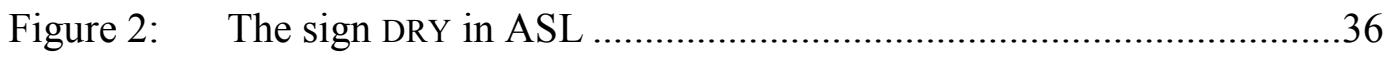

Figure 3: Initial and final states of the classifier predicates

CL-B:spoon_flattens and CL-FlatO:earring_flattens

Figure 4: ASL classifier construction representing the independent movement of two entities.

Reprinted from Aronoff et al. (2003: 71)....................................113

Figure 5: Illustrations of the DGS signs EAT, BECOME.FAT, and RUN ............149

Figure 6: Degrees of indirectness for English resultatives ...........................192

Figure 7: Example of a trial. The video at the top describes a causative situation in ASL, while the three videos below feature the different sentence types (resultative, causative, juxtaposition). .....200

Figure 8 'A person walks dragging dog' from Aronoff et al. (2003:71 )......210 
Notational Conventions for Sign Language Glosses

\begin{tabular}{|c|c|}
\hline SPOON & a lexical sign \\
\hline \#JOKER & a fingerspelled sign \\
\hline A.LOT & $\begin{array}{l}\text { single sign represented by more than one English } \\
\text { word in the gloss }\end{array}$ \\
\hline CL-B:person_steps_on_object & $\begin{array}{l}\text { a classifier predicate, where the letter following the } \\
\text { hyphen indicates the handshape for the sign and the } \\
\text { activity described by the sign follows the colon }\end{array}$ \\
\hline $\mathrm{TABLE}^{\wedge} \mathrm{SASS}_{\text {:rectangle }}$ & compound sign \\
\hline lf-GIVE-rt & $\begin{array}{l}\text { agreeing verb moving from one location in signing } \\
\text { space to another. The first location (lf = left, from } \\
\text { the signer's perspective) often indexes the referential } \\
\text { locus of the subject, while the second location } \\
\text { (rt = right) indexes the object. }\end{array}$ \\
\hline IX-1 & first person pronoun \\
\hline IX-lf/IX-rt & $\begin{array}{l}\text { pointing signs with pronominal or determiner-like } \\
\text { uses: } \\
\text { 'lf' = the signer points to his left, } \\
\text { ' } \mathrm{rt} \text { ' = the signer points to his right, } \\
\text { ' } \mathrm{fr} \text { ' = the signer points in front of himself } \\
\text { 'addr' = the signer points to the addressee }\end{array}$ \\
\hline POLISH-shoe & $\begin{array}{l}\text { A verb that agrees in (end) location with its object } \\
\text { argument }\end{array}$ \\
\hline BEAT + & reduplication of a sign to express durativity or aspect \\
\hline
\end{tabular}


Non-manual syntactic markers

\begin{tabular}{|c|l|}
\hline top & topic \\
\hline $\mathrm{rs}$ & role shift \\
\hline $\mathrm{y} / \mathrm{n}$ & polar question \\
\hline $\mathrm{fb}$ & furrowed brows, marks content questions \\
\hline $\mathrm{hs}$ & headshake, negation marker \\
\hline
\end{tabular}

Prosodic cues

bl lf/bl rt body lean to the left or right

Glossing conventions from cited examples

\begin{tabular}{|l|l|}
\hline IX-md & point towards a low locus in signing space \\
\hline or & $3^{\text {rd }}$ person subject and $1^{\text {st }}$ person object agreement \\
3 -HELP-1 & \\
\hline LOOK-AT & $\begin{array}{l}\text { single sign represented by more than one English } \\
\text { word in the gloss }\end{array}$ \\
\hline
\end{tabular}

xvii 


\section{Chapter 1: Introduction}

In an iconic scene from the movie Matilda, a boy is forced to devour an enormous chocolate cake by the evil headmistress Ms. Trunchbull. After stuffing the last piece of cake into his mouth, he picks up the plate triumphantly and licks up every last bit of chocolate frosting, until the plate is clean. This complex event consists of several subevents that cannot easily be described in a single clause. In fact, only the last two subevents of the boy licking the plate and it becoming clean may be encoded in one clause in English. We can either compress these two subevents into the lexical causative clean (1a), which focuses on the result state but does not tell us how Bruce accomplished this feat, or we can use a resultative construction (1b). The resultative encodes both the licking and the becoming clean subevents in separate predicates that form part of a single clause.
(1) a. Bruce cleaned the plate.
b. Bruce licked the plate clean.

Languages differ markedly in the kinds of events they can describe in a single clause. In the scenario above, what determines the availability of a single-clause description for licking and becoming clean but not, say, for eating the cake and picking up the plate, or picking up the plate and licking it, seems to be the presence of a causal relationship between the subevents. While languages like English and German provide both lexical and syntactic resources to encode causally connected events in one clause, other languages provide only one of those options. Take, for example, Kalam, a language of Papua New Guinea. Kalam has few verb roots that denote causal chains; thus to 
express that some entity "broke X", one has to use a multiclausal construction paraphraseable as "something happened to X and it broke" (Pawley 2011: 15). Despite the lack of lexical resources for representing complex causal events, Kalam makes frequent use of serial verbs to describe causal chains in a single clause, for example pak $w k$ - (lit. strike shattered) 'shatter sth.' and tb kluk yok- (lit. cut gouge displace) 'gouge sth. out' (2011:29). Romance languages such as Spanish, on the other hand, possess lexical but no syntactic means for expressing complex causal events on the clausal level. Spanish (2a) is a rough translation equivalent of (1a) but adds manner of causation via a prepositional phrase. In contrast, (2b) cannot be translated as a resultative with manner of causation and result predicates. The adjective limpio must be interpreted as a nominal modifier rather than as a resultative secondary predicate. In order to add a result state to a manner verb, a subordinate clause $(2 \mathrm{c})$ is necessary.
a. Bruce limpió
el plato con su lengua.

Bruce clean.PAST the plate with his tongue

'Bruce cleaned the plate with his tongue.'

b. Lamió el plato limpio.

lick.PAST the plate clean

'He licked the clean plate.'

\# 'He licked the plate clean.

c. Lamió el plato hastaque quedó limpio.

lick.PAST the plate until COMP remain.PAST clean

'He licked the plate until it was clean.' 
In light of the vast cross-linguistic variation in how densely event-structural information can be packaged, this dissertation investigates the monoclausal encoding of complex cause-result events in German Sign Language (Deutsche Gebärdensprache, DGS) and American Sign Language (ASL). The current work thus represents a departure from languages traditionally studied in research on event structure in that it focuses on a different modality of communication: signed languages.

DGS is the primary language of approximately 80,000 deaf and hard-of-hearing people in Germany and received official recognition as an independent language in 2002. Its origins can be traced back to, at the latest, the foundation of the Federation of the Deaf in 1848. Due to an "oralist" education tradition started by Samuel Heinecke and reinforced by the Congress of Milan (1880), signing was actively suppressed in German schools for the deaf during most of the $20^{\text {th }}$ century (Leonhardt 2002). Given the resulting lack of a standard variety, DGS exhibits substantial regional and sociolinguistic variation, which may or may not be leveled over time due to standardization pressures such as increased interregional contact between Deaf communities and improved visual communication technologies (Hillenmeyer \& Tilmann 2012). Data for the current study were elicited from speakers in the Berlin and Göttingen areas. Syntactically, DGS is predominantly head-final with SOV word order across clause types and postnominal adjectives and determiners (Happ \& Vorköper 2006).

ASL is the primary language of Deaf and Hard-of-hearing signers in the United States and parts of Canada. Estimates range from 500,000 to two million users in the US alone (Lane et al. 1996); 34 states currently recognize ASL as a foreign language for purposes of fulfilling academic modern language requirements. ${ }^{1}$ The origins of ASL can

\footnotetext{
${ }^{1} \mathrm{http}: / /$ ncssfl.org/view-state-report/. Accessed 5/18/2017.
} 
be traced back to the establishment in 1817 of the first school for the deaf in Hartford, Connecticut; its development was influenced by French Sign Language as well as existing indigenous sign languages (e.g. Martha's Vineyard Sign Language) and homesign systems. Given the dominant role of residential schools for the deaf in the transmission and development of the language, regional variation in ASL centers around schools for the deaf (Lucas et al. 2001). Data for the present study was collected in Austin, TX, with the exception of the data for Chapter six, which was generated via a nationwide online survey. In contrast to DGS, ASL is predominantly head-initial, with SVO basic word order and typically prenominal adjectives (Loos 2014).

DGS exhibits various similarities to other European sign languages including Polish, Swiss German, Austrian, and French Sign Language (LSF). However, so far no reliable evidence for a genealogical relationship between DGS and LSF, and therefore between DGS and ASL, has been produced (Wittmann 1991).

The choice of DGS and ASL as the sign languages investigated in this study is motivated as follows. First, the lack of historical contact between the languages and fundamental differences in their syntactic organization allow us to isolate the potential impact of the visual-manual modality on the expression of causal relationships between events. Section 5.2 in particular explores to what extent iconic properties of visual languages influence and homogenize the expression of different aspects of causative situations. Second, the vast majority of sign language users are bilingual in at least one sign language and in a (written form of a) spoken language, raising the question of to what extent the linguistic encoding of event structure in any given sign language is influenced by contact with a socio-politically dominant spoken language. DGS and ASL are in constant contact with German and English, which both use resultative constructions to express complex cause-result events. Chapters five and six analyze the 
syntax and semantics of resultative constructions in DGS and ASL against the backdrop of their English and German counterparts. One goal of the dissertation is to show that while DGS and ASL possess similar resources for monoclausal event description as German and English, they impose a different set of constraints on the use of resultative constructions. These findings confirm a major claim of sign language research since the 1960s. Despite undeniable language contact effects, signed languages are not mere visual-manual copies of a surrounding spoken language but have independent grammars that need to be investigated in their own right.

Studying the encoding of complex cause-result events on the clausal level in DGS and ASL will place our understanding of the mechanisms involved in the linguistic description of events on a broader typological and empirical footing. Inasmuch as resultative constructions form part of the core explananda of theories of argument realization, secondary predication, aspect (e.g. telicity), and the linguistic expression of causation, the present study aims to lay groundwork for future research at the syntax and lexical semantics interface in signed languages. Previous work on event structure in sign has focused to a large extent on lexical and morphological aspect (Grose 2008; Klima \& Bellugi 1979; Rathmann 2005) and on the potential of classifier predicates for expressing complex causal and motion events (Benedicto et al. 2008; Kegl 1985; Supalla 1990). The present study expands our understanding of the syntactic resources that sign languages have for sequentially encoding event structure and causality within a clause. Because a thorough understanding of clause boundaries is required for addressing these issues, a major contribution of this thesis lies in reviewing and adding to existing clausehood diagnostics for sign languages. A third focus of the dissertation is to determine the exact nature of the causative relation expressed in ASL resultatives and to compare it to resultative semantics in English. 
The following overarching research questions guide this investigation:

1. Do DGS and ASL encode complex cause-result events as resultative constructions?

2. If so, what are the syntactic and semantic constraints on the use of these constructions? This question breaks down into the following components:

a. Given existing cross-linguistic variation among resultatives, can both activity and accomplishment verbs serve as primary predicates that express the causing activity of a resultative in DGS and ASL?

b. Does the causally affected entity have to be an argument of the primary predicate?

c. Are there semantic restrictions on possible combinations of causing and result predicates? More specifically, can durative and punctual causing verbs be combined with gradable and non-gradable result predicates?

d. Are resultatives limited to expressing prototypical causation where a causer brings about a change of state in an affected entity immediately and through physical manipulation (direct causation)? Do similar factors determine what counts as direct causation in English and ASL?

This dissertation is structured as follows. Chapter 2 situates resultative constructions within a typology of causatives and points out cross-linguistic variation in the syntax and semantics of the construction. It then familiarizes the reader with current syntactic analyses of resultatives, focusing specifically on small clause and complex predicate theories. Further, semantic restrictions on the possible combinations of cause 
and result predicates in English resultatives are introduced and theoretical accounts in terms of homomorphic event-to-scale mappings are discussed. After delineating the main syntactic and semantic issues that form the focus of current linguistic research into resultatives, chapter two concludes with an overview of the sign language literature on causatives in general and resultatives in particular.

Chapter 3 lays out methodological considerations guiding the data collection for this dissertation. Three main elicitation methods were used. In a pilot study, DGS and ASL participants were asked to produce concise descriptions of short videos depicting complex cause-result events. In the next step, potential candidates for resultative constructions from the pilot were further investigated via a grammaticality judgment task that also tested the validity of clausehood diagnostics for the two sign languages under investigation. Chapter 3 describes participants, materials, and procedure for both elicitation methods. A third task involving acceptability judgments of ASL resultatives in different causative situations is described along with the results of that study in chapter 6 .

Since resultatives are by definition monoclausal, a prerequisite for establishing their use in DGS and ASL is having a sizeable inventory of reliable clausehood diagnostics. Chapter 4 opens with a critical evaluation of existing tests for clause boundaries in the spoken and signed language literatures. Two types of tests are of interest for this study: Diagnostics that distinguish between single clauses and two or more coordinate or juxtaposed clauses, and diagnostics that focus on the difference between a full embedded CP and infinitival predicate argument structures. The latter have rarely been discussed in the sign language literature, hence the present study proposes two additional diagnostics, center-embedding and rightward wh-movement across a clause. 
Chapter 5 opens by surveying the different strategies for encoding cause-result events encountered in the pilot study. Special emphasis is placed on iconic representations of various components of the causative situation afforded by the visualspatial modality. The remainder of chapter 5 discusses the syntax and semantics of two resultative constructions in DGS and one in ASL. For each construction, evidence for its monoclausality is presented first, followed by a discussion of potential semantic constraints on possible causing and result predicate combinations. The two DGS resultatives differ in word order, with the result predicate either preceding or following the causing predicate. I propose that both constructions contain complex cause-result predicates but differ in their semantics: Only the [Result Cause] construction exhibits a homomorphic mapping that prevents durative causing verbs from combining with nongradable result predicates. I propose a small clause analysis for ASL resultatives and show that, in contrast to their English counterparts, they do not exhibit semantic constraints on cause and result predicate combinations.

Chapter 6 asks whether ASL resultatives are subject to other semantic constraints that have been claimed to operate on resultative constructions in English. Single-clause causatives are said to denote direct causation, which has been claimed to involve an intentional causer who acts directly on an affected entity and brings about a change of state in that entity immediately. Since these claims have not been tested empirically for resultatives in any language, the first part of Chapter 6 presents the first empirical investigation of factors that influence the degree of directness of causation in English. The results of this study then inform controlled experiments on directness of causation in ASL resultatives. I show that both constructions are sensitive to at least two degrees of directness, and that ASL resultatives differ from English resultatives in not being sensitive to the causer's intentions. 
In chapter 7, I summarize the findings of the present work and provide answers to the research questions introduced in this chapter. I address the theoretical implications of my conclusions with respect to the linguistic encoding of event structure and to the typology of resultative constructions. The chapter concludes with suggestions for future research. 


\section{Chapter 2: Situating the resultative as a causative construction: Insights from spoken and signed languages}

\subsection{INTRODUCTION}

Before we can begin to answer the question of whether ASL and DGS have a resultative construction, we need a better understanding of what resultatives are. The present chapter starts by situating resultatives within a typology of causative constructions (section 2.2) before focusing on the resultative construction itself (2.3). Section 2.3.1 provides a description of cross-linguistic differences and similarities between resultatives, followed by the main syntactic analyses proposed for them (2.3.2), and the semantic constraints operating on the construction (2.3.3). Section 2.4 summarizes and critically evaluates the sign language literature pertaining to causative constructions in general and resultatives in particular.

\subsection{CAUSATIVE CONSTRUCTIONS IN SPOKEN LANGUAGES}

The causative situations that are cross-linguistically encoded in causative constructions typically involve a causing event that temporally precedes (or is coextensive with) a caused event. The caused event tends to consist of a change of state in the affected participant or causee. It is presumed that this change of state would not have occurred at the time in question if the causing event had not occurred (assuming that all other circumstances remain the same). This rather rough sketch of the Lewisian counterfactual theory of causation stems from Shibatani (1976) and shall serve as the basis for a brief discussion of causative constructions in spoken languages.

While serving the same basic function of encoding a causative situation, causatives come in various shapes that can be organized along a continuum of formal compactness or syntheticity (Comrie 1981; Dixon 2000; Givón 1980; Shibatani \& Pardeshi 2002). On the synthetic end of the continuum are lexical causatives such as kill 
and tear, which encode causation as part of their lexical meaning. Thus, kill necessarily describes a situation in which a causer performs some (underspecified) action that leads to a terminal change of state in the causee. The causal relationship may also be marked overtly on the verb via affixation or stem-internal morphological processes. Examples of stem-internal change (taken from Dixon (2000)) can be found in Gulf Arabic, where consonant doubling creates causative verbs from intransitives (e.g. xarab 'go bad' vs. $x a r r a b$ 'make go bad, ruin'), or in the vowel lengthening that marks causatives in Kashmiri (mar 'die' vs. ma:r 'kill'). Japanese has a productive causative suffix -(sa)se, which attaches to transitive or unergative verbs like hasira 'run' in (3).

a. Ziroo-ga hasit-ta. Jiro-NOM run-PAST 'Jiro ran.' b. Taroo-ga Ziroo-ni/o hasira-se-ta Taroo-NOM Jiro-DAT/ACC run-CAUS-PAST 'Taro had/made Jiro run.'

[Shibatani \& Pardeshi 2002: 87]

Even farther towards the analytic side of the causative continuum are serial verb constructions featuring a causative and a lexical predicate in the same clause. Dixon (2000) illustrates this type of construction in Tariana, where causative and lexical verb share a grammatical subject. In (4), both a 'make' and hna 'eat' agree with the $1^{\text {st }}$ person causer although the children are the agents of the eating event. In section 2.3 we will see that resultative constructions occupy the same region of the synthetic-analytic continuum as serial verb constructions in that both contain two lexical predicates within the same clause. It should be added here that while neither serial verb constructions nor resultatives encode causation lexically or morphologically, they are included under the umbrella term 'causative' by virtue of describing causative situations. Chapter six discusses how the causal meaning arises in these constructions. 
nu-inipe-nuku

kwaka-mhade nu-a

nu-hna

1sg-children-TOP.NON.A/S how-FUT 1sg-make 1sg-eat

'How will I get my children to eat (if I can't hunt anything)?'

[Aikhenvald 2000:160]

Syntactic or periphrastic causatives occupy the analytic end of the causative continuum, since causing and caused events are encoded in separate yet hierarchically organized clauses. Typically, the causative verb heads the main clause while the lexical verb heads an embedded clause, which in turn may be finite as in the Macushi example in (5a) or non-finite, as in English (5b). Periphrastic causative constructions further vary in the structural position of the causee. In Macushi, it receives ergative marking from the embedded verb, while being marked as the object of the main clause verb in English. Dixon points out a third option, which is illustrated in the ergative alignment of agreement prefixes in Canela-Kraho in (5c): The first person causee is doubly marked; once as the object of the causative verb to, and once as the single argument of the embedded verb jōt 'sleep'.

a. [imakui’pî kupî Jesus-ya] emapu’tî yonpa-‘pî makui-ya teuren [Macushi] bad do Jesus-ERG CAUS try-PAST Satan-ERG FRUST

'Satan unsuccessfully tried to make Jesus do bad.'

b. John forced/caused him [to eat a worm].

c. Capi te [i-jōt na] i-to [Canela-Kraho]

Capi PAST $1 \mathrm{sgS}$-sleep SUBORDINATOR $1 \mathrm{sgO}$-CAUS

'Capi made me sleep.'

[a. and c. cited in Dixon 2000: 36]

While this formal continuum of causative constructions exhibits some functional overlap, lexical and analytic causatives typically differ in the types of causative situations they describe. An overview of the relevant semantic distinctions will be discussed in chapter 
six. For the remainder of this chapter, I focus on a causative that lies closer to the lexical end of the continuum and is at the center of the present study: the resultative construction.

\subsection{RESUlTATIVE CONSTRUCTIONS}

Resultative constructions are unique among causatives in overtly expressing both the manner of the causing event and its result, without stating the causal relation explicitly. This section starts with a cross-linguistic description of the construction with a focus on English. Section 2.3.2 then introduces the main syntactic theories for analyzing resultatives, while 2.3.3 discusses restrictions on the combination of cause and result predicates induced by event composition. Lastly, section 2.3.4 compares resultatives proper to resultative serial verb constructions so as to highlight their syntactic and semantic similiarities.

\subsubsection{The resultative construction: Description and typology}

First described by Halliday (1967) as resultative attributes, resultative constructions constitute a type of secondary predication on the clausal level: A verb is complemented by an XP that denotes the result state brought about by the event denoted by the verb. Simpson (1983) observes that result XPs denote stage-level properties rather than permanent characteristics of an entity, while the main verb of a resultative construction encodes a change of state (freeze, dye, break) or surface contact (beat, wipe, $r u b)$. Resultatives differ from other types of secondary predication, for example depictives, in that the state denoted by the XP only holds after the onset of the verbal action. In (6a), the table is not clean when Sean begins wiping, but the result state is reached at the end of the wiping event. In the depictive (6b), however, the table (or Sean) 
is clean throughout the event denoted by the verb. Resultatives and depictives also differ in their syntactic distribution, as their co-occurrence in (6c) illustrates. They are strictly ordered with respect to each other, with the resultative immediately following the object (hence the ungrammaticality of (6d)).

(6) a. Sean wiped the table clean.

b. Sean sold the table clean.

c. Mary hammered the metal flat hot.

[McNulty 1988: 38]

d. *Mary hammered the metal hot flat.

Both types of secondary predication share a surface syntactic structure, which is represented in (7a). Result XPs may be adjective phrases (7b), noun phrases (7c), or prepositional phrases (7d), but typically not verb phrases. A main verb followed by a verbal XP is classified as a serial verb construction (SVC), but given the difficulties in determining parts of speech in signed languages, and especially adjectives (Loos 2014; Zeshan \& Schwager 2008), the term resultative construction is used somewhat loosely in this work to cover result XPs that denote stative or change-of-state predicates. Since this is the focus of the present study, PP and NP result phrases will not be discussed.
a. NP V (NP) XP
b. The pond froze [AP solid].
c. She dyed his favorite pants [NP an aggressive orange].
d. Let us beat swords [pp into ploughshares].2

AP resultatives take various shapes. They tend to be transitive, except when they are headed by an unaccusative verb such as freeze in (7b). The affected participant of a

\footnotetext{
2 Title of a sculpture by Yevgeny Vuchetich, found in the United Nations garden.
} 
resultative may or may not be selected by the main verb; the former are often labeled Control resultatives and the latter ECM (Exceptional Case Marking) resultatives after Wechsler (1997). The plate in (8a) is selected by lick, since the sentence is acceptable without the result AP and the thematic role assigned by the verb is identical in the resultative and simple transitive sentences. The unacceptability of a reflexive object without a result AP $(8 \mathrm{~b})$ shows that laugh does not select himself. Non-selected reflexive objects in this construction are therefore commonly referred to as fake reflexives (Simpson 1983). In contrast to the unergative laugh, eat typically takes an object. Since eat assigns a patient/incremental theme role to its object, the only available interpretation for the simple transitive (without empty) in (8c) is that the fridge itself is eaten. When the result XP empty is added, we understand that John consumed the unnamed contents of the fridge. As (8d) shows, this understood participant cannot also be expressed as an argument of the verb. The difference in semantic roles assigned to the fridge in the simple transitive versus the resultative suggests that, in the latter, the affected participant is not subcategorized by the verb. Hence, resultatives with a non-selected object are built on unergative or de-transitivized verbs. It follows that obligatorily transitive verbs such as break cannot occur with a non-selected NP. We can easily imagine a scenario where a clumsy dishwasher broke all the dishes in the cupboard, but we cannot express that scenario using (8e). The distinction between semantically selected and non-selected NPs plays an important role both in syntactic and semantic analyses of resultatives, and I will come back to it below.
a. Mary licked the plate (clean).
b. Harry laughed himself*(breathless).
c. John ate the fridge (empty). 
d. John ate (*the food) the fridge empty.

e. *The dishwasher broke the cupboards empty.

A last descriptive fact to consider here is the relationship between the result predicate and the direct object of the clause. As first noted by Simpson (1983) and elaborated in Levin and Rappaport Hovav's (1995 ) Direct Object Restriction, result XPs have a strong tendency to predicate of the object of the resultative rather than an indirect (9a) or oblique argument (9b) of the verb. In all previous examples, the result predicate describes a result state of the direct object of the construction, except in (7b), where it predicates of the surface subject of an unaccusative verb. Since the subjects of unaccusatives are assumed to be underlying objects that surface as subjects for purely syntactic reasons, Levin and Rappaport Hovav's Direct Object Restriction still holds. However, Wechsler (1997) shows that results can predicate of subjects rather than objects: As a result of the event of following in $(9 \mathrm{c})$, the subject the wise men undergo the change of location denoted by the result state out of Bethlehem; and likewise it is the subject the sailors that arrive clear of the rocks in (9d). According to Wechsler, arguments have to be patients in order to serve as the subject of a result XP, but they need not be direct objects (further counter-examples to the DOR can be found in Verspoor 1997 and Rappaport Hovav \& Levin 2001).

(9) a. *Mary gave the guppies fish food to death.

b. *John kicked at the door open.

c. The wise men followed the star out of Bethlehem. [Wechsler 1997: 313]

d. The sailors managed to catch a breeze and ride it clear of the rocks. 
Cross-linguistically, resultative constructions vary with respect to the descriptive properties introduced above. Some languages do not allow resultatives at all, including the Romance languages, Javanese, Hebrew, and Czech (Son \& Svenonius 2008), while others, such as the Germanic languages, allow them relatively freely. Among the languages that have resultative constructions, we find substantial variation in the types of resultatives allowed. Japanese, for example, only licenses a subclass of Control resultatives, in which the result state is lexically entailed by the verb. ${ }^{3}$ Thus, (10a) is acceptable because someta 'dyed' entails a change in color further specified by pinkuni 'pink'. In contrast, (10b) is judged ungrammatical, since hitting somebody does not entail a result state that can be further specified by 'bloody' (Washio 1997).

a. Mary-ga doresu-o pinku-ni some-ta

[Washio 1997: 5-6] Mary-NOM dress-ACC pink dye-PAST

'Mary dyed the dress pink.'

b. * karera-wa sono otoko-o timamire-ni nagut-ta they-TOP the man-ACC bloody hit-PAST 'They beat the man bloody.'

Korean allows a wider range of Control resultatives than Japanese, but also has no ECM resultatives (Kim 1993). Sentence (11a) exemplifies a Korean Control resultative, whose affected participant bears accusative case. Non-selected NPs such as sinpal 'shoes' in (11b) are not raised into the matrix clause via exceptional case marking but bear nominative case and remain inside a result clause, as illustrated in (11c).

\footnotetext{
3 As Washio (1997) points out, this is true only of constructions with a non-verbal result predicate. Japanese also has VV resultative compounds with fewer restrictions on the change-of-state denoting verb.
} 
(11) a. Mary-nun kumsok-ul [napcakha-key] twutulki-ess-ta

Mary-TOP metal-ACC flat-COMP hammer-PAST-DEC

'Mary hammered the metal flat.'

b. *ku-nun [sinpal-ul talh-key] talli-ess-ta

he-TOP shoes-ACC threadbare-COMP run-PAST-DEC

c. ku-nun [sinpal-i talh-key] talli-ess-ta

he-TOP shoes-NOM threadbare-COMP run-PAST-DEC

'He ran (his) shoes threadbare.'

[Wechsler \& Noh 2001: 16-17]

Williams (2008) provides a typological overview of word order in resultatives (including constructions with verbal result predicates) and shows that it correlates with basic word order in a language and with the phrasal or, arguably, the categorical status of the result constituent. The distinction between Control and ECM resultatives does not seem to have an effect on word order. Looking at such typologically diverse languages as English, Igbo, Paamese, Malayalam, and Japanese, Williams finds that result phrases (where a phrase is defined via the ability to take an adverbial modifier) follow the causing verb and the object in verb-initial languages (12a), while they immediately precede the verb in verb-final languages (12b). Cross-linguistically the third order is only attested with verbal result predicates: As exemplified for verb-final Japanese in (12c), the result predicate may immediately follow the causing predicate. Since the verbs form a complex predicate, no adverbs can intervene between them, leading Williams to postulate that the phrasal status of the result constituent is the main factor determining word order.

\section{a. Verb-initial languages: Subject Verb Object ResultP}

Suzie hammered the metal (extremely) flat. 
b. Verb-final languages: Subject Object ResultP Verb

John-wa niku-o (totemo) yawaraka-ku ni-ta

J.-TOP meat-ACC (very) soft-INFIN boil-PAST

'John boiled the meat (very) soft.' [Washio 1997: 9]

c. Verbal result predicate: Subject Object Verb Result

$$
\begin{aligned}
& \text { John-ga Mary-o uti (*korituyoku) korosi-ta } \\
& \text { J.-NOM M.-ACC shoot (efficiently) kill-PAST } \\
& \text { 'John (efficiently) killed Mary by shooting.' }
\end{aligned}
$$

[Williams 2008: 510]

\subsubsection{The syntax of resultatives}

I now turn to a discussion of the syntactic structure of resultative constructions. Resultatives have been analyzed in both generative and functional theoretical frameworks, each illuminating different aspects of the construction. Since the main goal of this dissertation is to assess whether certain cause-result expressions in DGS and ASL share a syntactic structure and semantic properties with resultative constructions in languages like English, I approached the data from a generative, principles and parameters based perspective. Its precise formalization of clause structure and diagnostics for determining clausehood make generative grammar particularly suitable for identifying and describing monoclausal constructions such as resultatives. It should be pointed out, however, that functional approaches such as Construction Grammar have provided valuable insights on the resultative construction (Boas 2003; Boas 2005; Goldberg 1995; Goldberg \& Jackendoff 2004; Iwata 2006). 
In contrast to generative grammarians, proponents of Construction Grammar assume that resultatives constitute a form-meaning pairing: A sentence of the form $\mathrm{NP}_{1}$ $\mathrm{VP}\left(\mathrm{NP}_{2}\right) \mathrm{XP}$ has the meaning ' $\mathrm{X}_{1}$ causes $\mathrm{Y}_{2}$ to become $\mathrm{Z}_{3}$ by means of the verbal subevent' (Goldberg \& Jackendoff 2004: 538). Assuming that the resultative construction itself carries meaning beyond the meaning of its predicate components allows construction grammarians to account for the causative semantics of the construction in a straightforward way. Since no element of a resultative overtly encodes causation, linguists working in a generative framework need to postulate covert operators or null affixes to capture this central fact about resultatives. However, because the focus of Construction Grammar is to account for the semantic similarities of a range of related subconstructions, less emphasis has been placed on properties of resultatives important to the current investigation. For instance, since the resultative construction comes with its own argument structure and licenses a causer $\left(\mathrm{X}_{1}\right)$ and a causee $\left(\mathrm{Y}_{2}\right)$ argument, typological variation between languages that have only Control resultatives versus languages that have only ECM resultatives has not been addressed in Construction Grammar. Neither have principled distinctions between Control and ECM resultatives when it comes to homomorphy requirements (discussed in section 2.3.2). The latter are furthermore argued to be based on exceptions or subclasses of the resultative construction that need to be memorized individually during language acquisition. Since this dissertation seeks to establish whether DGS and ASL have both Control and ECM resultatives and whether the former exhibit homomorphic mappings, generative research that has addressed these questions informs the current investigation.

Generative syntactic accounts of resultatives focus on two related issues: the position of the affected participant and the type of phrase projected by the result predicate. The position plays an important role in accounting for semantic restrictions on 
combinations of causing and result predicates, while the result phrase type establishes the monoclausal nature of resultative constructions. This section is mainly concerned with the syntax of the result phrase, which will enable me to assess the monoclausal status of resultatives in ASL and DGS.

Simpson (1983) treats the result XP as a complement to the main verb rather than an adjunct, a hypothesis that has received much empirical support for English (Carrier \& Randall 1992; Levin \& Rappaport Hovav 1995; Rothstein 2004). It has been observed that verbs s-select a result predicate that denotes a (stage-level) property rather than a dynamic process or activity (13a). Further, this result XP is internal to the VP, since in contrast to depictives (13c), it is obligatorily included in do so ellipsis (13b) and appears closest to the verb when accompanied by another secondary predication (13d) or a proper adverb (13e). Lastly, when undergoing long wh-extraction, result XPs exhibit the weak subjacency effects (13f) associated with argument small clauses (13g) rather than the strong island effects (caused by ECP violations) of depictives (13h).

(13) a. Mary hammered the tuning fork flat $/ *$ resonate.

b. *Bill fastened the shutters open, and Mary did so shut.

c. Jason wiped the table tired and May did so wide awake.

[Levin \& Rappaport Hovav 1995: 49]

d. Jane painted the car $_{\mathrm{i}} \mathrm{red}_{\mathrm{i}} \mathrm{drunk}_{\mathrm{j}} / \mathrm{drunk}_{\mathrm{j}}$ red $_{\mathrm{i}} . \quad$ [Rothstein 2004: 61]

e. Jane painted the car red slowly/*slowly red.

f. *How hot do you wonder whether John heated the wine?

g. ??How intelligent do you wonder whether John considers Bill?

h. **How ill do you wonder whether Mary drank the wine?

[Dalmi 2005: 152] 
Assuming that the result predicate forms (part of) the complement of the causing verb, different syntactic structures have been proposed to underlie resultative constructions. These proposals differ mainly in whether the result predicate and the postverbal NP form a constituent or not. While Small Clause Theory assumes that they form a clausal constituent, Predication Theory analyzes both NP and result XP as complements of the verb in a ternary branching structure where predicational relationships are established via symmetric c-command (Williams 1983, Carrier \& Randall 1992). A third approach analyzes cause and result predicate as a predicate complex that jointly takes the postverbal NP as its object. I will address small clauses and complex predicates here and leave aside Predication Theory, as it requires syntactic machinery that is not independently motivated elsewhere in the syntax (ternary branching, establishing predication via co-indexation of predicate and NP).

Small Clause Theory (Stowell 1983) assumes that a predication relation holds between the result predicate and the affected participant. This relation is established via sisterhood in a small clause (SC) (14b). As exemplified in the epistemic small clause in (14a), these constituents are morphologically and structurally reduced in comparison to full clauses in English since they do not exhibit any inflectional morphology.
a. Jackie considers [sc Helen smart].
b. Jackie shook [sc Helen awake].

Nonetheless, Contreras (1995) shows that they must have at least some functional structure on top of the lexical projection of the SC predicate. Using evidence from NPI licensing, he demonstrates that the postverbal NP asymmetrically c-commands the small clause predicate and must therefore sit in the specifier of a functional projection. A negative polarity item needs to be inside the c-command domain of its controller, and if the NP and the predicate inside the SC were sisters and thus c-commanded each other, the misanthropic (15a) and (15b) should be equally acceptable. The ungrammaticality of $(15 b)$ suggests that anybody is higher up in the tree than its controller no. 
(15) a. I consider nobody any good.

[Contreras 1995: 139]

b. $*$ I consider anybody no good.

Echoing Contreras, Guéron and Hoekstra (1995) propose that the functional projection in whose specifier anybody sits is agreement, which establishes the predication relation, and that small clauses differ from full clauses in lacking a tense operator. Crosslinguistic evidence for an agreement projection in small clauses comes, for example, from Finnish resultatives and French small clauses: Postverbal NP and result predicate agree in number in Finnish (16a), and in gender and number in French (16b).

a. Vauva konttasi housunsa vihreiksi. baby.NOM crawled pants.PL.ACC.3Px green.PL.TRA

'The baby crawled his/her pants green.' [Kim \& Maling 1997: 197 ]

b. Je considère la candidate trop vieille /*vieux /*vieilles. I find the.FEM candidate.FEM too old.FEM/ old.MASC/ old.FEM.PL 'I find the (female) candidate too old.' [Starke 1995: 250 ]

The proposed structure of resultative constructions in Small Clause Theory following Hoekstra (1988) and Guéron and Hoekstra (1995) is provided for sneeze him awake in Figure 1.

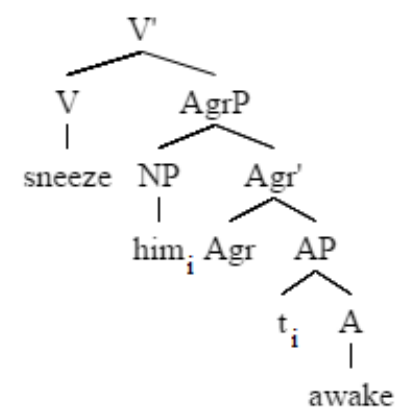

Figure 1: Small clause analysis of resultatives 
Hoekstra (1988) and more recently Kratzer (2005) argue that all resultatives at least in English, German, and Dutch, are formed from intransitive verbs, and that the direct object interpretation of the postverbal NP in Control resultatives arises from semantic (Kratzer) or pragmatic (Hoekstra) principles. In broad strokes, if a piece of metal ends up flat as the result of a hammering event, it is world knowledge that lets us assume that the hammer was acting directly on the metal. Alternatively, Control resultatives have been analyzed as taking small clause control complements à la John hammered the metal ${ }_{i}\left[P R O_{i}\right.$ flat . The PRO subject of the small clause in this analysis is controlled by the direct object of the matrix verb (e.g. Stowell 1995).

An alternative to both Small Clause and Predication Theory was first proposed in Chomsky (1955/75) and assumes that the causing verb and the result XP initially form a complex predicate with cumulative selectional restrictions. In one representative analysis, Neeleman and van de Koot (2002) propose that the predicates are semantically integrated via identification or embedding. With (obligatorily) transitive verbs, the lexical semantic representation of the result predicate is identified with the result state component of the verb, while unergative verbs compose with secondary predicates via embedding. General interpretive principles such as the fact that activities can embed a result state but not vice versa ensure that the lexical semantic representation of the causing verb embeds that of the result state rather than the other way around. The resulting predicate complex then takes the postverbal NP as its internal argument. Adopting a VP shell analysis (Larson 1988), the verb moves to little $v$ in English (17a), while remaining in situ in Germanic OV languages like Dutch and German (17b) (Neeleman \& van de Koot 2002, also Müller 2002 for German).
a. [vP John $\left[v\right.$ sneezed- $v$ [vP him $\left[v \mathrm{t}_{\mathrm{V}}\right.$ awake $\left.\left.\left.\left._{\mathrm{A}}\right]\right]\right]\right]$.
b. [CP dass [TP ...[vP John $\left[v v\right.$ [vP ihn $\left[\mathrm{v} \mathrm{wach}_{\mathrm{A}}\right.$ niest $\left.\left.\left.\left.]\right]\right]\right]\right]$.
that John him awake sneeze 
Ultimately, the main difference between the small clause and the complex predicate approach is whether the result predicate projects a clause-like constituent to the exclusion of the causing predicate or not; and whether that constituent contains the postverbal NP. Both approaches have attracted their own sets of criticisms (for example Boas 2003). The very existence of small clauses is called into question by the failure of [NP XP] to pass run-of-the-mill constituency tests (e.g. replacement by a proform, topicalization, or serving as answer to a question). Balazs (2012) claims that small clauses can function as subjects and therefore form phrasal constituents, yet her examples (18a) and (18b) are somewhat marginal. In comparison, causing and result predicate behave as a single constituent at least in German and Dutch (for the latter, see Neeleman \& van de Koot 2002). The German predicate complex wach niesen 'sneeze awake' in (18c) may be topicalized and is co-referential with the proform das 'that'.

a. [sc Tommy and Zaneeta in a relationship] wasn't good for Mayor Shinn's blood pressure.

b. Eulalie considered [sc Tommy and Zaneeta in a relationship] bad for Mayor Shinn's blood pressure. [Balazs 2012: 12]

c. Wach niesen, das kann John gut. awake sneeze that can John good 'John is good at sneezing (people) awake.'

In contrast to the complex predicate approach, which lumps all resultatives together, SC theory can distinguish syntactically between Control and ECM resultatives. Such a distinction is desirable to account for cross-linguistic differences between languages that have only Control but not ECM resultatives. We will further see in the next section that restrictions on the combinability of cause and result predicate are sensitive to this distinction and a syntactic theory that reflects it is thus preferable. 


\subsubsection{The semantics of resultative constructions}

Resultatives denote a single event derived from but not identical to the eventualities denoted by their component predicates. As first discussed in Dowty (1979), the derived eventuality represents an accomplishment, consisting of an activity and a resulting change of state in the object (following Vendler's 1957 classification of aktionsarten). ${ }^{4}$ Verbs in the resultative construction denote either processes, which lack a change-of-state component (wipe, hammer, shake), or they encode a change of state (break, freeze); whereas the secondary predicate in resultatives contributes a result state. When the verb denotes a change of state, the result predicate aligns with the end state implied by the verb rather than introducing a completely new state (termed weak resultatives in Washio 1997, e.g. He broke the bottle open/*useless).

The main explanandum of any aspectual theory of resultatives is how the individual eventualities contributed by verb and adjective compose, given that there is no overt marking of such composition. Beavers (2012) provides a concise overview of the difficulties involved in developing a single analysis of all attested resultatives: In a nutshell, a theory of event composition in resultatives has to allow for both activity and change verbs (but exclude statives) as well as explain the observed differences between Control and ECM constructions. To address the first point, one line of research assimilates all verbs to change verbs, assuming that activities have the potential for an (unspecified) result state (e.g. Wechsler 1997, Rothstein 2004). The alternative route involves assimilating change verbs to activities such that all verbs in resultatives denote processes, which are composed with the state-denoting XPs via some causal operator/morpheme/head (e.g. Hoekstra 1988, Kratzer 2005, Folli \& Harley 2004).

\footnotetext{
${ }^{4}$ It should be noted that resultatives can also denote achievements, provided that the causing verb is a semelfactive (shoot, knock) or an achievementand itself, and the adjective is non-gradable (e.g. He shot/knocked the sheriff dead).
} 
The difference between Control and ECM resultatives does not fall out from either approach but is represented via optional argument sharing (Carrier \& Randall 1992), multiple theta-role assignment to the same NP (e.g. Pustejovsky 1991 ), or different type-shifting rules to create transitive and intransitive change verbs (Rothstein 2004). I mention the distinction here because it has repercussions for the two types of semantic constraints on resultatives investigated in this dissertation: Only Control resultatives are subject to combinatory restrictions on cause and result predicates and express direct causation. No such constraints seem to apply to ECM resultatives (but see Levin 2015 for potential directness constraints on ECM resultatives). I will return to directness of causation in resultatives in chapter six and focus on the combination of cause and result predicate for the remainder of this section.

Restrictions on which activity verbs can combine with which types of adjectives in a resultative are generally considered a result of telicity (aspectual boundedness). Resultatives pattern with lexical accomplishments in passing Dowty's (1979) telicity diagnostics: Given a definite, specific postverbal object, both are acceptable with in temporal adverbials but less so with for adverbials (19) and give rise to the imperfective paradox (20). A telic predicate describes an event with a natural and definite endpoint, hence something that can be completed within a particular amount of time (as opposed to an activity such as \#John wiped the floor in an hour). The fact that such a complex event consists of both process and result subparts also means that no single subpart is identical to the event as a whole, giving rise to the imperfective paradox. For example, no true subpart or subinterval of wiping the floor clean in (20b) encompasses the final result state of the floor being completely clean; hence the complex event is not entailed by any of its subintervals. Compare this to the simple activity John is wiping the floor, which does entail that John wiped the floor. 
(19) a. John cleaned the floor in/? for an hour.

[Beavers 2012: 915]

b. John wiped the floor clean in/?for an hour.

(20) a. John is cleaning the floor. $\nRightarrow$ John has cleaned the floor.

b. John is wiping the floor clean. $\nRightarrow$ John has wiped the floor clean.

The question thus arises how telicity is introduced into a resultative construction when neither of its predicative components is telic. Wechsler (2005) and Beavers (2002, 2008) argue that resultative constructions are subject to a temporal dependency relation best characterized as a homomorphic mapping between the event and its affected participant. Homomorphic mappings relate two algebraic objects while preserving certain aspects of the structure of each, in this case the set of ordered subevents of the causing event and the set of degrees on a property scale contributed by the result predicate. Following Krifka's (1998) homomorphic model of telicity, Wechsler proposes that temporally adjacent parts of the wiping event in (19b) correspond to adjacent and progressively higher degrees on the scale of cleanliness of the table. Telicity arises when the scale denoted by the result predicate provides a final endpoint to the event. There is an upper bound to how clean an object may become (namely when no speck of dirt is left on it), which provides a natural endpoint to the wiping event (Wechsler 2005). Wechsler argues that only Control resultatives require a homomorphic event-argument mapping since the affected participant forms part of the argument structure of the verb.

Two predictions follow from a homomorphic account of telicity in resultatives. First, the result XP has to introduce a salient natural endpoint to the event, and second, co-extensiveness requires that the causing event and the change of state in its affected participant happen either both instantaneously or both over time. Wechsler (2005) explores the first prediction for adjectival XPs and claims that only non-gradable adjectives and gradable adjectives associated with an upper-bounded scale can provide a suitable endpoint for the event. As already discussed, flat in (21a) provides such a suitable endpoint, since the event ends when the spoon is completely flat. Both flat and 
useful are gradable adjectives (they accept degree modifiers, as in (21b)) and are therefore interpreted with respect to a standard - but they differ in how this standard is supplied. Closed-scale adjectives like flat have a lexically supplied standard that corresponds to the maximum degree on the associated scale, while open-scale adjectives like useful have to be interpreted with respect to some contextual standard and therefore cannot take modifiers such as completely (21c) (Hay et al. 1999; Kennedy 1999; Kennedy $\&$ McNally 2005). Wechsler argues that boundedness must be a lexico-semantic feature of the result predicate since the semantic composition of causing verb and result predicate occurs at the lexical level, before contextually supplied standards become available. In addition to open-scale adjectives, the boundedness requirement excludes adjectives such as wet in (21(21d), whose inherent minimum standard is not sufficiently salient to provide the required endpoint to a resultative. Objects can be characterized as wet as soon as they exhibit a minimal degree of moisture, but this inherent standard is frequently overruled by contextual standards: A father might, for example, not consider his child's toothbrush as wet if said child sprinkled only a few drops of water on it to get out of brushing their teeth. Wechsler therefore classifies adjectives with a minimum inherent standard as de facto open-scale.

(21) a. Mary hammered the spoon flat/*useful.

b. The spoon is very flat/useful.

c. The spoon is completely flat/*useful.

d. Sandra wiped the table clean $/{ }^{*}$ wet.

Note that the maximal endpoint closed-scale adjectives in (21) co-occur with durative verbs such as hammer and wipe. Under the event-argument homomorphism model, non-gradable adjectives may also occur in resultative constructions, but only when complementing punctual verbs. Wechsler (2005) first notes that a durative verb like beat in (22) can occur with gradable adjectives like senseless but is incompatible with non-gradables like dead. 
(22) a. The outlaw knocked/beat the sheriff senseless.

b. The outlaw knocked/*beat the sheriff dead.

[Beavers 2008: 247]

Following Krifka's (1998) idea of modeling events and their participants as mereological (part) structures, Wechsler (2005) provides an explanation for the durativity - gradability correlation in terms of the compatibility of the objects denoted by the verbal and adjectival expressions. Beavers (2008) formalizes these ideas as follows: Durativity and gradability are conceptualized in terms of two part structures that can either be minimally complex or complex and that map onto each other. Punctual events and non-gradable scales constitute minimally complex objects (MCOs) by virtue of having only two parts: a beginning and an end. Durative events have a beginning, a middle, and an end portion and thus form complex objects (COs), as do gradable scales with their infinite number of degrees. In a resultative, like in any dynamic predicate, event and scale have to be both MCOs or both COs to ensure that there is "enough" event to map onto a scale or vice versa. If we further take into account that many adjectives in English are underspecified for gradability and can be interpreted either as gradable (e.g. flat in (23a)) or as nongradable (flat in (23c)), This approach predicts which cause and result predicate combinations should be (un)grammatical:

(23) $\sqrt{ }$ Durative verb + (maximal endpoint) gradable adjective

a. John watered the tulips flat.

$\sqrt{ }$ Punctual verb + non-gradable or underspecified adjective

b. John shot the sheriff dead.

c. John stomped the flowers flat (with one quick motion).

* Durative verb + non-gradable adjective

d. *John beat the sheriff dead. 
The restrictions on combinability in (23) have been studied in depth for English but to my knowledge have not been replicated in other languages. This is partially due to the paucity of studies focusing on resultative constructions in languages other than English. For German, Mandarin, and Japanese, however, we know that resultative constructions may consist of durative verbs and open-scale adjectives (24a, c, d,e), and at least in German, a durative verb may combine with a non-gradable adjective, as the unfortunate ducks in (24b) illustrate.

German

a. Der Friseur sprüht die Haare der Kundin nass. the stylist spray.3SG the hair the.FEM.GEN client wet 'The stylist is spraying the client's hair wet.'

b. Rentner füttern Enten tot. 5 retiree feed ducks dead 'Senior citizens feed ducks to death.'

\section{Mandarin}

c. wo qiāo-wú-shēngxī-de xiàchuáng dào xiliañjiān qù

I quiet-no-sound-ADV get.up arrive wash.face-room go wèi tā xĩ-shī le yī tiáo máojīn for he wash-wet PFV one CLF towel 'I got up quietly, I went to the toilet and I soaked a towel for him.'

[Basciano 2011: 16]

Japanese

d. John-ga gomu-o nagaku nobasi-ta. John-NOM rubber-ACC long stretch-PAST

(lit.) 'John stretched the rubber long.'

\footnotetext{
${ }^{5}$ http://www.bild.de/news/inland/tierquaelerei/fuettert-enten-tot-47518646.bild.html, Accessed 11/7/2016.
} 


\section{e. John-ga musuko-o joobu-ni sodate-ta. John-NOM son-ACC tough-COP bring.up-PAST}

(lit.) 'John brought up his son tough.'

[Uegaki 2014: 4]

To account for such cross-linguistic variation in homomorphic mapping requirements, researchers have proposed that the syntactic or thematic structure of English resultatives differs from that of their German and Mandarin counterparts. Williams (2014) argues that Mandarin verbs only take an eventive argument, voiding the requirement for a homomorphic mapping, while Kratzer (2005) and Müller (2002) propose that German only has ECM-type resultatives. For Japanese, Uegaki has argued that the causing verb, which has to denote a change of state, introduces the scale along which the complex event is measured. The result phrase acts as a scale modifier by contributing an endpoint to the verbal scale. This endpoint may be based on either an absolute standard, as contributed by the scale of maximal endpoint adjectives, or on the contextually determined standard associated with open-scale adjectives.

The present study investigates whether cause-result constructions in ASL and DGS exhibit the combinatory restrictions listed in (23) in order to establish whether they are characterized by homomorphic event-to-scale mappings or not.

\subsubsection{A note on Serial Verb Constructions (SVCs)}

As discussed in section 2.3.1, many sign languages lack robust part-of-speech diagnostics, which prevents us from establishing the verbal versus adjectival status of the result predicates discussed in this dissertation. It is thus very much possible that these predicates are verbal and the constructions in which they occur are serial verb constructions. SVCs are frequently used in sign languages to express other types of complex events, such as complex movements (see Supalla 1990 for ASL, Slobin \& Hoiting 1994 for Dutch SL, and Benedicto, Cvejanov, \& Quer 2008 for Argentinian and 
Catalan SL). Allowing for the possibility that resultatives in ASL and DGS may be SVCs, the question then arises whether we would expect them to exhibit a different syntax and different semantic constraints on combinability and directness than what I have described in the preceding sections. The preliminary answer is no. Just like resultatives proper, SVCs are monoclausal constructions that express a single, if complex, eventuality via (at least) two predicates (Aikhenvald 2006). In fact, some researchers on resultatives consider them essentially the same construction and assume that in both cases, the second(ary) predicate is embedded under the main verb (Collins 1997; Stewart 1998; Tomioka 2006). In contrast to (ECM) resultatives, SVCs always involve argument sharing (Baker 1989; Collins 1997). Semantic parallels have also been observed: Stewart (1998) claims that resultative SVCs in Èdó are sensitive to direct causation constraints, since they require that "there is a strict cause-effect relationship between the verbs and there is not time lapse between the eventualities that they express" (1998: 16). Like resultatives in English, Èdó result SVCs are telic while their component verbs are not, suggesting that telicity is a constructional feature of SVCs as well. Wechsler (2003) discusses SVCs in Thai and finds that their second(ary) predicates determine the aspectual properties of the complex event: Change-of-state motion predicates best translated into English as 'arrive' and 'enter' impose telicity on an event and require a homomorphic mapping between motion and change of state events. In (25), khâw 'enter' licenses an interval adverbial and forces the odd reading in which it took Piti ten minutes to walk into the school - a walking event preceding the entering event cannot be included in the interval. 
(25) Piti den khâw (pay nay) rooprian nay welaa sìp naatii.

Piti walk enter go in school in time ten minute

'Piti spent 10 minutes walking into the school.'

[Wechsler 2003: 7]

To summarize, we have seen evidence that supports the hypothesis that resultatives proper and resultative SVCs essentially differ only in the lexical category of their secondary predicate but otherwise exhibit similar syntactic and semantic characteristics. This allows a description of resultative constructions in ASL and DGS independent of the part of speech of the result predicate.

\subsection{HOW ARE CAUSAL RELATIONS EXPRESSED IN SIGNED LANGUAGES?}

A recent discussion in a facebook group devoted to sign linguistics featured the question of how ASL expresses causative events. The fact that this question was posted by an eminent researcher in the field in 2016 and received a number of puzzled responses by equally eminent sign linguists may serve as anecdotal evidence for how little is known about the expression of causal relations in signed languages. What we do know is summarized in this section. For clarity of presentation's sake, the discussion is structured by morpho-syntactic type of causative, starting with lexical causatives (section 2.2.2), followed by morphological (2.4.3) and periphrastic causatives (2.4.4) as well as pragmatically implied causation (2.4.5), and concluding with an overview of what we know so far about resultatives in signed languages (2.4.6). Before delving into the discussion of causative expressions in sign languages, however, I will provide a brief overview of pertinent phonological and morpho-syntactic characteristics of (most) signed languages. 


\subsubsection{A whirlwind tour of sign language grammars}

The visual-manual modality affords grammatical uses of the body in space that linguists working primarily on spoken languages may not be familiar with. Looking at a typical ASL sentence such as (26) from my corpus, we see that sign language examples typically consist of two to three lines: the first line contains non-manual grammatical or prosodic information whose temporal extent over the manual signs is marked by the length of the black line underneath. In (26), raised eyebrows indicating topic marking accompany the first three signs of the utterance. Non-manual marking encompasses all grammatical behaviors that are not executed by the hands, such as eyebrow movement, gaze, blinks, as well as head and torso movements. The second line in (26) provides a gloss for the manual signs, which are represented via their English translation equivalents in small caps. Bear in mind that the choice of gloss does not represent an analysis of the syntactic and semantic distribution or even the word class of the ASL sign; the sign DEAD, for example, can describe a property as well as a verbal achievement.

top

RUN CL-1:person_run_in_circle DEAD, IX-lf RABBIT TEND-lf POSS-lf

'As for running (themselves) to death, rabbits tend to do that.'

Pronominal reference is established by pointing to a referential locus associated with a particular referent and is glossed as IX (for index) followed by a location in signing space (e.g. IX-lf means the signer points to their left, where the rabbit had been established previously in the discourse). Referential loci are also exploited in the agreement system of many sign languages in that predicative signs may either be signed at or face the referential locus of one of their arguments (typically the patient), or move 
from or towards that locus. Thus, the hands start at the signer's chest for TEND-lf 'tend to' in (26a), and then move towards the signer's left, showing agreement with the referential locus of the rabbits. Phonotactic constraints bar some signs from agreeing, for example body-anchored signs like KNOW, which is performed at the forehead.

Every sign consists of a handshape with a particular orientation, a location, and a movement. The sign DRY in Figure 2, for example, is characterized by a handshape with a downward-facing palm (orientation) and both an internal and a path movement executed at the chin (location). The hand describes a path from the contralateral side of the chin outwards, while a hand-internal movement leads to a handshape change to $(\mathrm{X})$.

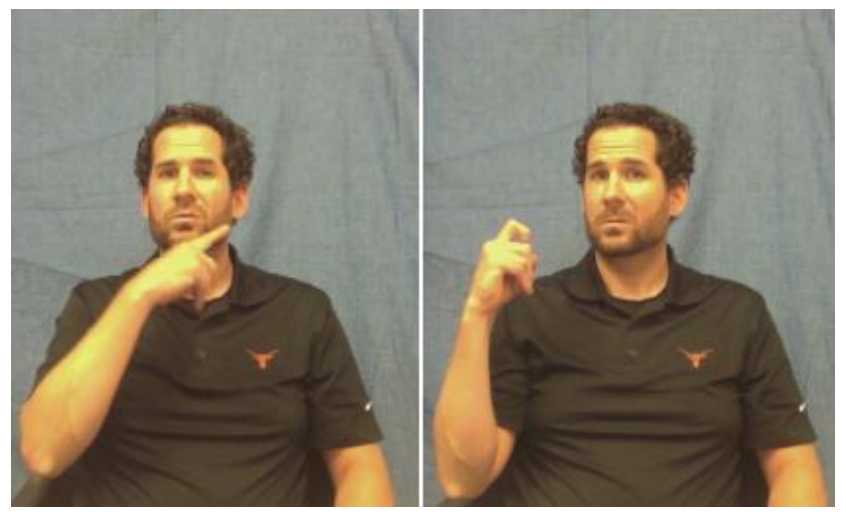

Figure 2: The sign DRY in ASL

These phonological parameters contrast: for example, changing only the location feature of DRY to [forehead] results in the sign SUMMER. In lexical signs, the phonological parameters are typically meaningless, while in so-called classifier predicates (marked as CL in glosses) they carry meaning. Take for example CL-1:person_run_in_circle in (26): The sign has the same (1)-handshape as DRY, but here the handshape represents an 
anthropomorphized rabbit (an upright entity) and the circular movement of the sign signifies circular motion of the referent. Classifiers abound in ASL and many other sign languages, and in addition to motion events denote spatial relations as well as shapes and dimensions of objects (for an overview of classifier predicates, see Sandler \& LilloMartin 2006).

Lastly, the spatial grammar of ASL coupled with the lower speed of the manual articulators compared to the vocal tract articulations (Klima \& Bellugi 1979) may have led to the development of simultaneous morphology to mark predominantly aspectual distinctions. Continuous or habitual aspect, and potentially durativity of events can be represented via changes to the movement contour or speed of execution of a sign.

Having completed our whirlwind tour of sign language grammar, we now turn to an overview of the existing literature on causation in ASL and other signed languages.

\subsubsection{Lexical causatives}

Engberg-Pedersen (2010) provides a comprehensive overview of causative expressions in Danish Sign Language (DTS). Her focus is on labile verbs such as ÅBNEDØR 'open a door', which have the same phonological form in the causative and the inchoative. She shows that the verbs in question constitute lexical rather than morphological causatives by examining whether the handshapes of the signs in question are morphemic. As we will see in the next section, handling classifier morphemes typically cross-reference an agentive causer in classifier predicates. Engberg-Pedersen shows that the handshapes of labile verbs in DTS originate from handling and whole entity classifiers but the former no longer function as agentive or causative morphemes in the lexicalized forms. They are neither necessary for introducing a causer nor does their presence force a causative use of the verb. Thus in (27a), we see that ÅBNE-DØR is used as

a causative in a request to open a door, but the verb's $\Rightarrow$ (B)-handshape represents the 
affected entity rather than a person's hand opening it. In contrast, the handling classifier

(S) used for BREAK in (27b) does not imply that someone snapped the ankle in two, but only describes the change of state. Engberg-Pedersen thus shows that these predicates, while presumably derived from predicates with morphemic handling and entity classifiers, have developed into lexical causatives in DTS.

a. PLEASE ÅBNE-DøR/

'Would you please open the door?'

[Engberg-Pedersen 2010: 53]

b. RH: PLUS ankle(M) / arm-horizontally / TWO arm-horizontally------- BREAK

LF: PLUS IX-wrist IX-wrist IX-wrist

'... and his ankle [was broken] in two places.'

[adapted from a longer example in Engberg-Pedersen 2010: 50]

The existence of transitively used predicates such as ASL KILL and DGS TÖTEN 'to kill' suggests that the two sign languages under investigation here make use of lexical causatives as well. However, detailed studies of the syntactic distribution of such verbs, and whether they alternate with lexical inchoatives are still outstanding. Future research should also investigate the status of handling and entity classifiers in lexical causatives derived from classifier predicates in ASL and DGS.

\subsubsection{Morphological causatives}

The earliest discussions of causative morphemes in ASL stem from the dissertation work of Bernstein (1980) and Supalla (1982). Studying the acquisition of motion and location verbs in ASL, Bernstein elicited morphological causatives, while Supalla investigated the corresponding inchoative verbs. They noticed that, in classifier predicates, an agentive (volitional) causer is typically cross-referenced on the verb via a handling classifier, and that these verbs systematically alternate with a set of inchoative 
verbs, which encode only the theme argument via a whole entity classifier. An example is provided in (28): In the transitive (a) variant, the predicate MOVE is formed with a (C)-handshape that represents the manual action of the causer handling and moving a book (hence both causer and affected participant are encoded in this handshape). This handshape is absent in the intransitive (b) variant, where only the falling book, that is the theme, is represented via the (B)-handshape classifier for flat entities. According to Benedicto and Brentari (2004), the handling classifier may be analyzed as a transitivizing morpheme which attaches to a movement root. If the handling classifier encodes causation and it has morphemic status, classifier predicates should be classified as morphological causatives.

a. IX BOOK C+MOVE

s/he book object_grab(handling classifier) + move_vertical-to-horizontal 'S/he took the (standing) book and layed it down on its side.'

b. BOOK B+MOVE

book 2D_flat_object(whole entity classifier) + move_vertical-to-horizontal 'The (standing) book fell down on its side.'

[Benedicto \& Brentari 2004: 769]

There is some discussion in the literature as to whether the handling classifier expresses causation or agency, with $\mathrm{Kegl}(1985,1990)^{6}$ arguing for the former and Benedicto and Brentari (2004) claiming that the external argument of such predicates is an agent rather than a causer. The distinction, however, seems to be a terminological rather than a substantive one and may be better described in terms of types of causation.

\footnotetext{
${ }^{6} \mathrm{Kegl}(1985: 131)$ extends her generalizations about the causer arguments to lexicalized transitive verbs in ASL (for example ENCOURAGE). Benedicto and Brentari (2004) note, however, that the causative/ inchoative contrast is neutralized in the process of lexicalization as one member of the verbal pair falls out of use and both causative and inchoative meaning are expressed by the same lexicalized verb. Hence, the focus of this discussion rests on classifier predicates only, since their iconic potential seems to be responsible in large part for whether they license a causer argument or not.
} 
Kegl (1985) already notes that predicates with a handling classifier ${ }^{7}$ by their very nature express physical handling of an object that thereby undergoes a change of state, which she ties to an affinity of these verbs to denote direct causation. Manipulative and direct causation often go hand in hand but they are independent semantic notions, and Benedicto and Brentari's data provide evidence that manipulation is the relevant distinction for the analysis of transitive classifier predicates. As their example (29) illustrates, a handling classifier may represent the action of a causer on an instrument, in this case a saw held with an $7(\mathrm{~S})$ - handshape, that in turn acts upon the affected object wood. The use of tools represents a case of indirect causation because the causer relies on an intermediary means to effect the change of state. At the same time, the causer brings about the result state via physical manipulation of an object, characterizing the use of tools as manipulative indirect causation.

IX \#PLANKS S-SAW_WOOD

3sg planks handling.classifier+saw_wood

'They sawed the planks.' [adapted from Benedicto \& Brentari 2004: 773]

Benedicto and Brentari analyze the external argument of predicates with a handling classifier as an agent rather than a causer because such predicates do not license all types of causers but only those that effect change in an object by physically manipulating either the object itself or a tool acting on it. ${ }^{8}$ Another way of framing this

\footnotetext{
${ }^{7}$ Both Kegl (1985) and Benedicto and Brentari (2004) make no distinction between productive classifier predicates and lexicalized forms with a handling classifier. Since Engberg-Pedersen (2010) has shown that handling classifiers in DTS no longer function as causative morphemes in some lexical predicates, I will focus only on classifier predicates here.

${ }^{8}$ One of Benedicto \& Brentari's main arguments for treating the external argument of a predicate with a handling classifier as an agent rather than a causer is Kegl's (1990: 156) observation that change-of-state verbs such as MELT and BOIL do not allow an external argument:

*COOK-PERSON MELT BUTTER

'The cook melted the butter.'
} 
distinction is to say that handling classifiers are causative morphemes but that they are restricted to expressing manipulative causation. Cross-linguistically, synthetic causatives tend to express manipulative rather than directive (telling someone to do something) causation, thus ASL follows a well-established typological pattern. The modality-specific visual iconic potential of signed languages arguably facilitates the development of manipulative causation morphemes. Not only can signs represent manual actions iconically, but such representation allows referencing both causer and causee in the verb's handshape (since, for example, a book is held differently from a cup), as Kegl (1985) notices. A directive causative morpheme could represent the causer's vocal or signed instructions, but arguably could not encode the causee (since there are no visually distinctive ways of talking to different persons). ${ }^{9}$ The question remains how direct the physical manipulation of an object needs to be for a causer to be licensed by a classifier predicate. As shown in (29), change effected with the help of a tool may be expressed via a causative morpheme, but according to Benedicto and Brentari (2004), actions such as melting butter cannot be expressed with an overt causer in ASL (see fn 8). Presumably, this is because the causer's relevant manual actions (such as holding a pan and switching on the stove) do not act upon the butter directly.

The analysis of the handling classifier as a causative morpheme restricted to expressing manipulative causation raises the question of whether other causative constructions in ASL and other signed languages are sensitive to this semantic distinction. If this sensitivity is indeed rooted in the heightened iconic potential of classifier constructions, one might expect that lexical or construction-based causatives

However, not only are both MELT and BOIL lexical predicates for which it is not clear whether a handling classifier could license an agent, but as the authors themselves note, MELT and BOIL are change-of-state verbs whose roots generally do not take a handling classifier. The mere fact that they do not is not evidence that handling classifiers mark agents, as suggested by Benedicto \& Brentari in a footnote, but might just as easily point to their status as marking causers.

${ }^{9} \mathrm{Kegl}$ (1985) proposes that some handling verbs can take on metaphorical meanings that express directive causation. She offers ENCOURAGE as an example, in which the hands "repeatedly push someone in a psychological sense to do something" (130). Since ENCOURAGE is a lexical verb, it is not clear whether its handshape has morphemic potential and can be treated as a true case of a directive morpheme. Even if this were the case, it would still be clear that handling classifiers are basically manipulative and only by metaphorical extension can come to be used for directive causation. 
would be less likely to make the distinction. This is something to keep in mind when discussing resultative constructions.

Tang and Yang (2007) investigate classifier predicates in Hong Kong Sign Language (HKSL) and claim that it is the verbal movement rather than a handling classifier alone that encodes (manner of) causation. Their argument is partially based on the existence of classifier predicates which typically denote destruction and/or a change in the size and shape of the affected participant, and which obligatorily co-occur with a secondary stative predicate that expresses the result state. In example (30a), a person tears a sheet of paper into several strips; this result is expressed via the classifier predicate CL:long_thin_objects. Tang and Yang argue that the presence of a handling classifier like the one in CL:tear_a_flat_object (30a) is not sufficient to encode causation in HKSL. They contrast such predicates with transitive verbs that cannot co-occur with a stative result predicate such as CL:break_a_cylindrical_object(by_hand) and argue that the latter encode a change of state in the affected participant via the movement component of the verb. Verbs whose movement encodes a change of state thus act as causatives by themselves, while other types of verbs need an additional result predicate to encode causation. If it was the presence of change-encoding movement that makes a classifier predicate causative in HKSL, it is difficult to see why the grammatical (30b) should be causative. CL:cut_with_a_flat_object 'chop' is a verb of destruction whose object MEAT changes size and shape very much like the object of shredding, yet no result predicate is necessary, suggesting that the classifier predicate is encoding causation (it licenses an external causer argument). I have thus shown some evidence suggesting that the role of movement in encoding causation via expressing a change of state may not be decisive. 
a. FEMALE PAPER CL:tear_a_flat_object CL:long_thin_objects

'A female shreds a piece of paper.'

b. MOTHER MEAT CL:a_3d_round_object CL:cut_with_a_flat_object

'Mother slices the meat with a chopper.'

[adapted from Tang \& Yang 2007: 1243-45]

What (30) shows, however, is that handling classifiers are neither sufficient nor necessary for encoding causation in HKSL. In (30b), an instrument classifier for a meat slicer fills the handshape slot of the classifier predicate, and yet the external argument refers to the human causer MOTHER, not to the chopper itself. Note that this case is different from example (29): In the ASL classifier verb S-SAW_WOOD, the causer is represented via how he handles the saw, while in $(30 \mathrm{~b})$, no reference to the manual actions of the causer MOTHER is made. If the verb does encode a causer's physical actions, those actions may involve body parts other than the hand, and this is true for ASL as well. In (31a), the classifier sign represents the father's legs and licenses an external causer argument. Additionally, in HKSL classifier predicates can license inanimate causers who do not act intentionally on the causee, nor do they have identifiable body parts that could be represented in causative handshape morphemes. As (31b) shows, WIND may serve as the external argument of a causative verb as well:

a. RH: DOOR FATHER CL:a_legged_person_kick

LH: DOOR CL:a_vertical_flat_surface CL:a_vertical_surface_swing_open

'Father kicks the door open.'

b. PAPER CL:a_flat_object_be_located_at_i, WINDCL:wind_blow_flat_object_away 'A piece of paper is located here; the wind blows the paper away.'

[adapted from Tang \& Yang 2007: 1247, 1251]

One thing to note is that while handling classifiers may not serve as causative morphemes in HKSL, the types of causation expressed in each of their examples involves 
manipulative causation in the sense that physical contact between causer and causee are required to bring about change in the causee.

In summary, we have seen attempts to identify causative morphemes in classifier predicates of several signed languages. Both handshape and movement have been suggested as encoding causation, but, at least in HKSL, neither morpheme seems to be necessary nor sufficient for expressing causation. The discussion has also shown that, even in ASL, the concept of the handling classifier may be too narrow to capture all physical manipulation of a causee that licenses an external causer argument, and that such classifiers should be included in a broader category of body part classifiers. ${ }^{10}$ Lastly, despite the uncertainty of which aspects of a classifier predicate encode causation, it has become clear that what they all share is which type of causation is expressed, namely exclusively manipulative causation.

\subsubsection{Periphrastic/syntactic causatives}

Little is known about the distribution and frequency of causative verbs and auxiliaries in the signed languages of the world. Kegl (1985) mentions four ASL verbs with clausal complements which typically express indirect causation: FORCE, CONTROL, SUPPORT, and CAUSE. Holscher (1992) adds ORDER, TELL, CONVINCE, and COAX to the list and offers insights about their lexical meaning and distribution. He notes that FORCE patterns with English 'make' and 'force', while the use of CONVINCE versus COAX depends on the social status of the causee: Both denote a change in the willingness of the causee, but CONVINCE is typically used with a causee whose social rank exceeds that of the causer. The general causative CAUSE is perceived as not core ASL but rather as "Englishy", which is unsurprising from a typological perspective, as analytic causatives in which the causative predicate expresses nothing but causation are cross-linguistically rare (Comrie 1981). Holscher's also reports that consultants use CAUSE only for events

\footnotetext{
${ }^{10}$ In cases where the affected participant cannot be encoded implicitly through the choice of a particular handling classifier, the non-dominant hand will often encode it via a size-and-shape classifier (31a).
} 
with a negative outcome, which further aligns the verb with its English counterpart. For an analysis of negative sentiment in English 'cause', see Childers (2016). None of the above causatives are used with inanimate causees, and we will see in the next section that they are also absent from affective constructions involving a stimulus causer and an experiencer causee in ASL.

One further ASL construction that may express causal relations analytically is the wh-cleft described in Wilbur (1996). As (32) illustrates, it consists of a wh-clause marked by raised eyebrows rather than the typical brow furrowing accompanying regular whquestions, and a focus phrase. The wh-element WHY overtly encodes a causal link between the result, which is expressed in the wh-clause of the construction (BUILDING SHAKE in (32)), and the cause, which is expressed in the focus phrase (EARTHQUAKE in (32)). According to Holscher (1992), the wh-cleft construction is restricted to describing events with an inanimate causer, while Wilbur's data (p.c./facebook comment) include animate causers and causees as well. Importantly, however, the wh-cleft construction can only be used when the caused subevent is presupposed, given information; thus in (32) the fact that the building shook has to be known to both interlocutors in order to use the construction felicitously.

brow raise

BUILDING SHAKE WHY, EARTHQUAKE

'The earthquake made the building shake.' [Wilbur 1996: 230]

Engberg-Pedersen (2010) briefly discusses causative verbs in DTS. The verb ARBEJDE 'make, do' is used as a general causative verb that, in contrast to ASL, occurs predominantly in affective constructions such as (33a). The causer may be animate or inanimate and the predicate heading the complement of ARBEJDE tends to be a stative verb denoting a psychological state, although some signers also allow dynamic intransitives such as 'leave'. In addition, the verb FORANDRE 'change' can be used for mystical types of causation effecting a permanent change in an entity, such as the DEAF 
and the DUMB mentioned in (33b). Both verbs form syntactically cohesive units with the result predicates, which Engberg-Pedersen tests via the subject pronoun copy diagnostic discussed in chapter four of this dissertation. Briefly, the fact that the subject (and topic) IX-md of (33a) can be repeated at the end of the utterance shows that IX-1 ANGRY is embedded under the causative predicate ARBEJDE rather than coordinated or simply juxtaposed to it.

a. top

IX-md / ARBEJDE IX-1 ANGRY / IX-md

'This makes me angry.'

b. DEAF / IX-rt FORANDRE HEAR / DUMB / IX-rt FORANDRE SPEAK /

'He maketh both the deaf to hear, and the dumb to speak.'

[adapted from Engberg-Pedersen 2010: 57-58]

In two further signed languages, syntactic causatives have been described that double as agreement auxiliaries. Quer and Frigola (2006) describe a causative agreement auxiliary AUX-DA in Catalan Sign Language (LSC), which like its counterpart in Greek Sign Language (GSL) historically derives from a lexical verb meaning 'give'. Working on GSL, Sapountzaki (2005) observes that the development of these auxiliaries parallels that of many analytical causatives in spoken languages such as Mandarin. ${ }^{11}$ Her example (34) illustrates that causative auxiliaries tend to precede the result predicate and index causer and causee via referential loci on the start and end points of the verb. It bears mentioning that in all three sign languages for which a native causative verb or auxiliary

\footnotetext{
11 Even in ASL, where neither CAUSE nor GIVE are consistently used to express caused psychological or physical states, GIVE can form part of a periphrastic expression of causation. The pilot data for this dissertation contain the following description of a scenario where a boy sneezes in a girl's face, causing her to become sick.

(ii) top $\underline{\text { top }}$ BOY SNEEZE GIVE-fr, GIRL IX-fr TAKE 1 , SICK, VERY.SICK 'The boy made the girl sick by sneezing.'
} 
has been described, the predicate combines with psychological predicates (EngbergPedersen 2010).

DEAF IN-GROUP loc:c $_{\text {SIGN-TOO-MUCH }}$ GIVE-AUX $_{1}$ GET-OVERWHELMED

[GSL]

'Deaf who are too talkative make me bored and overwhelmed.'

[Sapountzaki 2005: 213]

\subsubsection{Implied/pragmatic causation in signed languages}

In her discussion of the range of linguistic expressions of causal relationships in DTS, Engberg-Pedersen (2010) notes that many unusual or infrequent causative situations are described via a series of juxtaposed clauses whose causal dependency is inferred rather than asserted. She tests whether morpho-phonological elements linking the clauses might serve as overt markers of causation but finds that neither the spatial arrangement of causer and causee nor non-manual marking nor the simultaneity of production of certain signs leads to a necessarily causal interpretation. Causal inferences can be canceled if, for example, a causer is set up via eye gaze at the right of the signing space, the causee is established on the left, and the predicate denoting the causing action moves from right to left, followed by the result predicate signed on the left. Likewise, holding the final handshape of the causing predicate while signing the result predicate on the other hand does not overtly encode causation. In (35), the sign SHOOT is held during the production of the following CL:animal_fall, yet the sentence can describe a scenario where the cow ducked from the shot or was shot by a different person than the agent of SHOOT.

RH: SHOOT $_{\text {lffr }}$-------------------/ COW /

[DTS]

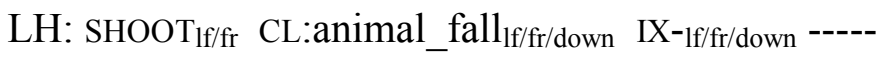

'...he fired and it fell, but it was just a cow.'

[Engberg-Pedersen 2010: 61] 
Many events involving non-canonical causation in ASL are expressed via biclausal structures whose causal relatedness is implied rather than overtly coded. Such events are frequently characterized by inanimate causers and/or non-canonical types of causation involving neither physical manipulation of an object nor directive causation. A case in point is the expression of affective events in which an inanimate stimulus brings about a psychological change of state in an experiencer. Such caused psych events have been described in detail in Winston (2013) and Healy (2015), who note that typically, the stimulus and the causing activity involving it are introduced in one clause in ASL, while the change of state in the experiencer is expressed in a second clause. In (36), the stimulus newspaper is featured in the first clause, and John's change of state in becoming angry is described in the second.

a. PAPER JOHN LOOK.AT (READ-paper), JOHN ANGRY

[ASL]

'Upon reading the newspaper, John became angry.'

[Winston 2013: 62]

Winston (2013) proposes that the two clauses in a caused psych event are syntactically integrated via a Link Phrase (following Ramchand's 2008 model of event structure) that takes the causing predicate in its specifier and the result clause in its complement. Although Winston attributes causative meaning to the LinkP, she does not test whether the relationship between the two clauses is non-defeasibly causal, hence it is possible that causation is implied rather than syntactically encoded via a functional phrase in this construction. Another candidate for overt expression of causation in caused psych events is the optional presence of the sign LOOK.AT, which, according to Winston, highlights the experiencer's active involvement or intentionality in the causing event (such as John's focusing on the newspaper in (36)). 


\subsubsection{Previous work on resultative constructions in signed languages}

Few studies have investigated resultative constructions in signed languages. In fact, back in 1990, Judy Kegl lamented that “[u]nfortunately for us, ASL doesn't seem to tolerate resultative constructions" (1990: 160). Dudis (2004), whose discussion of change-of-state descriptions in ASL touches on resultatives, echoes Kegl's claim, noting that consultants do not accept resultatives with an overtly expressed causee. In contrast, Engberg-Pedersen (2010) describes resultatives in Danish SL in passing, while Rathmann (2005) and Wright (2014) provide examples of what they call "resultative verb constructions" and "lexical result state markers" in ASL. Rathmann claims that the secondary predicate in these constructions illustrates the extent of change a causee undergoes, as illustrated in (37) for emptying a glass, drawing a circle, and flattening a piece of metal. ${ }^{12}$ Two recent theses examine examine the topic of resultatives and SVCs more closely and will be discussed below. Kentner (2014) looks at morpho-phonological reflexes of durativity and gradability in ASL Control resultatives, while Lau (2012) describes the behavior of a host of different SVCs in Hong Kong Sign Language (HKSL), including resultative SVCs.

a. BOY IX $\mathrm{i}_{\mathrm{D}}$ DRINK WATER EXTENT-down+hold

'A boy there drank a glass of water empty.'

b. BOY IX $X_{i}$ DRAW CIRCLE OUTLINE-circle+hold

'A boy there drew a circle in a complete circle.'

c. BOY IX $\mathrm{X}_{\mathrm{i}}$ HAMMER METAL FLAT-down+hold

'A boy there hammered a metal flat.'

[Rathmann 2005: 109]

\footnotetext{
12 Note that while Rathmann presents the sentences in (37) as a prosodic unit, Wright's result state markers are set off from the remainder of the clause prosodically by, for example, an emphatic squint (p.c.). It is thus necessary to examine whether the result-denoting predicate can form part of the same clause (and prosodic unit) as the causing verb and its object.
} 


\subsubsection{Kentner (2014)}

Kentner (2014) focuses on Control resultatives in ASL and examines whether they exhibit event-to-scale homomorphism as proposed in Beavers (2008) and Wechsler (2005). Based on acceptable combinations of durative verbs like HAMMER with the nongradable predicate DEAD in her data, Kentner concludes that at least some ASL Control resultatives do not require a homomorphic mapping.

Given Kentner's focus on event structure and the semantics-phonology interface, she does not investigate the syntactic structure of ASL resultatives in detail. All her cause-result descriptions are embedded under one CP since they can occur in the whclause of a wh-cleft construction (illustrated in example (32)). However, it is not clear whether the result predicate projects a full clause akin to She hammered the metal such that it became flat, or an infinitival (small) clause as in She hammered the metal flat. In chapter four, I will discuss diagnostics that potentially differentiate between the two analyses and will provide a detailed syntactic analysis of ASL resultatives in chapter five.

Kentner presents evidence against a homomorphic mapping of the causing event onto the scale contributed by the result predicate in ASL resultatives. Her conclusions are partially based on the phonological form of the predicates involved rather than on their semantics alone. ${ }^{13}$ In Table 1, I summarize the combinatory possibilities in Kentner's data without reference to the phonological form of the result predicate.

\footnotetext{
${ }^{13}$ Kentner adopts Wilbur's (Event) Visibility Hypothesis (Wilbur 2003; Wilbur et al. 2012), which posits that signed languages make both event and scale structure visible via morphemes that encode durativity and telicity. Kentner expands Wilbur's hypothesis in assuming that gradability on adjectival predicates should have similar phonological reflexes to durativity in verbal predicates, since durative and gradable predicates encode semantically similar notions. This assumption, however, is not supported by Wilbur's or Beavers (2008) work. Further, Wilbur's work on the visibility of endpoints in scale structure focuses on the behavior of open-scale adjectives in a particular endpoint-imposing construction rather than differences in the citation forms of adjectives with different scale types. In sum, the phonological forms associated with the semantic notions of gradability and maximal endpoint scales that Kentner uses in her study do not stand on solid empirical footing. Therefore, this summary focuses on the semantic diagnostics applied to the result predicates in her study.
} 
Table 1: $\quad$ Attested Combinations of Cause and Result Predicate in Kentner (2014)

\begin{tabular}{|l|l|l|}
\hline $\begin{array}{l}\text { Result predicate } \backslash \\
\text { causing verb }\end{array}$ & Durative & Punctual \\
\hline Maximal-endpoint & HAMMER METAL DEFLATE & SHOOT TIRE DEFLATE \\
\hline Open-scale & WASH TABLE CLEAN & WASH $_{\text {(by-machine) }}$ CLOTHES CLEAN \\
\hline Non-gradable & HAMMER DUCK DEAD & SHOOT DUCK DEAD \\
\hline
\end{tabular}

Kentner finds that, in contrast to English, durative predicates in ASL may combine with open-scale and non-gradable result predicates. Note, however, that only one example of each category (CLEAN for open-scale adjectives and DEAD for non-gradable ones) are tested and that my consultants differ from Kentner's in treating CLEAN as a maximal endpoint predicate (see chapter three for scale diagnostics). To test whether ASL resultatives do not exhibit homomorphic constraints in line with both Wechsler (2005) and Beavers (2008), we need to investigate a larger dataset. In the present study, cause and result predicates are therefore selected solely on the basis of semantic criteria, and the dataset contains more than one token of each possible cause-result combination.

\subsubsection{Lau (2012)}

Lau's (2012) dissertation on HKSL provides the first systematic description and syntactic analysis of serial verb constructions (SVCs) in a sign language. Particular types of SVCs have been investigated in ASL, Sign Language of the Netherlands (NGT), Argentinian SL, and Catalan SL, yet the majority of these studies describe the expression of complex motion events consisting of a manner of motion and a path of motion predicate (ASL: Supalla 1982, 1990; NGT: Slobin \& Hoiting 1994, Bos 1996; Argentinian and Catalan SL: Benedicto et al. 2008). These complex motion SVCs are characterized by a shared subject and the fact that no material (e.g. no pronouns) can 
intervene between the two predicates. Prosodically, Slobin \& Hoiting (1994) describe the articulation of the verb sequence in NGT as "smooth and continuous ..., with no intervening break" (490). Bos (1996) describes a second type of what she calls 'double verb constructions' in NGT. They consist of an action predicate followed by one of four light verbs: CALL, GIVE, TAKE, and GO. In contrast to the complex motion SVCs described earlier, the two verbs in this construction do not have to be adjacent.

Lau identifies eight types of SVCs in HKSL, two of which are resultative SVCs. In both types, two or more verbs are concatenated, where the first verb in the series is a transitive classifier predicate and denotes a causing event, while the second one is always unaccusative and describes either a change of state (if it is a classifier predicate) or a result state (if it is a lexical verb). The second verb in the series may serve both as a resulting change of state for the first verb and as a causing event for a third predicate which denotes yet another change of state. The fourth clause in (38) (utterance boundaries are indicated by //) illustrates how a boy kicking a can of paint causes an event of the can toppling over, which in turn causes paint to spill out from the can.

BOY NOT.KNOW walk+CL_SEM:a_human_legged_entity//

'Lit. The boy was walking instinctively [without paying attention, CL]...'

IX-paint ${ }_{i}$ PAINT $_{i}$ be-located ${ }_{\mathrm{a}}+\mathrm{CL} \_$SASS: a_round_object// 'There was a bucket of paint...'

BOY NOT.KNOW walk+CL_SEM_a_human legged_entity//

'The boy was walking instinctively [without paying attention, CL]...' 
hand 1: $\mathrm{KICK}_{\mathrm{a}}+\mathrm{CL} \_\mathrm{SEM}$ : a_human_entity

hand 2: CL_SASS: a_cylindrical_object ${ }_{\mathrm{a}}$

'The boy kicked the bucket of paint...'

$\underline{\text { head tilt left }}$

TOPPLE + a CL_SASS: a_cylindrical_object '(and as a result) the bucket of paint toppled...'

hand 1: spill-out-from ${ }_{\mathrm{a}}+\mathrm{CL} \_$SASS:liquid

hand 2: be_located+CL+SASS: a_toppled_cylinderical_object $\mathrm{a} / /$

'(and) the paint spilled from the bucket.'

[Lau 2012: 204]

Example (38) illustrates the two ways in which sharing of the affected participant across all verbs in an SVC in HKSL can be marked morpho-phonologically. On the one hand, the classifier representing the can of paint $(,, C)$ is retained throughout the production of each verb in the series ('kick', 'toppling', and 'spill-out-from'). The classifier may either serve as a locative referent on the non-dominant hand or may be incorporated into the dynamic toppling predicate in (38). On the other hand, the verbs forming part of the SVC exhibit locative agreement in that they are signed in the same location as the referential locus of the affected participant: The can of paint is established at a location 'a' towards which location each classifier predicate is signed.

A major contribution of Lau's dissertation is methodological in nature. She critically evaluates existing clausehood diagnostics in HKSL and convincingly shows that 53 
the constructions she investigates are monoclausal. Lau establishes monoclausality via temporal adverbs, the scope of the negative marker NOT-HAVE, and the aspectual marker FINISH with respect to the component eventualities of the SVCs. Lau's diagnostics will be further discussed in chapter four.

Lau also claims that the second predicate in HKSL SVCs enters the syntactic derivation as a complement to the main predicate rather than as an adjunct. Unfortunately, her claim rests on rather weak diagnostics, namely the obligatoriness of the second verb and the distribution of the VP adverb. With respect to obligatoriness, Lau argues that the result predicate cannot be omitted from an SVC because "it must be present to show the resulting state as part of the complex event" (2012: 308). This may be read as a felicity requirement (the utterance without the result XP does not describe the complex event adequately) or as a grammaticality requirement (the utterance is judged ungrammatical without the result XP). It is not clear which reading is intended, but if omission of the result VP only produces an infelicitous but not an ungrammatical sentence, no evidence for a complementation structure has been provided. The second diagnostic, the distribution of VP adverbs, is equally problematic. Lau follows Chomsky's (1986) Adjunction Prohibition in assuming that a complement cannot be leftadjoined to; hence if the second VP is s-selected by the matrix verb, no VP adverb should be able to take scope over it. While this is what Lau observes for VP adverbs in resultative SVCs (they precede the first verb and only scope over it), the question remains whether her adverbs cannot scope over the second verb for syntactic reasons (adjunction to a complement) or for semantic ones. The VP adverbs she uses include CARELESSLY and EFFORTLESSLY, which entail that the action thus modified must be under volitional control of an agent. This tends to be the case for the causing subevent but not for the caused subevent - for example, falling is not typically under the volitional control of an 
agent. It is not clear whether Lau elicited VP adverbs that do not require volition/control on the part of the subject.

In summary, Lau (2012) shows that resultative SVCs are monoclausal constructions in HKSL. Given the lack of reliable diagnostics, the nature of the syntactic composition of cause and result predicates remains an open question. Note further that the empirical base of Lau's discussion are classifier predicates, leaving us to wonder whether SVCs may be formed with lexical predicates as well, and how (and if) the sharing of an affected participant is phonologically expressed there. While lexical predicates can also agree with their theme argument, their handshapes are fixed and thus cannot incorporate the theme argument.

We have thus seen that at least ASL and HKSL allow the expression of a complex cause-result event with the help of two (or more) predicates that exhibit a higher degree of syntactic integration than juxtaposition or coordination. Two questions driving the present study are 1) whether we can more clearly delineate the nature of the syntactic composition between cause and result predicate, and 2) whether we can confirm semantic constraints on Control resultatives in ASL and DGS. Chapter four examines the first question by evaluating and developing clausehood diagnostics for ASL and DGS, while chapter five addresses the second question. First, however, chapter three introduces the methodology for data collection employed in this dissertation. 


\section{Chapter 3: Methodology}

\subsection{INTRODUCTION}

The methods described in the following sections guided the data collection on clausehood diagnostics (chapter four) as well as on the syntax and semantics of resultative constructions (chapter five). Section 3.2 details the selection of participants, while section 3.3 discusses tasks and procedures used in the video elicitation pilot. In section 3.4, I describe stimuli and procedures for a grammaticality judgment study that produced the main data set for this dissertation. The methods for data collection on directness of causation in ASL will be described in chapter six.

\subsection{PARTICIPANTS}

An accurate description of resultatives should represent and predict signers' intuitions about the construction. In order to tap into the linguistic intuitions of the ASL and DGS user communities, native signers were recruited via UT's Deaf and Hard of Hearing listserv and the subject pool of the Experimental Sign Lab at the University of Göttingen. The researcher also contacted her acquaintances from the Deaf communities in Austin and Berlin. The definition of "native" in the context of sign language research warrants some discussion, since only five to ten per cent of sign language users acquire their primary language in a way that is comparable to first language acquisition in hearing children. Given the various etiologies of deafness, most prelingually deaf children have hearing parents who do not sign. As a consequence, these children may first be exposed to a sign language in pre-school or even later. The final state grammar of signers exposed to ASL past the age of three differs significantly from that of native signers in such areas as sentence processing (Mayberry 1993); therefore one criterion for inclusion 
in this study was exposure to ASL by age three. ${ }^{14}$ Detailed demographic information about each participant is provided in Table 2 for ASL and Table 3 for DGS. Each participant either used signed and spoken language to the same extent in their daily lives or used ASL/DGS primarily. All participants were reimbursed for their time in cash or giftcards.

\footnotetext{
14 An exception was made for ASL signer P23, who exhibited a heightened metalinguistic awareness in discussing differences between ASL and English. His grammaticality judgment responses do not differ noticeably from those of the other participants, warranting his inclusion in the study.
} 
Table 2: $\quad$ Linguistic and Demographic Background of ASL Participants

\begin{tabular}{|c|c|c|c|c|c|c|}
\hline $\begin{array}{l}\text { Parti- } \\
\text { cipant }\end{array}$ & Sex & Age & $\begin{array}{l}\text { Age of } \\
\text { Exposure }\end{array}$ & Deaf relatives & Education & Language Use \\
\hline P1 & Female & 34 & 0 & $\begin{array}{l}\text { Parents, } 2 \\
\text { older siblings }\end{array}$ & $\begin{array}{l}\text { HS } \\
\text { Diploma }\end{array}$ & $\begin{array}{l}80 \% \text { ASL, daily with } \\
\text { family and friends, } \\
\text { written English with } \\
\text { hearing people when } \\
\text { necessary }\end{array}$ \\
\hline P2 & Female & 44 & 3 & 2 deaf siblings & MA & $100 \%$ ASL \\
\hline P3 & Male & 37 & 2 & None & MA & $\begin{array}{l}\text { balanced, though } \\
\text { higher percentage of } \\
\text { English in the } \\
\text { workplace }\end{array}$ \\
\hline P4 & Female & 33 & 0 & $\begin{array}{l}\text { Parents, } 1 \\
\text { older sibling }\end{array}$ & MA & $\begin{array}{l}\text { balanced in all } \\
\text { environments, but } \\
\text { uses SEE sometimes }\end{array}$ \\
\hline P20 & Female & 64 & 0 & $\begin{array}{l}\text { Parents, 1 older } \\
\text { sibling }\end{array}$ & BS & $\begin{array}{l}80 \% \text { ASL, English } \\
\text { for school/writing }\end{array}$ \\
\hline P21 & Male & 59 & 0 & $\begin{array}{l}\text { Parents, } 2 \\
\text { younger } \\
\text { siblings }\end{array}$ & - & $\begin{array}{l}\text { balanced } \\
\text { ASL/English, ASL } \\
\text { with family and } \\
\text { friends }\end{array}$ \\
\hline P23 & Male & 24 & 4 & None & $\begin{array}{l}\text { Some } \\
\text { college }\end{array}$ & $\begin{array}{l}\text { balanced } \\
\text { ASL/English }\end{array}$ \\
\hline P24 & Male & 32 & 0 & $\begin{array}{l}\text { Parents, } 2 \\
\text { older brothers }\end{array}$ & $\begin{array}{l}\text { Some } \\
\text { college }\end{array}$ & $\begin{array}{l}90 \% \text { ASL use at } \\
\text { home and in work } \\
\text { environment }\end{array}$ \\
\hline P25 & Female & 31 & 0 & $\begin{array}{l}\text { Parents, } 4 \\
\text { older siblings }\end{array}$ & $\begin{array}{l}\text { HS } \\
\text { Diploma }\end{array}$ & $\begin{array}{l}90 \% \text { ASL use, } \\
\text { English only for } \\
\text { socializing with } \\
\text { hearing people }\end{array}$ \\
\hline P26 & Male & 46 & 0 & $\begin{array}{l}\text { Parents, } 1 \\
\text { younger } \\
\text { brother }\end{array}$ & BS & $\begin{array}{l}\text { balanced in all } \\
\text { environments }\end{array}$ \\
\hline P27 & Female & 33 & 0 & $\begin{array}{l}\text { Parents, } 1 \\
\text { older brother }\end{array}$ & MA & $\begin{array}{l}80 \% \text { ASL (home, } \\
\text { friends), } 20 \% \\
\text { English (reading, } \\
\text { typing) }\end{array}$ \\
\hline
\end{tabular}


Table 3: $\quad$ Linguistic and Demographic Background of DGS Participants

\begin{tabular}{|c|c|c|c|c|c|c|}
\hline $\begin{array}{l}\text { Parti- } \\
\text { cipant }\end{array}$ & Sex & Age & $\begin{array}{l}\text { Age of } \\
\text { Exposure }\end{array}$ & Deaf relatives & Education & Language Use \\
\hline $\mathrm{P} 5$ & Female & 32 & $3-4$ & none & M.A. & $\begin{array}{l}90 \% \text { DGS, German } \\
\text { with family and in } \\
\text { public life }\end{array}$ \\
\hline P6 & Female & 30 & 0 & $\begin{array}{l}\text { Parents, } 1 \\
\text { younger sister }\end{array}$ & B.A. & $\begin{array}{l}80 \% \text { DGS, some } \\
\text { written German in } \\
\text { professional life }\end{array}$ \\
\hline P7 & Male & 30 & 0 & $\begin{array}{l}\text { Parents, } 1 \\
\text { younger sister }\end{array}$ & B.A. & $100 \%$ DGS \\
\hline P8 & Female & 31 & 0 & Parents & $\begin{array}{l}\text { HS } \\
\text { Diploma } \\
\text { (Abitur) }\end{array}$ & $\begin{array}{l}\text { balanced DGS (with } \\
\text { family) and } \\
\text { LBG/written } \\
\text { German (with } \\
\text { friends, at work) }\end{array}$ \\
\hline P9 & Female & 30 & 0 & $\begin{array}{l}\text { Parents, } 2 \\
\text { siblings }\end{array}$ & B.A. & $\begin{array}{l}\text { 99\% DGS, some } \\
\text { LBG with } \\
\text { grandparents }\end{array}$ \\
\hline $\mathrm{P} 12$ & Female & 37 & 0 & $\begin{array}{l}\text { Parents, } 1 \\
\text { older brother }\end{array}$ & $\begin{array}{l}\text { HS } \\
\text { Diploma } \\
\text { (Fachhoch } \\
\text { schulreife) }\end{array}$ & $\begin{array}{l}80 \% \text { DGS, German } \\
\text { in some private and } \\
\text { professional } \\
\text { interactions }\end{array}$ \\
\hline P13 & Female & 33 & 0 & $\begin{array}{l}\text { Parents, } 1 \\
\text { younger sister }\end{array}$ & B.A. & $90 \%$ DGS \\
\hline
\end{tabular}

\subsection{TASKS AND PROCEDURES}

Data collection for this dissertation was accomplished during multiple one-on-one and one-on-two interview sessions over the course of two and a half years. The elicitation tasks which are described in this and the following section are summarized in Table 4, which also provides an overview of how many and which participants completed each task. The present section 3.3.1 describes tasks one and two, while section 3.4 focuses on task three through five. Tasks four and five are subsidiary to and inform the design of task three, a grammaticality judgment task through which most of the data analyzed in 
chapters four and five were elicited. More information on task six is provided in section 5.3.1.3.

Table 4: $\quad$ Overview of Tasks Used in Data Collection for Chapters Four and Five.

\begin{tabular}{|l|l|l|l|l|l|}
\hline \multirow{2}{*}{} & \multicolumn{1}{|c|}{ Task } & \multicolumn{4}{c|}{ Participants (P) } \\
\cline { 3 - 7 } & & \multicolumn{2}{|c|}{ DGS } & \multicolumn{2}{c|}{ ASL } \\
\cline { 3 - 7 } & & No. & \multicolumn{1}{|c|}{ ID } & No. & \multicolumn{1}{c|}{ ID } \\
\hline 1 & Video elicitation & 5 & P5-P9 & 1 & P1 \\
\hline 2 & Translation of English and German resultatives & 3 & P5-P7 & 1 & P1 \\
\hline 3 & Grammaticality judgment (GJ) task & 6 & P6-P13 & 7 & $\begin{array}{l}\text { P1, } \\
\text { P20-26 }\end{array}$ \\
\hline 4 & $\begin{array}{l}\text { Grammaticality judgment task to determine the } \\
\text { syntactic category of result predicates }\end{array}$ & 1 & P6 & 7 & $\begin{array}{l}\text { P1, } \\
\text { P20-26 }\end{array}$ \\
\hline 5 & $\begin{array}{l}\text { Truth judgment task to determine the scale } \\
\text { structure of result predicates }\end{array}$ & 3 & P5-P7 & 1 & P1 \\
\hline 6 & $\begin{array}{l}\text { Grammaticality judgment task on predicate fronting } \\
\text { in DGS }\end{array}$ & 2 & P6-P7 & n/a & n/a \\
\hline
\end{tabular}

In order to get a first impression of how signers describe cause-result events while minimizing the influence from spoken language contact, 18 short video sequences were shown to five DGS signers and one ASL signer. The sequences were partly taken from popular movies and cartoons and partly recorded for the purposes of this study. Each sequence showed an animate causer performing an action on an animate or inanimate causee, such as licking a plate, shooting an opponent, or jumping on an earring. Importantly, the action brought about a definite change in the causee (e.g. the plate becoming clean, the opponent dying, and the earring flattening). The videos were presented on a 15" screen and participants were instructed to describe the video sequences in "one short sentence" to the researcher, who could not see the screen. All 
participants initially produced multi-sentential descriptive utterances and had to be prompted to repeat their description in a more concise form.

To elicit possible permutations of the participants' initial productions and to encourage participants to produce single clause utterances, a translation task was developed to complement the video elicitation and was presented to three of the five original DGS consultants and to the ASL consultant. To ensure elicitation of all possible combinations of durative/punctual cause and (non-)gradable result predicates, eight new cause-result scenarios were added. ${ }^{15}$ The productions elicited by the video and translation tasks exhibited considerable inter-signer variation in the prosodic contours accompanying a given utterance as well as in acceptability judgments. Consequently, a structured grammaticality judgment task was designed to circumvent individual differences in sign production and present signers with identical stimuli to evaluate. The task is described in the next section.

\subsection{GRAMMATICALITY JUDGMENT TASK}

To establish the syntax of the cause-result descriptions elicited through video and translation stimuli in the pilots, a grammaticality judgment (GJ) task was constructed and presented to seven native signers of ASL and six native signers of DGS. The stimuli, procedure, and coding of the data are described below.

\footnotetext{
${ }^{15}$ At the same time, two of the video elicitation scenes were not replicated in the translation task because no participant was able to provide a concise one-sentence description for these items. One involved "beer goggles", which in German may be expressed via the resultative "to drink someone beautiful", while the other focused on a bird defecating on a man's jacket. The target resultative here would have been "The bird pooped the jacket dirty", but participants consistently chose a more depictive representation of the bird's actions.
} 


\subsubsection{Stimuli}

To describe the stimuli used in this study it is first necessary to motivate the selection of causing and result predicates and then to describe further considerations in the choice of resultative constructions and the contexts in which they appear. Section 3.4.1.1 thus presents an overview of the causing and result predicates used here, including a brief discussion of the part of speech of the result predicates and their associated scales. Section 3.4.1.2 discusses the choice of causer and causee as well as the relevant contexts in which the resultatives were judged.

\subsubsection{Causing and result predicates}

The cause-result scenarios constructed for this task overlap for the most part with the video and translation stimuli used in the pilot studies. A few scenarios were altered to ensure that all combinations of causing and result predicates were presented in the stimulus set. Causing predicates varied in durativity (durative versus punctual) and results were either open- or closed-scale gradable predicates or non-gradable predicates. A full overview of the tested cause-result combinations is provided in Table 5 below. The classification of result predicates as maximal endpoint, open scale, or non-gradable is explained later in this section. There is at least one stimulus probing each combination of cause and result predicates, but due to an oversight in the design phase, the ECM constructions with a non-gradable result were only elicited as translations from two ASL signers (P1, P27). In DGS, ECM constructions with a punctual verb and non-gradable result were elicited from two signers (P6, P9). DGS signers commented that five stimuli described far-fetched or unnatural situations; these items were replaced with different stimuli in the ASL task (the relevant items are marked as ASL or DGS in Table 5). The resulting grammaticality judgment task contained 22 different cause-result scenarios for 
DGS and 23 for ASL. The causing verbs have either clearly durative or clearly punctual uses, with JUMP being the only verb used both in punctual and durative (iterative) forms (e.g. JUMP FAMOUS vs. JUMP+ DESTROY).

Table 5: $\quad$ Cause-Result Stimuli for Grammaticality Judgment Task Organized by Durativity of Causing Predicate and Gradability of Result Predicate

\begin{tabular}{|c|c|c|c|c|}
\hline \multirow{2}{*}{\multicolumn{2}{|c|}{ Causing predicate }} & \multicolumn{3}{|l|}{ Result predicate } \\
\hline & & \multicolumn{2}{|l|}{ Gradable } & \multirow[t]{2}{*}{ Non-gradable } \\
\hline & & Maximal endpoint & Open scale & \\
\hline \multirow[t]{2}{*}{ Control } & Durative & $\begin{array}{l}\text { LICK NO.TRACE.LEFT } \\
\text { (ASL) } \\
\text { LICK CLEAN (DGS) } \\
\text { HAMMER FLAT(B) } \\
\text { SAND SMOOTH }\end{array}$ & $\begin{array}{l}\text { POLISH SHINY } \\
\text { SPRAY WET } \\
\text { SHAKE AWAKE } \\
\text { JUMP+DESTROY(ASL) } \\
\text { JUMP CL:break (DGS) }\end{array}$ & $\begin{array}{l}\text { BEAT DEAD } \\
\text { RIDE DEAD (DGS) }\end{array}$ \\
\hline & Punctual & $\begin{array}{l}\text { PUNCTURE FLAT(O) } \\
\text { (ASL) } \\
\text { CHARM DRY }\end{array}$ & $\begin{array}{l}\text { KICK OPEN.DOOR } \\
\text { CHARM UGLY }\end{array}$ & $\begin{array}{l}\text { CHARM PREGNANT } \\
\text { SHOOT DEAD }\end{array}$ \\
\hline \multirow[t]{2}{*}{ ECM } & Durative & $\begin{array}{l}\text { EAT NO.TRACE.LEFT } \\
\text { (ASL) } \\
\text { EAT EMPTY (DGS) } \\
\text { intransitive: } \\
\text { RUN DRY }\end{array}$ & $\begin{array}{l}\text { SWEAT WET (ASL) } \\
\text { SIT WARM (DGS) } \\
\text { intransitive: } \\
\text { EAT BECOME.FAT }\end{array}$ & LECTURE DEAD (ASL) \\
\hline & Punctual & JUMP FLAT(L) & $\begin{array}{l}\text { SNEEZE AWAKE } \\
\text { intransitive: } \\
\text { SNAP FAMOUS (ASL) } \\
\text { JUMP FAMOUS (DGS) }\end{array}$ & SNAP PREGNANT \\
\hline
\end{tabular}

The result predicate FLAT was signed in three variants in ASL (B, O, and L) while the DGS sign model used a single form. Where ASL uses NO.TRACE.LEFT, the corresponding 
DGS predicates are CLEAN and EMPTY. The result predicates CLEAN and SMOOTH in DGS are only distinguished by mouthing ('sauber' vs. 'glatt'), and a classifier predicate is used to describe a broken trampoline. Illustrations of the above signs can be found in Appendix C. The sign glossed LECTURE in ASL means 'give a talk' and is typically used intransitively.

As mentioned in chapter two, the categorial status of the result predicates in the resultative construction is difficult to determine without a set of standard part-of-speech diagnostics. The result predicates used in this study were tested for acceptability in typical modification slots. ${ }^{16}$ As shown in (39), attributive adjectives typically follow the noun but precede a determiner in DGS (Happ \& Vorköper 2006), while the prenominal slot is preferred for modification in ASL (Loos 2014).

DGS: Subject [object Noun Property Determiner] Predicate

ASL: Subject Predicate [object Property Noun]

Most target result predicates may occur in the DGS property slot, as illustrated for CLEAN and FLAT in (40).

\footnotetext{
16 Specifically, seven ASL and one DGS participants were presented with a plausible context in which one of the result predicates functioned as a nominal modifier. To illustrate the procedure further for DGS, the participant was then asked to provide a binary grammaticality judgment on whether this sign could be inserted in the property slot of the 'Subject [object Noun Property Determiner] Predicate' construction. An example is provided in (iii), for which P6 indicated that CLEAN in the modification slot (iiia) was equally acceptable as when it served as the primary predicate of the sentence (iiib).
}

(iii) Context: A mother shows her daughter a dirty and a clean plate and asks her which plate she wants. The daughter answers:

a. IX-1 PLATE CLEAN IX WANT 'I want the clean plate.'

b. PLATE IX CLEAN. IX-1 IX WANT

'The plate there is clean. I want it.' 
a. IX-1 PLATE CLEAN IX WANT.

'I want the clean plate.'

b. IX-1 SPOON FLAT IX WANT.NOT

'I don't want the flat spoon.'

DEAD, DRY, SHINY, and FAMOUS cannot occur between the noun and the determiner but may nonetheless be used as NP-internal modifiers. To give two examples, DEAD in (41a) clearly modifies HAMSTER IX-rt but is not the main predicate of the sentence. DRY in (41b) modifies T-SHIRT, but the primary predicate of this sentence is BRING. ${ }^{17}$

a. IX-1 [NP HAMSTER IX-rt DEAD] BURY MUST

[DGS]

'I have to bury the dead hamster.'

b. [NP T-SHIRT DRY], IX-rt BRING-1

'As for the dry T-shirt, I'll bring it.'

top nod

[ASL]

c. SEE FRIDGE NO.TRACE.LEFT, PUT-If BEER

'Do you see the empty fridge, put the beer there.'

top

d. DOOR OPEN.DOOR, PICK

'Pick the open door!'

In the ASL stimulus set, only NO.TRACE.LEFT and OPEN.DOOR were not readily accepted as prenominal modifiers; receiving on average a GJ rating of 3 (out of 5, for details on the

\footnotetext{
${ }^{17}$ Note that IX-rt in (41b) cannot be parsed as a determiner, since P6 only accepts this sentence if a pause is introduced between DRY and IX-rt.
} 
rating scale, see section 3.4.2). However, both were acceptable as postnominal modifiers inside the NP, as shown in (41c) and (41d). Two consultants also rejected FLAT(B) in prenominal position, potentially due to mismatching non-manuals accompanying the carrier sentence. To summarize, while I cannot say with certainty whether the result predicates in this study function as adjectives or as verbs in the resultative construction, I have at least shown that most of them can be used as adjectives in their respective languages. There is thus at least a possibility that the result predicates in ASL and DGS resultatives are adjectival.

Aside from testing result predicates for their potential to function as attributive adjectives, the scale structure associated with each result predicate was tested with one ASL and three DGS consultants. Three predicates were hypothesized to be non-gradable: DEAD, PREGNANT, and 'broken', expressed via the lexical predicate DESTROY in ASL and as a classifier predicate CL:break in DGS. As expected, consultants rejected intensifying modifiers such as WOW (ASL), FULL (DGS), or SUPER (DGS) with DEAD and PREGNANT. For ASL DESTROY and DGS CL:break, on the other hand, intensifiers were consistently accepted and the predicates were interpreted as gradable with a minimal endpoint: Since the property of being broken is predicated of a trampoline in this study, even a small tear renders it unusable (minimal endpoint), but it can always be "more broken" (no maximal endpoint). DESTROY and CL:break were thus re-classified as de-facto open-scale predicates.

To further examine the scale structure of gradable result predicates, a truth judgment test was developed and run with the same participants. To my knowledge, neither ASL nor DGS has modifiers that are sensitive only to the presence vs. absence of a maximal endpoint on a property scale: Signers are reluctant to use the literal equivalent of 100 per cent in ASL, and DGS FULL 'completely, really' may be used as a mere 66 
intensifier or as an epistemic particle signaling the signer's commitment to the truth of the statement. Thus, instead of using modifiers, I developed a truth judgment task using scenarios such as (42). Consultants were presented with a context in which two children/teenagers, John and Mary, discuss the property in question. The consultants were then asked to side with either John or Mary; the follow-up question Who is right? asks them to contemplate whether a given property could always hold to a higher degree or not. If the scale associated with WET has a maximal endpoint, participants should claim that John is right in (42).

(42) Scenario: John and Mary are playing outside. Suddenly it starts raining and they get soaked while running home. John looks at his wet pants and claims:

John: PANTS WET[int]. MORE WET, IMPOSSIBLE

Mary counters: POSSIBLE. CLOTHES ALWAYS CAN MORE WET

Who is right?

Due to logistic constraints, the DGS participants completed the truth judgment task via an online survey rather than an in-person interview. Consequently, they were presented with DGS glosses rather than natural productions of the stimuli sentences. Given that the signers all participated in the grammaticality judgment task described below, they were familiar with each result predicate and would have been able to identify the corresponding sign for each result predicate gloss.

The results of the truth judgment task reveal that most gradable result predicates in ASL and DGS pattern with their English translation equivalents. The only predicates that consistently differ in both languages are AWAKE and OPEN.DOOR, which are judged to 
have a maximal endpoint. Since my consultants insisted that there is an upper limit to being awake and a door cannot open beyond a $180^{\circ}$ angle, statistical models applied to the data to test for homomorphic constraints were run twice. In one model both predicates were coded as open-scale like their English translation equivalents, and the other treated them as maximal-endpoint predicates. In DGS, the consultants further disagreed whether WET has a maximal endpoint or not, thus here too, statistical models were run with either classification.

\subsubsection{Further considerations in stimulus selection}

Aside from causing and result predicates, each potential resultative contained an animate causer, while causees varied in animacy. All target utterances were presented under a single intonational sentence contour without pauses; non-manual question marking for both polar and wh-questions extended across the entire utterance.

Each construction was presented in a context that would naturally elicit it. For example, 'running oneself dry' may not seem like an everyday action, but when presented in a context where someone went swimming and did not bring a towel to dry off, it becomes a plausible course of action. Furthermore, contexts were constructed to satisfy presuppositional or emphatic requirements on the use of a particular diagnostic. Final wh-words have been argued to carry an existential presupposition about their referent in ASL similar to wh-clefts in English (Abner 2011; Neidle 2002). The contexts in which the final $w h$-word diagnostic in this data ${ }^{18}$ are presented thus add an existential presupposition about the causer to the common: In (43), the clean plate and the tomato-

\footnotetext{
18 Presupposition-implying contexts were created for the wh-diagnostic in ASL and DGS, although there is no literature on final $w h$-words in DGS triggering an existential presupposition. To allow for the possibility that DGS behaves like ASL in this regard, parallel contexts were created, since non-presuppositional whwords should be acceptable in them as well.
} 
sauce stained mouths of Mike and John strongly imply that one of them licked the plate clean and Mary is simply trying to establish that person's identity.

(43) Context ${ }^{19}$ : Mary walks into the kitchen and sees that a plate that had just been covered in tomato sauce is now clean. Mike and John are standing next to the plate, their mouths covered in tomato sauce. Mary asks:

\section{brows furrowed}

LICK+ PLATE NO.TRACE.LEFT WHO

'Who licked the plate clean/empty?'

For the subject-pronoun copy diagnostic in ASL, all target sentences were embedded in polar questions (see Zeshan 2004 for the observation that subject pronoun copy frequently accompanies polar questions) and contexts that invite emphasis on the subject. With one exception, each target sentence contained a second person subject, following one consultant's suggestion that they prefer pronoun doubling with second persons but use a general question marker with third person subjects. An example is provided in (44). The subject pronoun copy diagnostic will be discussed in detail in section 4.4.3.

(44) Context: One morning, Harry Potter wakes up with his face horribly disfigured. $\mathrm{He}$ and his friends set out to find out who put a spell on him so that they can reverse it. Harry asks his enemy:

brows raised

IX-addr CHARM POSS-1 FACE UGLY IX-addr

'Did you put a spell on my face to make it ugly?'

${ }^{19}$ All contexts were presented in ASL and DGS, respectively, and are only rendered in English here to facilitate comprehension for a sign-naïve readership. 
Lastly, all contexts for a DGS clausehood diagnostic involving modal verbs (discussed in section 4.5.1) featured deontic and dynamic readings for each modal, since DGS modal verbs reportedly have no epistemic uses (Happ \& Vorköper 2006). An example of a dynamic modal context is given in (45). In addition, the modal MUss 'must' was only used to describe an externally imposed requirement. An internally recognized necessity to do something such as for example I really must clean my room cannot be expressed in DGS using MUSS (Happ \& Vorköper 2006).

Context: Susi is bored. Her mother proposes:

IX-addr SHOE POLISH+ CAN SHINY

'You can polish the shoe(s) shiny.'

All target sentences with their contexts as well as a brief video introducing the task were recorded by a native signer of ASL and DGS, respectively. The videos were then edited to show a white dot accompanying the target sentence, which helped participants identify the part of the video they needed to evaluate. Appendices D and E contain glosses of each ASL and DGS target sentence as well as English and German translations of the contexts in which they were embedded.

\subsubsection{Procedure}

The grammaticality judgment tasks for ASL and DGS were conducted as one-onone or one-on-two interview sessions in and around Austin, Berlin, and Göttingen. The researcher interacted with either one or two participants at the same time and explained the consent procedure in ASL or in a mixture of DGS and German, respectively. After signing the consent form and filling out a brief language background questionnaire, 
participants watched an introductory video explaining both the task and the rating procedure. To familiarize them with the stimuli and introduce the concept of the naturalness of a target sentence, participants were then shown two example sentences illustrating natural and ill-formed ASL or DGS sentences and asked to evaluate the sentences. They were further encouraged to use the entirety of the rating scale, which consisted of a 5-point Likert scale populated by emoticons ranging from $\odot$ to $\otimes$. The choice of emoticons over numbers is motivated by a desire a) to avoid association with the German school system's grading scheme, which ranges from 1 (very good) to 6, and b) to keep the rating scales consistent across GJ tasks in ASL and DGS. Not only are emoticons more intuitive than numbers, but the danger of German participant's using a school-based grading system allows for different interpretations of the scale by ASL and DGS signers: The cut-off point for a failing grade in the German system is 4, making the interval between a 4 and a 5 potentially more significant than any of the other intervals for DGS participants.

ASL participants evaluated 90 sentences in blocks of 20 to 30 stimuli; DGS participants evaluated 100 sentences. Each block was followed by a short break. Participants had the chance to watch videos a second time, engage in discussion about the acceptability of a given sentence with the researcher and, if applicable, another participant, but they were reminded that in the end, it was their own intuitions that mattered and that there was no right or wrong response. Each interview lasted from two to two and a half hours and participants were compensated for their time. 


\subsubsection{Coding and analysis}

Participants' pencil-and-paper responses were entered into Excel and each observation was categorized according to sentence type (e.g. resultative versus coordinate clauses) and diagnostic (e.g. subject pronoun copy). Resultatives were further classified by whether the causee was selected by the verb, durativity of the causing verb, and scale structure of the result predicate (maximal endpoint, open scale, or non-gradable). Grammaticality judgment ratings were transposed from emoticons to a numerical scale ranging from $1=\odot$ to $5=\odot$; to facilitate statistical analysis. While grammaticality judgments constitute ordinal data, continuous methods were used throughout the analyses since the dependent variable has more than three levels and did not exceed a skewness of +/- 2 for any given model (Byrne 2013). Statistical analyses were performed in R (R Core Team 2016); details are provided in the following chapters. 


\section{Chapter 4: Determining clause boundaries in signed languages}

\subsection{INTRODUCTION}

Delineating what constitutes a clause is crucial to the investigation of many structural phenomena in language. Whether it be resultatives or basic constituent order, an informed discussion of any clause-level phenomenon requires a clear understanding of where a clause starts, where it ends, and whether it embeds any further clauses. Identifying clause boundaries is notoriously difficult in sign languages: Not only does the sign linguistics literature lack a standard set of diagnostics for identifying them (Johnston \& Schembri 2007; Tang \& Lau 2012), but even the usefulness of the clause as a unit of grammatical organization of signed utterances has been called into question (Hodge 2013). In this chapter, I provide an overview and critical evaluation of the syntacticosemantic diagnostics for clausehood that have been proposed to date in the spoken and signed language literatures. Recall that ASL is underlyingly SVO, whereas DGS sentences follow SOV order (Glück \& Pfau 1997; Happ \& Vorköper 2006; Steinbach 2007; Fischer 1975; Liddell 1980; Padden 1983). While some syntactic diagnostics are indifferent to this typological difference, others that are discussed here seem to mostly apply to SOV languages. Since the main goal here is to distinguish resultatives from other types of multi-verb constructions, I discuss both tests that discriminate between coordinate clauses and any type of hierarchical clause structure (section 3.4), and tests that gauge the size of the embedded constituent (i.e. a full vs. infinitival clause) (section 3.5). The chapter starts off by identifying some of the specific problems involved in determining clause boundaries in signed languages (section 3.2) and explaining why some clausehood diagnostics commonly used in spoken language research are not applicable to the current study.

The overall goal of this chapter is to better understand the diagnostics currently at our disposal for use in this study and to expand their inventory. In addition to identifying shortcomings of existing clausehood diagnostics and proposing appropriate modifications, I will propose two tests that, to my knowledge, have not been discussed as 
diagnostics for clause boundaries in the sign literature. In restrictions on rightward whmovement and center-embedding we will see tests that not only distinguish between coordinate and dependent structures, but that also tell us whether an embedded constituent projects a full clause or not.

\subsection{WHY CLAUSES ARE DIFFICULT TO SPOT IN SIGNED LANGUAGES}

Clauses can be defined functionally or in terms of categorial constituent structure. In the functional sense, a clause minimally contains a (typically verbal) predicate and all of its arguments. This syntactic definition is closely aligned with the semantics of clauses, which denote a proposition that can be assigned a truth value; they express "a complete thought" (Kroeger 2005). Most sign linguists agree that sign languages have such a functionally defined category of clause, but Hodge (2013) notes that in Australian Sign Language, complete ideas are frequently expressed as non-linguistic enactments (constructed action) in narratives. Since events and their participants can thus be represented non-linguistically, she calls into question the usefulness of analyzing every signed utterance in terms of its clausal structure. While most signed languages documented so far seem to make use of constructed action and dialogue to some degree, they also exhibit more conventionalized clausal structure. For an overview, see Liddell (1980); Padden (1983) for ASL, and Glück and Pfau (1997) for DGS.

The grammatical category 'clause' has also been defined in terms of constituent structure, as a Complementizer Phrase (CP) or Inflectional Phrase (IP). Evidence for functional projections in signed clauses has been developed in the analysis of such diverse phenomena as $w h$-movement (requires a CP, e.g. Petronio \& Lillo-Martin 1997; Neidle et al. 2000), topicalization (TopP, e.g. Liddell 1980; Neidle et al. 2000), and point-of-view operators introducing role shift (Speech Act Phrase, e.g. Quer 2005). I adopt this second definition of clause in the present discussion and investigate properties that correlate with signed clauses. 
Since the broader goal of this chapter is to provide a set of tools to determine whether a cause-result sentence in DGS and ASL consists of a single clause, or at least does not contain a 'full' second clause, a few further distinctions need to be introduced here. Since we have evidence of both clause linkage and subordination in sign languages (Liddell 1980; Padden 1983; Pfau et al. 2016; Tang \& Lau 2012), a distinction between matrix and subordinate clauses is necessary. Subordinate clauses can further be divided into 'full' tensed clauses with an independent subject that project a finite $\mathrm{T}$, and 'infinitival' clauses whose null subject depends on an argument of the matrix clause and which is either tenseless or has dependent tense. Now, most sign languages, including DGS and ASL, do not have morphological tense, reducing the distinction between full and infinitival clauses to the presence/absence of an independent subject (Geraci \& Aristodemo 2016; Göksel \& Kelepir 2016). The distinction is nonetheless useful since it correlates with syntactic properties such as the availability of center-embedding (see section 4.5.2) and rightward wh-movement (section 4.5.3). In chapter five, I will show that DGS resultatives and ASL Control resultatives contain at most an infinitival clause.

Carving up the sign stream into discrete clauses is complicated by two factors: On the one hand, morpho-syntactic devices such as complementizers and conjunctions that mark clause boundaries are optional (Tang \& Lau 2012). On the other hand, prototypically nominal signs can take on predicative functions in many sign languages: A pointing sign, for example, may establish a referent in the signing space in determinerlike function, or it can predicate a particular location of said referent. Given the frequent omission of arguments that have previously been established in the discourse, a DGS utterance like (46) may contain as many as three clauses (a) or as few as one (b) (potential clause boundaries are marked by the symbol |). The same is true for ASL, where the SOV word order of (46) may surface with aspectually marked or agreement verbs, as well as with classifier predicates (Chen Pichler 2001). 
WOMAN (IX-rt) | PLATE (IX-fr) | LICK-plate.

a. 'A woman is there. A plate is there. (She) licks the plate.'

b. 'The woman licked the plate.'

The sign language literature has primarily drawn on the prosodic organization of signed utterances for cues marking clause boundaries. Engberg-Pedersen, for example, determines cohesion in Danish SL causatives by looking at whether all signs in the construction are "made with the same facial expression throughout and with one downward-upward movement of the signer's head" (2010: 58). Prosodic markers in visual-manual languages include changes in facial expression as well as head and torso movements that structure a signed utterance rhythmically. While researchers acknowledge that there is no isomorphic relationship between syntax and prosody in signed languages, eye blinks have been identified as markers of clause boundaries in both DGS and ASL (Herrmann 2010; Wilbur 1994). However, blinking is neither obligatory at the end of a sentence nor restricted to clausal constituents: A signer may combine several sentences under one intonational contour marked by a final blink in fast signing (Wilbur 1999), or they may blink intra-clausally after topics, between a subject and its predicate, or within an NP containing a relative clause (Herrmann 2010). Other candidates for boundary markers are pauses and holds, where the handshape of a sign is held for at least three frames at the final location (Hansen \& Heßmann 2007). Where they occur, pauses and holds often accompany the end of a sentence, but they are both optional and infrequent. ${ }^{20} \mathrm{~A}$ related cue involves an utterance-final increase in sign duration, which has been discussed as phrase-final lengthening in the literature (Coulter 1993; Grosjean \& Lane 1977; Wilbur 1999). Grosjean \& Lane (1977) show that the final signs of conjoint and independent clauses are held longer than clause-internal signs; however the difference between conjunct-final and conjunct-internal signs only surfaces at slowerthan-normal signing rates.

\footnotetext{
${ }^{20}$ Hansen and Heßmann (2007) find no pauses and only four holds in a 33 second text, compared to 17 eye blinks.
} 
To summarise, no single prosodic cue has been identified that can reliably predict the end of a signed clause. This finding highlights the need for syntactico-semantic diagnostics that are sensitive to clause boundaries. These will be the focus of the next two sections, preceded by a brief discussion of commonly used syntactic clausehood diagnostics that are inapplicable to the study of complex events in signed languages.

\subsection{WHY SOME ESTABLISHED CLAUSEHOOD DIAGNOSTICS FAIL}

Now that we have seen some of the specific issues sign linguists struggle with when trying to delimit clauses, let's turn to syntactic and semantic diagnostics that work around these issues. To exemplify the problem at hand, take a look at (47). Like most signed languages, ASL and DGS lack obligatory overt complementizers and conjunctions (but see Davidson (2013) for an overview of the syntactic distribution and semantics of ASL conjunctions). At the same time, they allow pro-drop for arguments activated in previous discourse. Consequently, the underlying syntactic structure of the cause-result expression in (47) could be (a) juxtaposed or conjoined sentences, (b) a main clause followed by a full dependent clause, or (c) a single clause with an embedded secondary predicate as in resultatives.

WOMAN IX-If SAND FLOOR SMOOTH

[ASL]

a. 'The woman sanded the floor (and it) became smooth.'

b. 'The woman sanded the floor (so that it) became smooth.'

c. 'The woman sanded the floor smooth.'

While the spoken language literature provides a plethora of clausehood diagnostics, many of them are language- or construction-specific and do not apply to the study of resultatives in signed languages. Below, I discuss commonly recommended diagnostics, specifically A-movement, ellipsis, and the scope of temporal and VP adverbs, and explain why they fail to illuminate the data at hand. 


\subsubsection{A-Movement: Passives}

Movement to argument positions such as passivization and raising are frequently used in spoken languages to test the monoclausal status of a construction. Carrier and Randall (1992) note that resultatives allow passives irrespective of the argument status of the causee; both Control (48a) and ECM resultatives (48b) can be passivized in English. In ECM constructions as in other types of small clauses (48c), the raised object can be promoted to subjecthood, in contrast to finite subordinate clauses, whose arguments cannot move into the matrix subject position due to locality constraints on passivization.

a. The socks were scrubbed clean (by the laundry attendant).

b. These soles have been danced thin (by a professional hoofer).

[Carrier \& Randall 1992: 196]

c. John is known to like chocolate.

d. *John is known that likes chocolate.

Agent-backgrounding strategies have been described for various sign languages (for an overview, see Barberà \& Hofherr Cabredo in press), but their status as syntactic passives has not been firmly established. In both ASL and DGS, a perspective shift from agent to patient can be achieved by the signer role shifting into the patient's perspective through changes in posture and facial expression. In combination with an eyegaze shift away from the addressee, these strategies have been argued to demote the agent (Hansen 2007; Janzen et al. 2001; Kegl 1990) but, as Barberà \& Hofherr Cabredo point out, perspective shift may be used for transitive objects as well as for passive subjects. Hence the center of perspective and grammatical role marking do not coincide, which leads the authors to conclude that role shift is not a syntactic object promotion strategy. Since syntactic object promotion is crucial to the use of passivization as a clausehood diagnostic, the test is too language-specific and does not apply to ASL and DGS. 


\subsubsection{Ellipsis}

We next turn to more construction-specific constraints on diagnostics. One of the usual suspects for distinguishing between the coordination analysis in (47a) and syntactically more integrated structures such as (47b) and (47c) is ellipsis. Coordinated but not embedded structures allow the omission of phonological material in one conjunct; for example the verb (gapping) in (49a) or a noun phrase (nominal ellipsis) as in (49b).

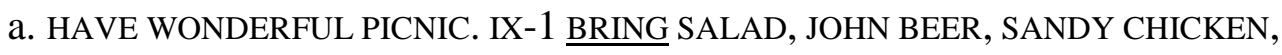 $\mathrm{hn}$}

TED HAMBURGER

'We had a wonderful picnic. I brought the salad, John (brought) the beer, Sandy (brought) the chicken and Ted (brought) the hamburger.'

[Liddell 1980: 31 ]

b. IX-1 ADORE CHOCOLATE, ALWAYS GOBBLE-UP

'I love chocolate, and always scarf (it) down.'

[Fischer \& Lillo-Martin 1990: 78]

As the above examples show, both phenomena are attested in ASL (see also Frazier and Yoshida (2012)) as well as other sign languages (e.g. HKSL, see Tang \& Lau 2012), but their applicability to resultatives is limited. Gapping requires identity of predicates in the constructions under consideration, and resultatives typically have different cause and result predicates (e.g. the result predicate SMOOTH in (47) cannot be gapped because it is different from the causing predicate SAND). Identity of arguments as required for the nominal ellipsis test is a given in resultatives; the patients of causing and result predicates are identical. However, it is characteristic of the construction that this argument surfaces but once; thus we lack an overt realization of both arguments (e.g. The woman sanded the floor the floor smooth) to use as a testing ground for whether one DP can be elided. 


\subsubsection{VP/AP adverb}

The placement and scope of adverbs is frequently used to show the monoclausality of serial verb constructions as complementation structures. Law (1996) observes that certain SVCs in Mandarin do not license a VP adverb preceding the second verb of the construction. Citing Chomsky's (1986) Adjunction Prohibition, Law argues that the inability of the second VP to take an adverb indicates its status as the first verb's complement. Complements that are s-selected by a lexical head do not allow left adjunction, as exemplified by the ungrammaticality of adjoining most of the time to the $\mathrm{CP}$ argument in (50a) or adjoining last year to the complement IP in (50b). Hence, (50a) is acceptable on a reading where something is appalling most of the time, but the frequency adverb cannot modify the embedded CP headed by that.
a. *It's appalling [CP most of the time [CP that he doesn't understand what is going on]].
b. *After [IP last year [IP she resigned]], she moved to Paris.

[McCloskey 1996: 56-58]

While Lau (2012) applies the diagnostic with limited success to SVCs in Hong Kong SL, ${ }^{21}$ the placement of VP or AP adverbs with respect to the result predicate cannot tell us much about the syntactic structure of resultatives for two reasons. First, note that manner and degree adverbs may precede the result predicate in English and scope only over that result predicate (51). Neither does this distribution of adverbs tell us about the complement vs. adjunct status of the result predicate, nor does it indicate the size of the result predicate (i.e. whether it projects a full clause or not). In chapter two, we saw that

\footnotetext{
${ }^{21}$ Lau applies a somewhat modified version of the diagnostic that relies on scope rather than adverb placement. She notes that while manner adverbs like quickly and carefully must scope over both verbs in some SVCs, they cannot scope over the result predicate in resultative SVCs. This is unexpected if the predicate complex behaves as a single eventuality, but it can be explained by independent factors such as the semantic incompatibility of result predicate and adverb. Lau's examples involve the unaccusative result predicate 'fall' modified by the manner adverb 'carelessly'. The adverb requires that the subject have volitional control over the activity expressed by the verb, which is generally not the case for falling (especially if it was caused by an independent causer).
} 
resultative clauses in English can be analyzed as infinitival clauses with at least some functional projections (e.g. agreement). The causing verbs shook and wiped in (51) thus s-select an AgrP as their complement and since manner adverbs like grumpily and obnoxiously adjoin directly to an AP rather than left-adjoining the AgrP, no Adjunction Prohibition violation is incurred. Secondly, the Adjunction Prohibition applies to complements of any size, making it impossible for adverb placement to diagnose whether the result phrase projects an AgrP or a full CP.
a. The sound of persistent knocking on his front door shook Ian grumpily awake. $^{22}$
b. John wiped the counter obnoxiously clean.

\subsubsection{Temporal adverbs}

While time-positional adverbs such as five minutes later or after a moment of indecision do not directly provide us with evidence for monoclausality, they have been used as indirect clausehood diagnostics in the SVC literature. Specifically, Bohnemeyer et al. (2011) argue that syntactic structure determines event segmentation in that syntactically simpler structures are construed as single events that cannot be segmented into subcomponents (they have the so-called Macro Event Property). Complex constructions containing embedded (small) clausal constituents, on the other hand, are construed as separate events that can be targeted by time-positional operators. Hence the adverbial after a moment of breathless suspense in (52) scopes over different events depending on the syntactic structure it modifies: In simple clauses and resultatives, the entire complex event including (manner of) causation and change of state are located with respect to some previous reference point. A reading where Floyd pushed/did something to the door and, after a moment of breathless suspense, it opened, is not

\footnotetext{
22 Source: Jade_Nolan, Aug 26, 2011, https://talk.csifiles.com/threads/dance-with-the-devil-ny-fic.62962/, Accessed 2/6/2017.
} 
available in (52a and b). Compare this to (52d), where the adverbial may either locate pushing and opening with respect to a previous reference point, or it may locate the opening subevent as following the pushing event after a moment of breathless suspense. Subordinate structures such as (52c) do not seem to carry an implicature that both matrix and embedded subevent occur at the same time, hence the time adverbial situates the events associated with matrix or the embedded verb separately to some reference time, but not both. ${ }^{23}$
a. Floyd opened the door after a moment of breathless suspense.
b. Floyd pushed the door open after a moment of breathless suspense.
c. Floyd said that Mary opened the door after a moment of breathless suspense.
d. Floyd pushed the door and it opened after a moment of breathless suspense.

[Bohnemeyer 2011: 48, except (c)]

In order to use a time-positional adverbial as indirect evidence for monoclausality, we would need to show that such adverbs necessarily locate both causing and change-ofstate subevents with respect to a reference time. ${ }^{24}$ Consequently, a pre-requisite for applying the diagnostic is that the temporal adverb be accepted in utterance-final position. In an SVO language like ASL, this is the only syntactically ambiguous position where adverbs may be interpreted as attaching to either the result phrase or the clause headed by the matrix verb. While Aarons et al. (1995) and Braze (2004) assert that

\footnotetext{
${ }^{23}$ It is not clear that even lexical causatives such as open really have Bohnemeyer et al.'s Macro Event Property. While time-positional adverbs target a complex opening event in its entirety, durational adverbs such as for an hour can scope over subevents: The most natural interpretation for Floyd opened the door for an hour is one where the result state 'open' obtained for an hour, not the entire opening event. Durational adverbs thus show that even complex events encoded in a single lexical item can be segmented into their subevents, rendering the MEP less useful for distinguishing more versus less complex syntactic structures.

${ }^{24}$ Lau (2012) shows that a temporal adverbial can scope over both subevents in an SVC in Hong Kong SL. While necessary, this is not sufficient evidence for the monoclausal status of SVCs in the language, since coordinate clauses can also be construed as one event over which the time-positional operator scopes. The difference between coordinate and monoclausal structures lies in the obligatory single-event interpretation of the latter.
} 
temporal adverbs can occur sentence-finally in ASL, there is a strong trend for them to be the first element in a signed utterance (Baker-Shenk \& Cokely 1980). The ASL consultant with whom I discussed the placement of temporal adverbs in resultatives confirms this trend and does not consistently accept temporal adverbs like FIVE MINUTE LATER in utterance-final position. Since she rejected this adverb in sentence-final position in two out of five resultative constructions, the diagnostic was determined to not be consistently applicable and was consequently not used in the present study.

\subsection{SPOTTING COORDINATION}

In this section, we explore semantic and syntactic diagnostics that distinguish coordination from single clauses and clausal embedding as a first step towards showing that syntactic dependencies exist between the cause and result constituents in ASL and DGS resultatives. The three diagnostics discussed here are negation, A' movement, and subject pronoun copy. While the first involves semantic scope, the latter two diagnostics are based solely on syntactic principles.

\subsubsection{Negation}

The scope of a negative operator discriminates between coordination and other multi-verb constructions in that negators scope over each conjunct individually. To illustrate, (53a) is only true in situations where Mary ate rice, because the negator in the first conjunct does not have scope over the second conjunct. Subordinate clauses and resultatives, on the other hand, are true as long as either predicate is negated, as illustrated in the formalizations of (53b) and (53c).

a. John didn't eat pasta and Mary ate rice.

$$
\neg\left(\text { eat }^{\prime}(j, p)\right) \Lambda \text { eat' }(m, r)
$$


b. John doesn't think that Mary ate anything.

$$
\begin{aligned}
& \text { i. } \neg\left(\operatorname{think}^{\prime}(j, \text { eat' }(m, a))\right) \\
& \text { ii. think' }\left(j, \neg\left(\text { eat' }^{\prime}(m, a)\right)\right)
\end{aligned}
$$

c. John didn't lick the plate clean. $\rightarrow \neg\left(\right.$ lick'$^{\prime}(j, p) \wedge$ clean' $\left.(p)\right)$

One way to tell whether a complex cause-result utterance is a resultative or a coordinate clause is thus to negate it and check whether it is only true when the result state holds. If that is the case, the cause-result utterance patterns with coordination. Otherwise, some level of embedding must be assumed, although the size of the embedded constituent (full $\mathrm{CP}$ or infinitival) cannot be determined with this diagnostic.

For languages like DGS, which prefer non-manual negation over a manual negator (Pfau 2001), one might consider looking at the scope of the negative headshake instead. Padden (1983) notes that in ASL, a negative headshake that spreads over conjoined clauses necessarily entails the negation of both conjuncts. Each conjunct essentially receives its own non-manual negation marker, which appears continuous because no non-negated material intervenes between the conjuncts. In contrast, a headshake that spreads from a matrix clause onto the embedded clause does not necessarily negate the embedded clause. One would thus have to test what the interpretive possibilities are when a negative headshake spreads over both predicates of a potential resultative: If the sentence is only true in a situation where neither the causing action nor the result state occurred, the predicates (or rather, their clausal projections) are coordinated. ${ }^{25}$

\footnotetext{
25 Preliminary evidence indicates that there may be further complications to this diagnostic which cannot be explored in detail here. When presented with the sentence MARY RUN CL-1:move_in_circles 'Mary ran around in circles' accompanied by a headshake, two ASL participants indicated that the sentence has to mean that Mary neither ran nor moved in circles. Complex motion descriptions like these have been described as monoclausal SVCs elsewhere (Supalla 1990) hence there is a possibility that coordinate and monoclausal structures are not distinguished in scope when accompanied by a headshake. A possible modification of the test is to check whether the headshake is obligatory over both prediates: In coordinate clauses, it can accompany only one conjunct (Padden 1983), but in SVCs and resultatives it presumably has to occur over both predicates.
} 
A third diagnostic involving negation is the licensing of NPIs. As observed in Schlenker (to appear-b), ASL ANY behaves like an NPI in that it only occurs in downward-entailing contexts such as (54a) but is unacceptable without a licensor, as illustrated in $(54 \mathrm{~b}) .{ }^{26}$

IX-a JOHN OFTEN MEET-MEET [INJURED PEOPLE]-b,

'John often meets injured people,

a. 6 BUT IX-a NEVER SHOW-b ANY HEART-SOFT

but he never shows them any kindness.'

b. 2.7 IX-a OFTEN SHOW-b ANY HEART-SOFT

'and he often shows them kindness.' [Schlenker to appear: 4]

For NEVER to act as licensor, it needs to establish a grammatical dependency to ANY. Schlenker notes that this dependency can hold within a clause or between a matrix and an embedded clause (55a), but it cannot cross independent clause boundaries such as are introduced by quotation (55b), or, presumably, coordination. Fleckenstein \& Yuwon (to appear) use this diagnostic to establish the syntactic scope of negation in ASL, but it may serve more generally as a diagnostic for coordination.

a. 5.3 IX-a JOHN OFTEN MEET-MEET [INJURED PRISONER PRISONER]-b, BUT IX-a NEVER SAY IX-a SHOW-b ANY HEART-SOFT

'John often meets injured prisoners, but he never says he shows them any kindness.'

b. 2.7 IX-a JOHN OFTEN MEET-MEET [INJURED PEOPLE]-b, BUT IX-a NEVER SAY

$\underline{\mathrm{RS}}_{\mathrm{a}}$

IX-1 SHOW-b ANY HEART-SOFT

'John often meets injured people, but he never says to them: 'I show (you) (my) kindness.' [Schlenker to appear: 5]

${ }^{26}$ Schlenker uses a 7-point acceptability scale where $7=$ fully acceptable. 
In summary, the scope of manual and/or non-manual negators as well as NPIs can help detect whether two predicates project coordinated or juxtaposed clauses, or whether syntactic dependencies exist between their projections.

\subsubsection{A' Movement: $W h$-movement and topicalization}

Restrictions on syntactic movement of arguments to non-argument positions in the functional periphery of a clause are frequently cited as indicators of clause boundaries in spoken and signed languages. Ross's (1967) Coordinate Structure Constraint first captured the observation that $w h$-words and topics can move out of some complement clauses (56a) in English, but they cannot move out of conjuncts (56b).

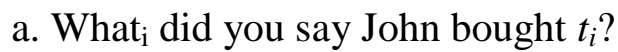

b. ${ }^{*}$ What $_{\mathrm{i}}$ did John eat an apple and Jim drink $t_{i}$ ?

Padden (1983) shows that this constraint holds in ASL as well, as MOTHER in (57a) cannot be topicalized out of the conjunct translated as 'he told his mother' ${ }^{27}$ LilloMartin (1992) goes one step further in claiming that all clauses, including subordinate ones, function as islands for movement in ASL. Her example (57b) illustrates that a DP like THAT COOKIE cannot be fronted to the topic position of the matrix clause. Glück and Pfau (1997) argue that similar extraction facts hold for DGS.

\footnotetext{
27 Transcription conventions for (57) are taken from the papers cited here: Subscripts a-k indicate referential loci or trace indices, INDEX stands for pronominal pointing signs. Lines above the gloss indicate the spread of non-manual marking, in this case the brow is raised and the head slightly tilted back for topic marking. In this paper, non-manuals are only indicated where they are relevant to a syntactic argument or when occurring in a quoted example.
} 
a.

$$
\begin{aligned}
& * \text { MOTHER, }{ }_{1} \mathrm{HIT}_{\mathrm{i}} \text { SISTER, }{ }_{\mathrm{j}} \mathrm{INDEX} \text { TATTLE } \\
& \text { intended: 'His mother, I hit my sister and he told.' }
\end{aligned}
$$

[Padden 1983: 77]

b.

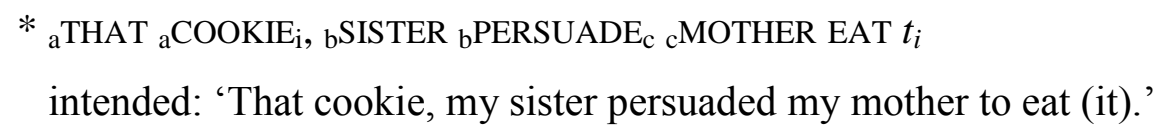

[Lillo-Martin 1992: 263]

Since movement cannot cross a full clause in this analysis, A' extraction provides a good diagnostic for any kind of clause boundary in ASL and DGS, whether it occurs between coordinate clauses or between a matrix clause and its subordinate clause.

However, several factors conspire to reduce the effectiveness of this diagnostic beyond identifying coordination. Lillo-Martin notes that there are several ways around actual movement out of dependent clauses. Topics, for example, may be base-generated in the functional periphery of the matrix clause as long as an overt or null resumptive pronoun remains in situ. Null pronouns of type pro are in turn licensed by agreement marking on the embedded predicate. While the syntactic status of agreement in signed languages is currently under debate, researchers agree that verbs can index their arguments via modifying their initial, final, or overall location to coincide with the location assigned to said arguments (their referential loci). Given their status as definites (Liddell 1980), topical referents are typically assigned a referential locus (EngbergPedersen 1993; Sze 2008), which increases the likelihood of a predicate agreeing with that locus. In fact, my consultants considered it unnatural for a predicate not to show agreement with a topicalized constituent. Hence, unless the utterances under investigation contain verbs that are categorized as "plain" in the sign literature (Padden 1983) because they cannot modify their location to index a referent, ${ }^{28}$ it is impossible to create a context where an element has to move in order to surface in the periphery of the matrix clause.

\footnotetext{
28 An example of a plain predicate is EAT in (57b): Since the form of the verb cannot index its object, no resumptive pronoun is licensed and therefore, MOTHER cannot be base-generated in the specifier of a topic phrase.
} 
Since it is this ability to move that would identify single clauses in ASL and DGS, the diagnostic can thus only be applied to utterances with embedded plain predicates. It also seems to apply to coordinate clauses with agreement verbs, since even a null resumptive pronoun licensed by the agreeing verb TATTLE in (57a) does not render the sentence acceptable. ${ }^{29}$

Even with plain predicates, two caveats concerning the interpretation of the data need to be addressed. Contrary to Lillo-Martin (1992)'s findings, clauses do not form islands for $w h$-movement for all ASL signers. My consultants consistently accept fronted wh-words in complex clauses containing a control clause (58a) or a full sentential complement $(58 \mathrm{~b})$. Note that both EAT and LOVE are plain verbs that do not license a pro resumptive pronoun, illustrating that WHAT and WHO in (58) have truly moved. ${ }^{30}$

a. WHAT $T_{i}$ YOU FORCE-lf \#JOHN-lf EAT $t_{i}$ IX-lf

[ASL]

'What did you force John to eat?'

b. WHO $_{\mathrm{i}}$ IX-rt \#BILL THINK IX-lf \#JOHN LOVE $t_{i}$

'Who does Bill think John loves?'

Similar differences in grammaticality judgments arose for topic movement in DGS. I could not replicate Glück and Pfau's (1997) findings that clauses block DP fronting, since my consultants allow topic movement out of control clauses (59a) and full sentential complements (59b). Extraction can thus only be used to identify full

\footnotetext{
${ }^{29}$ Lillo-Martin (1992) is not clear on this point. On the one hand, she accepts Padden's judgment of (57a) as ungrammatical, while at the same time claiming that null resumptive pronouns can save a coordinate structure such as (iv), where parentheses indicate optionality. Given that the null pronoun in the second conjunct of (iv) exhibits referential identity with the overt resumptive pronoun of the first conjunct, (iv) could be analyzed as gapping. For lack of disambiguating data, I assume with Padden (1983) that null resumptive pronouns cannot license base-generated topics or $w h$-words in coordinate structures.
}

(iv) WHO ${ }_{\mathrm{a}}$ MARY LIKE * ${ }_{\mathrm{b}}$ PRONOUN) (BUT) ${ }_{\mathrm{c}} \mathrm{JOHN}_{\mathrm{c}} \mathrm{HATE}_{\mathrm{b}}\left({ }_{\mathrm{b}}\right.$ PRONOUN)? [Lillo-Martin 1992: 261]

30 These observations are echoed in Schlenker (to appear-a), who notes that a wh-object can be extracted from a role-shifted clause with a plain verb into the matrix clause (at least when the wh-word is doubled in sentence-initial and -final positions). 
subordinate clauses when they contain morphologically plain predicates and after establishing that, in the signers' idiolect(s), clauses form islands for topic and whextraction.

a. $\mathrm{t}$

[DGS]

CAKE $_{\mathrm{i}}$ IX-rt, I FORCE-fr EAT $t_{i}$ IX-fr

'The cake, I forced you to eat (it).'

b.

CAKE $_{\mathrm{i}}$ IX-fr, I THINK I FINISH EAT $t_{i}$

'The cake, I think I've eaten (it).'

In summary, $A^{\prime}$ movement serves to identify coordinated clauses but cannot easily tell us more about the complexity of an embedded constituent. Göksel and Kelepir (2016) propose a modification of the diagnostic that does not require overt movement but relies on semantic scope instead. For languages without wh-movement such as Turkish SL ( T1D), sentences with wh-words in embedded clauses are interpreted as questions, suggesting that the interrogative scopes over the matrix clause. A question interpretation is presumably not available for coordinated structures in which only one conjunct contains an interrogative. This modified variant of the diagnostic is applicable for ASL but not for DGS, which seems to prefer wh-movement over wh-in situ (Grin 2014).

\subsubsection{Subject pronoun copy}

Subject pronoun copy is likely the most frequently cited clausehood diagnostic in the sign language literature. Liddell (1980) first observed that a pronominal point in utterance-final position in ASL can refer back to the sentential subject, whether that subject is expressed overtly or not. Such pronoun copies are frequently accompanied by a head nod and are not separated with a pause from the rest of the utterance. Padden (1983) noted syntactic constraints on the co-reference potential of final pronoun copies that can 
be exploited for identifying coordinate clauses. As illustrated in (60a), a pronominal copy may be co-referential with the subject of a simple clause such as IX-rt WOMAN. Padden claims that such a co-reference relation can be established when a dependent clause intervenes between subject and copy, as is the case for the pro-dropped subject of FORCE in (60b) and the final first-person pronoun. Crucially, however, a pronoun copy cannot refer back to the subject of the first conjunct in a coordinated structure: The final index sign in the ungrammatical (60c) shares the referential locus ' $a$ ' with ANN, the subject of the first conjoined clause. According to Petronio (1993), the final pronoun copy rightadjoins to the matrix $\mathrm{C}$ and $\mathrm{m}$-commands a co-referential subject. In a coordinated structure, the final copy can only look inside the second conjunct, where it does not find a co-referential subject, resulting in ungrammaticality.

\section{a. IX-rt WOMAN IX-rt READ SOMETHING IX-rt}

'The woman is reading something.'

b. ${ }_{1}$ FORCE $_{i}$ MAN $_{i}$ GIVE $_{j}$ BOY ${ }_{j}$ POSS BOOK $_{1}$ INDEX

[Padden 1983: 73]

'I forced the man to give the boy his book, I did.'

c. ${ }_{\mathbf{a}} \mathbf{A N N}_{\mathbf{i}}$ SAD BUT ${ }_{b}$ JOHN HAPPY ${ }_{\mathbf{a}}$ INDEX $_{\mathbf{i}}$

[Petronio 1993: 29]

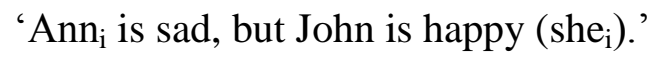

Subject pronoun copies have also been observed in DGS and a number of other signed languages, and for all of them, the literature agrees on the acceptability of simple clauses with pronoun copies like (60a) and on the fact that such copies in coordinate structures like (60c) are not accepted. However, signed languages seem to vary systematically when it comes to the acceptability of pronoun copies in sentences containing embedded clauses. Languages like ASL allow pronominal subject copies following all types of complement clauses, while Sign Language of the Netherlands (NGT) does not allow final pronouns to refer back across any kind of subordinate clause (van Gijn 2004). For a third class of signed languages, the size of the embedded clause seems to matter. Göksel and Kelepir (2016) have recently shown that final pronoun 
copies are only acceptable following complements of WANT-type verbs but not of KNOWtype verbs in Turkish Sign Language (T1D). Only WANT-type verbs allow centerembedding of their complements, a property that Geraci and Aristodemo (2016) have linked to taking an infinitival complement in SOV languages like T1D and LIS (Italian Sign Language). It thus stands to reason that languages like $\mathrm{T}_{1} \mathrm{D}$ disallow final pronoun copies following full sentential complements, but that such pronouns can refer back to the matrix subject if an infinitival complement clause intervenes. ${ }^{31}$ The examples in (61) summarize the typological possibilities for pronoun copies following dependent clauses: (61a) in conjunction with (61b) show that ASL allows subject pronoun copies with full and reduced complement clauses, $(61 b+c)$ illustrate that NGT does not allow subject pronoun copy with any type of subordinate structure, and $(61 \mathrm{~d}+\mathrm{e})$ show that in $\mathrm{T}_{1} \mathrm{D}$ final pronoun copies are accepted with complements of WANT but not of KNOW.

a. IX-1 DECIDE IX-i SHOULD i-DRIVE-j SEE CHILDREN IX-1

'I decided he ought to drive over to see his children, I did.'

[Padden 1983: 73]

b. *MARIJKE IX-rt KNOW INGE IX-lf lf-COME-1 IX-rt

[NGT] intended: 'Marijke knows that Inge comes to me.'

c. *IX-If WANT HOUSE GO.TO IX-If intended 'He wants to go home.'

[van Gijn 2004: 92, 94]

d. *? ALI-k IX-k IX-1 UNIVERSITY WORK KNOW IX-k intended: 'Ali knows that I am working at the university.'

e. ALI-k IX-1 UNIVERSITY WORK WANT IX-k

'Ali wants me to work at the university.'

[Göksel \& Kelepir 2016: 73]

\footnotetext{
31 Since signed languages tend not to mark tense morphologically and lack obligatory subjunctions, I adopt Geraci, Cecchetto, and Zucchi (2008)'s suggestion to consider full sentential complements those clauses that behave like independent clauses except for potential non-manual marking accompanying them. Crucially, full sentential complements need to exhibit overt subjects that do not depend on any arguments of a matrix clause (control and raising structures).
} 
DGS seems to pattern with $\mathrm{T}_{1} \mathrm{D}$ rather than with ASL or NGT. My five DGS consultants produced and evaluated 18 variants of the sentences in (62) and rejected 13 of them. Of the five accepted utterances, three are tokens of (62c), which contains an object control clause. Two of the DGS signers also produced the utterances in (62) as polar questions and judged only one token acceptable, again the one using the control verb FORCE. The fact that the signers reject pronoun copies following full dependent clauses but sometimes accept them with an infinitival verb suggests that DGS and T1D share similar restrictions on subject pronoun copies.

\section{a. IX-1 BELIEVE.NOT DOCTOR EXIST TIME FOR-fr IX-1}

[DGS]

'I don't think the doctor has time for you.'

\section{b. IX-1 HOPE \#JOHN IX-rt rt-EMAIL-fr IX-1}

'I hope John emails you soon.'

\section{c. IX-1 \#HANS IX-rt FORCE-rt WORM EAT IX-1}

'I forced Hans to eat a worm.'

Recognizing that restrictions on subject pronoun copy are language-specific has important repercussions for the applicability of the diagnostic. While the phenomenon can only distinguish between coordinate clauses and a higher degree of syntactic integration in languages like ASL, it can identify monoclausal utterances in NGT, since only those allow the addition of subject pronoun copies. In languages like $\mathrm{T}_{1} \mathrm{D}$ and potentially DGS, utterance-final pronouns can identify whether a particular constituent forms a full clause or shows a higher degree of syntactic integration with the matrix clause, as control and raising constructions do.

As a matter of research practice, I would further suggest that subject pronoun copies be embedded in polar questions rather than used in declaratives. In her typological overview of interrogative constructions in signed languages, Zeshan (2004) points out that final pronoun copies typically accompany yes/no questions. This observation is echoed by Petronio (1993), who notes that in ASL doubling constructions including 
pronoun copy are common in polar questions. Framing the diagnostic as a polar question has the advantage of not requiring a particularly emphatic context for the utterance. ${ }^{32}$ During my data collection for both ASL and DGS, some consultants initially rejected subject pronoun copies in simple declarative clauses even when provided with a context that invited emphasis on the subjects. Embedding final pronominal points in a polar question improved their overall acceptability in simple clauses for at least two signers. A further advantage of this modified diagnostic is that it provides an additional prosodic cue for clause boundaries. The entire polar question, including the final point, is marked by the non-manual feature brow raise, suggesting that the utterance in question forms at least an intonational phrase.

Two final notes on applying the diagnostic may be useful. First, it is important to keep in mind that the various subject-like referents in the utterance under investigation cannot be identical if the diagnostic is to offer any syntactic insights. The acceptability of the hypothetical DGS example (63a) does not allow the conclusion that the utterance contains a subordinate rather than two coordinate clauses. Both predicates have a first person subject, so the final pronoun copy can m-command a co-referential subject in the second clause. It does not need to look any further for a subject in the first clause to mcommand, hence there is no way to ascertain whether this type of government is possible. The diagnostic thus does not work for the equivalent of fake reflexives such as $\mathrm{He}$ danced himself tired, in which the subject of the causing and the result predicate are coreferential.

\section{a. IX-1 COKE DRINK THEN BURP IX-1}

'I drank a coke and then burped, I did.'

b. IX-rt WOMAN MAN IX-lf SHAKE-lf AWAKE-lf IX-rt

\#‘The woman shook the man awake, she did.'

?'The woman shook the man. She woke up.'

\footnotetext{
32 Padden (1983:71) observes that subject pronouns are copied in declaratives for emphatic or confirmation purposes.
} 
A second related caveat concerns marginally acceptable cases of pronoun copies that nonetheless indicate a coordinate structure. In (63b), the intended subject of AWAKEIf is the man, as indicated by both the extralinguistic context (the action sequence was presented on video) and the indexing -lf on the verb. Nonetheless, the only available interpretation for this utterance is that the woman woke up. This strongly suggests that the clauses containing SHAKE and AWAKE are at best coordinated, since the final pronoun cannot look outside of the clause containing AWAKE for a co-referential subject. In order to salvage the utterance, the phonologically null subject of AWAKE is interpreted as coreferential with IX-rt, namely the woman. In summary, it is important to ascertain that the final pronoun is not co-referential with the subject of the clause (candidate) immediately preceding this pronoun.

Given that the diagnostics discussed in this section all allow a distinction between a coordinate and a subordinate structure for resultatives, the subject pronoun copy test was adopted for the ASL data in this study. It was chosen not only because it is wellstudied and frequently used (e.g. by Engberg-Pedersen 2010 for complex causatives), but also because it combines syntactic with prosodic evidence (the cause-result predicates are presented under a single intonational question contour). For ASL, this diagnostic thus complements tests that focus on the size of the embedded constituent, which are discussed in the next section.

\subsection{A CLOSER LOOK AT EMBEDDED CLAUSES}

Showing that cause-result expressions in ASL and DGS are not coordinated (or juxtaposed) clauses is only half the battle. Ideally, we also want to see some evidence that the result predicate does not head a full clause but either projects an infinitival clause or forms a complex predicate with the manner of causation verb. The diagnostics discussed in this section discriminate between full clausal embedding and higher levels of syntactic integration and thus bring us a decisive step closer to understanding what resultatives look like in signed languages. Below, I first discuss the placement and scope of modal 
verbs and sentential center-embedding, which apply to SOV languages only. I then discuss rightward wh-movement and the scope of time-positional adverbs.

\subsubsection{Placement and scope of modal verbs}

Modal verbs in DGS occur either in second position or clause-finally and are limited to one modal per clause (Pfau \& Quer 2007). As the examples in (64) show, a final modal scopes only over the clause it immediately follows. In (64b), a full complement clause ${ }^{33}$ intervenes between the matrix predicates BELIEVE or SAY and MUST, hence the modal can only be interpreted with respect to the subordinate clause. In order for MUST to scope over BELIEVE or SAY, the modal needs to precede the right-dislocated complement clause (64c). To complete the picture, a final modal verb takes semantic scope over the second conjunct only in a coordination structure (64d).

a. IX-1 APPLE EAT MAY

[DGS]

'I am allowed to eat an apple.'

b. IX-1 BELIEVE/SAY IX-fr APPLE EAT MUST

'I believe/say that you must eat an apple.'

\#'I have to believe/say that you are eating an apple.'

c. IX-1 BELIEVE MUST IX-fr APPLE EAT

'I must believe that you are eating an apple.'

d. IX-1 APPLE EAT IX-fr WATER DRINK MUST

'I eat an apple and you have to drink water.'

\#'I have to eat an apple and you (must) drink water.'

To establish whether a cause-result expression contains a full subordinate clause or not, one thus needs to check whether a sentence-final modal like MUST in (65) can

\footnotetext{
33 The same facts hold when the subject of the subordinate clause is pro-dropped: In the sentence OBELIX ${ }_{1}$ $\left(\mathrm{IX}_{1}\right)$ KNOW (IX $)$ MAGIC POTION DRINK MAY.NOT 'Obelix knows he may not drink any magic potion' (Happ \& Vorköper 2006: 471) we see that the negated modal still refers only to the subordinate clause.
} 
scope over the causing predicate, in this case SPRAY. If the reading provided for (65) is not available, the result predicate in all likelihood projects its own full clause. ${ }^{34}$

'The hairdresser has to spray the hair wet.'

\subsubsection{Center-embedding}

I now turn to two diagnostics that, to my knowledge, have not been discussed in detail in the sign literature on clausehood diagnostics. The first, center-embedding, applies to SOV languages only, but the rightward movement discussed in the next section applies to SOV and SVO languages alike.

In SOV languages like German, nominal complements precede the verb (66a) while clausal complements tend to occur in extraposed position to the right of the verb (66d). This deviation from OV word order is often attributed to a trade-off with the increased processing cost associated with computing a syntactically complex centerembedded structure (Hawkins 2004). While full complement clauses are typically banned from the pre-verbal position (66c), center-embedded infinitival clauses such as (66b) are acceptable.

a. ... dass Fritz [DP ein Buch] gelesen hat. that Fritz a.ACC book read has

'...that Fritz read a book.'

b. ... dass Max [тр das Buch zu lesen] versucht hat. that Max the.ACC book to read tried has '... that Max tried to read the book.'

\footnotetext{
34 When applying this diagnostic in DGS, it is important to keep in mind that modal verbs only have deontic interpretations in the language. Thus, an epistemic reading of (65) along the lines of "The hairdresser sprayed the hair, so it must be wet" is unavailable.
} 
c. ?* ...dass Peter, [cP dass es wieder regnen wird], behauptet hat. that Peter that it again rain will claimed has

d. ...dass Peter behauptet hat, dass es wieder regnen wird.

'... that Peter claimed that it will rain again.'

[Bader et al. 2013: 63-65]

The same distribution of full and infinitival complement clauses holds in sign languages with SOV word order like Italian SL (LIS, see Geraci \& Aristodemo 2016 ) and DGS. DP and Control clause objects in DGS may be center-embedded (67a-b), but full complement clauses are obligatorily extracted $(67 \mathrm{c}-\mathrm{d})$. Since resultatives do not contain a full embedded clause, we thus predict that if a given cause-result utterance is a resultative, the result predicate (and its subject) should be able to precede the causing predicate. ${ }^{35}$

a. HANS [DP WORM] EAT.

'Hans ate a worm.'

b. IX-1 HANS

'I forced Hans to eat a worm.'

c. * IX-3 [CP IX-2 2-HELP-3 MUST] SAY

[Pfau \& Steinbach 2005: 516]

d. IX-3 $t_{\mathrm{i}}$ SAY [CP/i IX-2 2-HELP-3 MUST]

'He says that you must help him.'

35 One thing to keep in mind when applying this diagnostic is that center-embedding of full clauses may sometimes be licensed when the relationship between matrix subject and predicate can be strengthened (Geraci \& Aristodemo 2016). In LIS, sentential-like complement clauses are accepted in pre-verbal position when accompanied by role shift, or whenever the matrix subject is indexed on the matrix verb. In the cause-result utterances discussed here, the causing verb does not exhibit agreement with the causer, nor is the result phrase accompanied by role shift. 


\subsubsection{Restrictions on rightward wh-movement - An empirical investigation}

\subsubsection{Introduction: Rightward movement does not cross clauses}

In contrast to center-embedding, the use of utterance-final wh-words as a clausehood diagnostic does not depend on the basic headedness of a language. Along with many other sign languages, DGS and ASL allow final wh-words (Aarons et al. 1992; Grin 2014; Jahnke \& Volk 2015) and thus arguably rightward wh-movement (but see Quadros (1999) and Aboh et al. (2005) for recent accounts of final wh-words as leftward plus remnant movement). Ross (1967) first formalized the intuition that rightward movement is subject to strict locality conditions. His Right Roof Constraint states that rightward movement is clause-bounded, possibly due to the greater processing load associated with maintaining the filler-gap dependency across several syntactic domains (Ackema and Neeleman (2002)). ${ }^{36}$ In line with these observations, Geraci and Aristodemo (2016) find locality constraints on rightward movement in LIS: A moved whword may cross a DP (68a), but it cannot cross a full extraposed clause (68b).

a. HOUSE BUY WHO

'Who bought a house?'

[Geraci \& Aristodemo 2016: 100]

b. ${ }^{*} t_{\mathrm{wHO}}$ THINK [ PIERO BIKE FELL] WHO

intended: 'Who thinks that Piero fell off the bike?'

[Geraci \& Aristodemo 2016: 115]

Let us take a look at the actual cause-result expressions found in the present study. In all of the ASL and some of the DGS constructions, the cause predicate precedes

\footnotetext{
36 Ackema \& Neeleman assume that short-term memory limitations force the parser to close off already processed structure and treat it as invisible to the syntax. Since the parser only looks for places to insert a gap after it has already identified a moved element, it follows that a rightward-moved element has to be in the same clausal unit as its trace, otherwise the parser seals off said clause and can no longer insert a gap into it once it comes across the rightward moved antecedent. It follows that rightward wh-movement from full complement clauses should be impossible, because the embedded clause has already been sealed off by the time the parser encounters the antecedent (Cecchetto, Geraci, Zucchi 2009 ).
} 
the result phrase (69), raising the question whether the result predicate heads an (extraposed) full clause or a smaller constituent. One way to find out is to see whether a $w h$-subject can move to the right of the result predicate in these sentences. If DGS and ASL are subject to similar locality constraints on rightward movement as attested in LIS, an acceptable final $w h$-subject indicates that the result phrase is smaller than a finite CP. The empirical question pursued in this section is whether locality constraints on rightward movement do in fact hold in the two sign languages under investigation.
a. JOHN LICK + PLATE $_{i}\left[\right.$ PRO $_{i}$ NO.TRACE.LEFT $]$
b. JOHN PLATE $\mathrm{LICK}^{+}\left[\mathrm{PRO}_{\mathrm{i}}\right.$ CLEAN $]$

[ASL]

[DGS]

'John licked the plate clean.'

\subsubsection{Methods}

In order to test whether DGS and ASL disallow wh-movement across a full (coordinate or subordinate) clause, six DGS and seven ASL consultants were presented with a set of simple, control, subordinate, and coordinate clauses. As part of the grammaticality judgment (GJ) task described in chapter three, each sentence was presented once with a final $w h$-word (as illustrated in (70)), and once with the wh-word in initial position. Control clauses were included to test whether infinitival clauses may intervene between filler and gap. 
'Who killed John?'

Control clause

b. $t_{\text {WHO HANS ZWING WURM ESS WER }}$

[DGS]

Hans force worm eat who

b'. $t_{\mathrm{WHO}}$ FORCE-rt JOHN IX-rt EAT WORM WHO

[ASL]

'Who forced Hans/John to eat a worm?'

Full complement clause

c. $t_{\mathrm{WHO}}$ GLAUB HANS WURM ESS WER

$[\mathrm{DGS}]^{38}$

believe hans worm eat who

'Who believes that Hans ate a worm?'

$c^{\prime} . t_{\mathrm{WHO}}$ SUSPECT JOHN KISS MARY WHO

[ASL]

'Who suspects that John kissed Mary?'

37 To ensure that participants were not basing their decisions on the length of an utterance rather than its syntactic complexity, we also obtained judgments on simple clauses with indirect objects and adverbials intervening between the $w h$-word and its trace. The sentence $t_{\mathrm{WHO}}$ SUSI IX-fr PURSE BIRTHDAY GIVE-fr WHO 'Who gave Susi a purse for her birthday?' for example, was produced as acceptable by 2 DGS signers. Furthermore, control clauses equal subordinate clauses in length but are hypothesized to pattern with simple clauses in grammaticality judgments. Lastly, the $w h$-words in the test sentences were almost all subjects, except in simple clauses, where I tested one $w h$-subject and one wh-object. The wh-subject received lower GJ ratings (3.17) than the wh-object (4.83), but given that 2 DGS signers also produced a final $w h$-subject in $t_{\mathrm{wHO}}$ SUSI IX-fr PURSE BIRTHDAY GIVE-fr WHO, we assume that final $w h$-subjects in simple clauses are generally acceptable.

38 The examples of full complement clauses in DGS are all based on transitive verbs. To show that rightward wh-movement is also not licensed across intransitive clauses that lack an external argument, one DGS participant (P7) judged the sentences in (v), which contain embedded stative and unergative predicates. Wh-movement across an intransitive is considered unacceptable, confirming that such movement does not depend on the transitivity of the embedded verb.
a. $1 t_{\text {WHO }}$ THINK HANS STUPID WHO
'Who thinks that Hans is stupid?'

b. $3 t_{\mathrm{wHO}}$ BELIEVE KASSANDRA DANCE GOOD WHO

'Who believes that Kassandra dances well?' 
Coordinate clause

d. $t_{\text {who NIES DANN BABY WACH WER }}$

[DGS]

sneeze then baby awake who

'Who sneezed and then the baby was awake?'

d'. $t_{\text {who }}$ EAT SALAD BUT JOHN IX-rt EAT PIZZA WHO

[ASL]

'Who ate a salad but John ate pizza?'

\subsubsection{Results and discussion}

In the next step, a linear mixed effects model was fit separately to the DGS and ASL data sets using $\mathrm{R}$ (R Core Team 2016) and lme4 (Bates et al. 2012). Since the prediction was that coordinate and subordinate clauses with final wh-words should receive significantly lower GJ ratings than simple and control clauses with final whwords, fixed effects for sentence type and wh-word order and their interaction were included in the models. The interaction was decomposed using the Tukey adjustment method to control the Type I error rate in pairwise comparisons. The final models also included a random intercept for participant. A random intercept for item was initially included but was removed due to non-significance. Visual inspection of residual plots did not reveal any obvious deviations from normality.

Table 6 summarizes the means and standard deviations for GJ ratings listed by sentence-type and language. It shows slight differences in the mean acceptability of rightward wh-movement between DGS and ASL. For DGS, we can confirm that rightward wh-movement across full complement clauses such as (70c and c') is significantly less acceptable than movement within a simple clause $(p=0.007)$ or across a control clause $(p=0.009)$. In ASL, wh-movement across a full complement clause is also significantly less acceptable than movement within a simple clause $(p=0.042)$. In contrast to DGS, full complement clauses are also less acceptable than control clauses, but this trend does not reach significance $(p=0.091)$. Lastly, $w h$-movement across a conjoined clause is significantly less acceptable than with any other sentence-type in ASL 
(simple $p<0.0001$, control $p=0.0001$, full complement $p=0.006$ ). For DGS, no significant difference between coordination and other sentence types was found, although on average coordinate clauses with final $w h$-words received lower GJ ratings than simple and control clauses. ${ }^{39}$

In summary, locality constraint on rightward movement hold in both DGS and ASL in that rightward $w h$-movement is significantly more acceptable within a clause (and across a control clause in DGS) than across a full (complement) clause. Consequently, the phenomenon can serve as a diagnostic for the presence of full clausal material in postverbal position, and has the advantage of being applicable across different verb classes.

Table 6

Means and Standard Deviations for Grammaticality Judgment Ratings of Final Wh-words in Different Sentence Types for DGS and ASL

\begin{tabular}{lcccc}
\hline & \multicolumn{3}{c}{ DGS } & \multicolumn{3}{c}{ ASL } \\
\cline { 2 - 5 } Sentence & $M$ & $S D$ & 4.36 & $S D$ \\
\hline Simple & 4.00 & 1.48 & 4.25 & 1.01 \\
Control & 3.83 & 1.03 & 3.19 & 1.16 \\
Subordinate & 2.18 & 1.47 & 1.43 & 1.29 \\
Coordinate & 2.83 & 1.17 & & 0.79 \\
\hline
\end{tabular}

${ }^{39}$ It is possible that there is a significant difference in acceptability between coordination and simple/control clauses with final $w h$-words in DGS and that our model failed to show this difference due to a lack of power. The sample size of coordinate clauses in both ASL and DGS was smaller (6 observations in DGS, 7 in ASL) than for each of the other sentence types (12 observations in DGS, 14 in ASL). 


\subsection{SUMMARY OF DIAGNOSTICS AND CONCLUSION}

The diagnostics presented in this chapter are summarized in Table 7. Tests that are not applicable to DGS or ASL due to their language- or construction-specific nature are not listed. The first three diagnostics distinguish coordination from any type of dependent structure, while the remaining three tests identify infinitival clauses or monoclausality proper. Red indicates that a given diagnostic results in unacceptability for a sentence type; for example subject pronoun copies cannot occur at the end of a coordinate clause while center-embedding is unacceptable with coordinated and full $\mathrm{CP}$ clauses.

Table 7: $\quad$ Summary of Clausehood Diagnostics that are Applicable to Cause-Result Expressions in ASL or DGS

\begin{tabular}{|l|l|l|l|}
\hline Diagnostic/Clause type & Coordinated & Full complement & $\begin{array}{l}\text { Infinitival complement } \\
\text { or single clause }\end{array}$ \\
\hline Monoclausality & $\mathrm{X}$ & $\sqrt{ }$ \\
\hline Subject pronoun copy & $\mathrm{X}$ & $\sqrt{ }$ \\
\hline A' movement (left) & $\mathrm{X}$ & $\sqrt{ }$ \\
\hline Negation & $\mathrm{X}$ & $\sqrt{ }$ \\
\hline A' movement (right) & $\mathrm{X}$ & $\sqrt{ }$ \\
\hline Center-embedding & $\mathrm{X}$ & $\mathrm{X}$ & \\
\hline Modals & &
\end{tabular}

As layed out in the next chapter, I used subject pronoun copy and rightward whmovement to analyze cause-result expressions in ASL, while relying on centerembedding and rightward wh-movement to describe the syntactic structure of potential DGS resultatives. The scope of modal verbs was used to test monoclausality of bare resultatives in DGS. Given that over 20 different cause-result combinations had to be 
tested for clausehood, I limited the number of diagnostics per language to two to three and gave syntactic diagnostics preference over those involving semantic scope; since the latter require eliciting more fine-grained intuitions on the part of consultants.

This chapter has accomplished two goals. On the one hand, I have identified shortcomings of existing clausehood diagnostics and suggested appropriate modifications, and on the other hand, I have proposed two new diagnostics based on findings on LIS by Geraci \& Aristodemo (2016). Some applicability issues seem problematic independent of modality, such as the identical subject requirement on gapping. Others are more specific to sign languages, in particular the limited applicability of the extraction diagnostic to morphologically plain verbs. This chapter also took a closer look at subject pronoun copy, a well-established and much-cited diagnostic. It was shown that final pronouns differ in informativeness as diagnostics across signed languages: While they are sensitive to even infinitival clauses in NGT, they can only differentiate coordination from any type of embedding in ASL. In a third type of signed languages including DGS and T1D, the acceptability of a final pronoun signals that the utterance does not consist of more than one full clause, but it may still contain smaller clause-like constituents such as control or raising structures.

Importantly, this chapter has contributed two new diagnostics and a modification of the subject pronoun copy test to the inventory of clausehood tests. I proposed that subject pronoun copies should be embedded in polar questions to avoid problems with contextual emphasis requirements and in order to benefit from brow raise as an additional prosodic cue for intonational boundaries in the target utterance. Since even a modified pronoun copy test can only distinguish coordination from different types of dependent structures, I introduced restrictions on rightward wh-movement and center-embedding as further diagnostics. While center-embedding of complement clauses requires SOV word order, rightward A' movement applies to SVO and SOV languages alike. Crucially, however, both are capable of discriminating between sentences that embed a full clause and those containing at most an infinitival clause, bringing us significantly closer to gauging monoclausality than coordination tests. 


\section{Chapter 5: The syntax and semantics of resultative constructions in DGS and ASL}

\subsection{INTRODUCTION}

The present chapter provides syntactic evidence for the existence of resultative constructions in DGS and ASL and discusses constraints on the possible combinations of causing and result predicates. Before diving into the syntax and semantics of resultatives however, I provide an overview of the range of constructions ASL and DGS users employ to talk about cause and effect. Section 5.2 focuses on unique aspects of causeresult expression in the visual-spatial modality. I discuss iconic representations of various components of a causative situation, as well as limitations on the iconic portrayal of event-to-scale homomorphy. Section 5.3 details the syntax and semantics of resultatives, first in DGS and then in ASL. For each resultative construction, I first present evidence for monoclausality, then discuss semantic constraints on the combination of cause and result predicate, and finally offer a syntactic analysis of the construction. Section 5.4 concludes this chapter.

\subsection{TAlKing ABOUt COMPLEX CAUSE-RESUlt EVENTS: A PILOT STUDY}

While this chapter focuses on monoclausal constructions involving an overt manner of causation and result predicate, this first section provides an overview of alternative strategies for talking about cause and effect as they were encountered in the

pilot study. Some of these constructions are unique to languages in the visual-manual modality and merit further investigation that, unfortunately, exceeds the scope of this dissertation. 
In the pilot study, signers viewed short video sequences featuring an animate causer performing an action that brought about a change of state in the animate or inanimate causee (e.g. shooting an opponent dead or licking a plate clean). Resultatives were not necessarily a speaker's first choice for describing such complex cause-result events. Even when instructed to produce single-sentence descriptions, native users of DGS and ASL produced a range of mono- and multiclausal constructions, as illustrated in (71) for shining a shoe and shooting someone dead. On the monoclausal end of the continuum, participants produced resultatives (71a) and lexical causatives (71b), while adverbial clauses such as (71c) formed the multiclausal end of the spectrum. Covert coordination of clauses was also attested, sometimes accompanied by temporal adverbials or a perfective marker (71d). Which construction a speaker chose depended in part on personal preference.

(71) a. WOMAN POLISH-shoe SHOE SHINY-shoe

'The woman polished the shoe shiny.'

b. MAN KILL OTHER MAN

'The man killed the other man.'

c. IX-screen WOMAN SHOE POLISH-shoe+ UNTIL SHINY

'The woman polished the shoe until it was shiny.'

d. WOMAN POLISH-Shoe+ FINISH END CLEAR, SHINY-shoe, CLEAN

'The woman polished the shoe (and) upon completion/in the end, (it's) shiny and clean.'

As illustrated in (71c), result predicates may be embedded in temporal clauses headed by UNTIL or marked by the adverbial connective THEN (72). DGS consultants 106 
employed this strategy more frequently than ASL consultants, who rarely used temporal clauses: There are 10 tokens of UNTIL (BIS) and four of THEN (DANN) in the DGS data, but only one token of each UNTIL and THEN in the ASL data. Several DGS consultants said that BIS is strongly preferred with durative verbs to highlight the passage of time throughout the activity. In fact, two consultants stated that BIS is obligatory when describing beating someone to death, while it can be left out if the punctual form of BEAT is used.

'Someone is asleep on a couch. (Her) friend shakes (her) and (she) wakes up.'

Other temporal markers that were produced spontaneously include NOW (73a) and SUDDENLY (73b). More frequently, however, the temporal relationship between cause and result subevents was only implied in the coordination or juxtaposition of clauses. While no manual coordinators were attested, cause and result clauses were sometimes conjoined with the help of non-manual coordination markers such as contrastive body leans as in (73c). More often, however, clauses were simply juxtaposed and their ordering iconically mirrored the order of events. In all complex event descriptions in both the ASL and DGS pilot data, the result clause follows the manner of causation clause. In (73d), for example, the three consecutive subevents involved in waking the sleeper were represented in three juxtaposed and prosodically distinguishable clauses. As we will see in the next sections, word order confirms the clausal separation of SNEEZE and WAKE-UP in (73c): If the two predicates in (73c) formed part of the same clause, the causee IX-lf 'she' would precede both of them. 
'The woman's hair is dry. (Someone) sprays (it), now (it) is wet.'

b. WOMAN IX-If MEAN CHARM+, SUDDENLY WOMAN UGLY

[DGS]

'The mean woman performs spells (and) suddenly the (other) woman is ugly.'

c.

bl lf

$\mathrm{bl} \mathrm{rt}$

bl rt

bl lf

[DGS]

WOMAN LIE-lf, WOMAN SIT-rt, IX-rt SNEEZE, IX-lf WAKE-UP IX-lf

'One woman is lying (on the sofa), another woman is sitting to her right. The woman on the right sneezes (and) the woman on the left wakes up.'

d. IX-screen PERSON-rt WOMAN THROUGH+ SLEEP THROUGH+. OTHER WOMAN

CL-1:approach-towards-left, SHAKE-lf+, IX-lf WAKE-UP.

[DGS]

'On screen there's a woman sleeping. Another woman walks up (to her), shakes (her), (and) she wakes up.'

One strategy for representing complex cause-result events stands out in that it exploits the visual iconic potential of signed languages. Classifier constructions allow the signer to depict the shared spatio-temporal profile of causing and result subevents by creating a blended space in which elements of event time and space are mapped onto the utterance situation (Liddell 2003, Dudis 2004). In (74), the signer's dominant right hand takes on the (1)-handshape representing an upright human walking towards a door. The handshape then changes to portray another part of that person's body, namely their leg. While the causer is thus consistently mapped onto the signer's dominant hand, the causee 'door' is represented as a size and shape specifier (B) on the non-dominant hand. At 
the moment the outstretched index finger of the dominant hand touches the palm of the

-hand, the wrist of the non-dominant hand rotates outward to signify 'open'. The dominant hand assumes the -handshape again and continues its movement forward into neutral space. Given the mapping of event time and spatial configuration onto the utterance situation, the touching of the signer's hands signifies contact between causer and causee, and the immediate sequence of stretching out the index finger and rotating the -hand's wrist show the overlapping temporal profile of the kicking and opening subevents.

RH: CL-1:person_walks CL-S/1:kick_at_door CL-1:person_walks

LH: $\quad$ CL-B:door------------door_opens

'Someone walks towards a door, kicks it open, and walks on.'

A second example of the event-depictive potential of classifier constructions is provided in (75) from DGS. Here, the spatial configuration of two cowboys facing each other in a duel is represented by the two hands in upturned $(\mathrm{H})$-shape held across from each other with palms facing. The signer then becomes a surrogate for one of the duelists, imitating his focused look at the opponent while keeping one hand on his weapon. The shared spatio-temporal profile of the causing event (shooting) and its result (dying) is reflected in the spatial configuration of the signer's hands and their sequenced movements. First, the dominant hand represents the shooter's gun being drawn and shot, and immediately afterward the non-dominant hand signs DIE on the left side of neutral space, in alignment with the surrogate's leftward gaze. As Lau (2012) points out for serial verb constructions in HKSL, this locative agreement on both causing and result predicates is also a way of marking argument (causee) sharing. 
(75)

[DGS]

squint, gaze left

RH: BOTH COWBOY CL-H:person_standing_facing_other_person, GUN-holster

LH: COWBOY CL-H:person_standing_facing_other_person,

RH: CL-L:draw_gun_and_shoot

LH: $\quad$ DIE-lf

'There are two cowboys standing and facing each other, waiting with their guns in their holster, one (cowboy) draws his gun and shoots, the other one dies.'

In addition to allowing the signer to include typical resultative event-structural information such as physical contact between causer and causee and a shared spatiotemporal profile, classifier constructions enable signers to illustrate the specific change of state a causee undergoes along some physical dimension. The two caused change-of-state predicates that involve a physical dimension in my data denote the flattening of an object (a spoon and an earring), and a person's extreme weight gain. Figure 3 illustrates the different classifier predicates used for flattening in ASL: On the left, the curved (openB)-hand represents the bowl of a spoon as it flattens while being hammered on. On the right, the handling classifier (flatO) depicts holding a curved earring that is flattened when someone jumps on it. 

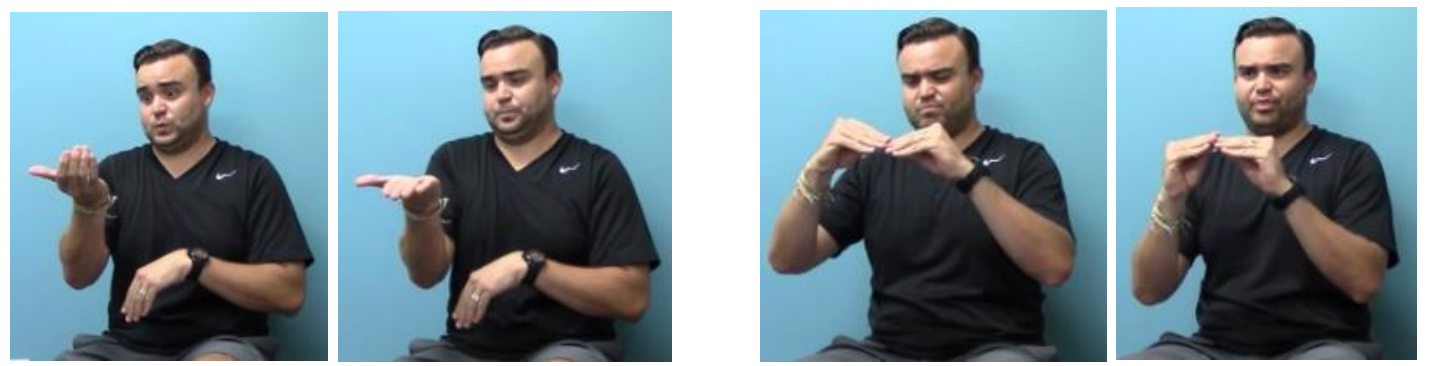

Figure 3: Initial and final states of the classifier predicates CL-B:spoon_flattens and CL-FlatO:earring_flattens

The final verb in serial verb constructions in spoken languages typically expresses a change of state rather than a result state. What is unusual about ASL and DGS in this respect is that the change-of-state predicate is typically followed by a result state predicate. ${ }^{40}$ In both (76a) from ASL and (76b) from DGS, the classifier predicate depicting the change of state in the spoon and earring, respectively, are followed by a lexical result state predicate FLAT. This is not the case for FAT, which indicates the consequences of an eating event by itself, as illustrated in (76c).

a. top [ASL]

PERSON HAMMER-spoon+ SPOON CL-B:curved_object_flattens FLAT

'A person hammers on a spoon (until) the spoon flattens, (it's) flat.'

\footnotetext{
${ }^{40}$ Like Danish Sign Language, both ASL and DGS use the lexical change-of-state verbs BECOME and VERÄNDER/UM to describe mystical changes of state (cp. Engberg-Pedersen 2010). Instead of using an inchoative form of a stative (e.g. BECOME.FAT), signers describe changes caused by spells or curses with the help of these lexical verbs:
} 
b.

EARRING BEGIN CL-BentB:convex_object, CL-FlatO:place_earring_on_ground. WOMAN CL-B:person_steps_on_object_on_ground, CL-FLATO:curved_object_flattens FLAT

'There's a convex earring, someone places it on the ground. A woman steps und the earring (and) it flattens, is flat.'

c. WOMAN ... A.LOT EAT GOBBLE BECOME.FAT

[DGS]

'The woman eats a lot, (she) gobbles up (food) (until) (she) becomes fat.'

Note that whenever a change-of-state predicate such as CLB:curved_object_flattens in (76a) occurs, it linearly follows the manner of causation predicate (in this case, HAMMER-spoon). Since sign languages use two independent articulators that may be employed simultaneously, one might expect that the simultaneous unfolding of causing event and change of state would most naturally be represented in a single classifier predicate featuring the manner of causation on one hand and the change of state on the other. In other words, it is physiologically possible to depict someone hammering on the bowl of a spoon while that bowl flattens out; or someone jumping on a curved earring and flattening it in the process; or a person eating while their guts expand. Classifier predicates in general allow the expression of complex events. Consider Figure 4, reported in Aronoff et al. (2003) as portraying a "recalcitrant dog that had to be dragged by its leash behind its master" (71). The predicate identifies both event participants and their respective activities including different paths of movement (straight versus zig zag). 


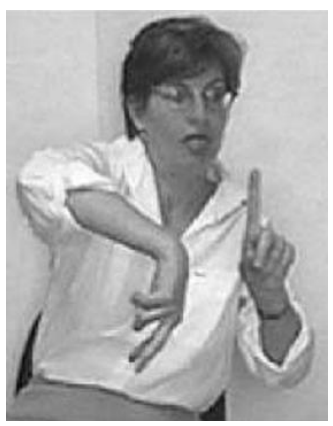

Figure 4: ASL classifier construction representing the independent movement of two entities. Reprinted from Aronoff et al. (2003: 71).

Yet the pilot data contain only one token of a classifier construction that represents the event homomorphy between causing event and change along a physical scale. Shown in (77), the signer described a hammering-flat event by placing his non-dominant hand in a curved 7 -shape in neutral space and producing the sign HAMMER towards the location of the non-dominant hand.

(77) RH: SPOON HAMMER-spoon+

LH: SPOON CL-curvedB:bowl_of_spoon_flattens '(She) hammered the spoon flat.'

Even in this single token of a manner-and-result denoting predicate, the signer did not decrease the curvature of his non-dominant hand gradually with each repetition of the hammering movement in truly homomorphic fashion. Rather, he stretched the hand flat in tandem with the last stroke of the hammer.

The absence of spontaneously produced classifier constructions denoting manner of causation and change of state raises the question whether we are dealing with a grammatical constraint on the amount of event structural information expressed in a 
single (classifier) predicate in ASL and DGS, or whether phonotactic constraints account for the absence of such predicates. Given the centrality of possible versus impossible verb meanings to the study of lexical semantics, it is worth dwelling on this point.

Lexical signs are subject to several phonotactic constraints including a strong trend towards monosyllabicity and the Symmetry and Dominance Conditions (Battison 1978) which determine possible handshapes, orientations, and movements of two-handed signs. Some researchers argue that classifier predicates are exempt from these constraints and frequently violate them (Aronoff et al. 2003, van Gijn et al. 2000). ${ }^{41}$ However, Eccarius \& Brentari (2007) claim that a feature-based Symmetry constraint applies across lexical and classifier forms in at least three sign languages (ASL, Swiss German SL, and Hong Kong SL) and requires that simultaneously articulated classifiers must have the same movement. The authors examine the classifier productions of 11 signers (two of them ASL signers) describing 40 drawings that typically elicit two-handed classifier predicates. Consistent with my data, they find that in all predicates in which the nondominant hand moves independently from the dominant hand and hand movement is not identical or symmetric, the classifier predicates are articulated sequentially rather than as one prosodic word. In the examples provided by Eccarius \& Brentari, sequentiality preserves the temporal order of (sub)events; for example when the signer first moves a nail towards a wall with the non-dominant hand before hammering on it with the dominant hand. Since these authors do not provide acceptability judgments for classifier predicates that their constraints rule out, their study may simply point to a bias against independent movement of the two hands in classifier predicates rather than to a strong

\footnotetext{
${ }^{41}$ It can be argued that the manner-denoting components of the complex predicates in question are frozen forms listed in the lexicon and therefore subject to the Symmetry and Dominance conditions, but they all developed from handling (HAMMER, EAT) or body part (JUMP) classifiers and are open to re-analysis as classifier predicates synchronically (Aronoff et al. 2013).
} 
prosodic constraint. Such bias is likely to be grounded at least partially in fine motor coordination and ease of production.

In addition to phonological constraints, Supalla (1990) points out physical limitations to simultaneity, such as producing a two-handed classifier morpheme at the same time as another one- or two-handed classifier morpheme. This would only be a concern for GOBBLE FAT in our data, since both signs are typically produced with two hands. However, to my knowledge, two-handedness is not distinctive in these signs (there is no one-handed competing morpheme in either ASL or DGS), thus nothing speaks against producing one-handed variants to depict an expanding gut while eating. 42

In order to show that grammatical constraints on expressing manner of causation and change of state in one complex predicate may be at play in addition to prosodic or articulatory constraints, a much more rigorous empirical study is necessary. After all, the absence of a phenomenon in a data set does not entail its ungrammaticality. ${ }^{43}$ While such a study is beyond the scope of this dissertation, there are both cross-linguistic and language-internal indications in favor of such a grammatical constraint. On the one hand, simultaneous forms were absent in Lau's (2012) study of serial verb constructions (SVC) in Hong Kong SL. Her resultative SVCs all involve sequential manner of causation and change-of-state predicates when, in some cases, a simultaneous construction might be

42 One further factor to consider is the nature of the video material from which the pilot data were elicited. For hammering and jumping something flat, the videos show someone acting directly on the causee and how it is affected. For GOBBLE FAT, participants saw an excerpt from a sitcom where someone rapidly eats an immense amount of pancakes and then the scene cuts to her looking morbidly obese. The process of gradually becoming fat is not shown on screen. While this may influence participants' productions, it is important to note that several participants did sign BECOME.FAT rather than FAT, thus going beyond what they saw on screen in describing the change of state. They simply did not depict it as co-extensive with the eating event.

43 In fact, Dudis (2004: 178) contains a potential counter-example. His overview of change-of-state expressions in ASL contains an example of a garbage compressor flattening a can, where the non-dominant hand represents the size and shape of the can, and it flattens to a 7 -hand as the garbage lever represented on the dominant hand presses down on it. The absence of such forms in our data may thus represent a strong trend rather than an absolute constraint. 
more parsimonious. Take her example (78), where an ice cream gradually melts as the sun shines on it: Since there is no reason to believe that the ice-cream classifier morpheme in 'melt ${ }_{\mathrm{a}}$ ' is obligatorily two-handed, there is no articulatory reason barring the simultaneous expression of sunshine and melting.

dom.h.: ICE CREAM. shine-on ${ }_{\mathrm{a}}+\mathrm{CL} \_$SASS:direct_light_from_sun

nond.h.:

$$
\text { CL_SASS:a_frozen_food }{ }_{\mathrm{a}}
$$

'Lit. That cloud covered the sky... There was an ice cream...The sunshine went through the cloud...(and) the sun shone on the ice cream...

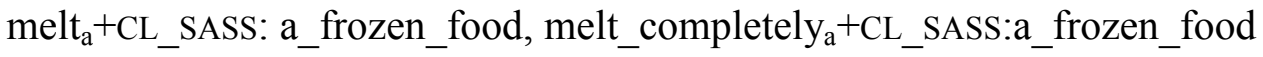
'... (and as a result) the ice cream melted, (and) (it) melted completely.'

[Lau 2012: 205]

Supalla (1990) provides compelling language-internal evidence for grammatical constraints on the amount of event structure a classifier predicate can express in ASL. His examination of complex motion predicates shows that a classifier predicate can express either manner or path (and direction) of movement, but not both. ${ }^{44}$ Instead, ASL signers choose a serial construction featuring a manner verb followed by a path predicate. Given these confirmed restrictions on the type of event components that can be expressed in a classifier predicate in ASL, it would not be surprising if a parallel set of restrictions barred manner and change of state from being expressed in one predicate. Similar restrictions have been proposed on expressing manner and result in English verbal roots

\footnotetext{
${ }^{44}$ Supalla mentions one exception involving the (V)-classifier morpheme representing human legs. This classifier may represent a manner of motion such as walking or falling as well as a path of motion.
} 
(Rappaport Hovav \& Levin 2010), although they seem to constitute a tendency rather than a strict constraint (Beavers \& Koontz-Garboden 2012). We thus need further research to determine whether the observed limitations on classifier predicates in ASL are based on articulatory constraints or are rooted in a modality-independent constraint that limits how much information about an event can be encoded in a single predicate.

To summarize this section, we have seen three strategies for expressing complex cause-result events that do not rely on resultative constructions: lexical causatives, temporal adverbials or adverbial clauses, and juxtaposition of causing and change of state clauses. We have further looked at the expressive potential afforded by visual iconicity in ASL and DGS. It has been shown that the visual-manual modality facilitates the encoding of the following aspects of a causative situation: direct manipulation of the causee by the causer, a shared spatio-temporal profile of causing and change of state events, and the iconic representation of change over time along some physical dimension. Nonetheless, phonotactic and/or grammatical constraints impose a limit on the iconic representation of event structure in signed languages. The simultaneous unfolding of a causing and a change of state event cannot be expressed in a single (classifier) predicate.

\subsection{RESULTATIVE CONSTRUCTIONS IN DGS AND ASL}

Turning to the main focus of this chapter, I argue in this section that both DGS and ASL can express complex cause-result events in a single clause. DGS has two resultative constructions that differ in the order of causing and result predicate. Section 5.3.1 introduces the [Result Verb] construction, while section 5.3.2 focuses on the [Verb Result] construction. ASL has one resultative construction, which is described and analyzed in section 5.3.3. 


\subsubsection{S-O-Result-Verb (DGS)}

While consultants did not produce S-O-Result-Verb resultatives during the video elicitation portion of the pilot, the construction was used by all three DGS consultants who participated in a follow-up translation task. Since this construction exhibits the same result-verb order as German resultatives, I first consider the possibility of influence from the German translation prompt onto the productions of my bilingual consultants. While I cannot exclude the possibility of this construction being influenced by language contact, the examples produced by the consultants and represented in (79) are by no means a manually coded form of German (LBG).

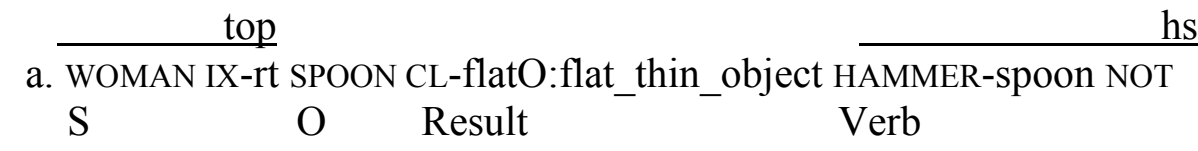

'The woman did not hammer the spoon flat.'

bl lf

b. OPPONENT PERSON-rt DEAD-rt SHOOT-rt WHO

O Result Verb S

'Who shot (their/the) opponent dead?'

'tischler' 'tischplatte' 'glatt' blow-out air

c. CARPENTER IX-If TABLE^SASS:rectangle SMOOTH SAND IX-lf

S O Result Verb

'The carpenter sanded the table top smooth, he (did).'

Where DGS and German differ in word order, this resultative construction patterns with DGS rather than German: The negator NOT is in final position (79a) rather than preceding the predicate complex and the $w h$-subject occurs sentence-finally (79b), which is ungrammatical in German. Furthermore, the utterances in (79) are characterized by 
lexical and grammatical properties of DGS that do not exist in German. Among them are the use of classifier predicates, subject pronoun copies (79c), and the indexing of verbal arguments via spatial agreement with their referential locus. To illustrate the latter point consider (79b), in which both DEAD and SHOOT in (79b) are signed on the right side of the neutral space in front of the signer, where the referential locus of OPPONENT has been established with the help of PERSON-rt. Typical DGS non-manual markers indicating topics or prosodic breaks (body lean to the left) strengthen the impression that the utterances in (79) are generated by a DGS grammar. Where mouthings from German are present, they tend not to accompany the verb, in line with the distribution of mouthing across sign languages; for an overview including Auslan, ÖGS, RSL and ISL, see Tkachman \& Sandler (2013). In short, if the [Result Verb] construction has been borrowed from German, it is nonetheless well-integrated into the grammar of DGS and as such invites further investigation. Consultants do not recognize it as a foreign construction; in fact, when asked whether they would also accept [Verb Result] word order in (79), two consultants claimed that that is what they had been producing all along and were not aware of a difference between the two word orders.

The stimuli in the grammaticality judgment task (described in chapter three) were designed to remind consultants that they were providing judgments of DGS rather than German sentences. In each S-O-Result-Verb construction, the predicate complex was embedded under a modal verb in final position. Modals occur in second position in German main clauses, while DGS is consistently verb-final. 


\subsubsection{Evidence for monoclausality}

This section presents a two-step argumentation in favor of the monoclausality of the S-O-Result-Verb construction. First, I show that the relevant target stimuli cannot be interpreted as two independent clauses and, second, that they do not embed a full subordinate clause.

Consider first the target resultative in (80): Aside from reading it as a monoclausal resultative (a), a biclausal interpretation such as (b) may be available. The symbol | indicates the potential clause boundary. In a topic-prominent null-subject language like DGS, it would not be uncommon for the subject of the second clause to remain unexpressed and for its object to be indexed solely via agreement on the verb.

(80) Context: Hans and Susi are playing with a hammer and wondering what to hammer on next. Hans suggests:

IX-addr ${ }_{i}$ SPOON IX-a FLAT-a $\mid\left(\right.$ pro $\left._{i}\right)$ HAMMER-a CAN

$\mathrm{S} \quad \mathrm{O} \quad$ Result Verb

a. 'You can hammer the spoon flat.'

b. 'You flatten the spoon. (You) can hammer on (it).'

Aside from a unified single IP prosody, the lexical semantics of the result predicate rules out such a biclausal analysis. If (80) contained two clauses, the only possible predicate in the first clause would be FLAT. As the unacceptable (81) shows, FLAT cannot occur in transitive clauses where it would license a causer (IX-addr) and a causee (SPOON IX-a). ${ }^{45}$ Since FLAT can thus not be interpreted as a lexical causative, it cannot head the potential first clause in (80). The same holds true of almost all the result predicates used in this

\footnotetext{
45 As motivated in chapter three, grammaticality judgments are provided on a 5-point Likert scale. Mean GJ ratings are provided to the left of an example where relevant.
} 
construction, with the exception of CL:break 'broken'. ${ }^{46}$ The S-O-Result-Verb constructions presented to participants are thus highly unlikely to have been interpreted as two independent clauses.

$\mathrm{y} / \mathrm{n}$

\subsection{IX-addr SPOON FLAT}

intended: 'Did you flatten the spoon?'47

To further establish the monoclausal nature of the S-O-Result-Verb construction I looked at the acceptability of center-embedding the result phrase. During the grammaticality judgment (GJ) task outlined in section 3.5.2, six DGS consultants evaluated 19 sentences in which the result predicate and its argument were centerembedded between the subject and the causing verb. The stimuli included 14 Control resultatives ([S O [PRO Result] Verb]) as exemplified in (82a), and five ECM constructions ([S [O Result] Verb]) as illustrated in (82b). Recall that GJs were obtained via a five-point Likert scale using emoticons rather than numbers.
a. 4.7 IX-addr SPOON IX-lf FLAT-lf HAMMER-lf CAN
'You can hammer the spoon flat.'
b. 4.8 IX-addr $\mathrm{COLD}^{\wedge} \mathrm{OPEN} \underline{\text { EMPTY EAT }}+$ MAY.NOT
'You may not eat the fridge empty.'

\footnotetext{
46 Some DGS signers reported that a lexical causative interpretation is available for some of the result predicates when the auxiliary PAM (personal agreement marker) is added. This auxiliary was however not present in any of the S-O-Result-Verb constructions that participants evaluated.

${ }^{47}$ Where appropriate, grammaticality judgment ratings precede a given example. The average GJ rating for this sentence was 2.3 .
} 
Center-embedding of the 19 result phrases was accepted by all participants $(M=4.09, S D=1.18)$. The 19 stimuli in this task include all possible combinations of cause and result predicates, but it is worth looking at the mean judgments for a more conservative set of stimuli. At the very least, the S-O-Result-Verb construction should encode Control resultatives that conform to homomorphism constraints. ${ }^{48}$ This prediction is borne out. Durative verbs with a maximal endpoint result predicate such as FLAT HAMMER in (82a) were rated above the overall mean at $M=4.63, S D=0.85(M=4.39$, $S D=1.04) .^{49}$ Punctual verbs with non-gradable result predicates were closer to the overall mean at $M=4.2, S D=0.75$ for PREGNANT CHARM (and $M=4.0, S D=0$ for ECM PREGNANT SNAP); only DEAD SHOOT is clearly more degraded at $M=3.0, S D=1.41$. Based on the assumption that full clausal complements cannot be center-embedded in DGS, we can thus conclude that the result phrase does not form a full clausal complement here and thus the S-O-Result-Verb construction patterns with single clauses with nominal or infinitival complements rather than multi-clausal structures.

\subsubsection{Control versus ECM and the homomorphy question}

Having established the monoclausal nature of the S-O-Result-Verb construction, we now turn to the question of whether this resultative allows both Control and ECM resultatives. Bear in mind that the study design was not balanced for Control versus ECM resultatives, because homomorphic constraints are predicted to hold only of Control resultatives. A second reason for eliciting more Control than ECM resultatives is that one

\footnotetext{
48 The conservative estimate assumes that result predicates may be specified for gradability, hence we include only punctual verbs with non-gradable results here rather than all combinations involving punctual verbs.

${ }^{49}$ Whenever relevant, results will be presented for two assumptions: Under one, AWAKE, WET, AND OPEN.DOOR are treated as maximal endpoint predicates, and under the second assumption, presented in parentheses, they are open-scale adjectives.
} 
of the goals of this dissertation is to determine whether DGS has resultatives, and we do not yet know whether it only allows Control or only ECM resultatives or both types. Control-style resultatives are predicted to be acceptable in languages that only have ECM resultatives. A resultative like She hammered the metal flat should be acceptable in an ECM-only language where hammer may detransitivize before resultative formation and the metal is licensed by the result predicate flat. On the other hand, ECM-style resultatives cannot be accommodated in languages with only Control resultatives, motivating the inclusion of more Control than ECM resultatives in this study. What we can say about ECM constructions is that their mean ratings do not differ significantly from those with non-selected causees $(M=4.16$ vs. $M=3.88)$, suggesting that the S-OResult-Verb construction allows both selected and non-selected causees.

Next, several hypotheses pertaining to homomorphic constraints operating on Control resultatives were tested. Based on Wechsler (2005) and Beavers (2002, 2008), it was hypothesized that durative verbs with open-scale or non-gradable result predicates should receive lower GJ ratings than durative verbs with maximal-endpoint gradable results. Open-scale result predicates cannot contribute the salient natural endpoint to the resultative that accounts for its telicity, while non-gradable predicates are incompatible in type (minimally complex objects in the sense of Beavers 2008) with durative events (complex objects). Punctual verbs should be compatible with any type of result predicate under the assumption that the latter are usually underspecified for gradability and can receive non-gradable readings. To test these hypotheses, a linear mixed effects model was fit to the data set using R (R Core Team 2016) and lme4 (Bates et al. 2012). Given the hypotheses, I included fixed effects for (non)-selected object, durativity of the main verb, and scale type of the result predicate in the model, as well as their interactions. The model also included a random intercept for participant. Tests of the two a priori 
hypotheses ${ }^{50}$ were conducted using Bonferroni adjusted alpha levels with a starting $\alpha=0.025(0.05 / 2)$. The means and standard deviations for each combination of causing verb and result predicate are provided in Table 8.

Table 8

Means and Standard Deviations for GJ Ratings of Center-Embedded Result Phrases in Control Resultatives. Numbers in parentheses were obtained by coding AWAKE, OPEN.DOOR, and WET as open-scale predicates. Numbers without parentheses represent treatment of these predicates as having a maximal endpoint.

\begin{tabular}{llll}
\hline \multirow{2}{*}{ Resultative type } & & \multicolumn{2}{c}{ GJ rating } \\
\cline { 3 - 4 } Durativity & + & \multicolumn{1}{c}{$M$} & \multicolumn{1}{c}{$S D$} \\
\hline \multirow{2}{*}{ Durative } & max $^{\mathrm{a}}$ & $4.63(4.39)$ & $0.85(1.04)$ \\
& open & $4.67(4.83)$ & $0.49(0.38)$ \\
& non & 3.75 & 0.89 \\
\multirow{2}{*}{ Punctual } & max & $4.67(4.83)$ & $0.49(0.41)$ \\
& open & $1.5(3)$ & $0.55(1.65)$ \\
& non & 3.58 & 1.24 \\
\hline
\end{tabular}

${ }^{\mathrm{a}} \max =$ maximal endpoint, non $=$ non-gradable

When coding AWAKE, OPEN.DOOR and WET as maximal endpoint predicates, I obtained the following results: Since, under this classification, two levels are missing from the data $($ ECM punctual verb + open-scale result and ECM punctual verb + nongradable), the significance of the three-way interaction could not be computed by the model. However, decomposing the three-way interaction shows that in Control

${ }^{50}$ The two hypotheses tested were that combinations of durative verb + maximal endpoint result receive higher GJ ratings than 1) durative verb + open-scale result and 2) durative verb + non-gradable result. 
resultatives, durative verbs receive significantly higher GJ ratings with a maximalendpoint predicate (e.g. (82a) than with a non-gradable predicate such as (83a) $(p=0.0034)$. Ratings for open-scale predicates such as $(83 \mathrm{~b})$ and maximal-endpoint ones, on the other hand, do not differ from each other $(p=0.89) .{ }^{51}$

\section{a. 3.7 ENEMY SUPERMAN DEAD BEAT+ MAY.NOT}

'The enemy may not beat Superman to death.'

b. 5.0 IX-addr POSS-1 HAIR WET SPRAY MAY

'You may spray my hair wet.'

GJ ratings for Control resultatives with a punctual verb are broken down in Table 9. A visual inspection of the means shows that the open-scale resultative UGLY CHARM receives lower ratings than both its maximal-endpoint and non-gradable counterparts.

\footnotetext{
${ }^{51}$ Interestingly, if we generalize over Control and ECM resultatives (as warranted by their similar GJ ratings) and test whether homomorphy constraints apply to all S-O-Result-Verb constructions in DGS rather than only those with selected objects, the model shows a significant two-way interaction between durativity and scale type: Durative verbs are significantly better with maximal endpoint results than with open-scale ones $(p=0.012)$. We do not find this effect when looking only at Control resultatives because it is the ECM item with a durative verb and an open-scale result (WARM SIT) that lowers the overall least square mean of the durative verb + open scale result combination from $M=4.63$ to $M=3.58$. This may very well be an item effect, but alternatively it suggests that the result predicate needs to introduce a salient endpoint to the event for at least ECM constructions in DGS. More data is clearly necessary to investigate homomorphic constraints on ECM resultatives further.
} 
Table 9

GJ ratings for Control Resultatives with Punctual Verbs in Center-Embedded Position. Resultatives are listed by the Scale Type of their Result Predicates.

GJ rating

\begin{tabular}{lll} 
Scale type & Resultative & $M$ \\
\hline Maximal endpoint & DRY CHARM & 4.8 \\
\hline Open & OPEN-DOOR KICK & 4.5 \\
& UGLY CHARM & 1.5 \\
\hline Non-gradable & PREGNANT CHARM & 4.2 \\
& DEAD SHOOT & 3.0 \\
\hline
\end{tabular}

As explained in the previous section, the lower rating for the latter is based on low ratings for DEAD SHOOT, for which I currently do not have a good explanation. Given that the punctual verb + open-scale category contains only one item under the current classification, it would be premature to conclude that, while result predicates seem to be underspecified for gradability, they still need to introduce a salient endpoint to the complex event. We are, however, in the unique position that all scale types in this condition were tested with the same punctual predicate CHARM. All else being equal, it is striking that while maximal-endpoint DRY CHARM (84a) and non-gradable PREGNANT CHARM (84b) received high GJ ratings, open-scale UGLY CHARM (84c) was considered degraded by all six participants. All three items were presented in similar invented (but plausible) contexts involving Harry Potter and fellow wizards, and their German translation equivalents all have a similarly low textual frequency. ${ }^{52}$ At the very least, we

\footnotetext{
52 We find zero occurrences of each item in the DeReKo (Deutsches Refrenzkorpus), one of the largest German reference corpora of written texts online; and between six and 20 hits for each item on Google.
} 
have shown a trend for punctual verbs to require a salient endpoint in the S-O-ResultVerb construction, whether it is introduced by a maximal-endpoint predicate or by a nongradable one.

\section{a. 4.8 HARRY TSHIRT DRY CHARM CAN}

'Harry can put a spell on the T-shirt to dry it.'

\section{b. 4.2 HARRY POSS-lf FRIEND \#RON PREGNANT CHARM CAN.NOT}

'Harry can't put a spell on his friend Ron to make him pregnant.'

\section{c. 1.5 IX-rt HARRY UGLY CHARM CAN}

'She can put a spell on Harry to make him ugly.'

In summary, coding AWAKE, OPEN.DOOR and WET as maximal endpoint predicates we find evidence for a homomorphic requirement on Control resultatives given that DGS signers find combinations of verbs denoting durative events with non-gradable results degraded. We find no clear requirement for gradable results to introduce an endpoint with durative verbs, but there may be such a requirement on punctual verbs.

If we assume that, contrary to the intuitions of the three DGS signers consulted on scale structure, WET, AWAKE, and OPEN-door have (de facto) open scales, a linear mixed model detects no homomorphy effects. Verbs denoting durative events are not rated significantly differently when they occur with maximal-endpoint results versus with nongradable results in Control resultatives $(p=0.4538)$. Turning to punctual verbs in Control resultatives, this model confirms a trend for open-scale results to be degraded when compared to maximal endpoint results $(p=0.119)$, but not non-gradable results $(p=0.5164)$. 
Since the first linear model presented in this section rests on a more solid empirical footing, I take its findings to reflect constraints on the S-O-Result-Verb construction in DGS. Grammaticality judgments show that this resultative allows both selected and non-selected objects and, at least with respect to selected objects, illustrates some constraints indicative of a homomorphic mapping between the causing event and the scale associated with the result predicate. Specifically, complex objects such as durative events should not be mapped onto a minimally complex, non-gradable scale, and punctual verbs preferably combine with a result predicate that contributes a salient endpoint to the complex event.

\subsubsection{Syntax of the S-O-Result-Verb construction}

While the monoclausality of the [Result Verb] construction has been established, the question remains how causing and result predicate compose. If the causing predicate takes an infinitival small clause complement, we expect the result phrase to form a constituent with its PRO subject to the exclusion of the causing predicate. Alternatively, causing and result predicate could form a complex predicate on the lexical level first and then jointly take the causee as their direct object. The two analyses make different predictions about the behavior of DGS resultatives with respect to diagnostics like fronting. Müller (2002) argues that German resultatives form complex predicates and shows that predicate fronting is subject to systematic constraints: The predicate complex may be fronted in its entirety (85a) or partially (85b), but only the result predicate can be fronted by itself (85b). Fronting the causing predicate alone is not acceptable (85c). 
a. Klein schneiden müssen Sie das Fleisch.

small cut must you-NOM the meat-ACC

'You have to cut the meat in small pieces.'

b. Klein müssen Sie das Fleisch schneiden

small must you-NOM the meat-ACC cut

c. ?? Schneiden müssen Sie das Fleisch klein.

cut must you-NOM the meat-ACC small

[Müller 2002: 238-239]

Müller attributes the unacceptability of a fronted causing predicate to the fact that it forms a complex with the result predicate and the head of a predicate complex cannot be fronted without the material embedded under it. He shows this to be the case for other predicate complexes in German, for example modal and lexical verbs. In (86a), erzählen müssen can be fronted as a complex, but the head müssen cannot be fronted by itself (86b).

a. Erzählen müssen wird er ihr ein Märchen.

tell must will he her a fairytale

'He will have to tell her a fairytale.'

b. *Müssen wird er ihr ein Märchen erzählen. must will he her a fairytale tell

[Müller 2002: 44]

In order to test whether DGS exhibits the same constraints on fronting as German, two DGS consultants provided GJ ratings on permutations of three resultatives and a sentence containing a modal. Due to logistic constraints, the ratings were obtained using 
DGS glosses rather than naturally produced sentences. ${ }^{53}$ The examples in (87) illustrate that modal verbs do not form a predicate complex with the head of their complement, since fronting the modal and lexical verb together is unacceptable (87a). Note that this unacceptability is not due to fronting of the lexical verb without its dependent, which is acceptable in DGS (87b). In resultatives, on the other hand, causing and result predicates can be fronted together (87c-e), 54 suggesting that they form a syntactic unit. top

a. 2.0 READ CAN, IX-addr BOOK WANT

'You want to be able to read the book (context: but you don't want to learn to read it.' top top

b. 4.5 READ IX-addr BOOK CAN, BUT CARRY, CAN.NOT

'You can read the book, but you can't carry it. top

c. 4.00 FLAT HAMMER, IX-addr SPOON CAN.NOT

'You can't hammer the spoon flat.'

top

d. 4.00 YES, WET SPRAY IX-addr POSS-1 HAIR MAY

'Yes, you may spray my hair wet.'

\footnotetext{
53 The DGS consultants who provided the ratings are familiar with sign language glosses given their previous consultant work and/or training in Deaf education. Nonetheless, not all prosodic components of the utterance could be controlled for (non-manual topic marking for fronted elements was indicated with lines above the gloss), allowing for the possibility that consultants interpreted the glosses somewhat differently. Other factors influencing grammaticality judgments were controlled as much as possible. Each target sentence was embedded in a context licensing contrastive focus on the fronted element(s), and consultants were reminded of the underlying form for each resultative to ensure permutations were based on the [Result Verb] construction rather than the [Verb Result] construction described in the next section. ${ }^{54} \mathrm{P} 6$ rates $(87 \mathrm{e})$ as $4, \mathrm{P} 7$ does not accept it (GJ rating 2).
} 
e. 3 EMPTY EAT IX-addr FRIDGE MAY.NOT

'You may not eat the fridge empty.'

Two further observations suggest that a complex predicate analysis characterizes the [Result Verb] construction better than a small clause analysis. First, in contrast to resultatives, DGS sentences that parallel small clause constructions in German and English are degraded when both predicates are fronted (88). Second, one of my two consultants judges fronting of the causing predicate alone somewhat degraded (3 for FLAT HAMMER and EAT EMPTY, 4 for WET SPRAY) while overall accepting a fronted result predicate (4 for EMPTY EAT and WET SPRAY, 2 for FLAT HAMMER). Keeping in mind interspeaker variation in GJ ratings, ${ }^{55}$ these observations provide tentative support for a complex predicate analysis of [Result Verb] resultatives in DGS.

\section{DANCE SEE, SUSI EMIL FINISH}

'Susi has seen Emil dance (context: but she hasn't heard him come home.)'

In summary, we have seen syntactic evidence from center-embedding and fronting which confirms that the S-O-Result-Verb construction is indeed a monoclausal resultative and that result predicate and causing verb are best analyzed as a complex predicate. The construction allows causees selected by the verb as well as those selected only by the result predicate (Control and ECM structures). We further saw evidence for a homomorphic event-to-scale mapping, since durative verbs cannot occur with non-

\footnotetext{
55 The second participant overall accepted fronting of the causing predicate ( 4 for FLAT HAMMER and EMPTY EAT, 3 for WET SPRAY) but found topicalization of the result predicate somewhat degraded (3 for FLAT HAMMER and EMPTY EAT, 4 for WET SPRAY).
} 
gradable result predicates in this construction. There also seems to be a preference for result predicates to contribute a salient endpoint to a punctual event, but this trend does not extend to durative causing verbs.

\subsubsection{S-O-Verb-Result (DGS)}

During both the video elicitation and translation tasks, DGS consultants frequently expressed cause-result events in a temporally iconic fashion. The manner of causation verb in these utterances would precede the change of state or result state predicate, thus mirroring the order of subevents. There is no parallel construction in German, making this a good candidate for a non-contact-induced resultative in DGS. However, the number of clauses in these complex event descriptions is sometimes difficult to determine: Productions describing the same event vary from clearly biclausal (89a) to potentially monoclausal constructions (89b). In (89a), for example, the causer IX-lf 'she' is not in the preverbal object slot but rather follows the verb, suggesting that IX-lf WAKE-UP forms a separate clause. No overt object pronoun intervenes between the predicates in (89b), hence we cannot know whether the utterance is monoclausal or contains an independent or embedded second clause.

a. IX-screen SOFA WOMAN LIE-lf SLEEP. FRIEND CL-1:approach_lf SHAKE-lf+

$\mathrm{S}$ Verb IX-lf WAKE-UP

$\mathrm{O} \quad$ Result

'A woman is lying on a sofa. (Her) friend walks up to her, shakes her (and) she wakes up.' 
b. WOMAN CL-1:person_lying_rt SLEEP THROUGH+. OTHER WOMAN SHAKE-rt

\section{$\mathrm{S}$}

Verb

WAKE-UP

Result

'A woman is lying down fast asleep. Another woman shakes (her) (and) (she) wakes up.'

In the next section, I show that the [Verb Result] construction with overt subject and object DPs do pattern with monoclausal constructions.

\subsubsection{Evidence for monoclausality}

The sentences in (90) illustrate problems one encounters when examining the monoclausality of utterances following S-O-Verb-Result word order. Leaving aside prosodic cues for now, each example in (90) can be parsed in at least two ways. The monoclausal interpretation is provided in (i), while (ii) shows a multiclausal parsing. Crucially, in both (90a) (ii) and (90b) (ii), the result and change-of-state predicates form a clause with a pro subject.

a. WOMAN PLATE THERE LICK CA:hold_plate_lick_over_it CLEAN
$\mathrm{S} \quad \mathrm{O}$
Verb
Result

i. 'The woman licked the plate there clean.'

ii. 'The woman licked the plate. (It is) clean.'

b. \#JENNY IX-rt POSS-rt CAT IX-lf SNEEZE AWAKE-lf

$\mathrm{S} \quad \mathrm{O} \quad$ Verb Result

i. 'Jenny sneezed her cat awake.'

ii. 'Jenny was over here. Her cat was over there. (She) sneezed. (It) woke up.' 
To determine whether the secondary predicate in these utterances projects an independent clause, we can apply the rightward wh-movement diagnostic. Recall that rightward movement in DGS cannot cross a full complement or independent clause; thus if the result predicate in the S-O-Verb-Result construction projects an independent $\mathrm{CP}$, rightward wh-movement across it should not be possible.

To test this hypothesis, grammaticality judgment ratings for eight (six $)^{56}$ S-OVerb-Result constructions with a final $w h$-subject were obtained from six native signers of DGS (see section 3.2 for details) and compared to their ratings for simple, control, subordinate, and coordinate clauses with final $w h$-words (as described in section 4.5.3.2). As exemplified in (91), the eight constructions selected for this comparison all have selected objects and conform to homomorphy requirements (durative verb + maximal endpoint result or punctual verb + non-gradable result). They were chosen under the conservative assumption that if [S O Verb Result] is a resultative construction, it should at least allow these combinations of primary and secondary predicate.

(91) Context: Susi walks into the kitchen and sees that a plate which up until a moment ago was covered in tomato sauce is now empty. Susi looks around the kitchen and sees Hans and Micha standing there with their mouths smudged in red. Susi asks:

\begin{tabular}{l} 
wh \\
\hline PLATE LICK CLEAN WHO \\
O Verb Result S
\end{tabular}

The mean ratings for each sentence type are presented in Table 10. Inspection of the raw means suggests that resultatives pattern with simple and control clauses in permitting rightward wh-movement. To investigate the difference in GJ ratings further, a

\footnotetext{
${ }^{56}$ As in previous experiments, I report in parentheses the findings based on treating WET, OPEN.DOOR, and AWAKE as open-scale predicates. This excludes SPRAY WET and SHAKE AWAKE from the analysis here.
} 
linear mixed model with sentence type as fixed effect and participant and item as random effects was fit to the data. Tests of the two a priori hypotheses ${ }^{57}$ were conducted using Bonferroni adjusted alpha levels with a starting $\alpha=0.025(0.05 / 2)$. Results confirm that rightward wh-movement is significantly more acceptable in S-O-Verb-Result constructions than across full subordinate clauses $(p=0.013)$. Movement across the result phrase is also marginally more acceptable than across a coordinate clause, although this trend does not reach significance $(p=0.158)$. Given that we only have six observations for coordinate clauses but 48 for resultatives, failure to obtain significance here may well be due to a lack of power. Lastly and as expected, GJ ratings for resultatives did not differ significantly from those for simple $(p=0.828)$ or control clauses $(p=0.639)$ at conservative alpha levels. Running the model with only six resultatives (leaving out the potentially open scale results SPRAY WET and SHAKE AWAKE) produces similar results. Resultatives are still significantly better with final $w h$-words than sentences containing subordinate clauses $(p=0.003)$, and they are significantly better than coordinate clauses $(p=0.049)$ while not differing from simple $(p=0.453)$ or control clauses $(p=0.297)$.

\footnotetext{
57 The two hypotheses tested were that resultatives receive higher GJ ratings than subordinate clauses and coordinate clauses.
} 
Table 10

Means and Standard Deviations for GJ Ratings of Final Wh-Words Across Different Sentence Types (DGS).

\begin{tabular}{|c|c|c|}
\hline \multirow[b]{2}{*}{ Sentence type } & \multicolumn{2}{|c|}{ GJ rating } \\
\hline & $M$ & $S D$ \\
\hline Simple & 4.00 & 1.48 \\
\hline Object Control & 3.83 & 1.03 \\
\hline Subordinate & 2.18 & 1.47 \\
\hline Coordinate & 2.83 & 1.17 \\
\hline Resultative $^{\mathrm{a}}$ & $4.14(4.4)$ & $1.16(0.97)$ \\
\hline
\end{tabular}

${ }^{\mathrm{a}}$ Includes only combinations of durative verb + maximal endpoint result and punctual verb + non-gradable result. The numbers in parentheses were obtained by coding AWAKE, OPEN.DOOR, and WET as open-scale predicates. Numbers without parentheses represent treatment of these predicates as having a maximal endpoint.

In summary, the acceptability of rightward wh-movement across the result phrase confirms that the result predicate does not project a full independent or complement clause and that the S-O-Verb-Result construction thus patterns with resultatives crosslinguistically in constituting an essentially monoclausal construction. The next section focuses on the semantics of this construction and determines which combinations of manner of causation and result predicate it licenses.

\subsubsection{Control versus ECM and the homomorphy question}

While we now know that the S-O-Verb-Result construction behaves like a resultative in expressing caused changes of state in an affected participant through a 
single clause, we still would like to know how versatile this resultative is and whether there are homomorphy-induced restrictions on which primary and secondary predicates can be combined. Before delving into that question, let us first say a few words about non-selected objects in the S-O-Verb-Result construction.

When we inspect the mean GJ ratings ${ }^{58}$ it first seems that resultatives with nonselected objects as in (92) are somewhat less acceptable $(M=3.73, S D=1.54)$ than those with selected objects $(M=4.25, S D=1.07)$, but this difference is not confirmed as significant or even as representing a trend $(p=0.51)$. For reasons outlined in section 5.3.1.2, fewer ECM constructions (5) were included in this study than Control resultatives (14), reducing the power to test significant differences in their acceptability. Nonetheless, the fact that ECM resultatives do not even exhibit a tendency to differ from Control resultatives in acceptability ratings suggests that the S-O-Verb-Result construction allows both Control and ECM resultatives.

a. 4.8 POSS-1 EARRING JUMP FLAT WHO

'Who jumped my earring flat?'

wh

\section{b. 3.5 BENCH SIT-bench WARM WHO}

'Who sat the bench warm?'

We next ask whether [Verb Result] resultatives are subject to similar homomorphy constraints as the ones discussed for the [Result Verb] construction in

\footnotetext{
58 To obtain the grammaticality judgments reported here, the target resultatives were embedded in the frame [Object Verb Result WHO], featuring a final $w h$-subject to ensure that consultants would parse the utterance as monoclausal.
} 
section 5.3.1.2. If each part of the causing subevent has to correspond to some degree on the scale associated with the result predicate in Control resultatives, then durative verbs with open-scale or non-gradable result predicates should receive lower GJ ratings compared to durative verbs with maximal-endpoint results. Punctual verbs are either compatible with any type of result predicate (under the assumption that these predicates are underspecified for gradability), or only with non-gradable ones.

To test these hypotheses, I fit a linear mixed effects model to the data set treating object selection, durativity of the main verb, and scale type of the result predicate as fixed effects, as well as their two- and three-way interactions. The model also included a random intercept for item and participant. The raw means and standard errors are reported in Table 11. A visual inspection of the data shows that, with the exception of punctual verb + open-scale result, all combinations of primary and secondary predicate are essentially acceptable. The results from fitting a linear mixed model over the data ${ }^{59}$ expand this finding in that no interaction or main effects were found to be significant. Importantly, there is no significant interaction between the durativity of the causing verb and the scale type associated with the result predicate $(p=0.248)$. Durative verbs receive similar GJ ratings in the S-O-Verb-Result construction whether they combine with maximal-endpoint, open scale, or non-gradable results. The same is true for punctual verbs.

The [Verb Result] construction thus does not seem to be subject to any homomorphy constraints. That it differs in this respect from the [Result Verb] construction is most clearly illustrated by looking at the difference in GJ ratings for BEAT

\footnotetext{
59 While the results presented here were obtained by classifying AWAKE, OPEN.DOOR, and WET as having a maximal-endpoint scale structure, I fitted the same model over a dataset that treats them as open-scale predicates. The results from this second model are identical in not producing any significant interaction or main effects.
} 
DEAD $(M=4.00)$ versus DEAD BEAT $(M=3.67)$ and CHARM UGLY $(M=3.33)$ versus UGLY CHARM $(M=1.5)$. While the homomorphy-defying combination of non-gradable result DEAD and durative verb BEAT is degraded in the [Result Verb] construction, it is more acceptable in the [Verb Result] construction. In contrast, putting a spell on someone to make them ugly seems fairly unacceptable no matter how you express it - but open-scale UGLY is still much less acceptable in the [Result Verb] construction than in its [Verb Result] counterpart.

In conclusion, while both constructions receive comparable overall GJ ratings ( $M=4.09$ for [Result Verb] and $M=4.12$ for [Verb Result]), [Verb Result] resultatives exhibit no obligatory homomorphic mapping from causing event to result scale.

Table 11

Means and Standard Deviations for GJ Ratings of Control SO Verb Result Constructions with a Final Wh-Subject. Numbers in parentheses were obtained by coding AWAKE, OPEN.DOOR, and WET as open-scale predicates. Numbers without parentheses represent treatment of these predicates as having a maximal endpoint.

\begin{tabular}{llll}
\hline \multirow{2}{*}{ Resultative type } & & \multicolumn{2}{c}{ GJ rating } \\
\cline { 3 - 4 } Durativity + & Scale & $M$ & $S D$ \\
\hline & $\max ^{\mathrm{a}}$ & $4.23(4.72)$ & $1.14(0.57)$ \\
Durative & open & $5(4.25)$ & $0(1.22)$ \\
& non & 4.13 & 0.99 \\
\hline Punctual & max & $4.42(4.33)$ & $0.79(0.82)$ \\
& open & $3.33(3.92)$ & $1.37(1.24)$ \\
& non & 3.92 & 1.24 \\
\hline
\end{tabular}

${ }^{\mathrm{a}} \max =$ maximal endpoint, non $=$ non-gradable 


\subsubsection{The syntax of the S-O-Verb-Result construction}

I propose that monoclausal [Verb Result] constructions in DGS are best analyzed as complex predicates that jointly take the causee as their object. I will present two arguments against the alternative hypothesis that sentences like (93a) and (93b) contain an extraposed infinitival clause. These arguments pertain to the surface position of nonselected objects and to the unacceptability of intervening material between the causing verb and the result predicate.

a. SUSI PLATE LICK-plate CLEAN-plate

S O Verb Result

'Susi licked the plate clean.'

b. MICHA COLD^OPEN EAT EMPTY

$\mathrm{S} \quad \mathrm{O} \quad$ Verb Result

'Micha ate the fridge empty.'

Consider first the placement of the causee $\operatorname{COLD}^{\wedge} \mathrm{OPEN}$ 'fridge' in the matrix object position of (93b). It is not an argument of the primary predicate EAT, since Micha did not eat the fridge but rather its unnamed contents. Instead, COLD ${ }^{\wedge}$ OPEN is the sole argument of EMPTY and thus should surface immediately to the left of this result predicate. We might speculate that [Verb Result] structures are underlyingly [Result Verb] and (93b) starts out as [MICHA [sc $\mathrm{COLD}^{\wedge} \mathrm{OPEN}$ EMPTY] EAT]. In that case, to obtain the right surface word order, the subject of EMPTY has to raise to the matrix object position, and the remaining small clause is optionally extraposed. However, we have no evidence of a case system in DGS that could motivate subject-to-object raising, and there 
is compelling evidence that subjects do not raise out of embedded clauses in this language. As the ungrammaticality of (94a) and (94b) illustrates, the subjects of complements of typical raising verbs such as WANT and EXPECT cannot raise into the matrix object position. In other words, IX-addr (94a) and HANS (94b) have to follow their matrix verbs. Since $\mathrm{COLD}^{\wedge} \mathrm{OPEN}$ 'fridge' in (93b) precedes the matrix verb EAT, it cannot have raised into this position but must be base-generated there. Following Neeleman \& van de Koot (2002), I propose that its licensor is the complex predicate [vo EAT EMPTY], which shares the cumulative selectional restrictions of its component predicates.

\section{a. 1.8 IX-1 IX-addr EXPECT GOOD} intended: 'I expect you to be good.'

\section{b. 1 IX-1 HANS WANT WORM EAT} intended: 'I want Hans to eat a worm.'

The question remains whether [Verb Result] constructions in which the causee $i s$ selected by the verb form a complex predicate or not. A resultative like (93a) could very

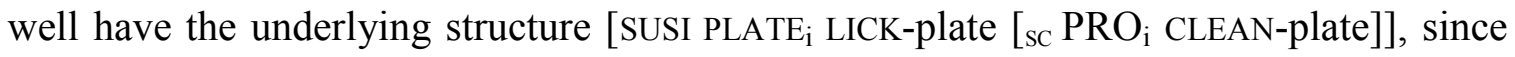
the selected causee PLATE is base-generated in the matrix object position. The distribution of modal verbs provides evidence against such an analysis and instead suggests that all [Verb Result] constructions contain a complex predicate. The small clause and complex predicate analyses make different predictions about the acceptability of material intervening between causing verb and result predicate. Nothing should be able to break up a complex lexical head like [vo Verb Result], but if the two predicates head separate phrases, higher verbal projections should be able to follow the matrix verb in a verb-final language like DGS. 
In order to test this hypothesis, I elicited grammaticality judgments from six DGS consultants on the same 19 S-O-Verb-Result constructions whose monoclausal resultative status was established in section 5.3.2.1. Each construction was presented with a modal verb intervening between cause and result predicates, as illustrated in (95). The contexts provided for each resultative make it clear that the modal scopes over the complex event as a whole.

(95) a. Context: Susi is watching her mother clean the house. She is impressed with all the things her mother can do and asks:

$\mathrm{y} / \mathrm{n}$

IX-addr SHOE POLISH CAN SHINY

$\mathrm{S} \quad \mathrm{O}$ Verb Result

'Can you polish the shoes shiny?'

b. Context: Susi has just finished a plate of spaghetti with delicious tomato sauce. She asks her mother:

$\mathrm{y} / \mathrm{n}$

IX-1 PLATE LICK MAY CLEAN

S O Verb Result

'May I lick the plate clean?'

On average, S-O-Verb-Result constructions with intervening modal verbs received lower GJ ratings $(M=3.19, S D=1.35)$ than their modal-less counterparts $(M=4.12$, $S D=1.22) .{ }^{60}$ A linear mixed model treating intervening modal as fixed effect and participant and item as random effects confirms the significance of this difference at $p<0.001$. When adding a fixed effect for selected object and an interaction term for the two fixed effects to the model, no significant interaction between the Control versus

\footnotetext{
60 To estimate the effect of an intervening modal, GJ ratings for constructions with the modal verb were compared to ratings for the monoclausal [Verb Result] construction with a final $w h$-subject.
} 
ECM status of a resultative and the acceptability of an intervening modal was detected. Since [Verb Result] resultatives with an intervening modal are equally degraded whether their causee is selected by the matrix verb $(M=3.26)$ or not $(M=2.96)$, a small clause analysis for cases like (93a) is not tenable.

In summary, the occurrence of non-selected causees in the matrix object position of S-O-Verb-Result constructions and the fact that modal verbs intervening between the two predicates are degraded support a complex predicate analysis. The complex predicate derives its argument structure from both of its components; the causee is contributed by the single argument of the result predicate, and the causer by the agent argument of the manner of causation verb.

One might wonder why in an overall verb-final language the causing verb precedes the result predicate in the predicate complex. Williams's (2008) typological generalizations about word order in resultatives cannot help solve this puzzle. As discussed in section 2.3.1, Williams predicts that SOV languages like DGS exhibit S-OVerb-Result word order just in case the result predicate does not project a phrase but forms part of a complex predicate. However, we find both [Result Verb] and [Verb Result] order in complex predicates in DGS. Turning to compounding as another instance of complex word formation in DGS, we find both verb-initial and verb-final compounds in the language: $\mathrm{KNOW}^{\wedge} \mathrm{EVERYONE}$ 'famous', THINK${ }^{\wedge}$ ALIKE 'agree', and DRY^SPIN 'dryer' (Becker 2000; Happ \& Vorköper 2006). Future research should investigate which factors determine the order of cause and result predicates in the predicate complex. It has been argued that in Japanese, another OV language that has verbal cause-result compounds, the second predicate heads the compound, aligning the structure with the overall headedness of the language. The compounds either map the argument structure of both their members onto causer and causee (e.g. tataki-kowasu 'hit-destroy, destroy by 143 
hitting', naguri-korosu 'strike-kill, kill by striking) or they inherit the argument structure of their second, intransitive member (obore-shinu 'be.drowned-die, be drowned to death, nomi-tsubureru 'drink-collapse, pass out from drinking) (Matsumoto 1996). Given the mixed argument structure of our DGS complex predicates, headedness cannot be determined on the basis of argument structure alone. Future studies should examine whether there are morpho-syntactic or semantic indications for treating the result predicate as the head in [Verb Result] constructions, especially when contrasted with the [Result Verb] construction discussed in 5.3.1.

Alternatively, predicate order at the $\mathrm{V}_{0}$ level could be influenced by temporal iconicity. Free from syntactic constraints for complement-head order operating on the phrasal level, the complex predicates can represent the sequence of events in cause-result scenarios iconically. Similar principles of temporal sequence have been proposed to govern the syntactic organization of serial verbs and verbal compounds in Mandarin (Tai 1985).

In summary, I have shown evidence that the S-O-Verb-Result construction patterns with single clauses with respect to rightward wh-movement. This monoclausal resultative is best analyzed as containing a complex cause-result predicate that licenses causees selected by both the causing verb and result predicate, or only by the result predicate (Control and ECM structures). We have seen no evidence for a homomorphic event-to-scale mapping in this construction.

\subsubsection{Bare XP resultatives}

A question that has received much attention in the literature on unaccusativity is whether resultatives can directly predicate of an underlying subject. Levin and 
Rappaport-Hovav's (1995) Direct Object Restriction captures a strong tendency for result predicates to apply to the direct object of a transitive verb or the underlying object of an unaccusative verb. The latter is illustrated for English in (96a) and German in (96b). When a result adjective predicates of the subject of a transitive verb (whose object has been suppressed), or of the subject of an unergative, a reflexive pronoun is typically inserted in direct object position (see (96d)). While this reflexive is obligatory in adjectival resultatives in German (Oya 2002), it does not always occur in English. Sentence (96c) shows that $d r y$ can be predicated of the agent subject of towel without a mediating fake reflexive. Both Wechsler (2005) and Rappaport Hovav and Levin (2001) base the distribution of the fake reflexive versus the bare result XP forms on the presence of event-to-scale homomorphy: As long as a resultative expresses that the change of state in the affected subject is co-extensive with the activity denoted by the verb and its result predicate provides a salient endpoint to the event, the bare XP pattern surfaces. Otherwise, an ECM resultative with a fake reflexive object has to be used.

(96) a. But Kambalny [volcano] surprised scientists when it shook awake on March 24 and began to erupt. ${ }^{61}$

b. beide Hälften so in den Ofen tun und warten, bis der Käse weich both halves this.way in the oven do and wait until the cheese soft geschmolzen ist. ${ }^{62}$ melt.PART AUX '[...] put both halves in the oven and wait until the cheese has melted soft.'

${ }^{61} \mathrm{http}: / /$ www.livescience.com/58442-kambalny-volcano-erupts-nasa-image.html, Accessed 4/11/17.

62 https://quit.im/notice/124062, Accessed 4/12/17. 
c. Uneventfully she climbed onto the dock and stripped off the wet swimsuit, then toweled dry and dressed $[\ldots] .^{63}$

d. Sie tanzte $*($ sich $)$ von ihren Verfolgern frei. she dance.PAST REFL of her pursuers free 'She danced free of her pursuers.' [Oya 2002:965]

To see whether DGS allows subject-oriented resultatives without the mediation of a reflexive pronoun, consultants were presented with resultatives headed by unergative (RUN, JUMP) and transitive verbs (EAT) whose result complements predicated of the agentive subject.

For the S-O-Result-Verb construction, six signers provided GJ ratings based on the five-point Likert scale introduced in chapter three. Their judgments are reported in (97). Judgments for the S-O-Verb-Result construction were collected from three DGS signers on a binary acceptability scale and are reported in (98). All signers agreed that 'RUN/CL-bentV:run_back_and_forth DEAD' and 'RUN++ BODY DRY' are unacceptable, ${ }^{64}$ while only one signer rejects EAT BECOME.FAT.

[Result Verb]

a. 3.0 SUSI IX-lf DRY RUNCAN

S Result Verb

'Susi can run (herself) dry.'

b. 2.3 SUSI FAMOUS JUMP-far CAN

$S$ Result Verb

'Susi can jump (herself) famous.'

\footnotetext{
63 https://findwords.info/term/toweled, Accessed 4/11/17.

${ }^{64}$ Specifically, the modal verb in these sentences cannot scope over the complex predicate but only over the result state, suggesting that no monoclausal interpretation is available for these sentences.
} 


\section{c. 3.67 IX-addr BECOME.FAT EAT MAY-NOT}

S Result Verb

'You're not allowed to eat (yourself) fat.'

(98) [Verb Result]

a. *FIELD, RABBIT CL-bentV:run_back_and_forth DEAD MUST

$$
\text { S Verb Result }
$$

'On a field, the rabbit had to run (himself) to death.'

b. * MAN RUN++ BODY DRY MUST

\section{S Verb O Result}

'The man must run himself dry.'

c. ? SABRINA EAT BECOME.FAT CAN/MUST

S Verb Result

'Sabrina can/has to eat (herself) fat.'

With the possible exception of eating oneself fat, it seems that DGS does not allow subject-oriented resultatives. I have shown in sections 5.3.1.2 and 5.3.2.2 that this ungrammaticality does not arise from a general constraint on intransitive verbs in resultatives; ECM resultatives with non-selected objects are fine. One might argue that DGS shows influence from German here, which requires a reflexive pronoun in all subject-oriented adjectival resultatives. However, DGS differs from German in not having a designated reflexive pronoun (Mehling 2010). Instead, reflexivity is expressed either through personal pronouns or by executing the verb on the signer's body, as illustrated in (99). 
PETER $_{\text {REFL }}-\mathrm{WASH}_{3 \mathrm{SG}}$ PRES

'Peter is washing (himself).'

[Mehling 2010: 104, adapted from German C.L.]

DGS signers do not insert a personal pronoun into subject-oriented resultatives when spontaneously producing [Verb Result] constructions, suggesting that mediation via an overt object pronoun does not license subject-oriented resultatives in DGS. Nonetheless, the expression of reflexivity via agreement with the signer's body seems to increase the acceptability of a subject-oriented resultative in both DGS constructions. Remember that eating oneself fat is considered more acceptable than running oneself dry or jumping oneself famous. A possible reason for its higher GJ ratings is that both EAT and BECOME.FAT pattern with the reflexive WASH in (99) in that parts of the signer's body represent both the agent and the patient of the complex event. As Figure 5 illustrates, the handling classifier of the frozen form EAT represents the agent of the eating subevent while the verb's orientation toward the body marks its goal. Meanwhile, the expanding form of the signer's body (as illustrated by his outward-moving arms) in BECOME-FAT show the theme of this subevent. Since both the goal argument of eating and the theme of becoming fat are represented by the subject's body, they can be co-identified. Crosslinguistically, ingestives like EAT have been analyzed as lexical reflexives akin to equally body-oriented middles (Amberber 2002; Jackendoff 1990; Krejci 2012). It is thus not surprising that the reflexive marking that co-identifies the agent and goal of EAT in DGS can be exploited for reflexive marking of subject-oriented resultatives. 


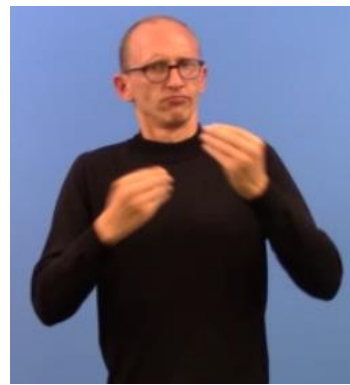

EAT

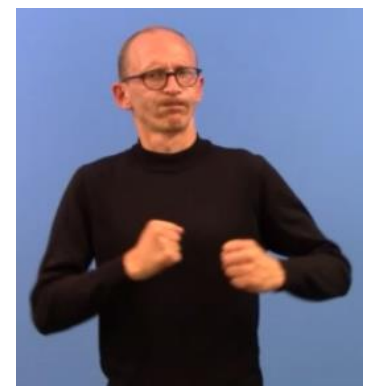

BECOME.FAT

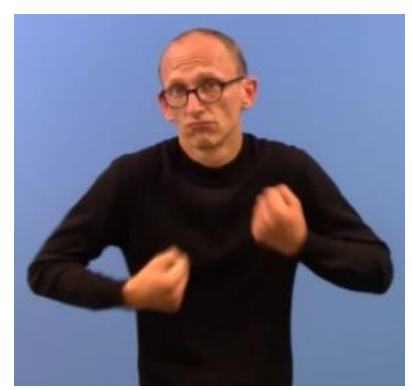

RUN

Figure 5: Illustrations of the DGS signs EAT, BECOME.FAT, and RUN

Note that this expression of reflexivity is not available for the other bare resultatives in (97) and (98). While RUN represents arm movement during running and thus maps the runner onto the signer's body (see Figure 5), neither DEAD nor DRY exhibit such a mapping. In FAMOUS JUMP, neither predicate maps its arguments onto the signer's body. We can thus hypothesize that subject-oriented resultatives in DGS require mapping of the arguments of each component predicate onto the signer's body to allow co-identification. In the absence of a designated reflexive pronoun, this type of agreement marking functions to express reflexivity. Further examination of a larger dataset of subjectoriented resultatives is necessary to confirm this hypothesis.

\subsubsection{S-V-O-Result (ASL)}

As one may expect in an SVO language, cause-result expressions in ASL share their English counterparts' word order: As illustrated in (100), the causer is followed by the manner of causation verb, which in turn is followed by the causee and the result predicate. 
WOMAN POLISH-Shoe SHOE SHINY-shoe
$\begin{array}{llll}\mathrm{S} & \text { Verb } \quad \mathrm{O} \text { Result }\end{array}$

'The woman polished the shoe shiny.'

Since ASL allows pro-drop, not all arguments of the construction need to be overtly expressed and, in fact, we find that causees that are introduced in previous clauses are frequently omitted in the resultative construction (101a) or are only indexed via locative agreement on the result predicate (101b). While both strategies yield adjacent cause and result predicates, it is unlikely that the two predicates form a syntactic unit to the exclusion of the causee. If that were the case, we would expect that ASL signers would sometimes place the causee after the verbal complex, but they never do.

(101) a. PLATE NO.TRACE.LEFT LEAVE GRAVY CL-5:spread_all_over_plate. WOMAN IX-lf CA:lick_plate NO.TRACE.LEFT.

\section{S Verb Result}

'There's an empty plate that has gravy all over it. The woman licks (it) empty.'

b. IX-rt SHOE CL-B:shoes_placed_side_by_side. WOMAN POLISH-rt SHINY-rt.

S Verb Result

'There are two shoes next to each other. The woman polishes (them) shiny.'

In his discussion of change-of-state expressions in ASL, Dudis (2004) claims that resultatives with an overt causee intervening between the cause and change-of-state predicates are unacceptable in ASL, as illustrated in (102). 
a. PRO-1 SNEEZE (*NAPKIN) FLAT-OBJECT.ON.FLAT-OBJECT.FALL

'I sneezed the napkin off the table.'

b. PRO DRINK (?POP) TO-ZERO-EXTENT

'S/he drank pop (from a bottle or glass) until none was left.'

[Dudis 2004: 170, translation for (b) summarized from author's description]

Nonetheless, each of my ASL consultants produced an overt pronominal or full NP causee at least sometimes during the pilot study, suggesting that Dudis observes a trend rather than a hard syntactic constraint. Furthermore, one consultant (P1) who was presented with an additional translation task to complement video elicitation (and thus encourage single-sentence responses) consistently produced overt causees. We can thus assume that constructions with an overt causer and causee are acceptable in ASL; all cause-result constructions discussed below in fact have an overtly expressed causee. ${ }^{65}$ In the following sections, I show that the S-V-O-Result construction patterns with monoclausal utterances and discuss potential homomorphy constraints on the combination of cause and result predicates. Bare XP resultatives will not be discussed, since we currently lack the diagnostics for determining their monoclausal status. ${ }^{66}$

\footnotetext{
${ }^{65}$ In one case, the causee is only expressed via a classifier handshape on the verb. OPEN.DOOR incorporates the causee DOOR in its handshape and consultants find it unnatural to express the causee as a separate lexeme.

66 Subject pronoun copies cannot tell us much since the subjects of cause and result predicates are coreferential. The copy would be acceptable even in coordinate clauses, since it may refer back to the subject of the result predicate. Rightward $w h$-movement has limited applicability for the same reason: We have shown in previous sections that the $w h$-subject can move across clauses whose subject is linked to an argument of the matrix clause. Since ASL is an SVO language, the scope of final modal verbs cannot easily be used to determine monoclausality in resultatives.
} 


\subsubsection{Evidence for monoclausality}

Given that ASL allows pro-drop, an S V O Result utterance like 'WOMAN POLISH-shoe SHOE SHINY-shoe' in (100) could easily be parsed as a biclausal construction consisting of a transitive clause (The woman polished the shoe) followed by an intransitive one ((It) is shiny). In cases where the causee is not selected by the verb such as 'IX-addr SWEAT SHIRT WET', monoclausal resultatives (You sweat the shirt wet) need to be distinguished from multiclausal constructions with the same surface word order (You sweat. The shirt is wet.)

To find out whether S-V-O-Result constructions necessarily involve two independent clauses or rather contain an embedded clause, the modified subject pronoun test described in section 4.4.3 was applied to 20 transitive cause-result scenarios (summarized in chapter 3, Table 3). In a first step, grammaticality judgment ratings for the six most conservative cause-result combinations (durative verb + maximal endpoint result and punctual verb + non-gradable result) were compared to judgments for a set of simple, subordinate, and coordinate clauses. Examples of this comparison set are provided in (103) and the mean GJ ratings for all sentence types are provided in Table 12.

(103) Simple sentence

$\mathrm{y} / \mathrm{n}$

a. IX-addr HIT MIKE IX-addr

'Did you hit Mike?' 
Subordinate clause embedded under a matrix predicate $\mathrm{y} / \mathrm{n}$

b. IX-addr TELL EVERYONE PERSON MIKE KISS MARY IX-addr

'Did you tell everyone (that) Mike kissed Mary?'

Two coordinate clauses

$\mathrm{y} / \mathrm{n}$

c. IX-addr addr-GIVE-1 MONEY, lf-GIVE-1 FLOWER IX-addr

'Did you give me money (and) he gave me flowers?'

Resultatives

$\mathrm{y} / \mathrm{n}$

d. IX-addr SAND+ TABLE SMOOTH IX-addr

'Did you sand the table smooth?'

Note that the means and standard deviations in Table 12 are based on different numbers of observations: A total of 42 judgments on six different S-V-O-Result constructions are compared to 6-7 judgments ${ }^{67}$ of one subordinate and coordinate clause each and 14 judgments of two simple clauses. That being said, the mean GJ ratings for coordinate clauses are unsurprisingly much lower than those for all other sentence types. I constructed a linear mixed model of GJ ratings as a function of sentence type (and participant as random effect), which confirms that sentence type predicts GJ ratings $(p<0.0001)$ and, more specifically, resultatives with final subject pronoun copies receive

${ }^{67}$ One observation was dismissed from the dataset after I noticed that the consultant in question interpreted the final subject pronoun copy in (103d) as an independent clause along the lines of "Your turn, explain yourself". 
higher ratings than coordinate clauses $(p<0.0001)$. These results confirm that ASL has S-V-O-Result constructions which exhibit a higher degree of syntactic integration than juxtaposition or coordination of cause and result clause.

Table 12

Means and Standard Deviations for GJ Ratings of Subject Pronoun Copy Across Different Sentence Types (ASL)

\begin{tabular}{lll}
\hline & \multicolumn{2}{c}{ GJ rating } \\
\cline { 2 - 3 } Sentence type & $M$ & $S D$ \\
\hline Simple & 4.71 & 0.47 \\
Subordinate & 4.79 & 0.39 \\
Coordinate & 1.5 & 0.84 \\
Resultative $^{\mathrm{a}}$ & $4.42(4.54)$ & $0.87(0.75)$ \\
\hline
\end{tabular}

\footnotetext{
${ }^{a}$ Includes only combinations of durative verb + maximal endpoint result and punctual verb + non-gradable result. The number in parentheses excludes SHAKE AWAKE and thus reflects the difference between classifying OPEN.DOOR and AWAKE as maximal endpoint predicates (including SHAKE AWAKE) and treating them as open-scale predicates.
}

The rightward $w h$-movement test allows us to go one step further and ask what the nature of the syntactic relationship between cause and result predicates is. Since rightward wh-movement is not acceptable across full clauses in ASL (see section 4.5.3), acceptable movement of a wh-causer to the right of the result predicate would indicate that this predicate does not project a full CP. If the latter is the case, the S-V-O-Result construction would pattern with resultatives in SVO languages like English. 
In order to test the acceptability of rightward wh-movement in ASL cause-result expressions, GJ ratings for six (five) ${ }^{68}$ resultatives with a final $w h$-subject were collected from seven native signers of ASL (see section 3.2 for participation criteria). In all six resultative constructions, which are illustrated in (104) with their average GJ ratings, the verb selected for the causee and matched the result predicate's object type (complex versus minimally complex) in case the S-V-O-Result construction is subject to homomorphy constraints. GJ ratings for these cause-result sentences were then compared to ratings for final $w h$-subjects in two simple clauses, two object control structures, three matrix + subordinate clauses, as well as one coordinate structure. Concrete examples of these sentence types can be found in section 4.5.3.2.

(104) a. 4.57 LICK PLATE CLEAN-plate WHO

'Who licked the plate clean?'

b. 3.57 HAMMER SPOON FLAT WHO

'Who hammered the spoon flat?'

c. 3.86 SAND TABLE SMOOTH WHO

'Who sanded the table smooth?'

d. 4.0 SHAKE IX-1 AWAKE WHO

'Who shook me awake?'

e. 3.57 SHOOT-rt SUPERMAN DEAD-rt WHO

'Who shot Superman dead?'

f. 4.43 CHARM HARRY PREGNANT WHO

'Who put a spell on Harry to make him pregnant?'

68 The number in parentheses excludes SHAKE AWAKE. 
The mean ratings for each sentence type are presented in Table 13. Inspection of the raw means suggests that resultatives pattern with simple and object control clauses in permitting rightward wh-movement. They receive higher GJ ratings than matrix+ subordinate clauses with a final $w h$-subject and far higher ratings than coordinate clauses with a final $w h$-element. To investigate the difference in GJ ratings further, a linear mixed model with sentence type as fixed effect and participant and item as random effects was fit to the data. Tests of the two ${ }^{69}$ a priori hypotheses were conducted using Bonferroni adjusted alpha levels with a starting $\alpha=0.025(0.05 / 2)$. Results confirm that rightward wh-movement is significantly more acceptable in S-O-Verb-Result constructions than across a coordinate clause $(p=0.0016)$. More importantly, movement across the result phrase is also significantly more acceptable than across a subordinate clause $(p=0.045)$. As expected, GJ ratings for resultatives do not differ significantly from those for simple $(p=0.6301)$ or object control clauses $(p=0.7927)$ at conservative alpha levels. Running the model without SHAKE AWAKE (whose result predicate AWAKE is classified as open scale rather than as having a maximal endpoint in English) produces similar results in that resultatives are still significantly better with final $w h$-words than coordinate clauses $(p=0.0043)$ but do not differ from simple $(p=0.4943)$ or control clauses $(p=0.6297)$. However, the trend for resultatives to be rated higher than matrix + subordinate clauses is not significant anymore $(p=0.1)$.

\footnotetext{
${ }^{69}$ The two hypotheses tested were that resultatives receive higher GJ ratings than subordinate clauses and than coordinate clauses.
} 
Table 13

Means and Standard Deviations for GJ Ratings of Final Wh-Words Across Different Sentence Types (ASL)

\begin{tabular}{llc}
\hline & \multicolumn{2}{c}{ GJ rating } \\
\cline { 2 - 3 } Sentence type & $M$ & $S D$ \\
\hline Simple & 4.36 & 1.01 \\
Object Control & 4.25 & 1.16 \\
Subordinate & 3.19 & 1.29 \\
Coordinate & 1.43 & 0.79 \\
Resultative & $4.12(4.00)$ & $1.17(1.19)$
\end{tabular}

\begin{abstract}
${ }^{a}$ Includes only combinations of durative verb + maximal endpoint result and punctual verb + non-gradable result. The number in parentheses excludes SHAKE AWAKE and thus reflects the difference between classifying OPEN.DOOR and AWAKE as maximal endpoint predicates (including SHAKE AWAKE) and treating them as open-scale predicates.
\end{abstract}

Looking more closely at the resultatives included in these models, one notes that three of the four lowest-rated resultatives on the $w h$-diagnostic are among them: HAMMER FLAT $(M=3.57)$, SAND SMOOTH $(M=3.86)$, and SHOOT DEAD $(M=3.57)$. The target sentences in which they occur may have been judged degraded for independent reasons. ${ }^{70}$ Since there are further no systematic differences in acceptability for any particular combination of cause and result predicate in these resultatives (see next section), I ran the model a second time using GJ ratings for all 20 resultatives. The mean rating for all

\footnotetext{
${ }^{70}$ Each of the target sentences in question (and only those) exhibit a slightly divergent eye gaze pattern from all the other $w h$-final resultatives in the study. Instead of using a unified prosodic contour, the language model looks down at the causee during the predicates but breaks gaze to look at the addressee when signing the causee (for example SPOON in (vii)). This eye gaze behavior may well have introduced unwanted prosodic and, possibly, syntactic breaks in the utterance, resulting in a lower GJ rating.

(vii) $\frac{\text { down }}{\text { HAMMER }} \frac{\text { addr }}{\text { SPOON }} \frac{\text { down }}{\text { FLAT }} \frac{\text { addr }}{\text { WHO }}$

'Who hammered the spoon flat?'
} 
resultative items taken together is $M=4.21(S D=1.05)$, which is significantly higher than the ratings for both coordinate $(p<0.0001$ at $\alpha=0.025)$ and subordinate structures ( $p=0.0024$ at $\alpha=0.05$ ) with a final $w h$-subject. These results confirm that the S-V-OResult construction patterns with simple and object control clauses but, crucially, differently from matrix + subordinate clauses and coordination in allowing rightward whmovement. Since the result phrase then projects at most an infinitival clause, this construction patterns with resultatives cross-linguistically in being essentially monoclausal.

The next section focuses on the semantics of this construction and shows that it imposes no systematic restrictions on the combination cause and result predicates.

\subsubsection{Control versus ECM and the homomorphy question}

Since the S-V-O-Result construction in ASL parallels the syntax of English resultatives, the question arises whether we also find parallelisms in the mapping of event to scale that restricts which cause and result predicates may be combined in English. According to Wechsler (2005), event to scale homomorphy is imposed only when the verb describing the manner of causation selects the causee, which is associated with the relevant scale. Hence, for this part of the study, a subset of the GJ data containing the 14 Control resultatives was examined. To complete the picture, grammaticality judgments were also collected for six ECM constructions, two of which are presented in (105). Their mean GJ ratings were found to be near-identical $(M=4.23)$ to those for Control resultatives $(M=4.2)$, confirming that ASL resultatives allow both selected and nonselected causees. ${ }^{71}$

\footnotetext{
71 To obtain the grammaticality judgments reported here, the target resultatives were embedded in the frame [Verb Object Result WHO], featuring a final wh-subject to ensure that consultants would parse the
} 


\section{a. 4.14 SWEAT SHIRT WET WHO}

'Who sweat (until) their shirt (was) wet?'

\section{b. 4.71 EAT IX-rt FRIDGE NO.TRACE.LEFT-rt WHO}

'Who ate (until) the fridge (was) empty?'

To find out whether the S-V-O-Result construction is subject to homomorphy constraints, Control resultatives were selected based on their variation in the durativity of the manner of causation verb (eight durative versus six punctual) and the type of scale associated with the result predicate. Due to the reclassification of DESTROY as open-scale and AWAKE and OPEN.DOOR as having a maximal endpoint (for further discussion of this issue, see section 3.4.1.1), different scale types have unequal representation: The study includes ten result predicates with a maximal endpoint, and five items with open and nongradable scales each. A second limitation introduced by the reclassification is that two combinations of cause and result predicate are instantiated by a single resultative: durative verbs with a non-gradable result (BEAT DEAD) and punctual verbs with an openscale result (CHARM UGLY). The former represents a more serious limitation since this combination is predicted to be ungrammatical if homomorphy constraints hold, and we would like to test this prediction on more than one resultative. That being said, having at least seven GJ ratings from different native signers for each combination of cause and result predicates ensures the robustness of the results even where only one resultative was tested.

The mean GJ ratings for all combinations and their standard deviations are reported in Table 14. Visual inspection of the means suggests that both durative and utterance as monoclausal. To complement the data from participants P1-P26, I also obtained judgments for LECTURE DIE and SNAP PREGNANT from P27. 
punctual verbs may be acceptably combined with any type of result predicate. In fact, the durative verb + non-gradable result (BEAT DEAD) combination received some of the highest overall ratings, and open-scale predicates do not differ in acceptability from maximal endpoint ones when combined with a durative verb. Homomorphy would predict unacceptability in both cases: A durative verb forms a complex object that should not be able to map onto a minimally complex object like a non-gradable predicate, and when it maps onto a comparably complex object, the latter still needs to introduce a salient endpoint to the event. Open-scale results do not provide such an endpoint.

Table 14

Means and Standard Deviations for GJ Ratings of Control $S V O$ Result Constructions with a Final Wh-Subject (ASL). Numbers in parentheses were obtained by coding AWAKE and OPEN.DOOR as open-scale predicates. Numbers without parentheses represent treatment of these predicates as having a maximal endpoint.

\begin{tabular}{llll}
\hline \multirow{2}{*}{ Resultative type } & & \multicolumn{2}{c}{ GJ rating } \\
\cline { 3 - 4 } Durativity & Scale & $M$ & $S D$ \\
\hline & max $^{\mathrm{a}}$ & $4(4)$ & $1.25(1.22)$ \\
Durative & open & $4.26(4.2)$ & $1.04(1.12)$ \\
& non & 4.71 & 0.76 \\
\hline Punctual & max & $4.45(4.25)$ & $0.77(0.85)$ \\
& open & $4(4.43)$ & $1.29(1.02)$ \\
& non & 4 & 1.18 \\
\hline a $\max =$ maximal endpoint, non $=$ non-gradable & &
\end{tabular}


The results of fitting a linear mixed model with object selection, durativity of the main verb, and scale type of the result as fixed effects confirm that ASL resultatives are not subject to homomorphy constraints. In addition to the main effects, the model also included terms for all of their two- and three-way interactions as well as a random effect for participant. Four hypotheses were tested: Under homomorphy, Control resultatives with durative verbs should have lower GJ ratings when combined with non-gradable (1) and open-scale (2) result predicates than when combined with maximal-endpoint results. Additionally, combinations (1) and (2) should also receive lower ratings in Control resultatives than in ECM constructions, provided that only the former are subject to homomorphy constraints. Tests of these four a priori hypotheses were conducted using Bonferroni adjusted alpha levels with a starting $\alpha=0.013(0.05 / 4)$. Since none of the contrasts reached significance, ${ }^{72}$ I conclude that durative verbs receive similar GJ ratings in the S-V-O-Result construction whether they combine with maximal-endpoint, open scale, or non-gradable results. The present study thus confirms Kentner's (2014) findings that ASL resultatives are not subject to homomorphy constraints. In the next chapter, I show that they do exhibit another semantic feature associated with resultative constructions: directness of causation.

\footnotetext{
72 Within Control resultatives, GJ ratings for durative verbs with maximal-endpoint result predicates do not differ from those for open-scale $(p=0.285)$ or non-gradable results $(p=0.048$ at $\alpha=0.013)$. Durative verbs with open-scale results do not receive higher ratings in ECM than in Control resultatives $(p=0.747)$, and neither do durative verbs with non-gradable results $(p=0.819)$. Similarly, non-significant results are obtained when fitting the model over a dataset that treats OPEN.DOOR and AWAKE as open-scale adjectives (Control resultatives with durative verbs + maximal endpoint versus open-scale results $p=0.58$ / versus non-gradable results $p=0.202$; Control versus ECM resultatives with open-scale results $p=0.917 /$ with non-gradable results $p=0.865$ ).
} 


\subsubsection{Syntax of the $S$-V-O-Result construction}

Based on the syntactic facts detailed in section 5.3.3.1, the S-V-O-Result construction with a selected causee is best analyzed as a monoclausal resultative. As illustrated in (106), the manner of causation verb takes an infinitival small clause complement headed by the result predicate. Since the verb selects the causee, the latter is assumed to control a PRO subject in the complement small clause (106).

$$
\begin{aligned}
& \text { MARY LICK-plate PLATE [SC PRO NO.TRACE.LEFT-plate] } \\
& \text { S V Verb } \quad \text { O }
\end{aligned}
$$

'Mary licked the plate clean.'

We should ask what makes the constituent headed by NO.TRACE.LEFT in (106) a small clause. Following Guéron and Hoekstra (1995), I assume that small clauses contain some functional architecture; more specifically, that they project agreement. NO.TRACE.LEFT in (106) indexes its argument by agreeing with its location: The dominant hand signs NO.TRACE.LEFT above the non-dominant hand, which maintains the handshape it had assumed for PLATE. Guerón and Hoekstra argue that the main difference between full and small clauses is not the presence of any functional projections but, crucially, the absence of a tense operator in small clauses. Since ASL lacks overt morphological tense marking, the presence of a tense operator in the result clause is difficult to establish. ${ }^{73}$ As

\footnotetext{
73 Aarons et al. (1995) argue that ASL does project a tense phrase whose head may be filled by lexical tense markers. To test its presence in the result clause, one would have to insert a modal or tense marker at the left edge of this clause and check whether it is acceptable without breaking the utterance up into independent clauses. This diagnostic is difficult to administer for a variety of reasons. First, inserting a tense marker into the lower clause carries the implication that the eventuality it describes holds at a different time from the causing event. As I will discuss in the next chapter, resultatives are characterized by the spatio-temporal unity of causing and result events, hence a lexical tense marker may be rejected by ASL speakers not for lack of a tense projection but because resultatives describe single events that occur at one point/period of time. Second, Aarons et al.'s lexical tense markers are in many cases homophonous with temporal adverbs and can only be distinguished from them via their distribution: Only tense markers can occur before negation and in doubling constructions. In order to test whether a tense marker can occur
} 
mentioned in chapter four, Geraci and Aristodemo (2016) point out a second phenomenon that frequently characterizes infinitival clauses and distinguishes them from full complement clauses. The subject of a Raising or Control clause is either controlled by or shared with an argument of the matrix clause and thus not independent. Geraci and Aristodemo thus use the (in)dependence of the subject rather than tense morphology to decide whether a clause is infinitival or not. Applying the same logic to the construction at hand, Control resultatives contain a Control clause whose PRO subject is controlled by the object of the manner of causation verb.

Resultatives with non-selected objects such as (107) can also be argued to contain small clauses. Here the causee remains inside the result clause, given that we have no evidence of a morphological case system in ASL that would license raising to object.

\section{MIKE EAT [sc IX-rt FRIDGE-rt NO.TRACE.LEFT-rt] \\ $\mathrm{S}$ Verb O Result}

'Mike ate the fridge empty.'

One sense in which the embedded small clause clause has fewer functional projections than prototypical transitive clauses is that their unaccusative or stative predicates do not project a voice head à la Kratzer (1996). It is this voice head (Chomsky's little v) that introduces the external argument lacking in unaccusative intransitives such as result clauses. If it is the absence of voice rather than a tense head that allows rightward whmovement across resultatives with non-selected objects, such movement should also be accepted across other types of unaccusatives. One of the matrix + subordinate test

in a result clause, that clause would also need to be negated or embedded in a doubling construction. This complicates the diagnostic beyond applicability because the result predicate should not be negated for independent reasons (for example, resultatives are telic and NO.TRACE.LEFT 'empty' imposes a much more salient endpoint to the event than NOT NO.TRACE.LEFT). 
sentences in the present study contained an embedded clause with an unaccusative predicate (THINK [JOHN STUPID] WHO 'Who thinks that John is stupid?') and can thus be directly compared to resultatives with non-selected causees. Bearing in mind the limited power of an unbalanced dataset (7 GJ ratings for THINK JOHN STUPID wHO versus 32 GJ ratings for ECM resultatives), the GJ ratings for an unaccusative embedded under THINK do not differ significantly from those for an unaccusative embedded under the causing verb $(M=3.71$ versus $M=4.23, p=0.309) .{ }^{74}$ In contrast, GJ ratings for a transitive embedded under THINK (THINK [JOHN EAT WORM] WHO) were significantly lower than those for ECM resultatives $(M=2.14, p<0.001)$. At this point it thus looks as if rightward wh-movement in ASL may be licensed by intransitive clauses in general and we therefore have no evidence that cause-result constructions with a non-selected causee are more syntactically integrated than subordination of a full clause. In contrast, such syntactic integration is present in Control resultatives via an argument sharing or control relation between the causing and the result clause.

To sum up, we have seen convincing evidence that ASL has Control resultatives whose syntax mirrors that of resultatives in other SVO languages (cp. Williams 2008). In contrast to English and in line with Kentner's (2014), Control resultatives in ASL are not subject to homomorphic constraints. This confirms that event-to-scale homomorphy in resultatives is not a universal phenomenon, and that it does not even necessarily characterize a language whose users are fluent bilinguals in English. ASL does not seem to have a second resultative headed by a complex cause-result predicate akin to the DGS S-O-V-Result construction. If such a construction existed, one would expect signers to produce [S [vo V Result] O] word order at least sometimes, which they do not.

\footnotetext{
${ }^{74}$ The p-value is based on a linear mixed model of the data with sentence type (matrix + subordinate versus ECM resultative) as fixed effect and item and participant as random effects.
} 


\subsection{CONCLUSION}

The present chapter has shown that both DGS and ASL possess resultative constructions as one of several means for expressing complex cause-result events. While we have seen convincing evidence for treating cause and result predicates as a complex predicate in DGS, surface word order suggests that ASL resultatives are better analyzed as embedding an infinitival clause that contains the result predicate and its argument.

In contrast to German or English, the secondary predicate in DGS and ASL resultatives may denote either a result state or a change of state. We have seen evidence that DGS allows non-selected objects in these constructions, while this could not be conclusively shown for ASL. Specifically, we need more fine-grained diagnostics to investigate to what degree a result phrase with a non-selected causee in ASL is syntactically integrated in the matrix clause. If there is no integration beyond full clause subordination, ASL patterns with languages like Korean that have Control but no ECM resultatives.

In addition to predication of non-selected objects, we asked whether DGS resultatives can directly predicate of the causer subject and the answer seems to be no. Similarly to German, subject-oriented resultatives need to be mediated by overt coreference marking. Where German uses a reflexive pronoun, DGS verbs can express reflexivity through mapping causer and causee onto the signer's body.

In both ASL and DGS, resultatives in which the result predicate follows the causing predicate do not exhibit event-to-scale homomorphy. These findings are in line with work on Japanese, German, or Mandarin that has established the language-specific nature of homomorphic relationships between the complex event and the scale associated with the result predicate. However, given that the [Result Verb] constructions in DGS do impose constraints on which causing and result predicates may combine, I have further 
shown that homomorphy constraints are not only language-specific but also constructionspecific. They further do not seem to depend on object selection alone, since both DGS resultative constructions have been analyzed as complex predicates that jointly select the causee. Nevertheless, the [Result Verb] construction exhibits homomorphic constraints while the [Verb Result] construction does not.

A remaining question is whether DGS has one resultative construction with variation in the order of cause and result predicates, or whether [Result Verb] and [Verb Result] are different constructions. The fact that they differ in semantic combinability constraints supports the latter analysis, although it is not clear at this point why the observed semantic contrast correlates with the different word orders. Beyond these differences in homomorphic mapping, no systematic semantic differences between [Result Verb] and [Verb Result] constructions were detected. To give an example, no subclass of verbs (durative vs. punctual, activity vs. change of state) or result predicates (gradable vs. non-gradable etc.) only surfaced with one word order. Usage differences are likely to exist but their investigation exceeds the scope of this dissertation.

As suggested in section 5.3.1, the [Result Verb] construction may have originated from language contact with German but differs from German in important ways. Syntactically, its causee does not receive case from the causing verb and semantically, it exhibits homomorphy constraints not observed in German. The [Verb Result] construction, on the other hand, seems to be the more common expression of complex cause-result events in DGS, potentially because it allows an iconic representation of the order of subevents. 


\section{Chapter 6: Directness of causation in English and ASL resultatives}

\section{1 INTRODUCTION}

Causative constructions differ in the range of causative scenarios they may describe. In English, I can portray a situation in which Mary hammered directly on a spoon until it was flat with any of the sentences in (108). In contrast, neither a lexical causative (108a) nor a resultative (108b) would be an appropriate description of Mary hammering on a roof tile which consequently falls right onto a spoon, effectively flattening it. Only the periphrastic causative (108c) can capture such a complex causative situation.

(108) a. Mary flattened the spoon.

b. Mary hammered the spoon flat.

c. Mary caused the spoon to become flat.

Since the 1960s, research on causatives has focused on the correlation between the degree of formal compactness of a causative and how directly the causing and caused events that it describes are related (McCawley 1968, Comrie 1981, Shibatani \& Pardeshi 2002, among others). Haiman (1985) claims that a principle of structural isomorphism accounts for the correlation: the more immediate and direct the relationship between causing and caused event, the more compact the causative construction that encodes it. We would thus expect a resultative construction in any language to describe situations in which causing and caused subevents are directly related. 


\subsubsection{Defining directness}

Researchers differ in what constitutes 'directness' in causative scenarios, so this section introduces the main semantic distinctions that have been claimed to affect the choice of a synthetic versus an analytic causative.

Control/agentivity. The degree to which a causee retains control over the caused event may influence whether a lexical or an analytic causative is chosen to describe a causative situation (Brennenstuhl \& Wachowicz 1976; Dixon 2000). A patientive causee cannot influence the unfolding of the caused event, while a causee with agentive properties may (Shibatani \& Pardeshi 2002). In a number of languages including Japanese, Korean, and Marathi, morphological causatives exclusively encode causative situations with a volitional, agentive causee. Inanimate, non-volitional causees are not permitted, as illustrated in (109a), but favor lexical causatives such as (109b) (Dixon 2000, Shibatani 1976).

\footnotetext{
a. *Taroo-ga kabin-o ware-sase-ta

Taroo-NOM vase-ACC break-CAUS-PAST

'Taro made the vase break.'

b. Taroo-ga kabin-o wat-ta
Taroo-NOM vase-ACC break-PAST
}

[Shibatani \& Pardeshi 2002:138]

Dixon (2000) lists volition and naturalness as two further semantic distinctions that seem closely related to the causee's degree of agentivity or control. In Swahili, for example, a morphological causative indicates that the causee performs the caused event willingly, while a periphrastic causative expresses situations where the causee is unwilling or their intentions are not consulted. In other words, being able to dissent is seen as a sign of the volitional agency of the causee. Dissent or non-compliance frequently require some level of force or violence on the part of the causer in order to achieve a particular change of state. Dixon's feature of naturalness of the causative situation goes hand in hand with control and volition in that it contrasts causative 
activities that happen effortlessly or naturally with those requiring the exertion of (psychological) force on the causee. ${ }^{75}$ In languages where naturalness plays a role, such as English, Russian, or Fijian, the more analytic causative construction respectively expresses special effort on the side of the causer.

Intentionality. In addition to considering the causee's role in the event, researchers have looked at features of the causer to determine whether a causative situation is expressed via a lexical or analytic causative. Cross-linguistically, compact causatives are associated with intentionally caused changes of state, while the more analytic causatives are preferred for accidental events (Dixon 2000). The Austro-Asiatic language Chrau, for example, uses an overt causative verb in combination with a lexical verb to express intentional events such as (110a), while an additional causative prefix on the lexical verb is necessary for the expression of accidental causation as in (110b).

$$
\begin{aligned}
& \text { a. ănh ôp dăq khlâyh } \\
& \text { 1SG CAUS } 2 \text { trap escape } \\
& \text { 'I made the trap spring (on purpose).' } \\
& \text { b. ănh ôp dăq ta-khlâyh } \\
& \text { 1SG CAUS } 2 \text { trap CAUS } \text {-escape }^{-} \\
& \text {'I made the trap spring (accidentally).' }
\end{aligned}
$$

[Thomas 1969:100 in Dixon 2000: 70]

(111) harse-ñ̃ wo misa-yato siat-っ

Harsha-ERG the woman-DAT kill-PERF

'Harsha killed the woman.'

[DeLancey 1983: 54]

\footnotetext{
75 Naturalness as defined by Dixon (2000: 72) is not completely synonymous with volition or control, since it encompasses scenarios where the causer exerts physical force to overcome some obstacle, for example He made the door open (with difficulty). For our purposes, however, it suffices to recognize that a lack of naturalness and a volitional causee often go hand in hand.
} 
For the Sino-Tibetan language Newari, DeLancey (1983) notes that intentionality is not a necessary condition for the use of a lexical over a morphological causative. Thus, siat-J 'kill' in (111) may describe accidental killings such as might result from Harsha physically assaulting the woman without intending to kill her, and her dying of a heart attack. ${ }^{76}$ Unintentional actions can thus be construed as directly causing a change of state in Newari. Wolff (2003) demonstrates that in English, intentionality in turn can render an otherwise indirect causation scenario into a direct one. He shows experimentally that this effect of intentionality relies at least partially on the fact that an intentional causer allows us to conceptualize potential intervening causers as tools, or enabling conditions exploited by the ultimate causer. He shows that the use of the lexical causative break in (112) is conditional on the girl's intentions: If she throws a ball at the vase with the intention of breaking it, native speakers of English use (112) in over 70 per cent of cases. However, if the girl is playing with a ball but loses control over it so that it bounces into a vase that subsequently breaks, speakers choose (112) in less than 10 per cent of event descriptions. According to Wolff, the ball can be treated as enabling the breaking of the vase only when the girl intends for this to happen. Otherwise, it is conceptualized as an independent causer that immediately brings about the breaking. Wolff does not detail whether it is sufficient for the causer to want to bring about the result, or whether he needs to intend to use the intervening causer as well. The latter condition is somewhat stricter and is instantiated in all of Wolff's examples.

(112) The girl broke the vase.

Intervening cause(r)s. The presence or absence of a cause(r) that intervenes between the subject of a causative sentence and the resulting change of state is also

\footnotetext{
76 Note that in English and several other languages, compact lexical causatives are compatible with indirect causation scenarios when the speaker is apportioning blame: You killed him! may be uttered when the addressee accidentally shot someone who died several days later of their internal injuries (unintentional, temporal distance), or in case there is an explosion in a mine causing the death of several miners, and the addressee owns said mine but has not brought its safety standards up to code (intervening cause by omission).
} 
known in the literature as 'mediacy' or 'directness vs. indirectness proper'. It has been argued to influence whether or not a compact causative (a lexical causative or a resultative) can describe a causative situation (Comrie 1981; Cruse 1972 on lexical causatives; Wolff 2003). The ball that struck the vase in (112) constitutes such an intermediate entity, and its presence in the chain of causality leads speakers to prefer a periphrastic causative such as The girl caused the vase to break. Another example is provided by Cruse (1972), who notes that the lexical causative open cannot describe situations in which the ultimate causer does not act on the affected object directly, but only directs another causer's actions. Thus, John opened the door is unacceptable in a scenario where John persuades Bill to push the handle and open a door. In most cases, the absence of an intervening cause $(\mathrm{r})$ correlates strongly with the presence of manipulative causation as described in Shibatani (1976). Acting directly on the affected participant typically involves physically manipulating it (e.g. pushing over a vase to break it), while indirectness can be introduced by either an independent inanimate causer (the ball in (112)) or by a human causee instructed to perform an intermediate causing action (Bill opening the door based on John's command). Shibatani calls the latter directive causation.

Spatio-temporal separability. Lastly, the formal causative continuum may be sensitive to whether the causative situation is conceptualized as one event or as bieventive (Martin 2000; Shibatani \& Pardeshi 2002). Causative situations that are treated as single events are more likely to be expressed with a compact causative. For Shibatani \& Pardeshi (2002), causing and caused subevents crucially have to share a temporal profile in order to be conceptualized as a single event. This intuition relates to an observation by Fodor (1970), who shows that a lexical causative like kill in (113a) refers to a single event whose components cannot be modified separately by temporal modifiers (both Bill's stabbing and dying have to occur on Sunday in (113a)). Causative situations that are conceptualized as containing two events (each of which can be modified by a separate temporal adverbial) are expressed via a periphrastic causative such as (113b). 
(113) a. *John killed Bill on Sunday by stabbing him on Saturday.

b. John caused Bill to die on Sunday by stabbing him on Saturday.

[Fodor 1970: 433]

In sum, a variety of factors determines our construct of "directness". When evaluating the degree of directness of any given causative situation, speakers take into consideration the intentionality of the causers' actions, the degree of control a causee has over the causing event, the passage of time between causing and caused event, as well as the presence of intervening cause(r)s during that time. The discussion above also suggests that no single factor is both necessary and sufficient for a situation to be construed as

directly caused. Intervening causers typically render a causative scenario indirect, but if they can be construed as intentional tools employed by the causer or as conventionally intermediate cause(r)s (Goldberg 1995), the situation can still be expressed with a lexical causative in English.

In line with McCawley (1978), I thus assume that the association of monoclausal causatives with direct causation has pragmatic origins. Syntactically simpler sentences (i.e. sentences involving less functional structure) are interpreted to refer to prototypical causative situations. Lakoff and Johnson (1980) characterize these causative situations as encountered first by children and as typically involving direct manipulation with an immediate physical effect on the patient. Any deviations from the causative prototype are signaled by syntactically more complex structures.

\subsubsection{Directness of causation in resultatives}

Parallel to lexical causatives, resultative constructions are assumed to describe direct causation. One of the first authors to argue for such a restriction on resultatives is Goldberg (1995), who claims that "the change of state must occur simultaneously with the endpoint of the action denoted by the verb" (194), allowing no time delay between causing action and change of state. Goldberg assumes that this constraint holds for 
Control and ECM resultatives alike, as her examples involve both types. She argues that Sam's death in the Control structure (114a) needs to follow the shooting immediately, and that likewise the causer's eating event in the ECM structure (114b) continues up to the onset of his sickness.

(114) a. Harry shot Sam dead.

[Goldberg 1995: 194]

b. He ate himself sick.

Rappaport Hovav and Levin (1999b) take up Goldberg's suggestion that direct causation applies to resultatives. They argue that it is not temporal contiguity but the absence of intervening events in the causal chain that determines the acceptability of a resultative. The ECM resultative in (115a) exemplifies the felicitous use of a resultative when the causing event ends before the affected participant enters the result state: The sentence is consistent with Sam having sung all day and still having a voice in the evening, yet waking up hoarse the next morning. Rappaport Hovav and Levin argue that the same temporal independence between the two subevents holds in Control resultatives, but their sole example of a Control resultative with an adjectival XP seems to exhibit temporal dependency: The mugs in (115b) become cleaner as the rinsing event unfolds, and they cease becoming cleaner after the rinsing ends. It is thus possible that directness of causation in Control resultatives includes temporal contiguity.

a. Sam sang himself hoarse.
b. He rinsed the tea mugs clean.

[Rappaport Hovav \& Levin 1999: 30, 43]

In her discussion of concealed causatives, Bittner (1999) examines resultatives as one of several constructions in which the causal relation between subevents is not explicitly stated. She claims that the operator introducing causality into the construction establishes a direct causal relation between causing and result subevent by default, and 
that directness entails the absence of intermediate causes: "Direct causation ... is immediate precedence [of events, CL] in the pragmatically determined causal order" (Bittner 1999: 28). ${ }^{77}$ Based on her distinction between overt and concealed causatives, Bittner predicts that lexical causatives and resultatives differ in acceptability in indirect causative situations. Since causality is lexically encoded in causatives such as break or open while being introduced by an operator in resultatives, the latter should be more strictly limited to direct causation. Lexical encoding allows some leeway for lexemespecific notions of causation, while a type-shifting operator typically does not encode non-logical types of meaning. It is therefore limited to introducing a default, direct notion of causation. Truth judgments confirm Bittner's predictions. ${ }^{78}$ A sentence like John shot the robber dead was judged clearly false in scenarios where John grazed the robber's ear, which brought on a heart attack that instantly killed the robber. The lexical causative John killed the robber by shooting her, on the other hand, was judged "basically true, but misleading" (Bittner 1999: 2).

Kratzer (2005) adopts Bittner's concept of direct causation and provides an explanation of the no-intermediate-cause constraint in adjectival resultatives in terms of event identification and constraints on the possible extensions of verbs. Specifically, she argues that an adjective such as leer 'empty' in (116) combines with a phonologically null [cause] affix, which turns its denotation from a property of states of being empty into a property of events of causing an entity to become empty.

\footnotetext{
77 Note that Bittner does not consider the degree of control of the causee to factor into the decision of intermediate causes. Thus, she characterizes a mother beating her child into eating rice as an instance of direct causation, although the child retains some control over the eating event.

78 Unfortunately, Bittner does not provide a description of the methodology for eliciting these truth judgments, nor does she indicate the number of participants.
} 
(116) Die Teekanne leer trinken

[Kratzer 2005: 177] the teapot empty drink

'To drink the teapot empty'

Crucially, such an event must contain the (onset of) the result state empty. The resulting property associated with leer [cause] is then identified with the property of events denoted by trinken 'drink'. It follows from principles of Event Identification that each part of the cause-to-become-empty event has to be part of the drinking activity, resulting in a direct causation interpretation: If I drink from the teapot until it is empty, then there are no links in the causal chain that are not part of the drinking event. If, however, I drank all the water in the well, thereby leaving no water to refill the teapot (Kratzer's famous example), then there are elements in the causal chain (for example someone pouring out some liquid that was originally in the teapot) that are not conventionally described by trinken and the resultative in (116) can therefore not describe such a situation. In that sense, the possible extensions of verb meanings determine the observed directness of causation in resultatives.

Lastly, Levin (2015) considers potential differences in how the directness constraint is realized in Control versus ECM resultatives. If directness of causation falls out from the syntactic structure of resultatives, as suggested in Dowty (1979) and Carrier and Randall (1992), a directness constraint should only hold of Control resultatives. As long as the postverbal NP is an argument of the matrix verb (as is the case in Control resultatives), it needs to undergo the action denoted by the verb, while such a requirement is merely a cancelable conversational implicature in ECM resultatives (Hoekstra 1988). Nonetheless, Levin assumes that certain directness constraints may apply to ECM resultatives as well. Following Wolff's (2003) definition of direct causation as the 
absence of intervening cause(r)s, she claims that the causer in Control resultatives physically manipulates/contacts the referent of the postverbal NP (or uses a tool to do so). For ECM resultatives based on typically transitive verbs, she posits that their unexpressed implicit NP object has to refer to an entity that "bears a close relation to the entity denoted by the postverbal NP" (6). Typically, this relation is instantiated by physical contiguity, for example in (117a) between a surface (the land) and an entity covering it (grass), or in (117b) between a container (teapot) and its contents (tea). However, physical contiguity is not a necessary condition, since the arguably transitive bark in (117c) licenses a resultative where its unexpressed object (the bark) merely "impinges" on the postverbal NP the neighbor (Levin 2015: 10). Not only is the notion of impingement not well-defined, but it also does not cover all cases in which no physical contiguity holds. In (117d), for example, the lungs do not literally contain a shriek, but rather the air which is expelled to create sound via the vocal folds. Thus, the predictive power of Levin's constraint on non-selected NPs is weakened by the fact that it undergenerates and does not account for all attested ECM resultatives. ${ }^{79}$

(117) a. The goats ate the land bare (of grass).

b. drink the teapot dry

c. bark the neighbor awake

d. Davina and I erupted from the knife-sharp grass, shrieking our lungs dry as we brandished our spears at the enemy soldiers.

[Levin 2015: 5, 13, 15]

\footnotetext{
79 Tomioka (2006) postulates that it is participating in the causing event that licenses non-selected NPs in ECM resultatives. The neighbor in (9c), for example, has to hear the dog's barking. If her waking was indirectly caused by a barking she did not hear, such a scenario could not be described with the resultative. Unfortunately, Tomioka does not provide evidence for the systematic nature of this constraint.
} 


\subsubsection{Predictions for directness of causation in English}

To my knowledge, none of the claims about directness of causation in English resultatives have been tested through controlled experiments. Wolff (2003) predicts that his no-intervening-cause hypothesis holds of different single-clause causatives, including resultatives, but his experiments focus on lexical causatives exclusively. To understand directness of causation in ASL better, it is thus instructive to take a step back and examine empirically which aspects of a causative situation determine the acceptability of resultatives in English. In the following discussion, a conservative interpretation of the construct 'direct causation' is assumed. Causation is direct only if a causer brings about a change of state in some participant intentionally and without intermediate cause(r)s or spatio-temporal distance between the causing and change of state subevents. On the assumption that resultatives only encode direct causation, the following hypotheses will be examined:

1. Resultatives cannot felicitously describe situations in which the result state does not hold at the end of the causing event. The temporal profiles of causing event and change of state need to overlap (Goldberg 1995).

2. Resultatives cannot felicitously describe situations in which an intermediate cause(r) intervenes between the ultimate causer in subject position and the object causee (Bittner 1999; Kratzer 2005; Rappaport Hovav \& Levin 1999a).

3. Resultatives can describe situations in which an intermediate entity can be conceptualized as a tool that enables the causer to bring about the intended result. The causer has to be a volitional agent and want for the change of state to occur (Wolff 2003). 
4. Resultatives with a non-selected object can only describe situations in which the unexpressed verbal object is physically contiguous (touching) the named causee (Levin 2015).

These hypotheses make predictions about how acceptable people find resultatives as opposed to periphrastic causatives for summarizing a given causative scenario. Consider the causative scenarios presented in (118). Hypothesis (1) predicts that John kicked the door open felicitously describes (118a) but not (118b), in which there is a temporal delay between John kicking the door and it opening. Since there is no intermediate event or causer involved in opening the door in (118b), hypothesis (2) predicts that this scenario should be compatible with a resultative description. Scenarios (118c) and (118d) both feature an intermediate causer, the ball that hits the door and causes it to open. However, according to hypothesis (3), only (118d) should be incompatible with a resultative because the ball in (118c) can be construed as enabling John to open the door and thus as a tool rather than an independent causer. Lastly, hypothesis (4) predicts that both (118c) and (118d) should be compatible with an ECM resultative, because at the beginning of the change of state event the ball makes physical contact with the door.

(118) John kicked the door open.

a. John wants to get into his home, but the door is stuck, so he kicks at it once and it opens.

b. John wants Mary to water his flowers while he is gone, so he programs his door to open automatically at $6 \mathrm{pm}$, when Mary is supposed to stop by. John likes technological gimmicks, so he bought a door that you can only program to open at a particular time if you kick it. John kicks it to set the opening 
mechanism for 6pm, and when Mary gets to John's place a little after 6pm, the door is open.

c. John wants to open his front door for his wife but he has his hands full and his foot is out of reach of the door as well. However, there's a ball lying nearby, so John kicks the ball at the door and it opens.

d. John is mad about something and needs to vent his anger. He kicks against a ball lying near him, and the ball accidentally hits a nearby door. The door opens.

\subsection{EXPERIMENT I: DIRECTNESS OF CAUSATION IN ENGLISH RESULTATIVES}

Experiment I tested the predictions of hypotheses (1) - (4) on the acceptability of English resultatives in direct versus indirect causation scenarios. Indirectness was defined as either temporal delay between the end of the causing event and the completion of the change of state (hypothesis 1) or the presence of an intervening cause(r) that cannot be construed as enabling the causer to bring about the result state (hypotheses 2 and 3). Participants read different causative scenarios and were asked to evaluate how appropriate a given resultative would be for describing what happened in the scenario. To establish whether participants perceived a causal chain between causer and ultimate result at all, they were also asked how appropriate a general causative such as John caused the door to open would be in a given scenario.

\subsubsection{Method}

\subsubsection{Participants}

The participants were 28 UT Austin undergraduates. All were native speakers of English and at the time of participation were enrolled in an introductory linguistics class. 


\subsubsection{Materials}

Twelve resultatives were tested in four causative situations each. Each causative situation was constructed as a combination of three binary factors: a) whether the causer intends for the change of state to occur or not, b) whether there is an intervening cause(r), and c) whether there is a temporal delay between causing action and completion of the change of state. While there are eight possible combinations of these factors $(2 \times 2 \times 2), I$ focus on the four causative scenarios that allow testing hypotheses (1) - (4). They are summarized in Table 15. The Direct scenario represents the prototype of direct causation, featuring an intentional causer who brings about the result state immediately and without intervening causers. In the IntInv (Intentional intervener) scenario, an intermediate entity intervenes between the intentional causer and the affected entity. Inv (Intervener) conditions only differ from IntInv scenarios in that the causer does not intend for the result state to come about. Lastly, Temporal (Temp) scenarios feature at least a 15 minute delay between the end of the causing action and the completion of the result state.

Table 15 Causative Scenarios Broken Down by Directness Components: Intentionality, Intervening Cause(r)s and Temporal Delay

\begin{tabular}{|l|l|l|l|}
\hline $\begin{array}{l}\text { Causative } \\
\text { scenario }\end{array}$ & $\begin{array}{l}\text { Intentional } \\
\text { causer (a) }\end{array}$ & $\begin{array}{l}\text { Intervening } \\
\text { cause (b) }\end{array}$ & $\begin{array}{l}\text { Temporal } \\
\text { delay }(c)\end{array}$ \\
\hline Direct & + & - & - \\
\hline IntInv & + & + & - \\
\hline Inv & - & + & - \\
\hline Temp & + & - & + \\
\hline
\end{tabular}

All hypotheses predict that English resultatives should felicitously describe Direct scenarios. Hypothesis (3) predicts that they are also appropriate for IntInv scenarios where the causer intentionally uses an intermediate entity as a tool to bring about a 180 
change of state. Hypothesis (4) predicts that all scenarios can be described with an ECM resultative as long as the non-selected causee is physically contiguous to the unexpressed verbal object. Lastly, hypothesis (1) predicts that resultatives are incompatible with Temp scenarios and hypothesis (2) predicts that they are unacceptable with Inv (and possibly IntInv) scenarios. An example of each causative scenario was given in (118), for a full list of scenarios, see Appendix G.

The 12 resultatives tested in this study are listed in Table 16 below. Each combination of cause and result predicate conforms to the homomorphy requirements of English discussed in Wechsler (2005) and Beavers (2008). All causers are human and all but two causees are inanimate objects. To minimize the influence of control or volitionality on the part of the causee, the two human causees are depicted as having limited control: One is a toddler and the other a brainwashed adult. To ensure maximal comparability, (near-) identical resultatives were selected for ASL and English where possible. Since more restrictive selection criteria informed the choice of ASL resultatives, the reader is referred to section 6.3.1.2 for further discussion of item selection.

Table 16 Resultatives tested in Experiment I

\begin{tabular}{|l|l|l|l|l|l|}
\hline kick open & kiss awake & iron flat & shoot dead & paint blue & spray clean \\
\hline punch open & shake awake & hammer flat & knock dead & dye blue & sand smooth \\
\hline
\end{tabular}

In addition to resultatives, participants were presented with cause and make causatives. These periphrastic causatives were included to ascertain that participants perceived a causal connection between the causing event and the final result state at all. If they accepted a periphrastic causative for describing a particular scenario but rejected a 
resultative in the same scenario, we could be certain that the latter describes a causal relation between subevents that is too indirect to be expressed with a resultative. Make served as the default causative verb here, while cause was used whenever the result was perceived as negative (e.g. John caused Mike to die), or when make wrongly implied a resistant human causee (e.g. Mary made John wake up).

\subsubsection{Procedure}

Data were collected using Qualtrics software, Copyright (C) 2017 Qualtrics. An online survey containing all 48 trials (4 conditions x 12 resultatives) was constructed such that the trials were distributed evenly across two sub-surveys and survey respondents were randomly assigned to one of the two sub-surveys, which each contained 24 items. Thirteen participants took one survey, 15 took the other. The within-subjects design ensured that each respondent saw all lexicalizations and provided six judgments per causative scenario. Since participants saw each resultative in two conditions, measures were taken to minimize priming effects from one causative scenario to the other: On the one hand, the order of trial presentation in each sub-survey was randomized for each respondent, and on the other, the two causative scenarios that participants evaluated for each resultative were varied systematically (e.g. sub-survey A presented kick open in Default and IntInv, but punch open in Inv and Temp). ${ }^{80}$

Before starting the survey, each respondent gave their consent, filled out a brief language background questionnaire, and read the task instructions. Respondents then clicked their way through 24 trials. Each trial began with a causative scenario followed

\footnotetext{
80 To avoid priming effects between conditions altogether, each survey respondent should see each resultative in only one condition. Budgetary limitations and a realistic assessment of how many respondents might be recruited resulted in a more compressed study design with participants seeing two conditions per resultative.
} 
by the question How appropriate are each of the following sentences for describing what happened?. Below the question, participants saw a resultative and a periphrastic causative and indicated appropriateness on a five-point Likert scale from "Not appropriate at all" to "Very appropriate". ${ }^{81}$ Lastly, they were asked to comment why a given resultative or periphrastic causative seemed inappropriate in a given scenario. The concept 'appropriateness' was modeled in the task instructions in terms of truth and specificity and was illustrated with an example. ${ }^{82}$ Survey respondents were reminded not to rank the target sentences with respect to each other directly, but were told that all or none of the sentences may be appropriate.

\subsubsection{Design and statistical analysis}

Causative scenario and sentence type (resultative versus general causative) were run within participants. A linear mixed effects model was fit to the data using R (R Core

\footnotetext{
81 The choice of a fully-labeled Likert scale over one using symbols or numbers is motivated by the need to clarify the meaning of the response categories. Furthermore, fully-labeled scales have a higher test-retest reliability than endpoint-labeled ones (Weng 2004).

82 Appropriateness was exemplified in terms of lexical relations rather than causal links in order not to bias participants towards a particular understanding of directness of causation. The instructions provide the following example:
}

(viii) Context:John and Mary are taking a walk in the woods. Suddenly, they see a wolf chasing a squirrel up a tree. After staring at the tree for a while, the wolf loses interest and leaves. Mary and John wait another five minutes and then resume their walk.

Possible sentences to evaluate here are:

a) John and Mary saw a dog chasing a squirrel.

b) John and Mary saw an animal chasing a squirrel.

c) John and Mary saw a wolf chasing a squirrel.

Survey respondents are told that the first sentence is not an appropriate description of the story, as Mary and John saw a wolf rather than a dog (truth). The second sentence is a fairly adequate description, since it is true but could be more informative (specificity). The third sentence is characterized as appropriate. 
Team 2016) and lme4 (Bates et al. 2012). First, causative scenario was run as a fixed effect with random effects for item and participant, then sentence type was added as a fixed effect, as well as their interaction term. Contrasts were decomposed using the Tukey adjustment method to control the Type I error rate in pairwise comparisons. Visual inspection of residual plots did not reveal deviations from normality.

\subsubsection{Results}

The means and standard deviations of the acceptability ratings for each type of causative scenario are presented in Table 17. The results provide evidence for the overall hypothesis that resultatives in English are restricted to direct causation. Resultatives received significantly higher acceptability ratings in the Direct condition than in any of the other scenarios (each contrast is significant at $p<0.0001$ ).

Table 17

Means and Standard Deviations for Acceptability Ratings of English Resultatives in Direct and Indirect Causation Scenarios

\begin{tabular}{lcc} 
& \multicolumn{2}{c}{ Acceptability rating } \\
\cline { 2 - 3 } Causative scenario & $M$ & $S D$ \\
\hline Direct & 4.83 & 0.46 \\
Temp & 3.43 & 1.32 \\
Intentional Intervener & 2.76 & 1.49 \\
(IntInv) & & \\
Intervener (Inv) & 2.42 & 1.37 \\
\hline
\end{tabular}


The results provide support for hypotheses (1) and (2). Specifically, the data show that a temporal delay between causing and result subevents significantly lowers the acceptability of a resultative description, as illustrated for kiss awake in (119). The resultative receives higher acceptability ratings when Mary's kiss wakes John instantly rather than after 15 minutes. The data thus support Goldberg (1995) rather than Rappaport Hovav and Levin (1999b).

(119) a. Direct scenario: John has to get up for work, but he's fast asleep. So Mary kisses him and he wakes up.

\subsection{Mary kissed John awake.}

b. Temporal delay scenario: Mary kisses John in order to wake him, but he is a sound sleeper and does not wake up right away. Somehow the kisses have registered, however, and John sleeps more lightly and wakes up after 15 minutes.

\subsection{Mary kissed John awake.}

The fact that resultatives also cannot describe events with an intervening cause(r) is illustrated for shoot dead in (120b) and supports Bittner (1999), Kratzer (2005), and Rappaport Hovav and Levin (1999b).

(120) a. Direct scenario: John wants to revenge his family's death at the hands of Mike. He aims, shoots, and hits Mike, and Mike dies on the spot.

\subsection{John shot Mike dead.}

b. Intentional Intervener scenario: John wants to revenge his family's death at the hands of Mike. He shoots Mike but barely grazes his shoulder. However, the shock of being shot gives Mike a heart attack and he dies on the spot.

\subsection{John shot Mike dead.}


c. Temporal delay scenario: John wants to revenge his family's death at the hands of Mike. He aims, shoots, and hits Mike, and Mike dies a few days later in the hospital from his internal injuries.

\subsection{John shot Mike dead.}

In contrast to previous analyses, the results of the present study allow a ranking of temporal distance and intervening causers in terms of the degree of indirectness they introduce. Taking another look at shoot dead, we see that the resultative is less acceptable when Mike dies of a heart attack induced by being shot (120b) than when his gunshot wound causes him to die within a few days (120c). While both factors render a causative scenario indirect enough to be significantly less compatible with a resultative, a temporal delay is still significantly more acceptable than an intervening cause $(\mathrm{r})(p<0.0001)$.

The results do not support hypothesis (3) based on Wolff (2003). Resultatives in the IntInv condition are rated significantly less acceptable than in both the Direct and Temp conditions (each at $p<0.0001$ ). Construing an intermediate entity as an enabling condition for bringing about the result state is thus insufficient to license a resultative. That is not to say that the causer's intentionality is irrelevant. In fact, resultatives are rated significantly higher in the IntInv condition than when the result is unintentional (Inv), but this effect is much weaker than the others noted so far at $p=0.024$. The scenarios in (121) illustrate the difference: In both the (a) and (b) scenarios, an intervening causer (a towel and a pair of jeans) turns the blouse blue, but the resultative is more acceptable when Mary intends for the intervener to dye the blouse. The results thus also provide evidence for Bittner's (1999) claim that resultatives are governed by stricter directness conditions than lexical causatives. 
(121) a. Intentional Intervener scenario: Mary wants to dye a delicate blouse of hers. She's afaraid the dye is too strong for the fabric, so she puts an old towel in blue dye, takes it out and wraps the blouse in it. The blouse takes on the blue dye from the towel.

\subsection{Mary dyed the blouse blue.}

b. Intervener scenario: Mary has just taken her old jeans from a bucket with blue dye. Carelessly she throws them on a chair to dry. She doesn't realize that there's a white blouse lying on the chair already. The blouse absorbs the blue dye from the jeans.

\subsection{Mary dyed the blouse blue.}

Lastly, no evidence in support of hypothesis (4) was found. All intervening causers in the IntInv and Inv conditions were in physical contact with the unexpressed verbal object at the onset of the change of state event, ${ }^{83}$ yet resultatives in both conditions were rated significantly less acceptable than in the Direct and Temp conditions.

It should be noted that the reduced acceptability of resultatives in any of the indirect conditions is not due to lack of a causal connection between the ultimate causer and the result state. As Table 18 shows, participants were quite willing to describe all causative scenarios with a periphrastic causative. Acceptability ratings for cause and make causatives did not differ significantly based on causative scenario, and general causatives received significantly higher acceptability ratings than resultatives in all indirect scenarios (each at $p<0.0001) .{ }^{84}$

\footnotetext{
${ }^{83}$ In two cases, the causee was undergoing an intervening event rather than contacting an intermediate causer. One causee fell off a roof and another suffered a heart attack.

${ }^{84}$ In the Direct condition, resultatives were significantly more acceptable than periphrastic causatives $(\mathrm{p}<0.0001)$. Judging from participants' comments, the different sentence types were not evaluated independently as encouraged by the task instructions, but some participants compared resultatives and periphrastic causatives. Since both truthfully describe a direct causation scenario, participants preferred the more informative resultatives over the less specific make and cause forms.
} 
Table 18

Means and Standard Deviations for Acceptability Ratings of General Causatives in Direct and Indirect Causation Scenarios

\begin{tabular}{lll}
\hline & \multicolumn{2}{c}{ Acceptability rating } \\
\cline { 2 - 3 } Causative scenario & $M$ & $S D$ \\
\hline Direct & 3.96 & 0.82 \\
Temp & 4 & 0.94 \\
IntInv & 4.06 & 0.95 \\
Inv & 4.01 & 0.97 \\
\hline
\end{tabular}

\subsubsection{Discussion}

Before drawing any general conclusions about the findings of Experiment I, it is worth taking a look at potential problems arising from the construction of the stimuli. During data coding and analysis, the following concerns about particular resultatives and causative scenarios used in this experiment arose.

The Direct and Temp scenarios for knock dead did not have an explicitly intentional causer, potentially reducing the acceptability of the resultative in these conditions. Running the model over all Direct and Temp scenarios with knock dead as a fixed effect (treating all observations for knock dead as 1 and all others as 0 ) revealed no significant differences; acceptability ratings for this item did not differ from those for other items that did feature an intentional causer.

In the IntInv scenarios for knock dead and shoot dead the causer wished to kill the causee but did not intend to use the intervening causes, a heart attack and a fatal fall, for this purpose. In fact, these two intermediate events are difficult to conceptualize as tools 
in any case, since their occurrence cannot be controlled by either causer or causee. I reran the model over all IntInv scenarios treating intentional tool use as a fixed effect (knock dead and shoot dead versus all remaining resultatives with intentionally used tools) effect revealed no significant differences in acceptability ratings. This suggests that the desire for a particular outcome may be a sufficient criterion for intentionality, at least if the outcome is as profoundly negative and final as death. ${ }^{85}$

One type of intervening causer in the IntInv and Inv conditions was a multipurpose tool that performed a variety of tasks such as painting, sanding, and hammering and could be activated by the causer's hand movements. In the IntInv condition, the causers gestured the causing activity while actually performing it in Inv scenarios. Someone would stand in front of the machine and for example gesture hammering, with the intention of having the machine hammer a spoon flat. In the corresponding Inv scenario, the causer would hammer a nail into the ground, and the machine would pick up on their hand motions and start hammering on whichever object was currently placed inside it (a spoon). The question thus arose whether IntInv scenarios received lower acceptability ratings overall because the causer was not actually performing the causing activity but simply gesturing it. Running the model with gesture as a fixed effect revealed no significant differences between IntInv scenarios with a gesturing versus an 'acting' causer.

In the Temp condition, isolating the effect of temporal distance between the end of the causing action and the completion of the change of state was complicated by the fact that most such temporal delays are enabled by an intervening cause(r) that sets off the change of state. For Experiment I, the time delay was highlighted in the description of

\footnotetext{
${ }^{85}$ Fillmore (1978) notes the importance of intent for a particular outcome in the realm of legal language. For a crime to be considered murder it is sufficient that the perpetrator had the malicious intention to kill, even if he ended up killing a by-stander instead of his target.
} 
the causative situation, while the importance of intervening cause(r)s was minimized in that they were properties of the causee or a non-salient instrument or process. Several causees, for example, were presented as having an unusual molecular structure that is slow to break down, such as rough wood or a type of metal that would flatten out over the course of an hour. Internal injuries resulting from a gunshot wound may serve as an example of a non-salient causee. Participants' comments revealed that such intervening cause(r)s were noticed by more than one participant in six out of the 12 Temp scenarios. ${ }^{86}$ Running the model with intervening cause(r) as fixed effect over all Temp scenarios revealed no significant differences in acceptability ratings. The effect of a temporal delay also robustly persists when re-running the model over all conditions using only the six resultatives without an intervening cause( $\mathrm{r})$ in the Temp condition $(p<0.0001)$.

As mentioned in section 6.2.1.2, the intervening cause(r)s in two IntInv scenarios (kiss awake and spray clean) were human and thus more difficult to conceptualize as enabling conditions. Despite efforts to minimize their control over the causative situation, one participant commented that the presence of a "second intelligent actor" rendered the respective resultatives unacceptable. The model was run first with kiss awake and then spray clean as a fixed effect, showing that spray clean received significantly lower acceptability ratings than the other resultatives $(p=0.048)$. To eliminate interference of a volitional intervening causer, both spray clean and kiss awake were removed from the dataset and the model was re-run on the remaining ten resultatives. The results are presented in Table 19.

\footnotetext{
86 The intervening cause(r)s in Temp scenarios were sandpaper (sand smooth), dye (dye blue), disinfectant (spray clean), the causee itself (kiss awake, kick open), and internal injuries (shoot dead).
} 
Table 19

Means and Standard Deviations for Acceptability Ratings of English Resultatives in Direct and Indirect Causation Scenarios (without spray clean and kiss awake)

\begin{tabular}{lcc} 
& \multicolumn{2}{c}{ Acceptability rating } \\
\cline { 2 - 3 } Causative scenario & $M$ & $S D$ \\
\hline Direct & 4.88 & 0.39 \\
Temp & 3.39 & 1.32 \\
IntInv & 3.02 & 1.46 \\
Inv & 2.57 & 1.39 \\
\hline
\end{tabular}

While IntInv exhibits the biggest increase in acceptability ratings (from 2.76 to 3.02), the original analysis does not change. Resultatives are significantly more acceptable in direct causation than in any other condition (each at $p<0.0001$ ), and a temporal delay is significantly more acceptable than an (un)intentional intervening cause(r) (Temp vs. Inv at $p<0.0001$, Temp vs. IntInv at $p=0.029$ ). The effect of construing the intervening cause $(\mathrm{r})$ as an enabling condition is stronger $(p=0.008)$ than in the original model $(p=0.024)$, however, while the difference between Temp and IntInv loses power. Assuming a stricter alpha level as is warranted by the high number of observations $(n=543)$, Temp and IntInv do not differ from each other but both receive significantly higher ratings than Inv.

Having addressed potential concerns of stimulus construction, I now turn to a more general discussion of the results. Experiment I confirms empirically that English resultatives are sensitive to directness of causation and only felicitously describe causative situations in which a causer brings about a change of state without temporal delay or intermediate causing entities. Further, the results show that each of these two 
factors independently decreases the acceptability of a resultative, and that intervening cause(r)s do so more than temporal distance. Based on these results I argue that we can distinguish at least two degrees of indirectness, as illustrated in (see Figure 6). We have seen no evidence that intentionality, which has been discussed as a directness factor in its own right, reduces the acceptability of a resultative independently. Recall that knock dead lacked an explicitly intentional causer in the Direct scenario, allowing us to isolate the effect of intentionality on acceptability ratings. The lack of a significant difference in acceptability ratings for knock dead versus all other resultatives aligns with native speakers' intuitions that it does not matter whether or not someone intends to wipe a spoon clean or hammer a spoon flat - the resultative is acceptable as long as the causer wiped or hammered on the spoon directly and without delay in the resulting state. However, an intentional causer can 'bump' the degree of indirectness by one level, since resultatives in scenarios with a temporal delay receive comparable ratings to those with an intentionally used intervening tool.

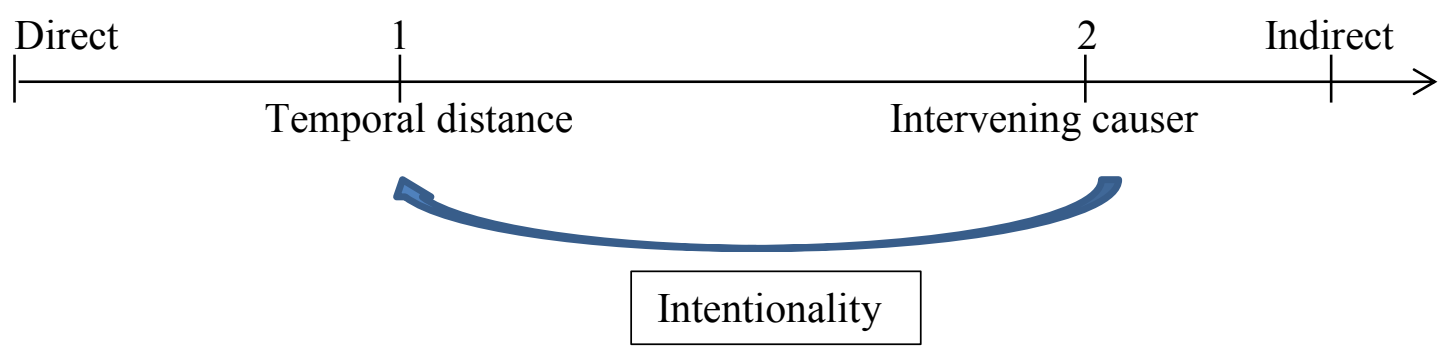

Figure 6: Degrees of indirectness for English resultatives

The construal of (in)directness as a set of significantly different degrees makes predictions which go beyond the scope of this dissertation but invite further testing. On the one hand, it predicts that an intentional causer can bump a temporal distance scenario 
down to degree zero on the indirectness scale. It further predicts that there may be additional degrees of remoteness which may either feature yet another directness factor or a combination of temporal distance and an intervening causer.

Now that we have a better understanding of which factors make up (in)directness in English resultatives, let us turn to ASL.

\subsection{EXPERIMENT II: DIRECTNESS OF CAUSATION IN ASL RESULTATIVES}

As demonstrated in section 5.3.4.1, ASL has a resultative construction that licenses selected (122a) and, potentially, non-selected objects (122b). The fact that ASL resultatives allow subject pronoun copies (122a) and rightward wh-movement across the result phrase (122b) provides evidence that they constitute single-clause causatives.

a. $\mathrm{y} / \mathrm{n}$

IX-addr SAND+ TABLE SMOOTH IX-addr

'Did you sand the table smooth?'

b. wh

$t_{\mathrm{i}}$ EAT IX-rt FRIDGE-rt NO.TRACE.LEFT-rt $\mathrm{WHO}_{\mathrm{i}}$

'Who ate the fridge empty?'

Given that typological studies point to cross-linguistic similarities in directness of causation constraints, we may expect to find such constraints at work in ASL as well. Resultative serial verb constructions in Lao and Ewe, for example, require unmediated contact between causer and causee at the onset of the change-of-state event. Just as in English, an intervening causer that serves as an instrument does not affect the 
acceptability of a resultative, while mediation by a human intervening causer renders the construction unacceptable (Bohnemeyer et al. 2011).

Experiment II tested whether the predictions of hypotheses (1) - (3) also hold of ASL resultatives in direct versus indirect causation scenarios. Since no evidence for hypothesis (4) was found in Experiment I, the hypothesis was not tested for ASL. Indirectness was defined as either temporal delay between the end of the causing event and the completion of the change of state (hypothesis 1) or the presence of an intervening cause(r) that cannot be construed as enabling the causer to bring about the result state (hypotheses 2 and 3). Participants watched different causative scenarios in ASL and evaluated how appropriate a given resultative would be for describing what happened in the scenario. To establish whether participants perceived a causal chain between causer and ultimate result at all, they were also asked how appropriate a periphrastic causative would be in a given scenario. In addition, participants judged the acceptability of juxtaposed causing and change-of-state clauses in direct and indirect scenarios to check whether directness is a property of the resultative construction or rather an effect of iconic interpretations of adjacent cause and result phrases.

\subsubsection{Method}

\subsubsection{Participants}

Twenty-five native and near-native ASL signers completed an online survey about directness of causation in ASL. They ranged in age from 18-64 (mean age 32); all use ASL on a daily basis and hold at least a high school diploma. Nineteen respondents were born to deaf parents and exposed to ASL from birth, while the remaining six 
participants had hearing parents and were first exposed to ASL between ages two and five.

\subsubsection{Materials}

Twelve resultatives were tested in four causative situations each. The causative situations were constructed according to the criteria outlined in section 6.2.1.2; a description of all the scenarios used can be found in Appendix F. The 12 ASL resultatives tested in Experiment II are listed in Table 20 below. Result predicates were chosen from the set of lexemes used in the grammaticality judgment study in chapter three (except BLUE), since their semantics and distributional behavior had been examined in the course of that study. Given the limited number of available result predicates, five of them occur twice in the stimuli, each time with a different causing verb.

Table 20 Twelve Resultative Constructions Tested for Directness of Causation

\begin{tabular}{|l|l|}
\hline 1. JOHN CL-S/1:kick OPEN-door & 2. JOHN CL-S/1:punch OPEN-door \\
\hline 3. MARY KISS JOHN AWAKE & 4. JOHN SHAKE MARY AWAKE \\
\hline 5. MARY JUMP EARRING FLAT(L) & 6. MARY HAMMER SPOON FLAT(B) \\
\hline 7. JOHN PAINT+ TABLE SHINY & 8. MARY POLISH SHOE SHINY \\
\hline 9. JOHN SHOOT MIKE DEAD & 10. MIKE BEAT+ JOHN DEAD \\
\hline 11. MARY SAND+ TABLE SMOOTH & 12. MARY DYE BLOUSE/CURTAIN BLUE \\
\hline
\end{tabular}

All causers are human and all but two causees are inanimate objects. Again, the influence of control or volitionality on the part of the causee was minimized by depicting the two human(-oid) causees as having limited control: One is a toddler and the other a 
spellbound genie. Since it was shown in section 5.3.4.2 that no systematic combinatory restrictions hold on cause and result predicate in ASL resultatives, the 12 lexicalizations below are not controlled for homomorphy requirements.

Lastly, a note on the choice of manner of causation verbs in Experiment II is in order. ASL has a large number of manner verbs that allow subtle distinctions in how an action is performed (e.g. which body part is involved, which type of object is affected). While English punch can describe such different actions as using one's fist in boxing and pressing buttons on a keypad, ASL uses different lexemes for these activities. Consequently, a resultative like PUNCH OPEN-door cannot be tested in a direct scenario where someone punches a door with their fist and an indirect scenario where someone punches digits into a keypad to program a door to open. The semantic specificity of ASL manner verbs thus influenced both the choice of causing verbs and the type of conditions in which they were presented.

In addition to a resultative (123a), participants were presented with two additional constructions per causative scenario. One was a wh-cleft construction that served as a periphrastic causative (123b), ${ }^{87}$ and the other consisted of two juxtaposed clauses separated by a pause and hand lowering (123c).

a. MARY KISS JOHN AWAKE

'Mary kissed John awake.'

${ }^{87}$ As demonstrated in section 2.4.4, the wh-cleft has periphrastic causative uses in ASL (Wilbur 1996). It was chosen in this study over the causative verb CAUSE due to concerns that native signers consider CAUSE "English-y" and that it further carries similar negative sentiment to its English counterpart. To maintain comparability to English cause and its underspecification for manner of causation, the wh-clefts used in this study ended in the general action verb DID rather than a more specific manner verb. 
br

b. JOHN AWAKE WHY, MARY DID

'It was kiss John awake that Mary did.'

c. MARY KISS. JOHN AWAKE.

'Mary kissed. John woke up.'

The purpose of the general causative was to check whether participants perceive a causal connection between the ultimate causer and the change of state even in indirect causation scenarios. The juxtaposition of clauses is introduced to check whether it is the syntactic structure of the resultative that imposes directness requirements or a different mechanism. It is possible that the simple sequencing of cause and effect phrases triggers a directness implication: Adjacent cause and result phrases may be interpreted iconically as temporally adjacent subevents. Support for a syntactically induced directness requirement would be substantially weakened if juxtaposed and resultative constructions were equally unacceptable in indirect causation scenarios.

\subsubsection{Procedure}

The data for the present study were generated using Qualtrics software, Copyright (C)2017 Qualtrics. An online survey containing all 48 trials (four conditions x 12 resultatives or lexicalizations) was constructed such that the trials were distributed evenly across two sub-surveys and survey respondents were randomly assigned to one of the two sub-surveys. Thirteen participants took one survey, 12 took the other. The within-subjects design ensures that each respondent sees all lexicalizations and provides six judgments per condition. Since participants saw each resultative in two conditions, measures were 
taken to minimize priming effects from one causative scenario to the other. On the one hand, the order of trial presentation in each sub-survey was randomized for each respondent, and on the other, the combination of conditions for each resultative was varied systematically (e.g. sub-survey A presented KICK OPEN.DOOR in Default and IntInv, but PUNCH OPEN.DOOR in Intervener and Temporal).

Before starting the survey, all respondents gave their consent, filled out a brief language background questionnaire, and watched a five-minute instructional video explaining the task in ASL. They then clicked their way through 24 trials, an example of which is provided in Figure 7. Each trial began with a short ASL video presenting a causative scenario followed by a question asking how appropriate the subsequent sentences were for describing what happened in the scenario. Below the question, participants saw a resultative, a periphrastic causative, and juxtaposed clauses. They rated the acceptability of each construction on a five-point Likert scale from "Not appropriate at all" to "Very appropriate". ${ }^{88}$ Lastly, participants were encouraged to comment on the (in)appropriateness of any particular sentence in the comment box at the bottom of each trial. The term "appropriate" was defined in the instructions in terms of whether the target sentences match the story and was illustrated with an example. ${ }^{89}$ Survey respondents

\footnotetext{
88 The choice of a fully-labeled Likert scale over one using symbols or numbers is motivated by the need to clarify the meaning of the response categories. Furthermore, fully-labeled scales have a higher test-retest reliability than endpoint-labeled ones (Weng 2004).

${ }^{89}$ Appropriateness is exemplified in terms of lexical relations rather than causal links in order not to bias participants towards a particular understanding of directness of causation. The instructions provide the following example:
}

(ix) Context: John and Mary are taking a walk when they see a wolf hunting a squirrel. The races up a tree and so, after a while, the wolf gives up and leaves. Mary and John little while and then head home. 
were reminded not to rank the target sentences with respect to each other directly, but were told that all or none of the sentences may be appropriate..$^{90}$ After completing the survey, participants were compensated for their time via Amazon giftcards.

'John and Mary are walking along and the see an animal chasing a squirrel.'

3. JOHN MARY FINISH SEE WOLF CHASE SQUIRREL

'John and Mary saw a wolf chasing a squirrel.'

Survey respondents are told that the first sentence is NOT APPROPRIATE, as Mary and John saw a wolf rather than a dog, while the second sentence is SORT-OF APPROPRIATE, since it is true but could be more informative. The third sentence is characterized as APPROPRIATE.

${ }^{90}$ Importantly, participants are encouraged to follow their own intuitions in their acceptability judgments and are reminded that there is no right or wrong answer. 


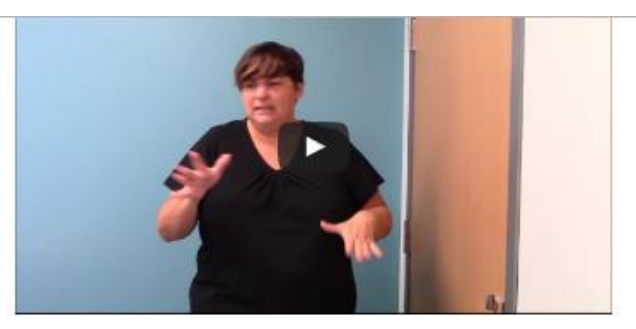

How appropriate is each of the following sentences for describing what happened?

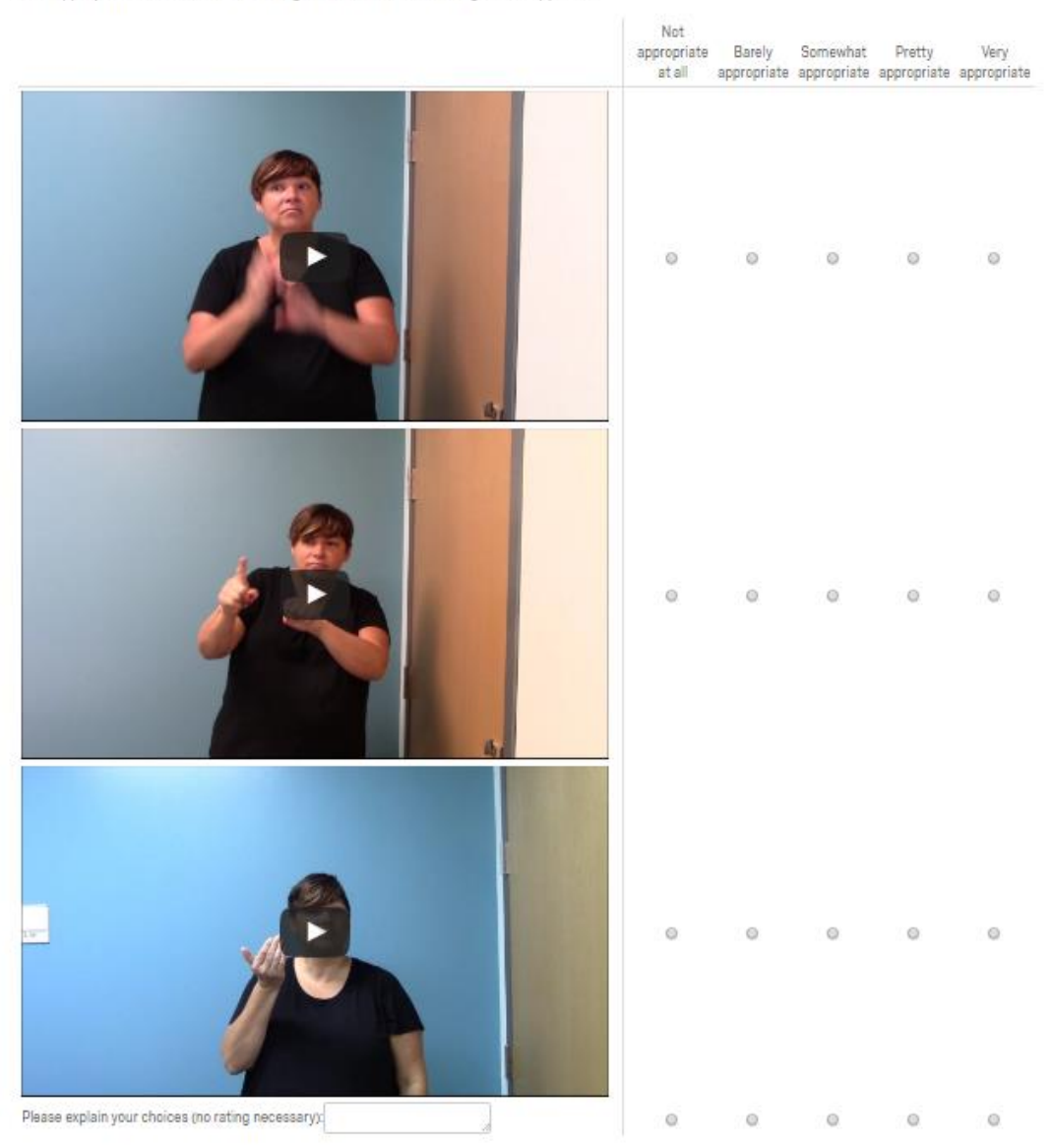

Figure 7: Example of a trial. The video at the top describes a causative situation in ASL, while the three videos below feature the different sentence types (resultative, causative, juxtaposition).

\subsubsection{Design and statistical analysis}

As in Experiment I, causative scenario and sentence type were run within participants. A linear mixed effects model was fit to the data using $\mathrm{R}$ ( $\mathrm{R}$ Core Team 
2016) and lme4 (Bates et al. 2012). First, causative scenario was run as a fixed effect with random effects for item and participant, then sentence type was added as a fixed effect, as well as their interaction term. Contrasts were decomposed using the Tukey adjustment method to control the Type I error rate in pairwise comparisons. Visual inspection of residual plots did not reveal deviations from normality.

\subsubsection{Results}

The means and standard deviations of the acceptability ratings for ASL resultatives in each type of causative scenario are reported in Table 21 . While the raw means for resultatives in the Direct and IntInv conditions are substantially lower than their English counterparts, the results provide evidence that ASL resultatives are also restricted to direct causation. ${ }^{91}$ Resultatives received significantly higher acceptability ratings in the Direct condition than in any of the other scenarios (each contrast is significant at $p<0.0001)$.

\footnotetext{
91 The raw means for all ASL sentences (resultatives, general causatives, and juxtaposed clauses) were below a 4 acceptability rating, raising the question whether signers considered the stimuli somewhat unnatural ASL. The language model was a deaf native signer of ASL with deaf parents and siblings, while participants commented on a few perceived phonological and grammatical errors in the stimuli, others explicitly stated that the resultatives were grammatical. The source of the overall lower acceptability ratings for ASL sentences seems to be the information gap between the original causative scenario and the onesentence summaries, be they resultatives or general causatives. Signers commented that even in Direct situations, the summary sentences left out too many details or were too simplified. Since the practice scenario provided in the instructions (shown in footnote 89) also features summary sentences that leave out subevents of the scenario (the squirrel racing up a tree, John and Mary taking a walk or walking home), the signers' dislike of the summary resultatives and general causatives may reflect a cultural or pragmatic preference in Deaf communities to make an utterance as informative as possible.
} 
Table 21

Means and Standard Deviations for Acceptability Ratings of ASL Resultatives in Direct and Indirect Causation Scenarios

\begin{tabular}{lcc}
\hline & \multicolumn{2}{c}{ Acceptability rating } \\
\cline { 2 - 3 } Causative scenario & $M$ & $S D$ \\
\hline Direct & 3.76 & 1.16 \\
Temp & 3.1 & 1.26 \\
Intentional Intervener & 2.48 & 1.37 \\
(IntInv) & & \\
Intervener (Inv) & 2.51 & 1.46 \\
\hline
\end{tabular}

Like their English counterparts, ASL resultatives are incompatible with either a temporal delay between causing and result subevents or an intervening cause(r), supporting that hypotheses (1) and (2) hold in ASL. The scenarios in (124) show that, for example, JOHN PUNCH OPEN.DOOR 'John punched the door open' is less acceptable if the door opens hours after John punched it (b) than if it opens immediately (a). The resultative is still less acceptable if John punched an intervening entity such as a punching bag to open the door (c).

(124) a. Direct scenario: John is a boxer. He's trying to enter his house, but the front door is stuck, so he punches it with his fist, and the door opens.

\subsection{JOHN PUNCH OPEN.DOOR}

'John punched the door open.'

b. Temporal delay scenario: John wants to program his door to open automatically at $6 \mathrm{pm}$, so his cleaner can get in. He likes funny gimmicks/mechanisms, so he bought a door that you can only program to open at a particular time if you 
punch it hard. John punches to set the opening mechanism for $6 \mathrm{pm}$ and when his cleaner gets there a little after $6 \mathrm{pm}$, the door is open.

\subsection{JOHN PUNCH OPEN.DOOR}

c. Intentional intervener scenario: John is a boxer. When someone rings his doorbell, he is training and too lazy to get the door. So he punches his punching bag in the direction of the door, it hits the door and the door opens.

\subsection{JOHN PUNCH OPEN.DOOR}

In fact, two levels of indirectness can be distinguished in ASL as well. Overall, resultatives in Temp scenarios receive significantly higher acceptability ratings than those with an intervening cause(r), whether this intermediate cause(r) is used as a tool $(p<0.0001)$ or not $(p=0.0001)$.

Lastly, the results provide no support for an attenuating effect of intentionality on the degree of indirectness of an intervening cause(r) (contra hypothesis (3)). As a visual inspection of the means shows, acceptability ratings for IntInv and Inv scenarios are almost identical. In contrast to English, the acceptability of an ASL resultative description does not increase when an intervening entity in the causal chain serves as a tool used by the causer to bring about the result state.

In addition to resultatives, periphrastic causatives were also tested for acceptability in the same direct and indirect causative scenarios. Mean acceptability ratings and standard deviations are reported in Table 22. 
Table 22

Means and Standard Deviations for Acceptability Ratings of ASL Periphrastic Causatives in Direct and Indirect Causation Scenarios

\begin{tabular}{lcc} 
& \multicolumn{2}{c}{ Acceptability rating } \\
\cline { 2 - 3 } Causative scenario & $M$ & $S D$ \\
\hline Direct & 2.69 & 1.41 \\
Temp & 2.63 & 1.36 \\
IntInv & 2.25 & 1.24 \\
Inv & 2.3 & 1.25 \\
\hline
\end{tabular}

In contrast to their English counterparts, periphrastic causatives in ASL were perceived as less acceptable descriptions of both direct and indirect causation. Looking at participant comments revealed that ASL users rejected the construction not because they did not perceive a causal chain between causer and result state but because it lacked detailed information about the event. Specifically, they commented that periphrastic causatives were "incomplete" and omitted information about the manner of causation. ${ }^{92}$

Periphrastic causatives thus cannot help to exclude the possibility that indirect scenarios were perceived as non-causal. However, they do show that not all causative constructions in ASL are sensitive to directness constraints but that this seems to be a property of the resultative construction only. As a visual inspection of Table 22 shows, periphrastic causatives receive similar acceptability ratings in each condition. Only in the IntInv condition do they receive significantly lower values than in the Direct condition,

\footnotetext{
92 English speakers also commented that make and cause causatives were "vague" and unspecific, but this affected their acceptability ratings only when a more appropriate construction (the resultative) was available, namely in Direct scenarios.
} 
and the effect is rather small $(p=0.02)$ when compared to effect sizes among resultatives (typically $p<0.0001$ ).

Juxtaposition of cause and change of state sentences did not form an acceptable construction for most participants. As Table 23 below illustrates, juxtaposed clauses received low ratings across causation scenarios, and participants' comments reveal that prosodic well-formedness rather than acceptability was the culprit. ${ }^{93}$ Signers considered a pause with hand-lowering between the two juxtaposed sentences "confusing", "choppy", and "breaking up the story/explanation".

Table 23

Means and Standard Deviations for Acceptability Ratings of Juxtaposed Cause and Result Clauses in Direct and Indirect Causation Scenarios

Acceptability rating

\begin{tabular}{llcc} 
Sentence type & Causative scenario & $M$ & $S D$ \\
\hline Juxtaposition & Direct & 2.77 & 1.26 \\
& IntInv & 2.01 & 1.15 \\
& Temp & 2.57 & 1.28 \\
& Inv & 2.18 & 1.22 \\
\hline
\end{tabular}

At this point, the results thus do not allow any conclusions as to whether directness is triggered by an iconic mapping of clause order onto event sequentiality or by

\footnotetext{
${ }^{93}$ Syntactic well-formedness does not seem to be an issue. One might hypothesize that constraints against a cataphoric pro-form such as in MARY KISS pro $_{\mathrm{i}}$. JOHN $\mathrm{JHWAKE}_{\mathrm{i}}$ 'Mary kissed and John woke up.' result in lower ratings. However, in that case juxtaposition should be worse in Direct and Temp scenarios, where the subject of the second clause is co-referential with the object of the first clause. As Table 8 shows, juxtaposition is more acceptable in those scenarios than in IntInv and Inv, where there is no coreferentiality between the two clauses but the object of the first clause is the intervening causer.
} 
the resultative construction itself. It is interesting to note that, despite lowered overall acceptability ratings, juxtaposed clauses exhibit a similar sensitivity to directness as resultatives: They are rated higher in the Direct condition than in IntInv $(p<0.0001)$ and Inv $(p=0.0002)$. Temporal delay scenarios, however, are as acceptable as Direct ones $(p=0.647)$, probably because some (but not all) signers interpret the pause as showing the passage of time between causing and change of state event. It is unclear whether the

remaining participants ignore the "weird pause" and interpret the construction as a resultative, thus accounting for similar directness effects in resultatives and juxtaposed clauses. Consequently, further research is necessary to determine the role of iconicity in triggering a directness requirement in ASL resultatives.

\subsubsection{Discussion}

Before drawing any general conclusions about the findings of Experiment II, a discussion of potential concerns regarding stimulus construction is in order. During data coding and analysis, the following concerns about particular resultatives and causative scenarios used in this experiment arose.

In the IntInv scenarios for SHOOT DEAD the causer wished to bring about the death of the causee but did not intend to use the intervening cause, a heart attack, for this purpose. As discussed in section 6.2.2.1, this intervening event cannot be conceptualized easily as a tool, since its occurrence cannot be controlled by either causer or causee. Running the model with SHOOT DEAD as a fixed effect across all IntInv scenarios revealed no significant differences in acceptability ratings. This provides further support for a more nuanced definition of intentionality as it pertains to directness: The desire for a 
particular (negative) outcome sufficiently establishes intentionality; the causer does not need to also want to use the intervening entity to bring about said outcome.

One type of intervening causer in the IntInv and Inv conditions was a multipurpose tool that performed a variety of tasks such as painting, sanding, and hammering and could be activated by the causer's hand movements. In the IntInv condition, the causers gestured the causing activity while actually performing it in Inv scenarios. The question thus arose whether IntInv scenarios received lower acceptability ratings overall because the causer was not actually performing the causing activity but simply gesturing it. Running the model with gesture as a fixed effect over all IntInv scenarios revealed no significant differences between scenarios with a gesturing versus an 'acting' causer.

In the Temp condition, isolating the effect of temporal distance between the end of the causing action and the completion of the change of state was complicated by the fact that most such temporal delays are enabled by an intervening cause(r) that sets off the change of state. For Experiment I, the time delay was highlighted in the description of the causative situation, while the importance of intervening cause(r)s was minimized in that they were properties of the causee or a non-salient instrument or process. In contrast to English, none of the ASL signers in Experiment II commented on the presence of such intervening cause(r)s in any of the 12 Temp scenarios. Nonetheless, I re-ran the model on all Temp scenarios treating intervening cause(r) as a fixed effect and conservatively assuming the presence of an intervening cause(r) in scenarios where it had been noticed by participants in Experiment I. ${ }^{94}$ The results show no significant differences in

\footnotetext{
${ }^{94}$ Specifically, I treated only the following scenarios as having "no intervener": Scenarios in which English speakers did not perceive an intervening cause( $\mathrm{r}$ ) and those with an intervening entity that occurs in both Direct and Temp conditions (e.g. HAMMER FLAT and SAND SMOOTH, where the causer uses a hammer or sand paper in all conditions). I excluded POLISH SHINY since it behaved like an outlier in being the only item to receive substantially higher GJ ratings in the Temp than the Direct condition. The resulting "no intervener" items were: HAMMER FLAT, JUMP FLAT, PAINT SHINY, DYE BLUE, and SAND SMOOTH.
} 
acceptability ratings between Temp scenarios with a perceived intervening cause(r) and those without one. The effect of a temporal delay also persists as a strong trend $(p=0.067)$ when re-running the model over all conditions using only the five resultatives without an intervening cause(r) in the Temp condition.

Lastly, the [+ human(oid)] feature of the intervening causer in KISS AWAKE (a toddler) and POLISH SHINY (a genie) may have significantly reduced the availability of a 'tool' construal for these intervening causers. I thus re-ran the model over all IntInv scenarios treating first KISS AWAKE and then POLISH SHINY as fixed effects, but neither of them turned out to be significant. To eliminate any possibility of interference of a volitional causer, I removed KISS AWAKE and POLISH SHINY from the data set and ran causative scenario as a fixed effect over the remaining ten resultatives. The mean for the IntInv condition increases slightly from 2.48 to 2.58 , but resultatives are still significantly more acceptable in Direct $(p<0.0001)$ and Temp conditions $(p=0.011)$. There is still no noticeable effect of construing the intervening causer as a tool, since resultatives receive similar ratings in IntInv than in Inv scenarios, and both are significantly lower-rated than resultatives in Temp scenarios.

Having addressed potential problems in stimulus construction, I now turn to a general discussion of the results. Experiment II has shown that the resultative construction in ASL is sensitive to the semantic construct 'directness of causation'. It has also shown that this sensitivity is construction-specific, since it does not extend to periphrastic causatives. ASL resultatives confirm typological observations that singleclause causatives are restricted to expressing direct causation. ASL resultatives pattern with English resultatives in several ways. Both constructions are sensitive to a temporal delay between the end of the causing event and the completion of the change of state (in line with hypothesis (1)), as well as to the presence of an intervening cause(r) (hypothesis 
(2)). Further, both ASL and English differentiate degrees of indirectness such that resultatives are degraded in situations involving temporal distance between cause and effect but are completely unacceptable when an intermediate cause(r) intervenes in the causal chain. However, the construct of directness in ASL is not identical to its English counterpart. While the degree of indirectness introduced by an intervening causer in English is reduced if the ultimate causer intends to bring about the result (in line with hypothesis (3)), intentionality does not affect the acceptability of resultatives in ASL. This difference in directness of causation constraints is likely linguistic in nature, since Deaf and hearing cultures in the US exhibit sufficient overlap to rule out culture-specific differences in the conceptualization of causality between ASL and English speakers.

Further research is needed to establish whether the different degrees of directness introduced by temporal distance and intervening cause(r)s constitute a linguistic or cognitive universal. The fact that we find consistent differences between these directness factors in both ASL and English could well be due to linguistic and cultural contact between the two speech communities.

Future work should further compare lexical causatives and resultatives in ASL to see if their directness constraints are identical or if we can find support for Bittner's (1999) claim that resultatives are subject to stricter directness requirements than lexical causatives. In addition, it would be interesting to test whether ASL resultatives are sensitive to the manipulative vs. directive causation distinction. The two instances of directive causation in my data (IntInv scenarios for KISS AWAKE and POLISH SHINY) suggest that resultatives behave like morphological causatives in ASL and only express manipulative causation, but more rigorous experimental testing is necessary. Lastly, a better test needs to be devised to isolate the effect of iconicity on triggering a directness reading in ASL resultatives. 


\section{Chapter 7: Conclusion}

Sign languages are known to allow the encoding of a large amount of information about events within single, polymorphemic verbs. The ASL classifier construction in Figure 8 describes a walking event involving two participants - a man and his dog - and furthermore encodes information about the spatial position of the two participants with respect to each other, their different types of movement (walking upright vs. on four legs), and their movement paths (straight line vs. zig zag).

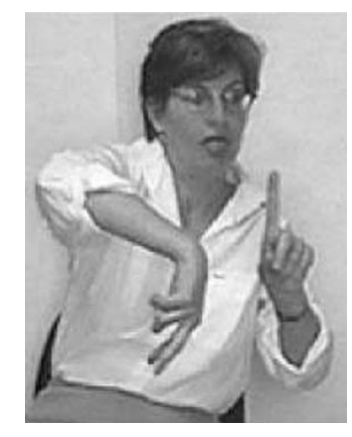

Figure 8 'A person walks dragging dog' from Aronoff et al. (2003:71)

In chapter five we saw that classifier constructions cannot freely encode any and all event components, but that phonotactic and/or grammatical constraints bar combinations of manner and result information within a single verbal root.

This dissertation has found no evidence that such constraints operate on the level of the clause in either DGS or ASL. To the contrary, both languages were shown to have monoclausal resultative constructions that express the manner by which someone caused a change of state as well as the ensuing result state. The present work has thus demonstrated that signed languages like DGS and ASL have not only lexical but also syntactic resources for packaging event-structural information densely. Over the last 
several decades, sign research has focused on the unique affordances of the visual-spatial modality for simultaneous packaging of grammatical and semantic information. Therefore a major contribution of this dissertation has been to highlight the potential of signed language for sequential event encoding on the clausal level.

DGS has two resultative constructions that differ in the order of causing and result predicates and exhibit different semantic restrictions. Evidence from fronting, intraposition of modal verbs, and the matrix object status of causees not selected by the verb suggests that both constructions contain a complex predicate rather than an infinitival small clause. The structural similarities extend further still: Both DGS resultative constructions allow activity and accomplishment verbs (e.g. HAMMER vs. CHARM) as primary predicates and license causers that are selected by both predicates or by the result predicate only (Control and ECM structures). In both constructions, result predicates cannot predicate directly of an underlying subject but require a reflexive marker to do so. Semantically, Control resultatives with [Result Verb] order differ from those with [Verb Result] order. Only the former exhibit a homomorphic event-to-scale mapping from durative events to gradable scales, as well as a preference for punctual events to be demarcated by result predicates that introduce a salient endpoint. In contrast, [Verb Result] constructions have no constraints on the combinability of causing verbs and result predicates.

ASL resultatives have S-V-O-Result word order and constitute single clauses according to the subject pronoun copy and rightward wh-movement diagnostics. Since causing and result predicates are discontinuous whenever an overt causee is present, there is no support for a complex predicate analysis in ASL. Rather the result predicate and its argument are assumed to form an infinitival clause. ASL resultatives resemble their DGS and English counterparts in allowing both activity and accomplishment verbs as primary 
predicates. ASL has Control resultatives and potentially ECM resultatives as well: Control resultatives exhibit a higher degree of syntactic integration than full $\mathrm{CP}$ embedding, since causing and result predicates share an argument. ECM resultatives lack this co-reference dependency and thus it is difficult to say whether they feature a full $\mathrm{CP}$ or an infinitival complement to the causing verb. Our current diagnostics are simply not sensitive enough to distinguish between finite and infinitival clauses, since rightward whmovement in ASL can cross both types of complements. Like their DGS [Verb Result] counterparts, Control resultatives do not impose restrictions on the combination of durative verbs and non-gradable or open-scale result predicates. The present work thus confirms Kentner's (2014) results and reveals a major semantic difference between English and ASL resultatives. However, chapter six showed that the two resultative constructions also share one component of their semantics. As the first empirical investigation of directness of causation in resultative constructions demonstrates, the acceptability of both ASL and English resultatives is sensitive to the degree of directness in the causative situation they describe. At least two independent degrees of (in)directness were identified in both languages: (1) a temporal delay between the end of the causing event and the completion of the resulting change of state and (2) the presence of an intervening cause(r). Despite these similarities, the factors that determine directness of causation are not identical in English and ASL. While the degree of indirectness introduced by an intervening cause(r) can be attenuated in English by the ultimate causer's intent to bring about the result state, ASL resultatives are not sensitive to the causer's intentions.

This dissertation has not only demonstrated empirically that DGS and ASL have resultatives, but that they differ in significant ways from parallel constructions in German and English. Both the S-O-Result-Verb resultative in DGS and the S-V-O-Result 
construction in ASL may be the products of language contact, but they diverge structurally and semantically from their German and English counterparts to a degree that does not support a mere code-switching analysis. As serializing languages, ASL (125a) and DGS (125c) permit change-of-state verbs as secondary predicates whereas English (125b) and German (125d) do not.

(125)

a. wh PUNCTURE TIRE FLAT(O) WHO

'Who flattened the tire by puncturing it?'

[English]

b. *Who punctured the tire flatten?

c. SUSI TRAMPOLINE CL-B:tear CAN.NOT

[DGS]

'Susi can't jump on the trampoline till it tears.'

d. *Susi kann das Trampolin nicht zerreißen springen.

[German] Susi can the trampoline not tear jump

Further, the sign resultatives differ in homomorphy constraints from their spokenlanguage counterparts. The S-O-Result-Verb construction in DGS exhibits a homomorphic mapping from durative events onto gradable scales associated with the result predicate, while German resultatives do not. Despite the gruesome imagery, it is perfectly acceptable to say Der Feind hat Superman totgeschlagen 'The enemy beat Superman dead' in German but not in DGS. The facts are reversed for ASL and English: As Wechsler (2005) and Beavers (2008) convincingly show, English resultatives are subject to homomorphic constraints whereas durative verbs in ASL resultatives can freely occur with open-scale and non-gradable result predicates. English and ASL further differ in their thresholds for indirect causation. While English resultatives are more acceptable 
when an entity intervening between causer and causee can be interpreted as an intentionally-used tool than when it cannot, the causer's intentions do not attenuate the degree of indirectness associated with an intervening causer in ASL.

In summary, resultatives in DGS and ASL differ from the corresponding constructions in German and English in selectional restrictions on the lexical category of the result predicate as well as in semantic restrictions on the combinability of causing and result predicates. Further, DGS has a second resultative whose [Verb Result] word order is not attested in German. We can thus conclude that despite superficial similarities, DGS and ASL resultatives differ sufficiently from their German and English counterparts to warrant treatment as independent constructions that are well-integrated into the grammars of DGS and ASL.

In chapter two, I briefly addressed the question of whether single-clause causeresult constructions in sign languages constitute serial verb constructions or resultatives proper. I concluded that without better part-of-speech diagnostics, it was impossible at this point to decide on the verbal versus adjectival status of the result predicate. While I maintain that we cannot know the part of speech of a state-denoting result predicate in a given Control resultative, we have seen evidence that at least DGS allows both verbal and adjectival secondary predicates. Like Kentner (2014), I elicited resultatives in both ASL and DGS with a secondary predicate that denotes a change of state, such as FLAT(O) 'flatten' or AWAKE 'wake up'. While these are clear cases of SVCs, the ECM constructions in DGS (and, if their monoclausal status can be confirmed, in ASL) are arguably not SVCs. In contrast to typical SVCs, the predicates in an ECM structure like The joggers ran their sneakers threadbare do not share any arguments (Foley \& Olsen 1985), suggesting that at least the ECM constructions in the sign languages under investigation are resultatives proper. It is not uncommon for a language to allow both 
resultative SVCs and AP resultatives; DGS here parallels other serializing languages like Èdó (Niger-Kongo, described in Stewart 1998).

The results presented in this work raise further questions in the domain of event structure, specifically concerning (a) the meaning of verb roots, (b) the encoding of telicity in resultatives, (c) argument realization, and (d) the nature of causal relations between events. I will address each of these concerns in turn.

Section 5.2 showed that classifier predicates in DGS and ASL tend not to encode manner of causation and change of state simultaneously. This gap in the meaning of verbal roots could confirm a cross-linguistic and cross-modal dispreference for manner + result encoding on the lexical level. However, for DGS and ASL classifiers to serve as evidence, one would first have to disentangle the potential effect of phonotactic constraints on such classifier predicates from a truly grammatical constraint. One way to take this investigation further would be to create manner + result classifier predicates that do not violate phonotactics and test whether they are accepted by native signers.

An open question raised by the present study is how telicity is encoded in DGS and ASL resultatives. Since durative verbs can be combined with open-scale predicates in both languages, it does not seem to be the upper-bounded scale associated with the result predicate that introduces telicity, as suggested in Wechsler (2005). Alternatively, one could hypothesize that open-scale predicates in DGS and ASL resultatives bear morphological telicity marking. Such an approach is in line with studies by Wilbur et al. (2012), who claim that open-scale adjectives in ASL can be coerced into a maximal endpoint reading by the addition of phonological "end-marking". If such marking could consistently be shown to characterize the result predicates in resultatives, we would not only have detected the source of telicity in these constructions but also provided additional empirical support for Wilbur's Event Visibility Hypothesis. Kentner's (2014) 
work on ASL resultatives suggests that open-scale adjectives like DIRTY can take endmarking in the resultative, but it is not clear whether this marking is obligatory and whether it simply denotes intensification or bounds the associated scale.

In future studies, I would further like to explore the expression of argumentsharing in Control resultatives. Lau (2012) noticed that shared arguments in HKSL resultative SVCs may be indicated via size-and-shape specifiers retained throughout the production of both predicates, or by shared locative agreement. In DGS and ASL resultatives, causing and result predicates sometimes agree in location with the causee, but agreement on the result predicate seems to be optional. I would like to explore which grammatical or discourse factors govern the overt expression of argument sharing. In the domain of argument realization, another topic for future research is the lack of subjectoriented resultatives in DGS. The exact nature and obligatoriness of reflexive marking on causing and result predicates needs further exploration, so that it can shed further light on hypotheses like Levin and Rappaport Hovav's Direct Object Restriction.

Lastly, the present work has significantly improved our understanding of the directness of causation construct. Not only have temporal distance and intervening cause(r)s been demonstrated to affect the degree of indirectness of a causative situation independently, but they were also empirically shown to influence it to a different degree. The striking similarities in directness constructs between English and ASL deserve further investigation. To establish whether they are the result of cultural and linguistic contact or the reflex of a cognitive universal, I plan to conduct similar experiments on DGS. I further hope to develop a diagnostic that clearly distinguishes between directness effects triggered by visual iconicity in sign languages and those imposed by the semantics of the resultative construction itself. 


\section{Appendices}

\section{APPENDIX A: VIDEO SEQUENCES FOR THE PILOT}

1. A woman picks up a plate with spaghetti sauce on it and licks over it several times. She then holds the plate up to the camera so we can see that it is clean.

2. We first see a picture of a woman holding a hammer. Next, we see someone hammering on a spoon until it is completely flat.

3. A woman holds a shoe brush, takes up a dull-looking blue shoes and polishes it for a while. The camera then zooms in to show the shiny shoe.

4. A baby is shown crying and kicking his legs. Over time, the baby's movements become less energetic, until he closes his eyes and is seen sleeping.

5. A woman is sleeping on a couch. A second woman walks in and shakes the sleeping woman (on the shoulder) until she wakes up.

6. Someone looking like Barack Obama walks off a stage and kicks a door open.

7. The Joker holds a crowbar and beats an injured Robin with it. In the last scene, Robin is seen lying on the ground, with the letters R.I.P. above him.

8. Teenage witch Sabrina is seen eating a vast amount of pancakes in a short period of time. In the last scene, the actress is shown in an enormous fatsuit.

9. A woman sits at a table, while another woman holds a spray bottle and sprays the sitting woman's hair with water from the bottle. The last scene zooms in on the woman's wet hair.

10. A man is shown emerging from a pool. He brushes water off his body, looks around him but cannot find a towel. Instead, he starts running laps around the pool and at the end of the last lap, puts on his dry T-shirt.

11. A man is sitting at a restaurant drinking a beer. Across from him sits a rather plain-looking woman. With each sip he takes, he sees her as more attractive.

12. A woman is sleeping on the couch, while another woman is sitting next to her reading. The woman who is reading has to sneeze, and the sleeping woman wakes up from the noise.

13. A rabbit is running up and down a field, sweating and working up a cloud of dust. As the dust settles, we see the exhausted rabbit fall over. The letters R.I.P. appear above him.

14. We zoom in on a woman's dirty feet. She then splashes her feet in the pool and at the end, her clean but wet feet are shown.

15. A cowboy draws his weapon and shoots his opponent, who falls down. The letters R.I.P. appear above him.

16. A concave earring is shown lying on the foot of a fleet of stairs. A woman walks down the stairs, jumps down the last step, and bends down to pick up the earring. We see that it is now flat rather than concave.

17. A princess is looking at herself in the mirror. A rat sorceress is seen approaching the princess while waving her hands performing a spell/curse. In the last seen, the princess' face is disfigured and green, and she has only 2 front teeth left. 
18. A bird flies above a man and empties its bowels. The bird's excrements land on the man's suit jacket. 


\section{APPENDIX B: PROMPTS FOR TRANSLATION TASKS INCLUDING CONTEXTS}

Instructions with example:

The following sentences describe the videos you saw at the beginning of today's interview. How would you express these sentences in ASL?

For every ASL sentence you produce, I will ask you to form two questions and one sentence with MUST at the end. Let me show you an example:

\section{Example:}

The man paints the wall red.

1. Does the man paint the wall red (he)?

2. Who paints the wall red?

3. The man must paint the wall red.

Analogous prompts were provided for the following target resultatives. Note that a topicalized form of intransitives was elicited using the prompts in brackets.

1. The woman licks the plate clean.

2. The woman hammers the spoon flat.

3. The woman polishes the shoes shiny.

4. The baby cries itself to sleep.(Cry themselves asleep, babies do that all the time)

5. Jenny shakes Sue awake.

6. Obama kicks the door open.

7. The Joker beats Robin to death.

8. Sabrina eats herself fat. (Eating themselves fat is what witches do)

9. The hairdresser sprays the client's hair wet.

10. The man runs himself dry. (Run himself dry, Bill often does (that))

11. Jenny sneezes her friend awake.

12. The rabbit runs himself to death. (Run themselves to death, rabbits quite often do (that)).

13. The woman splashes her feet clean.

14. Clint shoots his opponent dead.

15. The woman jumps the earring flat.

16. The witch hexes the princess ugly.

Additional scenes with context:

17. Context: Mary can't have children but really wants a daughter. She does have a fairy godmother, however. 
The fairy godmother hexes/charms Mary pregnant.

18. Context: Mia loves jumping on the trampoline and does so every day. One day, the surface is so worn that it breaks Mia's mom says:

Mia, you jumped the trampoline to pieces.

19. The carpenter sands the table top smooth.

20. Context: The son comes home from college and eats everything he can find in the fridge. The father comments (in worried tone):

He ate the fridge empty!

21. Context: The evil stepmother has emptied a bucket of water over Cinderella, so that she can't go to the ball in soaking wet clothes. Enter the fairy godmother.

The fairy godmother hexes/charms Cinderella's dress dry.

22. Context: A giant who has a cold is sitting at the table. Suddenly he has to sneeze, and everything on the table falls down.

The giant sneezed the table empty.

23. Context: Sue is sitting in a cold concert hall in winter. She has to use the restroom, and when she comes back, somebody else has taken her seat. She says:

Aww, and I had already sat that seat warm.

24. Context: The witch wants to fatten Hansel up but he keeps saying that he's not hungry.

The witch hexes Hansel hungry.

25. Context: Mike Powell is an athlete. In 1991, he broke the world record for broad jump by jumping $8.95 \mathrm{~m}$, which hasn't been topped yet. With this jump, he instantly became famous. You could say:

Mike jumped himself famous. (Jumping himself famous, only Mike can do) 
APPENDIX C: ILLUSTRATIONS OF SOME RESULT PREDICATES

ASL

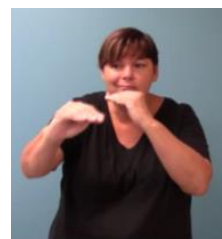

FLAT(B)

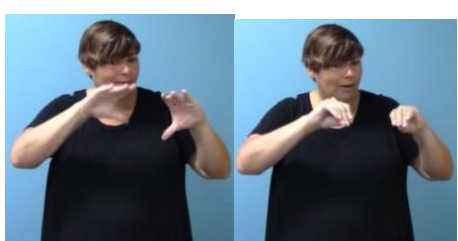

FLAT(O)

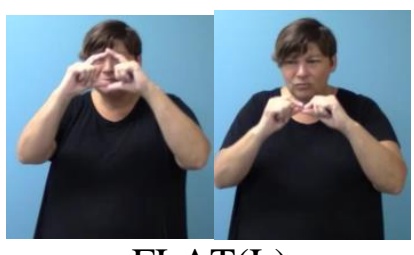

FLAT(L)

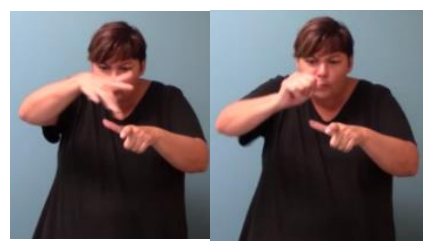

NO-TRACE-LEFT

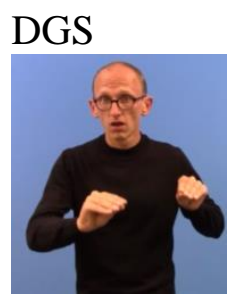

FLAT

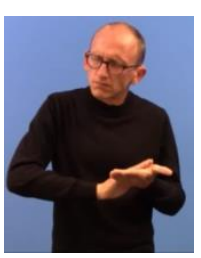

CLEAN/SMOOTH

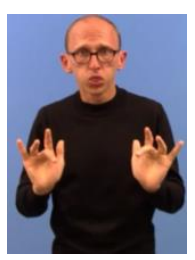

EMPTY

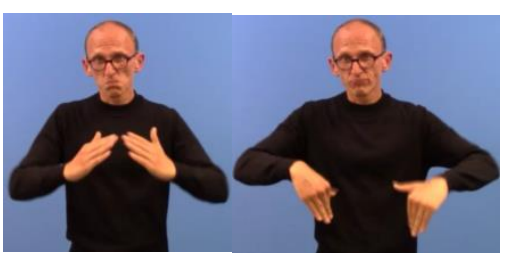

CL:break/tear 


\section{APPENDIX D: ASL GRAMMATICALITY JUDGMENT TASK (CONTEXT WAS PRESENTED IN ASL)}

Diagnostic 1: Final wh-subject

Final wh-subjects in simple, subordinate, and coordinate clauses.

1. Mary saw on the news that John was killed. She doesn't know who did it, so she asks:

\section{KILL JOHN WHO}

2. Mary saw on the news that John was killed. She doesn't know who did it, so she asks: WHO KILL JOHN

3. John has left a cake on the kitchen counter, and when he gets home, there are only crumbs left. So he asks:

\section{EAT MY CAKE WHO}

4. John has left a cake on the kitchen counter, and when he gets home, there are only crumbs left. So he asks:

\section{WHO EAT MY CAKE}

5. Mary is a teacher. She sees John spit out a worm. She knows her students are constantly daring each other to do silly or dangerous things, so she asks:

\section{FORCE JOHN EAT WORM WHO}

6. Mary is a teacher. She sees John spit out a worm. She knows her students are constantly daring each other to do silly or dangerous things, so she asks:

\section{WHO FORCE JOHN EAT WORM}

7. John and Mary are in the $3^{\text {rd }}$ grade. John has just walked up to Mary and kissed her. She thinks this must be a joke or a dare between him and his friends, so she asks his friends:

\section{PERSUADE JOHN KISS ME WHO}

8. John and Mary are in the $3^{\text {rd }}$ grade. John has just walked up to Mary and kissed her. She thinks this must be a joke or a dare between him and his friends, so she asks his 
friends:

\section{WHO PERSUADE JOHN KISS ME}

9. Mary walks into the classroom and sees that someone has written "John is stupid" on the board. She asks:

\section{THINK JOHN STUPID WHO}

10. Mary walks into the classroom and sees that someone has written "John is stupid" on the board. She asks: WHO THINK JOHN STUPID

11. Mary and her friends are watching a movie. In the movie, John is offered $\$ 10,000$ for eating a worm. John hesitates with the worm in his hand - at that point, Mary stops the movie and asks her friends:

\section{THINK JOHN EAT WORM WHO}

12. Mary and her friends are watching a movie. In the movie, John is offered $\$ 10,000$ for eating a worm. John hesitates with the worm in his hand - at that point, Mary stops the movie and asks her friends:

\section{WHO THINK JOHN EAT WORM}

13. At school, Mike sees John and Mary come out of the storage room. Mary looks flustered/is blushing. Mike points to the couple and asks everyone around him:

\section{SUSPECT/BELIEVE JOHN KISS MARY WHO}

14. At school, Mike sees John and Mary come out of the storage room. Mary looks flustered/is blushing. Mike points to the couple and asks everyone around him:

\section{WHO SUSPECT/BELIEVE JOHN KISS MARY}

15. The teacher asks what her students had for lunch. Everybody is talking at once and the teacher only catches snippets of what they are saying, so she asks back:

\section{EAT SALAD BUT JOHN EAT PIZZA WHO}

16. The teacher asks what her students had for lunch. Everybody is talking at once and the teacher only catches snippets of what they are saying, so she asks back:

\section{WHO EAT SALAD BUT JOHN EAT PIZZA}


Final wh-subjects in resultatives

17. Mary walks into the kitchen and sees that a plate that had just been covered in tomato sauce is now clean. Mike and John are standing next to the plate, their mouths covered in tomato sauce. Mary asks:

\section{LICK+ PLATE NO-TRACE-LEFT WHO}

18. Mike walks into the kitchen and sees that his favorite spoon is completely flat. Next to it lies a hammer. Mike asks: HAMMER+ SPOON FLAT WHO

19. In the morning, John walks into his carpenter's workshop. He sees that the table he meant to sand down today is already smooth. So he asks:

\section{SAND TABLE SMOOTH WHO}

20. Mary owns a used clothes store. She inspects her inventory and walks past a row of shoes. One of the pairs looks particularly shiny. She stops and asks her employees:

\section{POLISH SHOE SHINY WHO}

21. Mary is playing with her friends. Her mom comes into the room and sees that Mary's hair is all wet. Next to Mary, there's a spray bottle on the table. Her mom asks:

\section{SPRAY+ YOUR HAIR WET WHO}

22. Mary and John are standing next to their mom's bed, looking mischievous. Their mom has just woken up. She looks mad and asks them:

\section{SHAKE ME AWAKE WHO}

23. Mary is reading. She hears her kids jumping up and down on a trampoline, then she hears a tearing sound. She checks up on the kids and sees them standing next to the broken trampoline, looking guilty. She asks:

\section{JUMP TRAMPOLINE BREAK WHO}

24. Mary is watching the new Superman movie with her dad. When a group of gangsters starts chasing Superman, Mary closes her eyes in fear. When she opens them again, Superman is lying dead on the ground. Mary asks her dad:

\section{BEAT+ SUPERMAN DEAD WHO}


25. Mary is reading. Her kids are amusing themselves by jumping down the staircase again and again. When Mary goes to check up on them, the kids are standing in a circle looking down at her earring, which is lying on the ground all flat. Mary asks:

\section{JUMP MY EARRING FLAT WHO}

26. Mary and Mike are watching Harry Potter. In the movie, Harry and his friends have just found shelter from the rain in a cave and Harry has taken off his wet t-shirt. Mary goes to the restroom and when she gets back, Harry's shirt is dry. She asks:

\section{CHARM HARRY'S SHIRT DRY WHO}

27. John comes home and sees that his front door is open and has a dirty footprint on it. He asks:

\section{KICK DOOR OPEN WHO}

28. Mike and Mary are watching Harry Potter together. Mike has to use the restroom. When he comes back, Harry's face looks disfigured and unrecognizable. Mike asks:

\section{CHARM HARRY UGLY WHO}

29. Mike and Mary are watching Harry Potter. Mary has to use the restroom. When she returns, Harry is pregnant. Surprised, Mary asks:

\section{CHARM HARRY PREGNANT WHO}

30. Mary is watching the new Superman movie with her dad. When a group of gangsters starts chasing Superman, Mary closes her eyes in fear. When she opens them again, Superman is lying dead on the ground. Mary asks her dad:

\section{SHOOT SUPERMAN DEAD WHO}

31. Mary is meeting her friends Mike and John at a bar. Mary gets briefly distracted from the conversation by the TV in the bar. When she looks back, Mike is telling John about a friend who just got broken up with and is crying so much they even woke up in the night because they were crying. Mary asks:

\section{CRY AWAKE WHO}

32. Mary hears a loud sneeze from the baby's room and then the baby starts crying. When she goes to check up on the baby, she sees John and Mike standing next to the crib. She asks: 


\section{SNEEZE BABY AWAKE WHO}

33. John and Mike went swimming but only brought a small towel that is not enough for both of them. So, one of them has to run laps around the pool in order to dry off. When they get home, their mother asks:

\section{RUN DRY WHO}

34. John, Mary, and Mike come home from school (college) for the weekend. When their mom opens the fridge on Saturday, it is empty. She asks her family: EAT+ FRIDGE NO-TRACE-LEFT WHO

35. John and his friends have decided to go to the gym for the first time in years. They brag about how much they work out, and back at the lockers, John asks them:

\section{SWEAT SHIRT WET WHO}

36. Mary is chatting with a friend. The friend tells her that one of the contestants of America's Next Topmodel had to leave the show because she had gained too much weight. Mary asks:

\section{EAT FAT WHO}

37. Mike is telling Mary about a movie he watched. In the movie, John finds an old lamp in the attic, rubs it to better see it, and a djinn appears. The djinn is so happy to be free that he gives John all his powers. John can now do magic by snapping his fingers. He wants to be famous, so he snaps and is instantly famous. Mary hasn't been paying close attention to Mike's story, so she asks:

\section{SNAP FAMOUS WHO}

38. John wants to go home after class but finds that the tires of his new bike are completely flat. He thinks somebody is messing with him and asks his classmates:

\section{PUNCTURE TIRE FLAT WHO}

Diagnostic 2: Subject pronoun copy

Subject pronoun copy in simple, subordinate, and coordinate clauses

39. Mary just learnt that John hit Mike. John usually never gets angry, and Mike is a big guy, so Mary is surprised. She double-checks with John:

YOU HIT MIKE YOU? 
40. Mary has just met Mike, who looks about 50 years old. He's telling her that he's going to law school. Mary is a bit surprised, given Mike's age, and she asks:

\section{YOU STUDENT YOU?}

41. John has heard a rumor that Mary forced John, the biggest bully in school, to eat a worm. When John next runs into Mary, he asks her incredulously:

\section{YOU FORCE JOHN EAT WORM YOU?}

42. Mike feels like a loser. To make himself more popular, he tells everyone that he kissed Mary, the most popular girl in school. After class, Mary's boyfriend walks up to him angrily and asks:

\section{YOU TELL EVERYONE PEOPLE YOU KISS MARY YOU?}

43. Mary is mad at John when he gives her money for her birthday, instead of a thoughtful gift. Mike, for example, brought her nice flowers. In disbelief, she asks John:

YOU GIVE-me MONEY, HE GIVE-me FLOWER YOU?

\section{Subject pronoun copy in resultatives}

44. Mary walks into the kitchen and sees that a plate that had just been covered in tomato sauce is now clean. Mike is sitting at the table, his mouth covered in tomato sauce. Mary asks:

\section{YOU LICK+ PLATE NOT-TRACE-LEFT YOU}

45. Mike walks into the kitchen and sees that his favorite spoon is completely flat. John is standing next to it, holding a hammer. Mike asks:

\section{YOU HAMMER+ SPOON FLAT YOU}

46. In the morning, John walks into his carpenter's workshop. He sees that the table he meant to sand down today is already smooth. So he asks Mary:

\section{YOU SAND TABLE SMOOTH YOU}

47. Mary owns a used clothes store. She inspects her inventory and walks past a row of shoes. One of the pairs looks particularly shiny. She stops and asks her employee 
John:

\section{YOU POLISH SHOE SHINY YOU}

48. Mary is playing with her friends. Her mom comes into the room and sees that Mary's hair is all wet. Mike is standing next to Mary holding a spray bottle. Her mom asks Mike:

\section{YOU SPRAY+ MARY'S HAIR WET YOU}

49. Mary is woken ungently from her sleep. She feels like someone shook her. John is standing next to her bed, smirking. She asks:

\section{YOU SHAKE ME AWAKE YOU}

50. Mary is reading. She hears John jumping wildly on the trampoline, until she hears a tearing sound. She goes to check what's going on and finds John standing next to a torn trampoline. She asks:

\section{YOU JUMP TRAMPOLINE BREAK YOU}

51. Several superheroes are gathered for a party at Batman's house. Batman has heard that one of the guests has finally killed the Joker, and in a boxing match of all things! He suspects it might have been Superman, so he asks him:

\section{YOU BEAT+ JOKER DEAD YOU}

52. Mary's kids are amusing themselves by jumping down the staircase again and again. When Mary goes to check up on them, the kids are standing in a circle looking down at her earring, which is lying on the ground all flat. John looks particularly guilty, so Mary asks him:

\section{YOU JUMP MY EARRING FLAT YOU}

53. Harry Potter and his friends are coming home soaked from the rain. Harry takes his wet T-shirt off and goes to the bathroom to towel off. When he gets back, his shirt is dry and Hermione is looking smug. He asks her:

\section{YOU CHARM MY SHIRT DRY YOU}

54. John comes home and sees that his front door is open and has a dirty footprint on it. 
His friend Mike is standing in the living room, so John asks him:

\section{YOU KICK DOOR OPEN YOU}

55. One morning, Harry Potter wakes up with his face horribly disfigured. He and his friends set out to find out who put a spell on him so that they can reverse it. Harry asks Malfoy:

\section{YOU CHARM MY FACE UGLY YOU}

56. One morning, Harry Potter wakes up and he is 7 months pregnant. He and his friends set out to find out who put a spell on him so that they can reverse it. Harry asks Malfoy:

\section{YOU CHARM ME PREGNANT YOU}

57. Batman is throwing a party for superheroes and heroes in general. He has heard that one of the guests has finally shot the Joker and killed him! He suspects it might have been Clint Eastwood, so he asks him:

\section{YOU SHOT JOKER DEAD YOU}

58. Mary hears a loud sneeze from the baby's room and then the baby starts crying. When she goes to check up on the baby, she sees John standing next to the crib. She asks:

\section{YOU SNEEZE BABY AWAKE YOU}

59. Mike comes home from school (college) for the weekend. When his mom opens the fridge on Saturday morning, it is empty. She asks Mike:

\section{YOU EAT+ FRIDGE NO-TRACE-LEFT YOU}

60. John goes to the gym for the first time in years. Back home, he puts his shirt in the wash. His wife Mary picks it up and is surprised that he worked out so much. To make sure it's really John's shirt and not her son's, she asks John:

\section{YOU SWEAT SHIRT WET YOU}

61. John wants to go home after class but finds that the tires of his new bike are completely flat. He knows Mary hates him, so he confronts her:

YOU PUNCTURE MY TIRE FLAT YOU. 
Use of result predicate as (prenominal) modifier

62. John has just arrived to Mary's party with a sixpack of beers. He wonders where to put it, since Mary's kitchen has two fridges. Mary tells him:

SEE FRIDGE NO-TRACE-LEFT, IX PUT-fridge ALCOHOL.

63. John has just arrived to Mary's party with a sixpack of beers. He wonders where to put it, since Mary's kitchen has two fridges. Mary tells him:

SEE NO-TRACE-LEFT FRIDGE, GO-AHEAD PUT-fridge

64. Mary is working in the garden and wants to mark where she planted some herbs. There's a flat and a curvy spoon on the table, so she asks Mike:

\section{GIVE-1 FLAT SPOON PLEASE}

65. Mary has just had a baby and is raving about how much she loves her son. She tells John:

\section{LOVE BABY SMELL, SMOOTH SKIN, DIMPLE}

66. Mary and Mike are successful book publishers. They're trying to decide on a cover for their new thriller. Mike says:

\section{SHINY COVER BOOK, IX MORE GET PEOPLE BUY++}

67. Mary comes home soaked from the downpour outside. Her boyfriend John says:

\section{GIVE-1 WET CLOTHES, IX1 PUT-dryer DRYER}

68. Mike and John are riding on the train. Mike keeps looking over to where two girls are sitting, one is staring out the window, the other one asleep. Mike tells John:

\section{THINK AWAKE GIRL IX CUTE.}

69. Mike and John are riding on the train. Mike keeps looking over to where two girls are sitting, one is staring out the window, the other one asleep. Mike tells John:

\section{THINK GIRL AWAKE IX CUTE}

70. Mary and Mike are cleaning out the garage. Mary suggests: 
WE HAVE.TO THROW.OUT DESTROY TRAMPOLINE

71. Mike walks in with disgust written all over his face. He tells Mary:

SEE DEAD COCKROACH IX HALLWAY

72. John and Mary got surprised by rain on their date. They run to John's place, where he says:

1SECOND WAIT, IX1 BRING DRY CLOTHES, PUT.ON

73. Mike and John are watching a game show. The contestant has to decide between 2 doors: one is open and holds a new car, the other one is closed and could be a house or nothing. Mike says to the TV:

PICK OPEN-door

74. Mike and John are watching a game show. The contestant has to decide between 2 doors: one is open and holds a new car, the other one is closed and could be a house or nothing. Mike says to the TV:

PICK OPEN DOOR

75. Mike is not a very nice person. When his friend asks him what he wants to give to charity, he says:

IX-arc CAN HAVE POSS1 UGLY BROWN SWEATER

76. John and Mike are walking by a group of women. Mike says to his friend:

I THINK PREGNANT WOMAN BLINK

77. Mary is laughing out loud at her desk. John walks over and asks what's so funny. Mary responds:

IX FRIEND EMAIL-1 VIDEO FAT CAT CL-V:cat_falls_off_table

78. Mary and John are walking along the street. Suddenly, Mary points excitedly across the street and says:

LOOK, LOOK, FAMOUS ACTOR IX

79. Mary and John are walking along the street. Suddenly, Mary points excitedly across 
the street and says:

\section{LOOK, LOOK ACTOR FAMOUS IX}

80. Mary wants to put in her earrings. She asks John to look for them on her nightstand:

$$
\text { GET-ATTENTION GIVE-1 IX FLAT(L) EARRING GIVE-1 }
$$

\section{Control sentences}

81. Mary is visiting John with her son Mike. Mike looks bored while the grown-ups are chatting, so John produces a doll and asks Mary

\section{JOHN LIKE PLAY DOLL Q}

82. Mary is late for work. She's walking her son to daycare, but he keeps skipping and jumping around and they're not advancing. Mary says:

GET-ATTENTION, STOP CONTINUE JUMP++

83. In an ASL class, the teacher asks his students:

\section{SHOULD ALL TEACHER STUDY \#ASL DEAF SCHOOL}

84. John comes home hungry from soccer practice. He asks his dad:

\section{WHEN FOOD READY palm-up}

85. Aunt Mary is visiting John. She's looking around his home but she can't find what she's looking for, so she asks John:

WHERE VASE IX1 GIVE-addr CHRISTMAS

86. Mary is invited to a birthday party. Her mother suggests:

\section{GIVE BIRTHDAY YOU FLOWER}

87. Mike is sad and John wants to console him. He tells his mom:

\section{JOHN LEND MY TOY^TRUCK WANT}

88. John is hungry and asks his dad: 


\section{EAT DAD LUNCH WHAT WE}

89. Mary has heard a rumor that a famous actress is coming to visit her school. She asks Mike:

\section{VISIT SCHOOL WHO 2-WEEK}

90. John and his mom are visiting his great aunt. Before they go in, the mother says:

\section{YOU EXPECT GOOD BOY}




\section{APPENDIX E: DGS GRAMMATICALITY JUDGMENT TASK}

Diagnostic 1: result + causing predicate with a final modal

1. Kontext: Susi hat gerade Spaghetti mit leckerer Tomatensauce gegessen. Ihre Mutter sagt:

\section{DU TELLER SAUBER LECK+ DARF}

2. Kontext: Hans und Susi spielen mit einem Hammer und überlegen, worauf sie hämmern können. Hans holt einen Löffel aus der Küche und sagt:

\section{DU LÖFFEL FLACH HÄMMER+ KANN}

3. Kontext: Hans und Susi spielen mit Schleifpapier und überlegen, was sie damit machen können. Hans sieht einen Tisch und schlägt vor:

DU TISCH GLATT SCHLEIF+ KANN

4. Kontext: Susi langweilt sich. Ihre Mutter schlägt vor:

DU SCHUH GLÄNZ POLIER+ KANN

5. Kontext: Susi spielt Friseur. Ihre Mutter sagt:

\section{DU MEIN HAARE NASS SPRÜH+ DARF}

6. Kontext: Susis Mutter schläft, aber Susi will mit ihr spielen. Ihr Vater warnt:

$$
\text { DU MAMA (AUF)WACH SCHÜTTEL+ DARF-neg }
$$

7. Kontext: Susi ist etwas pummelig. Sie springt auf einem Trampolin, und Hans glaubt, das Trampolin geht gleich kaputt. Aber Micha sagt:

\section{SUSI TRAMPOLIN CL:B_kaputt SPRING+ KANN-neg}

8. Kontext: Susi schaut den neuen Superman-Film mit ihrem Vater. Sie hat Angst um Superman und sagt zu ihrem Vater:

FEIND SUPERMAN TOT SCHLAG+ DARF-neg

9. Kontext: Susi ist etwas pummelig. Sie springt eine Treppe hinunter. Micha sieht, dass auf einer Stufe ein runder Ohrring liegt. Er sagt zu seinem Freund Hans: 


\section{SUSI OHRRING FLACH SPRING KANN}

10. Kontext: Susi sieht Harry Potter mit Hans. Im Film hat sich Harry gerade vor dem Regen in eine Höhle gerettet und sein nasses T-Shirt ausgezogen. Susi spekuliert:

\section{HARRY T-SHIRT TROCKEN ZAUBER KANN}

11. Kontext: Susi und Hans spielen im Keller. Die Kellertür klemmt, also schlägt Susi vor:

\section{DU TÜR AUF-tür TRET KANN}

12. Kontext: Susi sieht Harry Potter mit Hans. Im Film will Hermine Harry verzaubern, damit er nicht erkannt wird von seinen Feinden. Susi spekuliert:

\section{HERMINE HARRY HÄSSLICH ZAUBER KANN}

13. Kontext: Susi tritt bei den Olympischen Spielen beim Weitsprung an und stellt einen neuen Weltrekord auf. Ihre Mutter erzählt stolz einer Freundin:

\section{SUSI BERÜHMT SPRING KANN}

14. Kontext: Susi sieht Harry Potter mit Hans. Beide finden zaubern toll, aber sie überlegen, was man mit Magie nicht erreichen kann. Susi hat eine Idee:

\section{HARRY RON SCHWANGER ZAUBER KANN-neg}

15. Kontext: Susi schaut den neuen Superman-Film mit ihrem Vater. Sie hat Angst um Superman und sagt zu ihrem Vater:

\section{FEIND SUPERMAN TOT SCHIEß DARF-neg}

16. Kontext: Susi war bockig und wird ohne Abendessen ins Bett geschickt. Sie schreit und weint in ihrem Zimmer. Der Vater will zu ihr gehen und sie beruhigen, aber die Mutter sagt:

\section{SUSI EINSCHLAF WEIN+ LASS}

17. Kontext: Susi hat Schnupfen und geht aus einem Zimmer, in dem ein Baby schläft. Hans schaut Micha fragend an und dieser erklärt: 


\section{SUSI BABY (AUF)WACH NIES WOLL-neg}

18. Kontext: Susi will unbedingt in den See springen, aber ihre Mutter will das nicht, weil sie kein Handtuch mitgebracht haben. Der Vater wendet ein:

\section{SIE TROCKEN RENN+ KANN}

19. Kontext: Susi kommt nach dem Sport hungrig nach Hause. Ihre Mutter erwartet noch Gäste zum Abendbrot und warnt:

\section{DU KÜHLSCHRANK LEER ESS+ DARF-neg}

20. Kontext: Hans sieht Susi im Freiluftkino und winkt sie zu seiner Grupper herüber. Susi bewegt sich nicht. Micha weiß, dass Susi mit ihrer Mutter da ist und von ihr einen Auftrag erhalten hat. Er informiert Hans:

\section{SUSI STUHL WARM SITZ+ MUSS}

21. Kontext: Susi will in 2 Wochen heiraten, aber in letzter Zeit hat sie ständig Heißhungerattacken und isst sehr viel. Ihre Mutter macht sich Sorgen, dass sie nicht in ihr Kleid passen wird. Sie sagt zu Susi:

\section{DU DICK ESS+ DARF-neg}

22. Hans schaut einen Film. Im Film wünscht sich Susi schon seit langem ein Baby, aber sie wird und wird nicht schwanger. Eines Tages reibt sie an einer alten Lampe, die sie gefunden hat,und ein Dschinn erscheint. Er kann sämtliche Wünsche mit einem Fingerschnipsen erfüllen. Hans überlegt:

\section{GEIST SUSI SCHWANGER SCHNIPSEN KANN}

23. Susi schaut einen Film. Im Film muss ein Bote dem König unbedingt dringend eine Nachricht überbringen. Er reitet und reitet und hetzt sein Pferd, bis das Pferd tot zusammenbricht. Susi sagt:

\section{BOTE PFERD TOT REITEN MUSS}

\section{Diagnostic 2: causing predicate + result - Intervening modal}

24. Kontext: Susi hat gerade Spaghetti mit leckerer Tomatensauce gegessen. Sie fragt: ICH TELLER LECK DARF SAUBER? 
25. Kontext: Hans und Susi spielen mit einem Hammer und überlegen, worauf sie hämmern können. Hans holt einen Löffel aus der Küche und fragt Susi:

\section{DU LÖFFEL HÄMMER KANN FLACH?}

26. Kontext: Hans und Susi spielen mit Schleifpapier und überlegen, was sie damit machen können. Hans sieht einen Tisch und fragt Susi:

\section{DU TISCH SCHLEIF KANN GLATT?}

27. Kontext: Susi schaut ihrer Mutter beim Putzen zu. Sie ist beeindruckt, was ihre Mutter alles kann und fragt:

\section{DU SCHUH POLIER KANN GLÄNZ?}

28. Kontext: Susi spielt Friseur. Sie fragt ihre Mutter :

\section{ICH DEIN HAARE SPRÜH DARF NASS?}

29. Kontext: Susis Mutter schläft, aber Susi will mit ihr spielen. Sie fragt ihren Vater:

$$
\text { ICH MAMA SCHÜTTEL DARF (AUF)WACH? }
$$

30. Kontext: Susi ist etwas pummelig. Sie springt auf einem Trampolin, und Hans macht sich Sorgen um das Trampolin. Er fragt seine Mutter:

SUSI TRAMPOLIN SPRING+ KANN CL:B_kaputt

31. Kontext: Susi schaut den neuen Superman-Film mit ihrem Vater. Sie hat Angst um Superman und fragt ihren Vater:

FEIND SUPERMAN SCHLAG+ KANN TOT?

32. Kontext: Susi hat einen alten runden Ohrring gefunden. Sie legt ihn auf den Boden, klettert auf eine kleine Mauer, und fragt ihre Mutter:

ICH OHRRING SPRING DARF FLACH?

33. Kontext: Susi sieht Harry Potter mit Hans. Im Film hat sich Harry gerade vor dem Regen in eine Höhle gerettet und sein nasses T-Shirt ausgezogen. Susi fragt Hans:

HARRY T-SHIRT ZAUBER KANN TROCKEN? 
34. Kontext: Susi und Hans haben etwas aus dem Keller geholt. Die Kellertür klemmt, also fragt Susi:

DU TÜR TRET KANN AUF-tuer?

35. Kontext: Susi sieht Harry Potter mit Hans. Im Film will Hermine Harry verzaubern, damit er nicht erkannt wird von seinen Feinden. Susi fragt Hans:

HERMINE HARRY ZAUBER KANN HÄSSLICH?

36. Kontext: Susi tritt zum ersten Mal bei den Olympischen Spielen beim Weitsprung an. Sie springt super. Ein Reporter fragt:

SUSI SPRING KANN BERÜHMT?

37. Kontext: Susi sieht Harry Potter mit Hans. Beide finden zaubern toll, aber sie überlegen, wo die Grenzen der Magie liegen. Susi fragt:

HARRY RON ZAUBER KANN-neg SCHWANGER?

38. Kontext: Susi schaut den neuen Superman-Film mit ihrem Vater. Sie hat Angst um Superman und sagt zu ihrem Vater:

FEIND SUPERMAN SCHIEß KANN TOT?

39. Kontext: Susi war bockig und wird ohne Abendessen ins Bett geschickt. Sie schreit und weint in ihrem Zimmer. Dem Vater tut das im Herzen weh und er fragt die Mutter:

SIE WEIN MUSS EINSCHLAF?

40. Kontext: Susi hat Schnupfen und sitzt in einem Zimmer, in dem ein Baby gerade schläft. Hans macht sich Sorgen und fragt die Mutter des Babys::

SUSI BABY NIES KANN (AUF)WACH?

41. Kontext: Susi war baden und mag es nicht, sich mit dem Handtuch abzutrocknen. Sie fragt ihre Mutter:

ICH RENN DARF TROCKEN?

42. Kontext: Hans kommt am Wochenende von der Uni nach Hause und hat großen 
Hunger. Er sieht, dass seine Mutter gerade den Kühlschrank abtaut und fragt:

\section{ICH KÜHLSCHRANK ESS+ DARF LEER?}

43. Kontext: Susi ist mit Hans im Biergarten. Die Bänke dort sind sehr kalt, also fragt sie ihren Vater:

DU BANK SITZ KANN WARM?

44. Kontext: Micha ist bei seiner Freundin Susi zu Besuch. Susi ist ein Model, und Micha ist überrascht, wieviel seine Freundin in sich hineinstopft. Sie fragt:

\section{DU ESS DARF DICK?}

Diagnostic 3: causing predicate + result - Final wh-subject

Final wh-subjects in simple, subordinate, and coordinate clauses.

45. Kontext: Susi sieht in den Nachrichten, dass Hans erschossen wurde. Sie fragt:

\section{WER HANS SCHIESSEN}

46. Kontext: Susi sieht in den Nachrichten, dass Hans erschossen wurde. Sie fragt:

\section{HANS SCHIESSEN WER}

47. Kontext: Susi liegt mit Magenverstimmung im Bett. Ihre Eltern wissen nicht, warum sie so krank ist und fragen ihren Bruder:

\section{WAS SUSI ESS}

48. Kontext: Susi liegt mit Magenverstimmung im Bett. Ihre Eltern wissen nicht, warum sie so krank ist und fragen ihren Bruder:

\section{SUSI ESS WAS}

49. Kontext: Die Lehrerin sieht, dass Hans weinend einen Wurm ausspuckt. In der Klasse sind Mutproben gerade modern, also fragt sie:

\section{HANS ZWING WURM ESS WER}

50. Kontext: Die Lehrerin sieht, dass Hans weinend einen Wurm ausspuckt. In der Klasse sind Mutproben gerade modern, also fragt sie: 


\section{WER HANS ZWING WURM ESS}

51. Kontext: Die Lehrerin sieht, dass Hans weinend einen Wurm ausspuckt. In der Klasse sind Mutproben gerade modern, also fragt sie:

\section{WER HANS ÜBERRED WURM ESS}

52. Kontext: Die Lehrerin sieht, dass Hans weinend einen Wurm ausspuckt. In der Klasse sind Mutproben gerade modern, also fragt sie:

\section{HANS ÜBERRED WURM ESS WER}

53. Kontext: In der Klasse wird momentan über Mobbing gesprochen und wie man sich wehrt. Sie schauen ein Video über Hans, der von einem älteren Jungen geärgert wird. Der Junge sagt zu Hans: Iss diesen Wurm. Die Lehrerin stoppt das Video und fragt:

\section{GLAUB HANS WURM ESS WER}

54. Kontext: In der Klasse wird momentan über Mobbing gesprochen und wie man sich wehrt. Sie schauen ein Video über Hans, der von einem älteren Jungen geärgert wird. Der Junge sagt zu Hans: Iss diesen Wurm. Die Lehrerin stoppt das Video und fragt:

\section{WER GLAUB HANS WURM ESS}

55. Kontext: In der Klasse wird momentan über Mobbing gesprochen und wie man sich wehrt. Sie schauen ein Video über Hans, der von einem älteren Jungen geärgert wird. Der Junge sagt zu Hans: Iss diesen Wurm. Die Lehrerin stoppt das Video und fragt:

\section{VERMUT HANS WURM ESS WER}

56. Kontext: In der Klasse wird momentan über Mobbing gesprochen und wie man sich wehrt. Sie schauen ein Video über Hans, der von einem älteren Jungen geärgert wird. Der Junge sagt zu Hans: Iss diesen Wurm. Die Lehrerin stoppt das Video und fragt:

\section{WER VERMUT HANS WURM ESS}

57. Kontext: Susi hört ein Niesen aus dem Kinderzimmer und dann schreit ein Baby. Sie geht ins Zimmer, sieht Hans und Micha am Kinderbett stehen und fragt:

\section{WER NIES DANN BABY AUFWACH}

58. Kontext: Susi hört ein Niesen aus dem Kinderzimmer und dann schreit ein Baby. Sie geht ins Zimmer, sieht Hans und Micha am Kinderbett stehen und fragt: 


\section{NIES DANN BABY AUFWACH WER}

\section{Final wh-subjects in resultatives}

59. Kontext: Susi kommt in die Küche und sieht, dass der Teller, auf dem eben noch Tomatensauce war, jetzt leer ist. Micha und Hans haben beide Tomatensauce um den Mund geschmiert. Susi fragt:

\section{TELLER LECK SAUBER WER?}

60. Kontext: Hans kommt in die Küche und sieht, dass sein Lieblingslöffel total platt ist. Daneben liegt ein Hammer. Er fragt:

\section{LÖFFEL HÄMMER FLACH WER?}

61. Kontext: Hans kommt morgens in die Tischlerei und sieht, dass der Tisch, den er heute abschleifen wollte schon glatt ist. Er fragt:

\section{TISCH SCHLEIF GLATT WER?}

62. Kontext: Der Nikolaus schaut sich eine Reihe von Kinderschuhen an. Bei einem besonders glänzenden Paar bleibt er stehen und fragt:

\section{SCHUH POLIER GLÄNZ WER?}

63. Kontext: Die Mutter kommt ins Zimmer zu Susi und ihren Freundinnen. Neben Susi steht eine Sprühflasche und Susis Haare sind nass. Die Mutter fragt:

\section{DEIN HAARE SPRÜH NASS WER?}

64. Kontext: Susi und Hans stehen schelmisch am Bett ihrer Mutter. Die Mutter ist gerade wach geworden und fragt unwirsch:

\section{ICH SCHÜTTEL (AUF)WACH WER?}

65. Kontext: Die Mutter hört ihre Kinder auf dem Trampolin springen, dann hört sie ein Reißen. Sie geht Nachschauen und findet ihre Kinder betreten vor dem kaputten Trampolin. Sie fragt:

\section{TRAMPOLIN SPRING+ CL:B_kaputt WER?}

66. Kontext: Susi schaut den neuen Superman-Film mit ihrem Vater. Als eine Gruppe Gangster auf Superman zugehen, hält sie sich die Augen zu. Als sie wieder hinschaut, 
liegt Superman tot am Boden. Sie fragt ihren Vater:

SUPERMAN SCHLAG+ TOT WER?

67. Kontext: Susi hört, wie ihre Kinder sich damit vergnügen, die Treppe

herunterzuhopsen. Nach einer Weile schaut sie nach dem Rechten und sieht, dass die Kinder auf ihren Ohrring schauen, der ganz platt am Fuß der Treppe liegt. Sie fragt:

OHRRING SPRING FLACH WER?

68. Kontext: Susi sieht Harry Potter mit Hans. Im Film haben Harry und seine Freunde gerade vor dem Regen in eine Höhle gerettet und Harry hat sein nasses T-Shirt ausgezogen. Susi geht kurz aus dem Zimmer, und als sie wiederkommt ist Harrys Shirt trocken. Sie fragt Hans:

\section{T-SHIRT ZAUBER TROCKEN WER?}

69. Kontext: Susi kommt nach Hause und sieht, dass die Haustür offensteht und ein Fußabdruck an der Tür ist. Sie fragt:

TÜR TRET AUF-tür WER?

70. Kontext: Susi sieht Harry Potter mit Hans. Sie geht kurz aufs Klo und als sie zurückkommt, sie Harry ganz hässlich aus. Sie fragt Hans:

\section{HARRY ZAUBER HÄSSLICH WER?}

71. Kontext: Susi schaut die Nachrichten über die Olympischen Spiele. Sie schaut kurz weg vom Fernseher und verpasst dabei den Namen eines Sportlers, der im Weitsprung einen neuen Weltrekord aufgestellt hat und nun weltberühmt ist. Sie fragt:

\section{SPRING BERÜHMT WER?}

72. Kontext: Susi sieht Harry Potter mit Hans. Susi geht kurz aus dem Zimmer, und als sie wiederkommt, ist Ron plötzlich schwanger. Sie fragt Hans:

\section{RON ZAUBER SCHWANGER WER?}

73. Kontext: Susi schaut den neuen Superman-Film mit ihrem Vater. Als eine Gruppe Gangster auf Superman zugehen, hält sie sich die Augen zu. Als sie wieder hinschaut, liegt Superman tot am Boden. Sie fragt ihren Vater: 


\section{SUPERMAN SCHIEß TOT WER?}

74. Kontext: Eine Frauengruppe diskutiert das Thema Männer. Alle sind sich einig, dass Männer die fremdgehen ihren Frauen sehr weh tun. Susi fragt in die Runde:

\section{WEIN EINSCHLAF WER?}

75. Kontext: Die Mutter hört ein lautes Niesen aus dem Kinderzimmer und kurz darauf schreit das Baby. Die Mutter schaut nach und findet Hans und Micha im Kinderzimmer. Sie fragt:

\section{BABY NIES (AUF)WACH WER?}

76. Kontext: Hans und Micha waren baden, hatten aber nur ein kleines Handtuck dabei. Das reichte nur für einen zum Abtrocknen, der andere musste rennen, bis er trocken war. Die Mutter fragt später:

\section{RENN TROCKEN WER?}

77. Kontext: Hans, Susi, und Micha kommen am Wochenende von der Uni nach Hause. Als die Mutter am Samstag morgen den Kühlschrank aufmacht, ist er leer. Sie fragt ihre Familie:

\section{KÜHLSCHRANK ESS+ LEER WER ?}

78. Kontext: Susi ist Hans im Herbst im Biergarten. Sie muss kurz aufs Klo und als sie zurückkommt, ist ihre Bank warm. Sie fragt:

\section{BANK SITZ WARM WER?}

79. Kontext: Susi unterhält sich mit einer Freundin. Die erzählt ihr, dass eine Teilnehmerin von Germany's Next Top Model das Haus verlassen muss, weil sie zu

dick geworden ist. Susi fragt:

\section{ESS DICK WER?}

\section{Result predicates as lexical causatives}

80. Die Mutter kommt in die Küche und sieht, dass der Abwasch gemacht ist. Sie fragt Susi: 


\section{DU TELLER SAUBER?}

81. Die Mutter sieht Susi mit einem Hammer und einem platten Löffel in der Hand. Sie fragt:

\section{DU LÖFFEL FLACH?}

82. Susi kommt in die Tischlerei und sieht Hans neben einem frisch geschliffenen Tisch. Sie fragt:

\section{DU TISCH GLATT?}

83. Der Nikolaus sieht Susi neben einem Paar blitzenden Schuhe und fragt:

\section{DU SCHUH GLÄNZ?}

84. Hans hat eine Sprühflasche in der Hand und Susis Haare sind nass. Die Mutter fragt Hans:

\section{DU SUSI HAARE NASS?}

85. Susi ist ausser Puste und steht neben einem kaputten Trampolin. Ihre Mutter kommt dazu und fragt:

DU TRAMPOLIN CL:B_kaputt?

86. Susi kommt ins Zimmer, als ihr Vater den neuen Superman Film schaut. Sie sieht, dass Superman tot auf dem Boden liegt und fragt:

\section{FEIND SUPERMAN TOT?}

87. Hans war mit T-Shirt baden. Die Mutter schickt ihn auf sein Zimmer, als sie später nachschaut, ist sein T-Shirt schon wieder trocken. Sie fragt erstaunt:

\section{DU T-SHIRT TROCKEN?}

88. Susis Mutter schaut ins Kinderzimmer und sieht, dass Susis Puppe keine Haare mehr hat und sie mit Filzstift angemalt ist. Sie fragt Susi:

\section{DU PUPPE HÄSSLICH?}

89. Micha und Hans unterhalten sich. Hans zeigt Micha ein Bild von seiner Freundin 
Susi, die hochschwanger ist. Micha fragt:

DU SUSI SCHWANGER ?

90. Die Mutter sieht Hans essen und sieht, dass der Kühlschrank leer ist. Sie fragt ihren Sohn:

DU KÜHLSCHRANK LEER?

91. Susi kommt zu ihrem Stuhl zurück und merkt, dass er warm ist. Sie fragt ihren Sitznachbarn:

DU MEIN STUHL WARM ?

\section{Control sentences}

90. Kontext: Eine Mutter erzählt ihrer Freundin:

HAND IX MIT PUPPEN SPIELEN LIEB

91: Kontext: Ein Gesetz lautet:

IX-addr TÖT DARF-neg

92. Zwei Gehörlosenpädagogen unterhalten sich. Der eine sagt:

\section{ALLE GEHÖRLOS^EEHRER \#DGS LERN MUSS}

93. Susi schaut den neuen Superman-Film mit ihrem Vater. Sie sagt zu ihm:

$$
\text { SUPERMAN FEIND PRÜGEL LIEB }
$$

94. Kontext: Susi hat Harry Potter geguckt und will nun ihren Teddy in eine Prinzessin verzaubern. Ihr Bruder Hans sagt:

MENSCH ZAUBER, KANN-neg

95. Kontext: Die Mutter fragt sich, ob Susi Allergien hat. Sie sagt zum Doktor:

\section{SUSI FÜNF MINUTE PERIODISCH NIES}

96. Kontext: Susi ist zum Geburtstag eingeladen. Ihre Mutter sagt. 
li-SCHENKEN-re GEBURTSTAG DU BLUMEN

97. Kontext: Hans ist traurig und Susi will ihn trösten. Sie sagt zu ihrer Mutter: ICH HANS-re WUENSCH PUPPE GEBEN-li

98. Kontext: Susi hat Hunger und fragt ihren Papa: ESS PAPA WAS MITTAG

99. Kontext: Susi hat gehört, dass irgendein Star bald ihre Schule besucht. Sie fragt Hans: li-BESUCH-re SCHULE WER 2-WOCHEN

100. Kontext: Micha und seine Mutter besuchen seine Großtante. Bevor sie klingeln, sagt die Mutter:

ICH DU ERWARTE BRAV 


\section{APPENDIX F: CAUSATION SCENARIOS FOR ASL DIRECT CAUSATION STUDY (SCENARIOS ARE DESCRIBED IN ENGLISH HERE)}

\section{KICK OPEN}

1a. John wants to get into his home, but the door is stuck, so he kicks at it once and it opens.

1b. John wants Mary to water his flowers while he is gone, so he is programming his door to open automatically at $6 \mathrm{pm}$, when Mary is supposed to stop by. John likes funny gimmicks/mechanisms, so he bought a door that you can only program to open at a particular time if you kick it. John kicks it to set the opening mechanism for $6 \mathrm{pm}$, and when Mary gets to John's place a little after 6pm, the door is open.

1c. John wants to open his front door for his wife but he has his hands full and his foot is out of reach of the door as well. However, there's a ball lying nearby, so he kicks the ball at the door and it opens.

1d. John is mad about something and needs to vent his anger. He kicks against a ball lying near him, and the ball accidentally hits a nearby door. The door opens.

\section{PUNCH OPEN}

2a. John is a boxer. He's trying to enter his house, but the front door is stuck, so he punches it with his fist, and the door opens.

2b. John wants to program his door to open automatically at $6 \mathrm{pm}$, so his cleaner can get in. He likes funny gimmicks/mechanisms, so he bought a door that you can only program to open at a particular time if you punch it hard. John punches to set the opening mechanism for $6 \mathrm{pm}$ and when his cleaner gets there a little after $6 \mathrm{pm}$, the door is open.

2c. John is a boxer. When someone rings his doorbell, he is training and too lazy to get the door. So he punches his punching bag in the direction of the door, it hits the door and the door opens.

2d. John is a boxer and is training with a punching bag. He has so much force in his arm that he punches the bag and it swings so far that it hits a door and that door opens.

\section{KISS AWAKE}

3a. John has to get up for work, but he's fast asleep. So Mary gives him a kiss and he wakes up.

3b. Mary kisses John in order to wake him, but he is a sound sleeper and does not wake up. Somehow the kiss has registered, however, as John starts tossing and turning and wakes up 15 minutes later.

3c. Mary is making pancakes with her 4-year-old son Mike. Her husband John is still asleep. She wants to wake him gently, so she gives Mike a kiss on the cheek and tells him to pass the kiss onto his dad. Mike gives his dad a kiss on the cheek and John wakes up. 
3d. Mary is playing with her 4-year-old son Mike. She gives him a kiss on the cheek and tells him to take that kiss to his dad. Mike runs over to his dad John and gives him a kiss. Mary doesn't know that John had been napping, and when Mike kisses him, he wakes up.

\section{SHAKE AWAKE}

4a. Mary has to get up for work but she's fast asleep. So John shakes her until she wakes up.

4b. John shakes Mary in order to wake her, but she is a sound sleeper and does not wake up. Somehow, she registers the shaking, however, as she starts tossing and turning and she wakes up after 15 minutes.

4c. John and Mary share a room. In the morning, John wants to wake Mary but he can't quite reach her, so he shakes the bed in which she is lying, and she wakes up.

4d. John is lying in bed. He reaches over for a book that's lying on the bed next to him, but he can't quite reach it. Instead of getting up, he reaches the bed and shakes it, so that the book will fall down and into his reach. He doesn't know that Mary is sleeping in the bed, so when he shakes it, she wakes up.

\section{JUMP FLAT}

5a. Mary has a pair of earrings. One has a concave shape, the other one is flat, but she wants both to look the same. She jumps on the concave earring and it becomes flat.

5b. Mary has a pair of earrings. One has a concave shape, the other one is flat, but she wants both to look the same. They're made from a special metal whose molecular structure takes a long time to break down. She jumps on the concave earring once to set off the flattening process. The metal slowly breaks down and an hour later, Mary has two flat earrings.

5c. Mary has a pair of earrings. One has a concave shape, the other one is flat, but she wants both to look the same. She puts the concave earring on the ground underneath a heavy stone that is wedged precariously between two other stones. Then she climbs up on a wall, jumps onto the stone and then onto the ground. The stone falls on the earring and it becomes flat. The earring becomes flat. Now both earrings look the same.

5d. Mary is practicing her jumping skills. She jumps from a high wall onto a stone that is wedged between 2 other stones. The stone she jumped on becomes unwedged and falls to the ground. In the process, an earring that was lying on the ground underneath the stone, becomes flat.

\section{HAMMER FLAT}

6a. Mary wants to use old spoons as garden markers. So she takes a spoon and hammer on it until it is flat. Mary wants to use old spoons as garden markers. So she takes a spoon and hammers on it until it is flat. 
6b. Mary wants to use her old spoon as a garden marker. It's made from a special metal whose molecular structure takes a long time to break down. She hammers on the spoon to start the flattening process. She waits for an hour and then the spoon is finally flat.

6c. Mary has a fancy new tool that can do a variety of different jobs, including hammering and sewing. The handling of the tool is very intuitive, you just gesture hammering and the tool registers your hand motion and performs a hammering motion on whatever object you give it. Mary tries it out. She places a spoon under the tool and gestures hammering. And really, the machine goes into hammering mode and the spoon becomes flat.

6d. Mary has a fancy new tool that can pick up a variety of different jobs, including painting, sewing, and hammering. If you gesture (what you want to do) to the machine, it will copy you. One day, Mary is walking past the machine with a spoon in her hand when she notices a nail sticking out from the floorboards. She sets her spoon down (as it happens right under tha machine) and hammers the nail into the floor. Erroneously, the machine interprets this as a command to action and starts hammering the spoon under it until it is flat.

\section{PAINT SHINY}

7a. John bought a new table for his living room. It's wooden and he wants to class it up, so he paints it with a clear finish/varnish. The table becomes shiny.

7b. John bought a new table for his living room. It's wooden and he wants to class it up, so he paints it with a clear finish/varnish. At first, the table looks just a bit darker, but dull, but after an hour it begins to look shiny.

7c. John has a fancy new tool that can do a variety of different jobs, including hammering and painting. The handling of the tool is very intuitive, you just gesture painting and the tool registers your hand motion and performs a painting motion on whatever object you give it. John places his new wooden table under the tool and mimics painting. Using a clear varnish, the tool goes into painting mode and the table becomes shiny.

7d. John has a fancy new tool that can do a variety of different jobs, including sewing, hammering, and painting. The handling of the tool is very intuitive, you just gesture painting and the tool registers your hand motion and performs a painting motion on whatever object you give it. John needs to move his table because he wants to paint the floorboards with a clear varnish, so he places the table under the machine and starts painting. The machine is accidentally set off and paints the table with a clear varnish as well so it becomes shiny.

\section{POLISH SHINY}

8a. Mary has a job interview in the morning and wants to look smart. She polishes her shoes and they become shiny.

8b. Mary has a pair of shoes that can be used for different occasions. They can have a rough or a shiny surface. To get the shoes to shine, you have to polish them and 
then wait 1 hour and they will start shining. So Mary polishes the shoes and an hour later, they're shiny.

8c. Mary inherited an old oil lamp from her uncle Aladdin. Her mom has told her to use magic only in emergencies, but she's lazy and uses it all the time. When she needs to polish her shoes, she rubs the oil lamp and commands the genie to do it, and her shoes become shiny.

8d. Mary is cleaning her new boss's room. She's very thorough and polishes every object and surface. She even polishes the button on the boss's shoe-shine machine so vigorously, that the machine starts and the shoes underneath it become shiny.

\section{SHOOT DEAD}

9a. John wants to revenge his family's death at the hands of Mike. He aims, shoots and hits Mike, and Mike dies on the spot.

9b. John wants to revenge his family's death at the hands of Mike. He aims, shoots and hits Mike, and Mike dies a few days later in the hospital from his internal injuries.

9c. John wants to revenge his family's death at the hands of Mike. He shoots Mike but barely grazes his shoulder. However, the experience gives Mike a heart attack and he dies on the spot.

9d. John wants to revenge his family's death at the hands of Mary. He shoots Mary but misses and hits Mike instead. He barely grazes his shoulder, but the experience gives Mike a heart attack and he dies on the spot.

\section{BEAT DEAD}

10a. John killed Mike's wife while driving drunk. Mike is so mad that he wants to kill John. He beats him and John dies.

10b. John killed Mike's wife while driving drunk. Mike is so mad that he wants to kill John. He beats him so hard that John has to go to the hospital, where he dies a few days later of his internal injuries.

10c. Mike wants revenge for John and Mary killing his son by driving drunk. Mike is beating Mary, and seeing that gives John a heart attack, of which he dies immediately.

10d. Mike is beating up Mary after school. Mary's father John is about to pick her up, is so shocked to see the beating that he has a heart attack and dies on the spot.

\section{SAND SMOOTH}

11a. Mary has just finished building a wooden table. She takes some sanding paper, sands the table top and it becomes smooth.

11b. Mary has just finished building a table from a very rough type of wood. She sands the table top for a while, which breaks up the molecular structure of the wood. After Mary has stopped sanding, it takes about an hour for the wood's structure to break up and flatten out, and then the table is smooth. 
11c. Mary has a fancy new tool that can do a variety of different jobs, including hammering and sanding. The handling of the tool is very intuitive, you just gesture sanding and the tool registers your hand motion and sands whatever object you give it. Mary places her new wooden table under the tool and gestures sanding. The tool starts in sanding mode and the table becomes smooth.

11d. Mary has a fancy new tool that can do a variety of different jobs, including paint, hammering and sewing. The handling of the tool is very intuitive, you just gesture sanding and the tool registers your hand motion and sands whatever object you give it. Mary wants to sand her floorboards and needs to get a table out of the way, so she places it under the machine and then starts sanding. Accidentally, the machine picks up her motion and sands the table until is it smooth. Oops.

\section{DYE BLUE}

12a. Mary just bought new curtains for her bedroom. They're white and boring, so she dyes them and they become blue.

12b. Mary wants to dye the curtains in her room. She puts them in a bucket with indigo dye, and when she takes them out, they are green. She lets them sit in the open air for 2 hours and when she comes back, they're blue.

12c. Mary wants to dye a delicate blouse. She's afraid the dye is too strong for the fabric, so she puts an old towel in the blue dye, takes it out and wraps the blouse in it. The blouse takes on the blue color from the towel.

12d. Mary has just taken her old jeans from a bucket with blue dye. Carelessly she throws them on a chair to dry. She doesn't realize that there's a white blouse lying on the chair already. The blouse absorbs the blue color of the jeans. 


\section{APPENDIX G: CAUSATION SCENARIOS FOR ENGLISH DIRECT CAUSATION STUDY}

\section{1. kick open}

1a. John wants to get into his home, but the door is stuck, so he kicks at it once and it opens.

1b. John wants Mary to water his flowers while he is gone, so he programs his door to open automatically at 6pm, when Mary is supposed to stop by. John likes funny gimmicks/ mechanisms, so he bought a door that you can only program to open at a particular time if you kick it. John kicks it to set the opening mechanism for $6 \mathrm{pm}$, and when Mary gets to John's place a little after 6pm, the door is open.

1c. John wants to open his front door for his wife but he has his hands full and his foot is out of reach of the door as well. However, there's a ball lying nearby, so John kicks the ball at the door and it opens.

1d. John is mad about something and needs to vent his anger. He kicks against a ball lying near him, and the ball accidentally hits a nearby door. The door opens.

How appropriate are each of the following sentences for describing what happened?

John kicked the door open.

John made the door open./John caused the door to open.

\section{2. punch open}

2a. John is a boxer. He's trying to enter his house, but the front door is stuck, so he punches it with his fist, and the door opens.

2b. John wants to program his door to open automatically at $6 \mathrm{pm}$, so his cleaner can get in. Since he likes technological gimmicks, his front door can be programmed to open at a later time by a hard punch. John punches to set the opening mechanism for $6 \mathrm{pm}$ and when his cleaner gets there a little after $6 \mathrm{pm}$, the door is open.

2c. John is a boxer. When someone rings his doorbell, he is training and too lazy to get the door. So he punches his heavy bag once in the direction of the door. The bag hits the door and it opens.

2d. John is a boxer and is training with a heavy bag. He has so much force in his arm, that when he punches the bag, it swings so far that it hits the door. The door opens.

How appropriate are each of the following sentences for describing what happened?

John punched the door open.

John made the door open.

3. kiss awake 
3a. John has to get up for work, but he's fast asleep. So Mary kisses him and he wakes up.

3b. Mary kisses John in order to wake him, but he is a sound sleeper and does not wake up right away. Somehow the kisses have registered, however, and John sleeps more lightly and wakes up after 15 minutes.

3c. Mary is making pancakes with her 4-year-old son Mike. Her husband John is still asleep. She wants to wake him gently, so she gives Mike a kiss on the cheek and tells him to pass the kiss onto his dad. Mike gives his dad a kiss on the cheek and John wakes up.

3d. Mary is playing with her 4-year-old son Mike. She gives him a kiss on the cheek and tells him to take that kiss to his dad. Mike runs over to his dad John and gives him a kiss. Mary doesn't know that John had been napping, and when Mike kisses him, he wakes up.

How appropriate are each of the following sentences for describing what happened?

Mary kissed John awake.

Mary caused John to wake up.

\section{4. shake awake}

4a. Mary has to get up for work but she's fast asleep. So John shakes her until she wakes up.

4b. John shakes Mary in order to wake her, but she is a sound sleeper and does not wake up. Somehow, she registers the shaking, however, as she starts tossing and turning and wakes up after 15 minutes.

4c. John and Mary share a room. One morning, John wants to wake Mary but he can't quite reach her from his bed. So he reaches over and shakes her bed, and she wakes up.

4d. John is lying in bed. He reaches over for a book that is lying on the edge of the bed next to him, but he can't quite reach it. Too lazy to get up, John instead shakes the bed to make the book fall down and into his reach. He doesn't realize that Mary is sleeping in the bed, so when he shakes it, she wakes up.

How appropriate are each of the following sentences for describing what happened?

John shook Mary awake.

John made Mary wake up./John caused Mary to wake up.

5. iron flat

5a. Mike wants to wear a dress shirt to his job interview. He has washed one but forgot to dry it on a hanger, so it's all crumpled. He irons the shirt until it is flat.

5b. Mike's new dress shirt is made from an interesting fiber. No matter how crinkly the shirt gets, you just have to iron it for a minute and it will become perfectly flat 
and crease-free 15 minutes later. The shirt's fibers react to the heat of the iron and flatten out over time. Mike tries it out one day: He passes the iron over the shirt, leaves to take a shower, and when he returns 15 minutes later, the shirt lies flat on the iron board.

5c. Mike has brought back some leaves from his walk in the park. He wants to press them and thinks he can flatten them by ironing, but the heat of the iron seems too intense. He lays the leaves out on the ironing board and places a thick towel on top of them. Then he moves the iron over the towel, and the leaves underneath become flat.

5d. Mike finds a beautiful leaf during a walk in the park. He puts it in the breast pocket of his jacket and has forgotten about it by the time he gets home. He puts the jacket in the wash, and, once dried, he irons it, including the breast pocket. The leaf falls out, and it is perfectly flat after the ironing.

How appropriate is each of the following sentences for describing what happened?

Mike ironed the leaf/shirt flat.

Mike made the leaf/shirt flat.

\section{6. hammer flat}

6a. Mary wants to use old spoons as garden markers. So she takes a spoon and hammer on it until it is flat. Mary wants to use old spoons as garden markers. So she takes a spoon and hammer on it until it is flat.

6b. Mary wants to use her old spoon as a garden marker, so she needs it to be flat. The spoon is made from a very hard metal whose molecular structure takes a long time to break down. Mary hammers on the spoon for a few minutes and then leaves. In the next hour, the metal slowly breaks down and the spoon becomes flat.

6c. Mary has a fancy new machine that can do a variety of jobs from hammering to painting to sewing. Operating the machine is very intuitive: If you want to paint something, you place it in the machine and perform a painting gesture, and the machine will do the job for you. Mary places a spoon in the machine and performs a hammering gesture. A little later, the spoon is flat.

6d. Mary has a fancy new tool that can do a variety of different jobs, including hammering and sewing. Operating the tool is very intuitive. If you gesture hammering, the tool registers your hand motion and performs a hammering motion on whatever object you give it. One day, Mary is walking by with a spoon in her hand when sees a nail sticking out the floorboards right by the machine. Mary sets the spoon down under the machine and goes to fetch a hammer. When she starts hammering the nail back into the floor, the machine copies her actions and hammers on the spoon until it becomes flat.

How appropriate is each of the following sentences for describing what happened? 
Mary hammered the spoon flat.

Mary made the spoon flat./Mary caused the spoon to become flat.

7. spray clean

7a. Mike's house is white. Since he lives right by the highway, the exhaust fumes from all the cars make the walls look dirty and grimy. Once a year, Mike takes a pressure washer and sprays the walls with water. For a little while, the walls become clean and white again.

7b. Mike hates cleaning, especially the tiled walls of the bathroom. So he uses a disinfectant bathroom cleaner that you simply spray onto any surface and let it soak for 15 minutes. Mike sprays it on the particularly nasty wall above the tub, leaves to make himself a sandwich, and when he comes back to check on his work 15 minutes later, the wall is clean.

7c. Mary has brainwashed her friend John to clean up after her: Whenever she sprays a little perfume behind her ears, John feels compelled to clean up around him. After dinner one evening, the kitchen needs cleaning and Mary doesn't feel like doing it, so she sprays some perfume behind her ears in John's presence, and he feels compelled to clean the kitchen.

7d. Mike works at a car wash and is tasked with cleaning the outer walls of the building housing the car wash machine with a pressure washer. He enjoys this task so much that he doesn't pay attention where all he's spraying the water. $\mathrm{He}$ accidentally sprays the button that starts the car wash machine and it is pressed down. The machine starts and the car sitting under it becomes clean.

How appropriate is each of the following sentences for describing what happened?

Mike sprayed the wall/car clean./Mary sprayed the kitchen clean.

Mike made the wall/car clean./Mary caused the kitchen to become clean.

8. sand smooth

8a. Mary has just finished building a wooden table. She takes some sanding paper, sands the table top and it becomes smooth.

8b. Mary built a new dinging room table from a very rough type of wood. She sands the table top for a few minutes, which breaks up the molecular structure of the wood. After Mary has stopped sanding, it takes about an hour for the wood's structure to break up and flatten out, and then the table top is smooth.

8c. Mary has a fancy new tool that can do a variety of different jobs, including hammering and sanding. Operating the tool is very intuitive. If you want to sand, you just make a sanding gesture and the tool registers your hand motion and sands whatever object you give it. Mary tries it out. She places her new wooden table 
under the tool and mimics sanding. The tool starts in sanding mode and the table top becomes smooth.

8d. Mary has a fancy new tool that can do a variety of different jobs, including hammering and sanding. Operating the tool is very intuitive. If you make a sanding gesture, the tool registers your hand motion and sands whatever object you give it. One day, Mary wants to sand the kitchen floor, and places the kitchen table under the machine to get $t$ out of the way. Once she starts sanding the floor, however, the machine registers her hand motions and sands the table top underneath until it is smooth.

How appropriate is each of the following sentences for describing what happened?

Mary sanded the table top smooth.

Mary made the table top smooth./Mary caused the table top to become smooth.

\section{9. shoot dead}

9a. John wants to revenge his family's death at the hands of Mike. He aims, shoots, and hits Mike, and Mike dies on the spot.

9b. John wants to revenge his family's death at the hands of Mike. He aims, shoots, and hits Mike, and Mike dies a few days later in the hospital from his internal injuries.

9c. John wants to revenge his family's death at the hands of Mike. He shoots Mike but barely grazes his shoulder. However, the shock of being shot gives Mike a heart attack and he dies on the spot.

9d. John wants to revenge his family's death at the hands of Mike. He shoots Mike but misses and hits Mary instead. He barely grazes her shoulder, but the shock gives Mary a heart attack and she dies on the spot.

How appropriate is each of the following sentences for describing what happened?

John shot Mike/Mary dead.

John caused Mike/Mary to die.

10. knock dead

10a. Mike is a professional boxer. One night, a robber attacks him in a dark alley, and Mike instinctively knocks him once with full force. The robber drops down dead.

10b. Mike is a professional boxer. One night, a robber attacks him in a dark alley, and Mike instinctively knocks him once in the head. The robber passes out and dies a couple of days later of his internal injuries.

10c. Mike is a professional boxer. John is in the mafia and has threatened to kill Mike's family. One night, Mike confronts John on the roof of his house in order to kill him. He knocks John once in the head. John stumbles backwards from the blow, falls off the roof and is impaled on a fence post. He dies immediately. 
10d. Mike and John are boxers. One night, they're sparring with each other on John's roof. Mike accidentally knocks John right in the head and John stumbles backwards and falls off the roof. He falls onto a fence post and dies immediately.

How appropriate is each of the following sentences for describing what happened?

Mike knocked the robber/John dead.

Mike caused the robber/John to die.

\section{1. paint blue}

11a. John has bought a new table for his living room. Since his couch is blue, he wants the table to match it, and so he paints the table in the same color.

11b. John has bought a new table for his living room. Since his couch is blue, he wants the table to match it. He paints the table and is surprised: the paint looks green at first. After an hour, when it has dried, the table looks blue, as planned.

11c. John has a fancy machine that can perform a variety of tasks, including hammering, sewing, and painting. Activating the machine is very intuitive, one simply gestures the action one wants the machine to perform. John wants to paint his table, so he places it underneath the machine and makes a painting gesture. The machine starts and the table becomes blue.

11d. John has a fancy machine that can perform a variety of tasks, including hammering, sewing, and painting. Activating the machine is very intuitive, one simply gestures the action one wants the machine to perform. One day John wants to paint the floorboards next to the machine with blue paint. He needs to move a table standing on the floor, so he moves it underneath the machine for the time being and starts painting. The machine is activated by John's painting action and paints the table underneath, which becomes blue.

How appropriate is each of the following sentences for describing what happened?

John painted the table blue.

John made the table blue./John caused the table to become blue.

12. dye blue

12a. Mary just bought new curtains for her bedroom. They're white and boring, so she dyes them and they become blue right away.

12b. Mary wants to dye the curtains in her room. She puts them in a bucket with indigo dye, and when she takes them out, they are green. She lets them sit in the open air for 2 hours and when she comes back, they're blue.

12c. Mary wants to dye a delicate blouse of hers. She's afraid the dye is too strong for the fabric, so she puts an old towel in blue dye, takes it out and wraps the blouse in it. The blouse takes on the blue color from the towel. 
12d. Mary has just taken her old jeans from a bucket with blue dye. Carelessly she throws them on a chair to dry. She doesn't realize that there's a white blouse lying on the chair already. The blouse absorbs the blue color of the jeans.

How appropriate is each of the following sentences for describing what happened?

Mary dyed the curtains/blouse blue.

Mary made the curtains/blouse blue./Mary caused the blouse to become blue. 


\section{References}

Aarons, Debra, Ben Bahan, Judy Kegl \& Carol Neidle. 1992. Clausal structure and a tier for grammatical marking in American Sign Language. Nordic Journal of Linguistics 15.103-42.

- 1995. Lexical tense markers in American Sign Language. Language, Gesture, and Space, ed. by K. Emmorey \& J.S. Reilly, 225-53. Hillsdale, NJ: Lawrence Erlbaum Associates.

Abner, Natasha. 2011. WH-words that go bump in the right. Paper presented to the 28th West Coast Conference on Formal Linguistics.

Aboh, Enoch, Roland Pfau \& Ulrike Zeshan. 2005. When a wh-word is not a wh-word: The case of Indian Sign Language. Yearbook of South Asian Languages and Linguistics, ed. by T. Bhattacharya, 11-43. Berlin: Mouton de Gruyter.

Ackema, Peter \& Ad Neeleman. 2002. Effects of short-term storage in processing rightward movement. Storage and Computation in the Language Faculty, ed. by S. Nootebom, F. Weerman \& F. Wijnen, 219-56. Dordrecht: Kluwer Academic Publishers.

Aikhenvald, Alexandra Y. 2006. Serial verb constructions in typological perspective. Serial Verb Constructions: A Cross-Linguistic Typology, ed. by A.Y. Aikhenvald \& R.M.W. Dixon, 1-68. Oxford: Oxford University Press.

Amberber, Mengistu. 2002. Quirky alternations of transitivity: The case of ingestive predicates. Language Universals and Variation, ed. by M. Amberber \& $\mathrm{P}$. Collins. Westport, CT.: Praeger.

Aronoff, Mark, Irit Meir, Carol Padden \& Wendy Sandler. 2003. Classifier constructions and morphologyin two sign languages. Perspectives on Classifier Constructions in Sign Languages, ed. by K. Emmorey, 53-84. Mahway, NJ: Lawrence Erlbaum Associates.

Aske, Jon. 1989. Path predicates in English and Spanish: A closer look. Paper presented to the Berkeley Linguistics Society, Berkeley, CA.

Baker-Shenk, Charlotte \& Dennis Cokely. 1980. American Sign Language: A Teacher's Resource Text on Grammar and Culture. Silver Spring, MD: T.J. Publishers, Inc.

Baker, Mark. 1989. Object sharing in serial verb constructions. Linguistic Inquiry 20.51353.

Balazs, Julie. 2012. The syntax of small clauses. Cornell University MA thesis.

Bates, D.M., M. Maechler \& B. Bolker. 2012. lme4: Linear mixed-effects models using S4 classes.

Battison, Robbin. 1978. Lexical Borrowing in American Sign Language. Silver Spring, MD: Linstok Press.

Beavers, John. 2002. Aspect and the distribution of prepositional resultative phrases in English. LinGO Working Paper \#2002-7. Stanford University: CSLI. 
-. 2008. Scalar complexity and the structure of events. Event Structures in Linguistic Form and Interpretation, ed. by J. Dölling, T. Heyde-Zybatow \& M. Schäfer, 245-65. Berlin: de Gruyter.

Beavers, John \& Andrew Koontz-Garboden. 2012. Manner and result in the roots of verbal meaning. Linguistic Inquiry 43.331-69.

Becker, Claudia. 2000. Gebärdenbildungsprozesse in der Deutschen Gebärdensprache: Zur Rolle von Komposita. Gebärdensprachlinguistik 2000: Theorie und Anwendung, ed. by H. Leuniger \& K. Wempe, 147-67. Hamburg: Signum Verlag.

Benedicto, Elena \& Diane Brentari. 2004. Where did all the arguments go?: Argumentchanging properties of classifiers in ASL. Natural Language and Linguistic Theory 22.743-810.

Benedicto, Elena, Sandra Cvejanov \& Josep Quer. 2008. The morphosyntax of verbs of motion in serial constructions: A crosslinguistic study in three signed languages. Signs of the time, ed. by J. Quer, 111-32. Seedorf: Signum.

Bittner, Maria. 1999. Concealed causatives. Natural Language Semantics 7.1-78.

Boas, Hans. 2003. A Constructional Approach to Resultatives. Stanford Monograph in Linguistics. Stanford: CSLI Publications.

-. 2005. Determining the productivity of resultative constructions: A reply to Goldberg and Jackendoff. Language 81.448-64.

Bohnemeyer, Jürgen, Nicholas T. Enfield, James Essegbey \& Sotaro Kita. 2011. The macro-event property: The segmentation of causal chains. Event Representation in Language and Cognition, ed. by J. Bohnemeyer \& E. Pederson, 43-67. New York: Cambridge University Press.

Bos, Heleen. 1996. Serial verb constructions in Sign Language of the Netherlands. Paper presented at the Fifth International Conference on Theoretical Issues in Sign Language Research, Montréal.

Braze, David. 2004. Aspectual inflection, verb raising and object fronting in American Sign Language. Lingua 114.29-58.

Brennenstuhl, Waltraud \& Krystina Wachowicz. 1976. On the pragmatics of control. Paper presented to the Proceedings of the 2nd annual meeting of the Berkeley Linguistics Society, Berkeley, CA.

Byrne, Barbara M. 2013. Structural Equation Modeling with Mplus New York: Taylor and Francis.

Carrier, Jill \& Janet Randall. 1992. The argument structure and syntactic structure of resultatives. Linguistic Inquiry 23(2).173-234.

Chen Pichler, Deborah. 2001. Word order variation and acquisition in American Sign Language. University of Connecticut dissertation.

Chomsky, Noam. 1986. Barriers. Cambridge, Mass.: MIT Press.

Collins, Chris. 1997. Argument sharing in serial verb constructions. Linguistic Inquiry 28.461-97.

Comrie, Bernard. 1981. Language Universals and Linguistic Typology: Syntax and morphology. Oxford: Blackwell. 
Contreras, Heles. 1995. Small clauses and complex predicates. Small Clauses, ed. by A. Cardinaletti \& M.T. Guasti, 135-52. San Diego, CA.: Academic Press.

Coulter, Geoffrey. 1993. Phrase-level prosody in ASL: Final lengthening and phrasal contours. Current Issues in ASL Phonology, ed. by G. Coulter, 263-72: Academic Press, Inc.

Cruse, D.A. 1972. A note on English causatives. Linguistic Inquiry 3.522-28.

Dalmi, Gréte. 2005. The Role of Agreement in Non-Finite Predication. Amsterdam/Philadelphia: John Benjamins.

Davidson, Kathryn. 2013. 'And' or 'or': General use coordination in ASL. Semantics and Pragmatics 6.1-44.

Dixon, R.M.W. 2000. A typology of causatives: Form, syntax and meaning. Changing Valency: Case Studies in Transitivity, ed. by R.M.W. Dixon \& A.Y. Aikhenvald, 30-83. Cambridge: Cambridge University Press.

Dowty, David. 1979. Word Meaning and Montague Grammar: The Semantics of Verbs and Times in Generative Semantics and in Montague's PTQ. Dordrecht, Boston, London: D. Reidel Publishing Company.

Dudis, Paul. 2004. Depiction of events in ASL: Conceptual integration of temporal components. UC Berkeley dissertation.

Eccarius, Petra \& Diane Brentari. 2007. Symmetry and dominance: A cross-linguistic study of signs and classifier constructions. Lingua 117.1169-201.

Engberg-Pedersen, Elisabeth. 1993. Space in Danish Sign Language: The Semantics and Morphosyntax of the Use of Space in a Visual Language. Hamburg: Signum.

-. 2010. Expressions of causation in Danish Sign Language. Sign Language \& Linguistics 13.40-67.

Fillmore, Charles J. 1978. On the organization of semantic information in the lexicon. Paper presented to the Papers from the parasession on the lexicon, Chicago, IL.

Fischer, Susan. 1975. Influences on word order change in American Sign Language. Word Order and Word Order Change, ed. by C. Li, 1-25. Austin: University of Texas Press.

Fischer, Susan \& Diane Lillo-Martin. 1990. UNDERSTANDing conjunctions. International Journal of Sign Linguistics 1.71-80.

Fleckenstein, Kristen \& Suwon Yoon. to appear. Negation in ASL: The role of Jespersen's Cycle and semantic restructuring. Proceedings of the 52nd Annual Meeting of the Chicago Linguistics Society (CLS 52).

Fodor, J. A. 1970. Three reasons for not deriving 'kill' from 'cause to die'. Linguistic Inquiry 1.429-38.

Foley, William A. \& Mike Olsen. 1985. Clausehood and verb serialization. Grammar Inside and Outside the Clause, ed. by J. Nichols \& A.C. Woodbury, 17-60. Cambridge: Cambridge University Press.

Folli, Raffaella \& Heidi Harley. 2004. Consuming results: Flavors of little-v. Aspectual enquiries, ed. by P. Kempchinsky \& R. Slabakova, 1-25. Dordrecht: Kluwer.

Frazier, M. \& M. Yoshida. 2012. Remarks on gapping in ASL. Snippets 26.11-13. 
Geraci, Carlo \& Valentina Aristodemo. 2016. An in-depth tour into sentential complementation in Italian Sign Language. A Matter of Complexity: Subordination in Sign Languages, ed. by R. Pfau, M. Steinbach \& A. Herrmann, 95-150. Boston/Berlin and Preston, UK: de Gruyter/ Ishara Press.

Geraci, Carlo, Carlo Cecchetto \& Sandro Zucchi. 2008. Sentential complementationin Italian Sign Language. Paper presented to the Proceedings of the 38th Western Conference on Linguistics, University of California at Davis.

Givón, Talmy. 1980. The binding hierarchy and the typology of complements. Studies in Language 4.333-77.

Glück, Susanne \& Roland Pfau. 1997. Einige Aspekte der Morphologie und Morphosyntax in Deutscher Gebärdensprache. Zeitschrift für Sprachwissenschaft 16.181-208.

Göksel, Aslı \& Meltem Kelepir. 2016. Observations on clausal complementation in Turkish Sign Language. A Matter of Complexity: Subordination in Sign Languages, ed. by R. Pfau, M. Steinbach \& A. Herrmann, 65-94. Boston/Berlin Preston, UK: de Gruyter.

Goldberg, Adele. 1995. Constructions: A Construction Grammar Approach to Argument Structure. Chicago: University of Chicago Press.

Goldberg, Adele \& Ray Jackendoff. 2004. The English resultative as a family of constructions. Language 80.532-69.

Grin, Konstantin. 2014. W-Fragen in der Deutschen Gebärdensprache. Universität Hamburg thesis.

Grose, Donovan. 2008. The geometry of events: Evidence from English and American Sign Language. Purdue University PhD dissertation.

Grosjean, François \& Harlan Lane. 1977. Pauses and syntax in American Sign Language. Cognition 5.101-17.

Guéron, Jacqueline \& Teun Hoekstra. 1995. The temporal interpretation of predication. Small Clauses, ed. by A. Cardinaletti \& M.T. Guasti, 77-107. San Diego, CA.: Academic Press.

Haiman, John. 1985. Natural Syntax: Iconicity and Erosion. Cambridge: Cambridge University Press.

Halliday, M.A.K. 1967. Notes on transitivity and theme in English. Journal of Linguistics 3.37-81.

Hansen, Martje. 2007. Warum braucht die deutsche Gebärdensprache kein Passiv?: Verfahren der Markierung semantischer Rollen in der DGS. Frankfurt am Main: Lang.

Happ, Daniela \& Marc-Oliver Vorköper. 2006. Deutsche Gebärdensprache: Ein Lehrund Arbeitsbuch. Frankfurt a.M.: Fachhochschulverlag.

Hawkins, John A. 2004. Efficiency and Complexity in Grammars. New York: Oxford University Press.

Hay, Jennifer, Christopher Kennedy \& Beth Levin. 1999. Scalar structure underlies telicity in degree achievements. Semantics and Linguistic Theory.127-44. 
Healy, Christina. 2015. Construing affective events in ASL. Gallaudet University dissertation.

Herrmann, Annika. 2010. The interaction of eye blinks and other prosodic cues in German Sign Language. Sign Language \& Linguistics 13.3-39.

Hillenmeyer, Margit \& Savina Tilmann. 2012. Soziolinguistik: Variation in der DGS. Handbuch Deutsche Gebärdensprache: Sprachwissenschaftliche und anwendungsbezogene Perspektiven, ed. by H. Eichmann, M. Hansen \& J. Heßmann, 245-70. Seedorf: Signum.

Hodge, Gabrielle. 2013. Patterns from a signed language corpus: Clause-like units in Auslan (Australian sign language). Macquarie University dissertation.

Hoekstra, Teun. 1988. Small clause results. Lingua 74.101-39.

Holscher, Daniel. 1992. A preliminary survey of causation and causative constructions in American Sign Language. Lafayette, IN: Purdue University thesis.

Iwata, Seizi. 2006. Argument resultatives and adjunct resultatives in a lexical constructional account: The case of resultatives with adjectival result phrases. Language Sciences 28.449-96.

Jackendoff, Ray. 1990. Semantic Structures. Cambridge, Mass.: MIT Press.

Jahnke, Sina \& Elisabeth Volk. 2015. Zur Syntax und Informationsstruktur der wBewegung in DGS: Eine empirische Untersuchung zur Position von w-Wörtern in Fragen und Frage-Antwort-Sequenzen. Georg-August-Universität Göttingen MA thesis.

Janzen, Terry, Barbara O'Dea \& Barbara Shaffer. 2001. The construal of events: Passives in American Sign Language. Sign Language Studies 1.281-310.

Johnston, Trevor \& Adam Schembri. 2007. Australian Sign Language: An Introduction to Sign Language Linguistics. Cambridge: Cambridge University Press.

Kegl, Judy. 1985. Causative marking and the construal of agency in ASL. CLS 21, Part 2: Papers from the parasession on causatives and agentivity, ed. by W.H. Eilfort, P.D. Kroeber \& K.L. Peterson, 120-37. Chicago: Chicago Linguistic Society.

- 1990. Predicate argument structure and verb-class organization in the ASL lexicon. Sign Language Research, ed. by C. Lucas, 149-75. Washington, D.C.: Gallaudet University Press.

Kennedy, Christopher. 1999. Projecting the Adjective: The Syntax and Semantics of Gradability and Comparison. New York: Garland Press.

Kennedy, Christopher \& Louise McNally. 2005. Scale structure, degree modification, and the semantics of gradable predicates. Language 81.345-81.

Kentner, Ashley. 2014. Event structure of resultatives in ASL. West Lafayette, Indiana: Purdue University MA thesis.

Kim, Jong-Bok. 1993. Syntax and semantics of Korean resultative constructions. Harvard Studies in Korean Linguistics, ed. by S. Kuno, I.-H. Lee, J. Whitman, M. J., Y.-S. Kang \& Y.-J. Kim, 471-82. Cambridge, MA.: Harvard University Department of Linguistics.

Kim, Soowon \& Joan Maling. 1997. A crosslinguistic perspective on resultative formation. Paper presented to the Texas Linguistics Forum, Austin, TX. 
Klima, Edward \& Ursula Bellugi. 1979. The Signs of Language. Cambridge, MA: Harvard University Press.

Kratzer, Angelika. 1996. Severing the external argument from its verb. Phrase Structure and the Lexicon, ed. by J. Rooryck \& L. Zaring, 109-37. Dordrecht: Kluwer Academic Publishers.

-. 2005. Building resultatives. Event Arguments, ed. by C. Maienborn \& Wöllstein, 177-212. Tübingen: Max Niemeyer Verlag.

Krejci, Bonnie. 2012. Causativization as antireflexivization: A study of middle and ingestive verbs. University of Texas at Austin M.A. thesis.

Krifka, Manfred. 1998. The origins of telicity. Events and Grammar, ed. by S. Rothstein, 197-235. Dordrecht: Kluwer.

Kroeger, Paul. 2005. Analyzing Grammar: An Introduction. New York: Cambridge University Press.

Lakoff, George \& Mark Johnson. 1980. Metaphors We Live By. Chicago, IL.: Chicago University Press.

Lane, Harlan, Robert Hoffmeister \& Ben Bahan. 1996. A Journey into the Deaf World. San Diego, CA: Dawn Sign Press.

Larson, Richard. 1988. On the double object construction. Linguistic Inquiry 19.335-91.

Lau, Sin Yee Prudence. 2012. Serial verb constructions in Hong Kong Sign Language. Shatin: Chinese University of Hong Kong dissertation.

Law, Paul. 1996. A note on serial verb constructions in Chinese. Cahiers de Linguistique - Asie Orientale 25.199-233.

Leonhardt, Annette. 2002. Einführung in die Hörgeschädigtenpädagogik. Stuttgart: UTB.

Levin, Beth. 2015. The ingredients of nonselected NP resultatives. Paper presented at the University of Utah Student Conference in Linguistics (UUSCIL), Salt Lake City.

Levin, Beth \& Malka Rappaport Hovav. 1995. Unaccusativity: At the syntax-lexical semantics interface. Cambridge, MA.: MIT Press.

Liddell, Scott. 1980. American Sign Language Syntax. The Hague: Mouton Publishers.

-. 2003. Grammar, Gesture, and Meaning in American Sign Language. Cambridge: Cambridge University Press.

Lillo-Martin, Diane. 1992. Sentences as islands: On the boundedness of A'-movement in American Sign Language. Island Constraints, ed. by H. Goodluck \& $\mathrm{M}$. Rochemont, 259-74. Dordrecht: Kluwer.

Loos, Cornelia. 2014. A class of their own: Adjectives in ASL. University of Texas, Austin, Ms.

Lucas, Ceil, Robert Bayley \& Clayton Valli. 2001. Sociolinguistic Variation in American Sign Language. Washington, D.C.: Gallaudet University Press.

Martin, Jack B. 2000. Creek voice: Beyond valency. Changing Valency: Case Studies in Transitivity, ed. by R.M.W. Dixon \& A.Y. Aikhenvald, 375-403. Cambridge: Cambridge University Press.

Matsumoto, Yo. 1996. Complex Predicates in Japanese: A Syntactic and Semantic Stud of the Notion 'Word'. Stanford: CSLI Publications. 
Mayberry, Rachel. 1993. First language acquisition after childhood differs from second language aquisition: The case of American Sign Language. Journal of Speech and Hearing Research 36.1258-70.

McCawley, James. 1968. Lexical insertion in a transformational grammar without deep structure. Paper presented to the Chicago Linguistics Society.

-. 1978. Conversational implicature and the lexicon. Syntax and semantics, vol 9: Pragmatics, ed. by P. Cole, 245-58.

McCloskey, James. 1996. On the scope of verb movement in Irish. Natural Language and Linguistic Theory 14.47-104.

McNulty, Elaine. 1988. The syntax of adjunct predicates. The University of Connecticut dissertation.

Mehling, Karin. 2010. Heute hier, morgen dort - Deixis und Anaphorik in der Deutschen Gebärdensprache. Nördlingen: Ludwig-Maximilians-Universität München dissertation.

Müller, Stefan. 2002. Complex Predicates: Verbal Complexes, Resultative Constructions, and Particle Verbs in German. Stanford: CSLI publications.

Neeleman, Ad \& Hans van de Koot. 2002. Bare resultatives. Journal of Comparative Germanic Linguistics 6.1-52.

Neidle, Carol. 2002. Language across modalities: ASL focus and question constructions. Linguistic Variation Yearbook 2.71-98.

Neidle, Carol, Judy Kegl, Dawn MacLaughlin, Ben Bahan \& Robert G. Lee. 2000. The Syntax of American Sign Language: Functional Categories and Hierarchical Structure. Cambridge, MA: MIT Press.

Oya, Toshiaki. 2002. Reflexives and resultatives: Some differences between English and German. Linguistics 40.961-86.

Padden, Carol. 1983. The interaction of morphology and syntax in American Sign Language. San Diego: University of California, San Diego dissertation.

Pawley, Andrew. 2011. Event representations in serial verb constructions. Event Representation in Cognition and Language, ed. by J. Bohnemeyer \& E. Pederson, 13-42. New York: Cambridge University Press.

Petronio, Karen. 1993. Clause structure in American Sign Language: University of Washington dissertation.

Petronio, Karen \& Diane Lillo-Martin. 1997. Wh-movement and the position of spec-CP: Evidence from American Sign Language. Language 73.18-57.

Pfau, Roland. 2001. Typologische und strukturelle Aspekte der Negation in Deutscher Gebärdensprache. Gebärdensprachlinguistik 2000: Theorie und Anwendung, ed. by H. Leuniger \& K. Wempe, 13-31. Hamburg: Signum.

Pfau, Roland \& Josep Quer. 2007. On the syntax of negation and modals in Catalan Sign Language and German Sign Language. Visible Variation: Comparative Studies on Sign Language Structure, ed. by P. Perniss, R. Pfau \& M. Steinbach, 129-61. Berlin: Mouton de Gruyter.

Pfau, Roland, Markus Steinbach \& Annika Herrmann (eds) 2016. A Matter of Complexity: Subordination in Sign Languages. Preston, UK: Ishara Press. 
Pustejovsky, James. 1991. The syntax of event structure. Cognition 41.47-81.

Quadros, Ronice Müller de. 1999. Phrase structure of Brazilian Sign Language: Pontífica Universidade Católica do Rio Grande do Sul dissertation.

Quer, Josep. 2005. Context shift and indexical variables in sign languages. Paper presented to the Proceedings from Semantics and Linguistic Theory, Ithaca, NY.

Quer, Josep \& Santiago Frigola. 2006. Crosslinguistic research and particular grammars: A case study on auxiliary predicates in Catalan Sign Language (LSC). Paper presented at the Workshop on Cross-linguistic Sign Language Research, Max Planck Institute for Psycholinguistics, Nijmegen.

R Core Team. 2016. R: A language and environment for statistical computing. Vienna, Austria: R Foundation for Statistical Computing.

Ramchand, Gillian. 2008. Verb Meaning and the Lexicon: A First Phase Syntax. Cambridge: Cambridge University Press.

Rappaport Hovav, Malka \& Beth Levin. 1999a. Two structures for compositionally derived events. Paper presented to the SALT Ithaca, NY.

-. 1999b. Two types of compositionally derived events. Ramat Gan, Israel /Evanston, IL: Bar Ilan University/ Northwestern University.

—. 2001. An event structure account of English resultatives. Language 77.766-97.

- 2010. Reflections on manner/result complementarity. Syntax, Lexical Semantics, and Event Structure, ed. by E. Doron, M. Rappaport Hovav \& I. Sichel, 21-38. Oxford: Oxford University Press.

Rathmann, Christian. 2005. Event structure in American Sign Language. Austin: University of Texas at Austin dissertation.

Ross, John R. 1967. Constraints on variables in syntax: MIT dissertation.

Rothstein, S. 2004. Structuring Events. Oxford: Blackwell.

Sandler, Wendy \& Diane Lillo-Martin. 2006. Sign Language and Linguistic Universals. Cambridge: Cambridge University Press.

Sapountzaki, Galini. 2005. Free functional elements of tense, aspect, modality and agreement as possible auxiliaries in Greek Sign Language. University of Bristol dissertation.

Schlenker, Philippe. to appear-a. Super monsters I: Attitude and action role shift in sign language. Semantics and Pragmatics.

- to appear-b. Super monsters II: Role shift, iconicity and quotation in sign language. Semantics and Pragmatics.

Shibatani, Masayoshi. 1976. The grammar of causative constructions: A conspectus. The Grammar of Causative Constructions: Syntax and Semantics 6, ed. by M. Shibatani, 1-42. New York: Academic Press.

Shibatani, Masayoshi \& Prashant Pardeshi. 2002. The causative continuum. The Grammar of Causation and Interpersonal Manipulation, ed. by M. Shibatani, 85126. Amsterdam: John Benjamins.

Simpson, Jane. 1983. Resultatives. Papers in Lexical-Functional Grammar, ed. by B. Levin, M. Rappaport \& A. Zaenen, 143-57. Bloomington, Indiana: Indiana University Linguistics Club. 
Slobin, Dan \& Nini Hoiting. 1994. Reference to movement in spoken and signed languages: Typological considerations. Proceedings of the Twentieth Annual Meeting of the Berkeley Linguistic Society, ed. by S. Gahl, S. Dalbey \& C. Johnson, 487-505. Berkeley, CA.

Son, Minjeong \& Peter Svenonius. 2008. Microparameters of cross-linguistic variation: Directed motion and resultatives. Paper presented to the Proceedings of the 27th West Coast Conference on Formal Linguistics, Somerville, MA.

Starke, Michal. 1995. On the format for small clauses. Small Clauses, ed. by A. Cardinaletti \& M.T. Guasti, 237-69. San Diego, CA.: Academic Press.

Stewart, Osamuyimen Thompson. 1998. The serial verb construction parameter. Montréal: McGill University dissertation.

Stowell, T. 1983. Subjects across categories. The Linguistic Review 2.285-312.

Supalla, Ted. 1982. Structure and acquisition of verbs of motion and location in American Sign Language. San Diego: University of California, San Diego dissertation.

-. 1990. Serial verbs of motion in ASL. Theoretical Issues in Sign Language Research, ed. by S. Fischer \& P. Siple, 127-52. Chicago: University of Chicago Press.

Sze, Felix. 2008. Topic Construction in Hong Kong Sign Language. University of Bristol dissertation.

Tai, James H-Y. 1985. Temporal sequence and Chinese word order. Iconicity in Syntax, ed. by J. Haiman, 49-72: John Benjamins.

Tang, Gladys \& Prudence Lau. 2012. Coordination and subordination. Sign Language: An International Handbook, ed. by R. Pfau, M. Steinbach \& B. Woll, 340-64. München: Walter de Gruyter.

Tang, Gladys \& Gu Yang. 2007. Events of motion and causation in Hong Kong Sign Language. Lingua 117.1216-57.

Tkachman, Oksana \& Wendy Sandler. 2013. The noun-verb distinction in two young sign languages. Gesture 13.147-80.

Tomioka, Naoko. 2006. Resultative constructions: Cross-linguistic variation and the syntax-semantics interface. Montréal: McGill University dissertation.

van Gijn, Ingeborg. 2004. The quest for syntactic dependency: Sentential complementation in Sign Language of the Netherlands. Utrecht: LOT dissertation.

van Gijn, Ingeborg, Sotaro Kita \& Harry van der Hulst. 2000. The non-linguistic status of the Symmetry Condition in signed languages: Evidence from a comparison of signs and spontaneous co-speech gestures. University of Amsterdam /Max-Planck Institute for Psycholinguistics/ University of Connecticut.

Vendler, Z. 1957. Verbs and times. The Philosophical Review 66.143-60.

Verspoor, Cornelia Maria. 1997. Contextually-dependent lexical semantics. Edinburgh: University of Edinburgh $\mathrm{PhD}$ dissertation.

Washio, Ryuichi. 1997. Resultatives, compositionality and language variation. Journal of East Asian Linguistics.1-49.

Wechsler, Stephen. 1997. Resultative predicates and control. Texas Linguistics Forum, 307-21. Austin. 
-. 2003. Serial verbs and serial motion. Proceedings of the workshop on Multi-Verb constructions Trondheim Summer School 2003, ed. by D. Beermann \& L. Hellan.

-. 2005. Resultatives under the "event-argument homomorphism" model of telicity. The Syntax of Aspect, ed. by N. Erteschick-Shir \& T.R. Rapoport, 255-73. Oxford: Oxford University Press.

Wilbur, Ronnie. 1994. Eye blinks and ASL phrase structure. Sign Language Studies 84.221-40.

-. 1996. Evidence for the function and structure of wh-clefts in American Sign Language. International Review of Sign Linguistics, ed. by W.H. Edmondson \& R. Wilbur, 209-55. Mahwah, NJ: Lawrence Erlbaum Associates.

-. 1999. Stress in ASL: Empirical evidence and linguistic issues. Language and Speech 42.229-50.

-. 2003. Representations of telicity in ASL. Proceedings from the Annual Meeting of the Chicago Linguistic Society, 354-68. Chicago: Chicago Linguistic Society.

Wilbur, Ronnie, Evie Malaia \& Robin A. Shay. 2012. Degree modification and intensification in American Sign Language adjectives. Logic, Language and Meaning, ed. by M. Aloni, V. Kimmelman, F. Roelofsen, G.W. Sassoon, K. Schulz \& M. Westera, 92-101. Berlin; New York: Springer.

Williams, Alexander. 1983. Against small clauses. Linguistic Inquiry 14.287-95.

-. 2008. Word order in resultatives. Paper presented to the West Coast Conference on Formal Linguistics, Somerville.

-. 2014. Causal VVs in Mandarin. The Handbook of Chinese Linguistics, ed. by C.-T.J. Huang, Y.-H.A. Li \& A. Simpson, 311-41. Chichester: Wiley Blackwell.

Winston, Charlotte. 2013. Psychological verb constructions in American Sign Language: Purdue University MA thesis.

Wittmann, Henri. 1991. Classification linguistique des langues signées non vocalement. Revue québécoise de linguistique T\&A 10.215-88.

Wolff, Philip. 2003. Direct causation in the linguistic coding and individuation of causal events. Cognition 88.1-48.

Wright, Tony. 2014. Strict vs. Flexible Accomplishment Predicates. Austin: University of Texas at Austin dissertation.

Zeshan, Ulrike. 2004. Interrogative constructions in signed languages: Crosslinguistic perspectives. Language 80.7-39.

Zeshan, Ulrike \& Waldemar Schwager. 2008. Word classes in sign languages. Studies in Language 32.509-45. 